\title{
The economic optimization of breeding programs in aquaculture
}

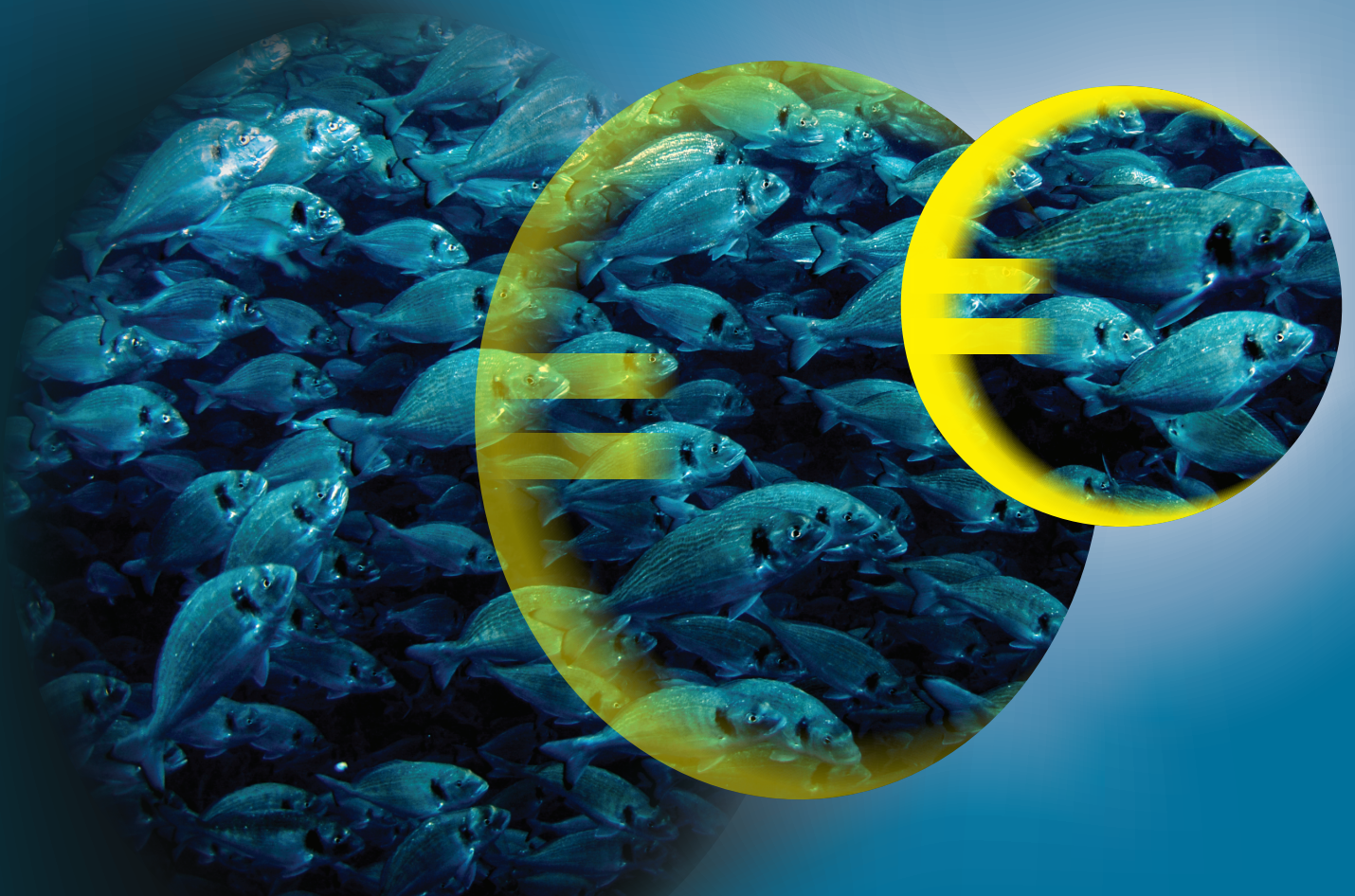

Kasper Janssen 



\section{Propositions}

1. For genetic gain economic values are equally important as accuracy and selection intensity.

2. Maximization of the benefit-cost ratio leads to underinvestment in breeding programs.

3. Some farmers gain temporarily while collectively farmers lose from technological advances.

4. Interdisciplinary research requires disciplinary concessions.

5. Many small reductions in carbon footprint at the household level sum up to a small reduction at the national level.

6. Growth in GDP does not improve societal well-being.

Propositions belonging to the thesis entitled

"Economic optimization of breeding programs in aquaculture"

Kasper Janssen

Wageningen, 4 June 2019 



\section{The economic optimization of breeding programs in aquaculture}

Kasper Janssen 


\section{Thesis committee}

\section{Promotor}

Prof. Dr J. Komen

Personal chair, Animal Breeding and Genomics group

Wageningen University \& Research

\section{Co-promotor}

Dr H.W. Saatkamp

Associate professor, Business Economics group

Wageningen University \& Research

\section{Other members}

Prof. Dr G.F. Wiegertjes, Wageningen University \& Research

Dr P. Knap, PIC, Germany

Dr B. Gjerde, Nofima, Norway

Prof. Dr J.A.M. van Arendonk, Hendrix Genetics, The Netherlands

This research was conducted under the auspices of the Graduate School of Wageningen Institute of Animal Sciences (WIAS). 


\title{
The economic optimization of breeding programs in aquaculture
}

\author{
Kasper Janssen
}

\section{Thesis}

submitted in fulfilment of the requirements for the degree of doctor at

Wageningen University

by the authority of the Rector Magnificus

Prof. Dr A.P.J. Mol,

in the presence of the

Thesis Committee appointed by the Academic Board

to be defended in public

on Tuesday 4 June 2019

at 1.30 p.m. in the Aula. 
Janssen, K.

The economic optimization of breeding programs in aquaculture, 199 pages.

PhD thesis, Wageningen University, Wageningen, the Netherlands (2019)

With references, with summary in English

ISBN: 978-94-6343-904-6

DOI: $10.18174 / 472285$ 


\section{Abstract}

Janssen, K. (2019). The economic optimization of breeding programs in aquaculture. $\mathrm{PhD}$ thesis, Wageningen University, the Netherlands

To meet the global demand for fish in a more sustainable manner, aquaculture needs to increase its economic and resource use efficiency. This can be achieved by genetic improvement of aquaculture species in breeding programs. The aim of this thesis is to study the economic optimization of breeding programs in aquaculture. First, the impact of selective breeding on European aquaculture was evaluated. Based on survey results, over $80 \%$ of the production was estimated to originate from breeding programs. Resulting economic benefits are predicted to increase cumulatively by about 100 million euro each year. For the economic optimization of breeding programs the first step is to optimize the relative emphasis on breeding goal traits, for which economic values need to be derived. This thesis presents a bio-economic model for the derivation of economic values of the production traits: growth rate, feed intake rate, mortality rate, and uniformity. The model was used to derive economic values for gilthead seabream aquaculture. The rate at which diseases spread across the farmed population is determined by $\mathrm{R}_{0}$. Methods for the derivation of the economic value of $\mathrm{R}_{0}$ for macro- and microparasitic diseases were developed. The method for macroparasitic diseases was used to derive the economic value of $\mathrm{R}_{0}$ for sea lice in Atlantic salmon aquaculture in Norway. Once economic values have been derived, a breeding program's design can be optimized. For an integrated breeding company cost-benefit analysis was used to evaluate alternative breeding program designs, with and without multiplier tier. Designs that shortened the genetic lag were shown to be more profitable. For each design the number of selection candidates was optimized with the objective to maximize the net present value, a measure of profitability. The optimum number of selection candidates was shown to increase with the length of the time horizon and production output of the company. For a specialized breeding company the allocation of budget over the numbers of phenotyped and genotyped full-sibs of selection candidates in performance tests was optimized with the objective to maximize gain in the aggregate genotype. The optimum was rather flat, but potential gains from optimization come at no extra cost. This thesis demonstrates that the optimization of breeding programs can improve the economic efficiency of aquaculture. 


\section{Contents}

Abstract 1

Chapter 1 General introduction 5

$\begin{array}{lll}\text { Chapter } 2 & \text { Impact of selective breeding on European aquaculture } & 17\end{array}$

Chapter 3 Derivation of economic values for production traits in aquaculture species

Chapter 4 Derivation of the economic value of $\mathrm{R}_{0}$ for macroparasitic diseases and application to sea lice in salmon

Chapter 5 Derivation of the economic value of $\mathrm{R}_{0}$ for microparasitic diseases

Chapter 6 Cost-benefit analysis of aquaculture breeding programs

Chapter 7 Economic optimization of full-sib test group size and genotyping effort in a breeding program for Atlantic salmon

Chapter 8 General discussion 



\section{1}

General introduction 


\subsection{Motivation and aim}

To meet the global demand for fish in a more sustainable manner, aquaculture needs to increase its economic and resource use efficiency. Most gains in resource use efficiency in livestock over the last 60 years should be attributed to genetic improvement by breeding programs (Havenstein et al., 2007; Havenstein et al., 2003; Rauw et al., 1998). In aquaculture phenotypic trends in resource use efficiency are generally favourable (Table 3 in Tacon et al., 2011), but the relative contribution of genetic improvement is unclear. Estimates of realized genetic gains are rare and fragmented, and have not been compiled to provide estimates of realized genetic gains in current breeding programs in European aquaculture. Although the general objective of a breeding program is to increase economic efficiency rather than resource use efficiency per se, resource use efficiency enters the economic objective via its relation to costs and revenues (Harris and Newman, 1994). Thus, the objective to increase economic efficiency simultaneously improves resource use efficiency, as evidenced by the positive trends in livestock mentioned above. The economic efficiency of aquaculture may be increased further by the economic optimization of breeding programs.

The first step in the economic optimization of a breeding program is to estimate how much the improvement of traits contributes to gain in farm profit. A trait's contribution to farm profit is given by its economic value in the breeding goal. Methods for the derivation of economic values of production traits in livestock are well-established, but have not often been tailored to aquaculture species. Sound methods for the derivation of economic values for disease resistance have not yet been developed at all, whereas disease resistance is of increasing importance in aquaculture breeding programs. Next steps should aim to optimize a breeding program's design in order to maximize its objective. Some theory on the optimization of breeding program design exists, but economic aspects are rarely considered explicitly.

The aim of this thesis is to study the economic optimization of breeding programs in aquaculture. Sub-objectives are:

1) To evaluate the impact of selective breeding on European aquaculture

2) To develop methods for the derivation of economic values in aquaculture species

3) To study the optimization of breeding program design 
This thesis is part of the EU-project 'FISHBOOST'. Box 1 provides a short description of the project.

\section{Box 1. FISHBOOST}

FISHBOOST aimed to improve the efficiency and profitability of European aquaculture by advancing breeding programs to the next level through collaborative research with industry. Focus species were: Atlantic salmon, common carp, European seabass, gilthead seabream, rainbow trout, and turbot. The potential for genetic improvement of production efficiency, including disease resistance, through detailed phenotyping and advanced genomic technologies was studied. The economic impact and producer's perceptions were assessed. The project consortium included of 14 RTD participants, 7 SMEs, and 1 NGO.

\subsection{Breeding goal and index}

In animal breeding, Hazel (1943) formalized the distinction between what is desired and how it is achieved by distinguishing between the breeding goal and the index. In the breeding goal the aggregate genotype $(\mathrm{H})$ is a linear function of breeding values with economic values as regression coefficients:

$\mathrm{H}=\mathbf{v}^{\prime} \cdot \mathbf{a}$,

where $\mathbf{v}$ is a vector of economic values and $\mathbf{a}$ is a vector of breeding values. In this thesis $\mathrm{H}$ is used to denote the aggregate genotype, while $\Delta \mathrm{H}$ is used to denote gain in the aggregate genotype due to selection. The breeding value is the additive genetic value of an animal for a specific trait. Economic values indicate how much breeding values contribute to $H$. The breeding goal defines for which traits genetic improvement is desired, which should be based on economic considerations (James, 1986). All traits of economic importance should be included (Gjedrem, 1972). Next to traits of economic importance, traits of social or environmental importance may be included in the breeding goal (Olesen et al., 2000), or traits may be weighed based on environmental impacts instead of economic values (Besson et al., 2016; van Middelaar et al., 2014). For the objective to maximize gain in farm profit economic values are the optimum way to balance the relative emphasis on breeding goal traits. Thus, weighing traits on any other basis than economic values compromises the goal of profit maximization (Gibson and Kennedy, 1990). The way that genetic improvement 
can be realized is irrelevant for the definition of the breeding goal, but is essential for setting up the index and corresponding design of the breeding program (James, 1986).

The index combines information of selection candidates and their relatives to predict $\mathrm{H}$ for each selection candidate. Any information that helps to improve the accuracy of this prediction may be included in the index. Each record in the index is given a weight, so that the correlation between the index and $\mathrm{H}$ is maximized (Hazel, 1943; Henderson, 1975). Thus, the importance of a record in the index depends on the proportion of variance it explains in $\mathrm{H}$, which follows from its correlation to traits in the breeding goal and their economic values (Cunningham, 1969).

\subsection{Derivation of economic values}

The economic value of a trait gives the change in farm profit per unit change in that trait while other traits in the breeding goal remain constant. Economic values may be derived from a profit function or from the regression of farm profit on traits using survey data. A profit function uses causal relations between traits and profit, whereas the regression approach uses observed relations. Because the causal relation is the better predictor of economic gain from genetic improvement, a profit function is more appropriate for the derivation of economic values (Goddard, 1998). A profit function may be a simple profit equation or a more complex bio-economic model. When using a profit equation, economic values are derived as partial derivatives. Definition of a profit equation may appear simple, but it is essential to account for quota that act on a farm level. Failure to account for quota may result in an inappropriate set of economic values (Besson et al., 2014; Groen, 1989). When using a bio-economic model, economic values are derived from a small change in one trait while others are kept constant, and the resulting change in profit divided by the change in the trait gives the economic value. Bio-economic models are increasingly being used for the derivation of economic values, because they tend to provide a more accurate representation of a production system than profit equations (Nielsen et al., 2014).

A much debated topic in the derivation of economic values is the appropriate level of evaluation. Relative economic values may differ when derived at different levels of evaluation (Moav, 1973). For example, relative economic values may differ when derived at the level of the breeding female and at the level of the finishing pig. Brascamp et al. (1985) aimed to resolve the issue by including 'normal profit' as a cost of production. Smith et al. (1986) proposed to rescale any predicted increase in output to the level before genetic 
improvement. Both methods result in consistent sets of economic values at different levels of evaluation. In favour of their method Brascamp et al. (1985) argued that profit converges to zero in the long run when an economy reaches equilibrium, and any deviation thereof is temporary by nature. Equilibrium, however, may not be reached within the time horizon in which genetic improvement is realized. In Norwegian salmon and trout farming, for example, operating margin, calculated as operating profit/operating revenues $\cdot 100 \%$, has consistently fluctuated around 20\% from 1996 through 2016 (Directorate of Fisheries, 2018), a period of about five generation intervals. Here, the assumption that the effect of genetic change on cost reduction equals the effect on benefits from increasing output does not hold, because an increase in output may be expected to have a $20 \%$ larger effect on profit than cost reduction. Or, as Groen (2003) phrased it: "when the marginal revenues of increased output per animal exceed the marginal costs of increased output per animal [...] breeding for increased output per animal will be beneficial". The method of Smith et al. (1986) effectively imposes a quota on production output, but this quota may be not be appropriate for the production system (McArthur, 1987). As an alternative method, Amer and Fox (1992) argued that economic values should be derived from the change in farm profit at the optimum level of output before and after genetic improvement. The wide diversity in farm sizes, however, suggests that the optimum is quite flat, which makes the theoretical prediction of the optimum irrelevant (Visscher et al., 1994). Furthermore, partial derivatives at any level of output correspond well to economic values derived at the optimum level of output for small changes in trait level (Amer et al., 1994). Thus, instead of trying to arrive at a consistent set of economic values at different levels of evaluation, it is more useful to consider which level of evaluation is relevant. This level is typically the farm, because this is where management decisions are taken and quota commonly apply at a farm level (Groen, 2003; Visscher et al., 1994). Economic values derived at the farm level will, therefore, best reflect true gains of genetic improvement.

Only few studies have derived economic values for aquaculture species. Most of these studies used profit equations that failed to account for quota that apply to the farm level. For example, increased survival was assumed to increase production output in Ponzoni et al. (2007). In reality, however, production output per production cycle will be constrained, e.g., by stocking density. With a constraint on production output per production cycle, increased survival will require less fish to be stocked to reach the same production output per production cycle. Besson et al. (2014) developed a bio-economic model to derive 
economic values for growth rate and feed conversion ratio for African catfish in recirculating aquaculture systems. They showed that quota on stocking density and nitrogen treatment capacity result different sets of economic values. Their model was specific to recirculating aquaculture systems and included only growth rate and feed conversion ratio as production traits. A model that is suitable for cage farming, the dominant form of aquaculture in Europe, that includes other relevant production traits has not yet been developed.

For production traits the relation between trait level and farm profit is generally direct and, therefore, relatively straightforward to model in a profit function. For disease traits, in contrast, the relation between trait level and profit is obscure and, therefore, much more difficult to model. Very few studies have attempted to derive economic values of disease traits (Bishop et al., 2004; Lobo et al., 2011), but only Amer et al. (1999) accounted for the complex relation between the dynamics of disease transmission and farm profit. Their method relied on an external epidemiologic model and is thereby of limited use for general application.

\subsection{Economic optimization of breeding program design}

Once the breeding goal has been defined, the design of the breeding program can be optimized to maximize its objective. The objective of an integrated breeding company differs from the objective of a specialized breeding company. Objectives are different, because integrated and specialized breeding companies accrue a different part of the benefits from genetic improvement.

For integrated breeding companies all benefits from genetic improvement are accrued by the company to the extent they are not passed on to the consumer. When demand is elastic, most benefits are accrued by the company. When demand is inelastic, most benefits are passed on to the consumer (Amer and Fox, 1992). For the optimization of breeding program design, however, it is irrelevant to differentiate between benefits accrued by the company and consumers, because this does not affect the ranking of alternative designs. For an integrated breeding company benefits of the breeding program are incurred at the time that genetic improvement reaches production. The difference in timing between the increase in genetic level in the nucleus and in production is the genetic lag. The value of money, however, decreases over time due to discounting. Thus, the longer the genetic lag, the lower benefits will be at their present value. But once genetic gain is realized in production, 
benefits will be incurred every production cycle as long as this genetic level is maintained. Benefits will increase further when additional genetic gain is realized. Costs are made up of costs for, e.g., facilities, rearing selection candidates, and genotyping. These costs are incurred prior to the timing of benefits. To account for differences in timing of costs and benefits, these need to be evaluated at their present values. The difference in the present value of benefits and the present value of costs is the net present value (NPV). A positive NPV indicates that benefits outweigh the costs. Thus, the objective of an integrated breeding company should be to maximize NPV, which requires the balance between costs and benefits to be optimized.

For specialized breeding companies only a proportion of the benefits from genetic improvement realized in production is accrued by the company via the sales of eggs or juveniles. If a specialized breeding company would accrue all benefits, there would be no incentive for producers to buy their products. Just as for integrated breeding companies, higher costs may be expected to generate more genetic gain, but the relation with benefits is unclear. To overcome this issue, the budget of a specialized breeding company can be treated as fixed, so that the objective should be to maximize $\Delta \mathrm{H}$. In this case the shadow value of the budget constraint can be used to judge if the budget should be decreased or increased.

Given the breeder's equation (Rendel and Robertson, 1950), factors that affect the selection intensity, accuracy, and generation interval are obvious targets for the optimization of breeding program design. Smith (1969) developed expressions to optimize the selection intensity in mass selection for the objective to maximize cumulative genetic gain up to some point in time. Namkoong (1970) developed expressions to optimize truncation points in two-stage selection for the objective to maximize $\Delta H$. Targeting both the selection intensity and accuracy, Dekkers et al. (1996) optimized the size of progeny groups in a specialized breeding company for dairy cattle for alternative objectives, including maximization of $\Delta \mathrm{H}$, semen sales, and net returns from semen sales. Apart from the elements in the breeder's equation, the genetic lag between improvement in the nucleus and in production is a crucial factor for the design of breeding programs. Skagemo et al. (2010) and Skagemo et al. (2014) showed that profit can be increased by shortening this genetic lag by selecting parents used for dissemination. In studies on the optimization of aquaculture breeding programs economic aspects have been considered only vaguely. For 
example, trait definitions were hypothetical or economic values of traits were not derived in accordance to theory (Martinez et al., 2006; Skagemo et al., 2014; Skagemo et al., 2010). The absence of realistic economic inputs results in hypothetical output, which is little informative on the potential for economic gain. When the potential for economic gain is not quantified, it may remain hard to judge the relevance of economic optimization.

As noted above, objectives of integrated and specialized breeding companies differ. Breeding programs with different objectives have different optimum designs (Dekkers et al., 1996). For integrated breeding companies the optimum structure for dissemination of genetic improvement from the nucleus to production is unclear. Furthermore, the relation between the optimum number of selection candidates, the length of the time horizon and production output is not known, and may differ for alternative breeding program designs. For specialized breeding companies a relevant question is how the allocation of budget over full-sibs of selection candidates in performance tests can be optimized to maximize $\Delta \mathrm{H}$. Factors that determine the optimum allocation of budget and the maximum $\Delta \mathrm{H}$ have not yet been studied.

\subsection{Thesis outline}

As an introduction to the status of breeding programs in European aquaculture, their impact is evaluated in chapter $\mathbf{2}$ based on results from a survey among breeding companies of the main species. The market share of breeding companies in aquaculture production is estimated, main characteristics of breeding companies per species are described, and estimates of genetic gain on growth performance are provided. For the economic optimization of breeding programs the first step is to derive economic values of traits. Chapter 3 provides a bio-economic model for the derivation of economic values of the production traits: growth rate, feed intake rate, mortality rate, and uniformity. The bioeconomic model is developed for production systems with quota on stocking density, such as cage farming, but can be modified to account for alternative quota. The bio-economic model is used to derive economic values for gilthead seabream. Chapter 4 provides a general method for the derivation of the economic value of $\mathrm{R}_{0}$, a measure of disease transmission rate, for macroparasites. This method is applied to derive the economic value of $\mathrm{R}_{0}$ for sea lice in Atlantic salmon aquaculture in Norway. In chapter 5 the method is extended for the derivation of the economic value of $R_{0}$ for microparasites. In chapter 6 cost-benefit analysis is used to evaluate alternative breeding program designs, with and 
without multiplier tier. The number of selection candidates is optimized to maximize NPV of the breeding programs. Relations between the optimum number of selection candidates and the length of the time horizon and production output of the company are studied. In chapter 7 the allocation of budget over the numbers of phenotyped and genotyped full-sibs of selection candidates in performance tests in a breeding program for Atlantic salmon is optimized to maximize $\Delta H$. Sensitivity analyses are performed on the maximum $\Delta H$ and the relative allocation of budget over activities at the optimum. Finally, in chapter 8 the economic impact of selective breeding on European aquaculture is evaluated by drawing from results of this thesis. Furthermore, the chapter provides a synthesis of the work on the definition of the breeding goal, and elaborates on methodology for the optimization of breeding program design.

\subsection{References}

Amer, P., Woolaston, R.R., Eady, S.J., McEwan, J.C., 1999. Economic values for sheep internal parasite resistance traits in New Zealand and Australia. Proc. Assoc. Advmt. Anim. Breed. Genet. 504-507.

Amer, P.R., Fox, G.C., 1992. Estimation of Economic Weights in Genetic-Improvement Using Neoclassical Production Theory - an Alternative to Rescaling. Anim Prod. 54, 341-350.

Amer, P.R., Fox, G.C., Smith, C., 1994. Economic Weights from Profit Equations - Appraising Their Accuracy in the Long-Run. Anim Prod. 58, 11-18.

Besson, M., Aubin, J., Komen, H., Poelman, M., Quillet, E., Vandeputte, M., van Arendonk, J.A.M., de Boer, I.J.M., 2016. Environmental impacts of genetic improvement of growth rate and feed conversion ratio in fish farming under rearing density and nitrogen output limitations. J Clean Prod. 116, 100-109.

Besson, M., Komen, H., Aubin, J., De Boer, I.J.M., Poelman, M., Quillet, E., Vancoillie, M., Vandeputte, M., Van Arendonk, J.A.M., 2014. Economic values of growth and feed efficiency for fish farming in recirculating aquaculture system with density and nitrogen output limitations: a case study with African catfish (Clarias gariepinus). J Anim Sci. 92, 5394-5405.

Bishop, S.C., Jackson, F., Coop, R.L., Stear, M.J., 2004. Genetic parameters for resistance to nematode infections in Texel lambs and their utility in breeding programmes. Anim Sci. 78, 185-194.

Brascamp, E.W., Smith, C., Guy, D.R., 1985. Derivation of Economic Weights from Profit Equations. Anim Prod. 40, 175-180.

Cunningham, E.P., 1969. The Relative Efficiencies of Selection Indexes. Acta Agric Scand. 19, 4548.

Dekkers, J.C.M., Vandervoort, G.E., Burnside, E.B., 1996. Optimal Size of Progeny Groups for Progeny-Testing Programs by Artificial Insemination Firms. J Dairy Sci. 79, 2056-2070.

Directorate of Fisheries, 2018. Key figures from Norwegian aquaculture industry 2017. Directorate of Fisheries, Norway.

Gibson, J.P., Kennedy, B.W., 1990. The Use of Constrained Selection Indexes in Breeding for Economic Merit. Theor Appl Genet. 80, 801-805.

Gjedrem, T., 1972. A study on the definition of the aggregate genotype in a selection index. Acta Agric Scand. 22, 11-16.

Goddard, M.E., 1998. Consensus and debate in the definition of breeding objectives. J Dairy Sci. 81, 6-18. 
Groen, A.F., 1989. Economic Values in Cattle-Breeding 2. Influences of Production Circumstances in Situations with Output Limitations. Livest Prod Sci. 22, 17-30.

Groen, A.F., 2003. Breeding objectives and selection strategies for layer production. in: Muir, A.M., Aggrey, S.E. (Eds.), Poultry genetics, breeding and biotechnology. CAB International, 101112 .

Harris, D.L., Newman, S., 1994. Breeding for Profit - Synergism between Genetic-Improvement and Livestock Production (a Review). J Anim Sci. 72, 2178-2200.

Havenstein, G.B., Ferket, P.R., Qureshi, M.A., 2003. Growth, livability, and feed conversion of 1957 versus 2001 broilers when fed representative 1957 and 2001 broiler diets. Poult Sci. $82,1500-1508$.

Havenstein, G.B., Ferket, P.R., Grimes, J.L., Qureshi, M.A., Nestor, K.E., 2007. Comparison of the performance of 1966- versus 2003-type Turkeys when fed representative 1966 and 2003 Turkey diets: Growth rate, livability, and feed conversion. Poult Sci. 86, 232-240.

Hazel, L.N., 1943. The genetic basis for constructing selection indexes. Genetics. 28, 476-490.

Henderson, C.R., 1975. Best Linear Unbiased Estimation and Prediction under a Selection Model. Biometrics. 31, 423-447.

James, J.W., 1986. Economic evaluation of breeding objectives in sheep and goats - General considerations. 3rd World Congress on Genetics Applied to Livestock Production.

Lobo, R.N.B., Pereira, I.D.C., Faco, O., McManus, C.M., 2011. Economic values for production traits of Morada Nova meat sheep in a pasture based production system in semi-arid Brazil. Small Rumin Res. 96, 93-100.

Martinez, V., Kause, A., Mantysaari, E., Maki-Tanila, A., 2006. The use of alternative breeding schemes to enhance genetic improvement in rainbow trout: II. Two-stage selection. Aquaculture. 254, 195-202.

McArthur, A., 1987. Weighting breeding objectives-an economic approach. In: Proceedings of the sixth annual conference of the Australian Association of Animal Breeding and Genetics, Perth 187-197.

Moav, R., 1973. Economic evaluation of genetic differences. in: Moav, R. (Ed.), Agricultural Genetics, 319-352.

Namkoong, G., 1970. Optimum Allocation of Selection Intensity in 2 Stages of Truncation Selection. Biometrics. 26, 465-\&.

Nielsen, H.M., Amer, P.R., Byrne, T.J., 2014. Approaches to formulating practical breeding objectives for animal production systems. Acta Agr Scand A An Sci. 64, 2-12.

Olesen, I., Groen, A.F., Gjerde, B., 2000. Definition of animal breeding goals for sustainable production systems. J Anim Sci. 78, 570-582.

Ponzoni, R.W., Nguyen, N.H., Khaw, H.L., 2007. Investment appraisal of genetic improvement programs in Nile tilapia (Oreochromis niloticus). Aquaculture. 269, 187-199.

Rauw, W.M., Kanis, E., Noordhuizen-Stassen, E.N., Grommers, F.J., 1998. Undesirable side effects of selection for high production efficiency in farm animals: a review. Livest Prod Sci. 56, $15-33$.

Rendel, J.M., Robertson, A., 1950. Estimation of genetic gain in milk yield by selection in a closed herd of dairy cattle. J Genet. 50, 1-8.

Skagemo, V., Sonesson, A.K., Meuwissen, T.H.E., Rye, M., 2010. Increased profits in aquaculture through optimised dissemination schemes. Aquaculture. 300, 65-72.

Skagemo, V., Sonesson, A.K., Meuwissen, T.H.E., Lillehammer, M., Rye, M., 2014. The dissemination of genetic improvement in salmon production. Aquaculture. 422-423, 78-83.

Smith, C., 1969. Optimum Selection Procedures in Animal Breeding. Anim Prod. 11, 433-442.

Smith, C., James, J.W., Brascamp, E.W., 1986. On the Derivation of Economic Weights in Livestock Improvement. Anim Prod. 43, 545-551.

Tacon, A.G.J., Hasan, M.R., Metian, M., 2011. Demand and supply of feed ingredients for farmed fish and crustaceans: trends and prospects. Food and Agriculture Organization of the United Nations (FAO), Rome, 1-87.

van Middelaar, C.E., Berentsen, P.B.M., Dijkstra, J., van Arendonk, J.A.M., de Boer, I.J.M., 2014. Methods to determine the relative value of genetic traits in dairy cows to reduce greenhouse gas emissions along the chain. J Dairy Sci. 97, 5191-5205. 
Visscher, P.M., Bowman, P.J., Goddard, M.E., 1994. Breeding objectives for pasture based dairy production systems. Livest Prod Sci. 40, 123-137. 



\title{
2 \\ Impact of selective breeding on European aquaculture
}

\author{
Kasper Janssen ${ }^{1}$, Hervé Chavanne ${ }^{2}$, Paul Berentsen ${ }^{3}$ and Hans Komen ${ }^{1}$ \\ ${ }^{1}$ Wageningen University, Animal Breeding and Genomics, Droevendaalsesteeg 1, 6708 \\ PB Wageningen, The Netherlands \\ ${ }^{2}$ Università degli Studi di Padova, Department of Comparative Biomedicine and Food \\ Science, Viale dell'Università 16, Agripolis, 35020 Legnaro (PD), Italy \\ ${ }^{3}$ Wageningen University, Business Economics Group, Hollandseweg 1, 6706 KN \\ Wageningen, The Netherlands
}

Aquaculture (2017) 472:8-16 


\begin{abstract}
Objectives of this study were to determine the combined market share of breeding companies in aquaculture production in Europe, to describe the main characteristics of breeding companies and their programs, and to provide per species estimates on cumulative genetic gain in growth performance. Surveys were conducted among breeding companies of five major species cultured in Europe: Atlantic salmon, rainbow trout, European seabass, gilthead seabream, and turbot. The market share was estimated as the combined egg or juvenile production of breeding companies relative to the total egg or juvenile production in Europe for each species in 2012. Cumulative genetic gain was estimated from the number of selected generations in current breeding programs, combined with genetic trends, reported selection responses in literature, and phenotypic differences. The combined market share of breeding companies ranged from $43-56 \%$ for seabass to $100 \%$ for turbot. The total volume of fish production in Europe that originated from selective breeding was 1653-1706 thousand tons, corresponding to $80-83 \%$ of the total aquaculture production. Over species, there were 37 breeding programs of which the majority performed family selection. Growth performance was universally selected upon. Cumulative genetic gain in growth performance varied from $+65 \%$ for turbot to $+900 \%$ for trout in terms of harvest weight, and from $+25 \%$ for turbot to $+200 \%$ for trout in terms of thermal growth coefficient. It is concluded that selective breeding has a major impact on European aquaculture and will contribute to future growth of the sector.
\end{abstract}




\subsection{Introduction}

In Europe the six main cultured finfish species are Atlantic salmon (Salmo salar), rainbow trout (Oncorhynchus mykiss), gilthead seabream (Sparus aurata), European seabass (Dicentrarchus labrax), common carp (Cyprinus carpio) and turbot (Scophthalmus maximus). Together their production accounts for $97 \%$ of the total aquaculture production in Europe (Table 1). Aquaculture plays an increasingly important role in global food production and this trend is expected to continue (FAO, 2014). If widely adopted, selective breeding will play an important role in securing the future demand for aquaculture products (Gjedrem et al., 2012).

The start of domestication of most species coincided with early advances in reproductive techniques, which in a few cases, dates back to more than a century ago. Selective breeding generally has a much shorter history and often followed the industrialisation of aquaculture as outlined below. The order in the following overview on breeding in aquaculture species is based on the length of the domestication history.

Table 1 Aquaculture production of six major finfish species in Europe in 2012 (FAO, 2015).

\begin{tabular}{lcc}
\hline Species & Production (1000 tons) & $\begin{array}{c}\text { Proportion of total } \\
\text { production }(\%)\end{array}$ \\
\hline Atlantic salmon & 1487 & 72 \\
Rainbow trout & 253 & 12 \\
Gilthead & 104 & 5 \\
seabream & & 3 \\
European seabass & 71 & 3 \\
Common carp & 67 & 1 \\
Turbot & 13 & 3 \\
Other & 70 & 100 \\
\hline Total Europe & 2065 & \\
\hline
\end{tabular}

\section{$\underline{\text { Carp }}$}

Common carp has the longest history of domestication. With the advancement in reproductive techniques during the 19th century, many different strains were developed in Germany and the Czech Republic (Komen, 1990). Since then genetic improvement has largely relied on crossbreeding of inbred strains and selective breeding plays only a minor role (Janssen et al., 2015; Vandeputte, 2003). Carp will, therefore, not be considered in this study.

\section{$\underline{\text { Trout }}$}

Rainbow trout was introduced to Europe from the USA in the period 1890-1900, with the primary intent to develop recreational fisheries (Crawford and Muir, 2008). These fish 
formed the genetic basis for modern trout farming (Gall and Crandell, 1992; Gross et al., 2007). Hatcheries at the time were part of (re)stocking programs and in selection most emphasis was placed on improvement of fecundity, early sexual maturity and off-season spawning (Donaldson and Olson, 1957; Gall, 1975; Millenbach, 1950). Commercial aquaculture of trout started to develop in the 1950's (Paisley et al., 2010) and in the 1970's multiple hatcheries performed selection schemes with the aim to improve traits relevant for aquaculture, such as bodyweight and precocious maturation, although the scientific basis of these breeding programs was limited (Aulstad et al., 1972; Gjedrem, 1985; Guyomard, 1981; Morkramer et al., 1985).

\section{$\underline{\text { Salmon }}$}

In the late 1960's fish from fish farm Mowi AS were used to set up the first breeding program for Atlantic salmon. This program formed the genetic basis for the currently produced Mowi strain (Glover et al., 2009). In the early 1970's AKVAFORSK collected fish from 40 Norwegian rivers, one Swedish river, and fish farm Mowi to set up the first family selection breeding program, from which the current AquaGen strain originates (Gjedrem, 2012; Gjedrem et al., 1991). Other strains with major contributions to currently farmed salmon in Europe are Bolaks, collected around 1974-1975, and Jakta, collected somewhere in the 1980's (pers. comm. Bakke, 2014).

\section{Seabream, seabass and turbot}

In the south of Europe aquaculture of European seabass and gilthead seabream started around the 1970's and was initially based on capture of wild larvae and juveniles. Following improvements in reproductive techniques, development of these industries accelerated in the 1990's (Coves et al., 1991; Divanach and Kentouri, 2000; Moretti et al., 1999). At that time the first breeding programs for seabass were being developed in several countries (Chatain and Chavanne, 2009). The first trials on selective breeding of seabream were carried out in the mid-1990's (Knibb et al., 1997; 1998) and it was only in the early 2000 's that the first commercial breeding programs of seabream were initiated (Brown, 2003; Thorland et al., 2006). Turbot aquaculture started in the 1970's in Scotland and its production expanded rapidly in Southern Europe since 1990. The first breeding programs were initiated in the mid 1990's (Danacher and Garcia-Vazquez, 2007).

In summary, the adoption of selective breeding has spread from the north of Europe towards the south. First attempts for genetic improvement were often based on relatively simple 
mass selection schemes, but as industries matured more advanced breeding practices such as family selection gained ground.

The impact of selective breeding on European aquaculture can be described by the combined market share of breeding companies in production, traits that are selected upon, and cumulative genetic gain. The first description of selective breeding in Europe was published in 2008 and was based on a survey conducted among breeding companies in Europe in 2006 (AquaBreeding, 2008). The study provided information on which traits were selected upon in breeding programs, but not on the combined market share of breeding companies in European production nor on cumulative genetic gain. On a global level it has been estimated that in 2010 approximately $8.2 \%$ of the aquaculture production originated from genetically improved stocks (Gjedrem et al., 2012). In developed countries this proportion was expected to be higher (Rye et al., 2010), but no specific estimates for the European situation are available. Data on selection response and cumulative genetic gain per species have been reported in literature, but these have not been analysed in order to estimate cumulative genetic gain in existing breeding programs. In this study improvements in growth performance, both in terms of harvest weight and thermal growth coefficient, are considered to be most illustrative for cumulative genetic gain, because these are quantitative traits that are universally selected among all five species (AquaBreeding, 2008).

Various methods to estimate cumulative genetic gain have been reported in literature. Genetic trend analysis, the regression of estimated breeding values on generations, provides good estimates of cumulative genetic gain (Blair and Pollak, 1984). Of indicative value is the selection response in early generations extrapolated to a higher current number of selected generations. The best predictors of cumulative genetic gain are common garden experiments, in which wild and selected fish are kept in the same environment to test their performance. In the same environment and in absence of genotype by environment interaction, phenotypic differences equal genetic differences (Blair and Pollak, 1984). Studies involving common garden experiments have, however, not been conducted, except for salmon (e.g., Glover et al. (2009) and Solberg et al. (2013)). Across environments, thermal growth coefficient (TGC) can be used alternatively to compare growth performance of wild and selected fish. TGC corrects for temperature effects on growth performance and is calculated as (Cho, 1992; Iwama and Tautz, 1981): 
$\mathrm{TGC}=\frac{\sqrt[3]{\mathrm{W}_{\mathrm{t}}}-\sqrt[3]{\mathrm{W}_{0}}}{\sum_{\mathrm{i}=1}^{\mathrm{t}} \mathrm{T}_{\mathrm{i}}} \cdot 1000$

where $W_{0}$ is initial weight; $W_{t}$ is weight at day $t ; T_{i}$ is daily average water temperature and $\sum_{\mathrm{i}=1}^{\mathrm{t}} \mathrm{T}_{\mathrm{i}}$ is the sum of daily water temperatures over the growing period. A trademark of TGC is that it corrects for heterogeneity in growing period and rearing temperature (SaeLim et al., 2013; Trong et al., 2013). Important sources of environmental variation are, thereby, corrected for, and differences in TGC of wild and selected fish provide a proxy for genetic differences.

The objective of this study was to assess the impact of selective breeding on European aquaculture by determining:

1. The combined market share of breeding companies

2. The main characteristics of breeding companies and their programs

3. Cumulative genetic gain in growth performance

1 and 2 are addressed based on surveys carried out among breeding companies in Europe. 3 is addressed by combining results from the surveys with a literature review.

In this paper the term 'breeding company' is defined as a company, institute or organization, either private or public, that operates a selective breeding program for a particular species. Some breeding companies operate separate breeding programs for multiple species. Europe is defined as the EU28, Norway, Iceland, Faroe Islands and the Isle of Man. Cumulative genetic gain is defined as genetic gain that has been build up over multiple generations of selection. Two types of selection are distinguished: mass and family selection. In mass selection breeding values are estimated based on own performance records only, whereas in family selection records on related individuals are also used.

\subsection{Materials and methods}

\subsubsection{Surveys among breeding companies}

In a first survey conducted in collaboration with AQUATRACE ${ }^{1}$, questionnaires were distributed among breeding companies in Europe (Chavanne et al., 2016). Breeding companies were identified in the AQUABREEDING ${ }^{2}$ research project, complemented by

\footnotetext{
AQUATRACE - https://aquatrace.eu/ - $7^{\text {th }}$ Framework Programme for research (FP7) ${ }^{2}$ AQUABREEDING $-6^{\text {th }}$ Framework Programme for research (FP6)
} 
internet search and snowball sampling (Goodman, 1961). This first questionnaire included questions related to the type of selection, the number of selected generations, selected traits, and the quantities of eggs or juveniles produced. Breeding companies were asked not to declare eggs or juveniles that were disposed, and to avoid double counting when both egg and juvenile production data were reported. For all species egg or juvenile production data of 2012 were collected, except for trout. For trout 2011 data were collected, because 2012 data were not available yet at the start of the survey. As not all companies completed this extensive first questionnaire, a second survey was carried out among the non-respondents of the first survey involving a limited number of questions. The aim of this second survey was to identify whether a breeding company employed mass or family selection and how many eggs or juveniles it produced.

\subsubsection{Total egg and juvenile production in Europe}

For the estimation of the market share of breeding companies, an estimate of the total egg or juvenile production in Europe was required. For seabass, seabream, and turbot, juvenile production data were retrieved from FEAP (FEAP, 2014a, incl. unpublished results). Trout and salmon breeding companies mainly sold eyed eggs, hence egg production data were collected for these species. Contrarily to juvenile production of seabass, seabream, and turbot, egg production data of trout and salmon were not routinely collected on a European level and had to be derived on a per country basis from various sources.

For salmon per country data were collected, depending on availability, on: number of eggs produced, import of eggs, export of eggs, and number of eggs used in domestic production. For all countries some data were missing and had to be derived from other data. The data were related as follows:

National egg production $=$ eggs used for domestic production + export - import

When the number of eggs used for domestic production could neither be obtained nor derived from Eq. 2, this figure was estimated from national fish production data, yield per smolt and egg to smolt survival, according to:

Eggs for domestic production = fish production/ yield per smolt/ egg to smolt survival 
In this equation, means of national fish production statistics of 2012 according to FEAP (2014a) and FAO (2015) were used as fish production data. Yield per smolt was $4.39 \mathrm{~kg}$ for Norway, $5.49 \mathrm{~kg}$ for the Faroe Islands (Marine Harvest, 2014), and it was assumed to be $4.5 \mathrm{~kg}$ for Iceland. Egg to smolt survival was assumed to be $80 \%$ (pers. comm. Bakke, 2014).

For trout no complete overview of the trade and use of eggs was required to estimate the egg production for every country. Only national egg production statistics per country were, therefore, collected. When the national egg production was unknown, it was derived with Eq. 2. The quantity of eggs used in production was estimated from fish production, assuming a mean harvest weight and survival, similar to Eq. 3.

\subsubsection{Market share of breeding companies}

Market share is defined as a firm's sales relative to the total sales of all firms in the same industry (Ghosh, 2004). Here, it was used first as the combined egg or juvenile production of breeding companies relative to the total egg or juvenile production in Europe for each particular species. The egg and juvenile production of breeding companies followed from the survey results. Second, to estimate the total aquaculture production in Europe that originated from selective breeding, market shares of breeding companies were multiplied by volumes of fish production per species (Table 1). This volume was divided by the total aquaculture production in Europe to estimate the market share of selective breeding.

For salmon the combined reported egg production of breeding companies was higher than the total egg production in Europe. The market share of breeding companies could, therefore, not be determined from the combined egg production of breeding companies relative to the total egg production in Europe. Instead, it was estimated as $100 \%$ (473 million eggs) minus the part of the egg production that with certainty could not be attributed to breeding companies on a per country basis.

\subsubsection{Cumulative genetic gain}

Cumulative genetic gain in trout was estimated both from reported selection responses and by comparison of TGC of wild and selected fish. Cumulative genetic gain in salmon was estimated from common garden experiments performed in recent generations. Cumulative genetic gains in seabass, seabream, and turbot were estimated both from reported selection responses and from genetic trends. One of the outcomes of the survey was the number of 
selected generations in current breeding programs. This information was used to extrapolate cumulative genetic gain in a studied generation to current generations in breeding programs. When cumulative genetic gain on either harvest weight or TGC could not be estimated directly, a standard production situation with regard to temperature, initial weight, and harvest weight was assumed to convert cumulative genetic gain in harvest weight to cumulative genetic gain in TGC, and vice versa.

\subsection{Results}

Out of 37 existing breeding programs, data of 28 were retrieved in the first survey. An additional nine breeding programs participated in the second survey. All information requested in either survey was obtained from participating breeding programs. There was only one seabream breeding program from which no data were obtained, but this program was of minor importance and was, therefore, ignored.

\subsubsection{European egg and juvenile production}

An overview of juvenile production data of seabass, seabream, and turbot is presented in Table 2. Greece was the major producer of juveniles for both seabass and seabream and Spain was the major producer of turbot juveniles. For turbot the reported juvenile production in Spain is probably closer to 17 million (pers. comm. Cabaleiro, 2015).

Table 2 Juvenile production of European seabass, gilthead seabream, and turbot per country in 2012 (FEAP, 2014a; unpublished results FEAP, 2014b).

\begin{tabular}{lccc}
\hline Country & $\begin{array}{c}\text { European seabass } \\
\text { (million juveniles) }\end{array}$ & $\begin{array}{c}\text { Gilthead seabream } \\
\text { (million juveniles) }\end{array}$ & $\begin{array}{c}\text { Turbot } \\
\text { (million juveniles) }\end{array}$ \\
\hline Croatia & 8.1 & 5.4 & 0 \\
Cyprus & 5.3 & 8.0 & 0 \\
France & 46.0 & 30.4 & 1.3 \\
Greece & 184.0 & 245 & 0 \\
Italy & 40.0 & 70 & 0 \\
Spain & 36.4 & 55.0 & a 19.0 \\
\hline Total Europe & 319 & 414 & 20.2 \\
\hline
\end{tabular}

${ }^{\mathrm{a}}$ This figure should rather be 17 million (pers. comm. Cabaleiro, 2015)

For trout the French egg production was based on the assumption that approximately $90 \%$ of the egg production originated from breeding companies in the survey (pers. comm. Haffray, 2015) (Table 3). The Polish egg production was calculated from fish production, assuming a mean survival of $35 \%$ and a harvest weight of $350 \mathrm{~g}$, corrected for the import of eight million eggs (pers. comm. anonymous, 2015) while export was assumed zero. The Swedish egg production was calculated from production assuming a mean survival of $45 \%$, a harvest weight of $2 \mathrm{~kg}$ and no export nor import of eggs (pers. comm. Funcke, 2015). The 
number of eggs used in production in England and Wales was 39 million, calculated from a fish production of 6824 tons (Reese, 2013), an egg to harvest survival of $50 \%$, and a harvest weight of $350 \mathrm{~g}$. This figure was used together with data of Northern Ireland (pers. comm. DARD Fisheries, 2014) and Scotland (Munro and Wallace, 2012) to calculate egg production in the UK.

Table 3. Production of eyed eggs of rainbow trout in Europe in 2011

\begin{tabular}{|c|c|c|}
\hline Country & $\begin{array}{l}\text { Production } \\
\text { (million) }\end{array}$ & Reference \\
\hline France & 400 & Estimate based on pers. comm. Haffray (2015) \\
\hline Denmark & 324 & pers. comm. Thomsen (2014) \\
\hline Italy & 265 & pers. comm. Grossi (2014) \\
\hline Spain & 259 & Ministerio de Agricultura (2014) \\
\hline Poland & 110 & Estimated from fish production \\
\hline Isle of Man & 50 & pers. comm. Dentler (2015) \\
\hline United & 48 & Estimate based on pers. comm. DARD Fisheries (2014), \\
\hline Kingdom & & Munro and Wallace (2012), Reese (2013) \\
\hline Norway & 40 & pers. comm. Korsvoll (2014) \\
\hline Finland & 21 & pers. comm. Kause (2014) \\
\hline Germany & 13 & Statistisches Bundesamt (2012) \\
\hline Sweden & 13 & Estimated from fish production \\
\hline Total Europe & 1543 & \\
\hline
\end{tabular}

For salmon the only unknown variables that could not be calculated directly using Eq. 2 or 3 were the Norwegian egg production and export of eggs (Table 4). The Norwegian export of eggs was calculated by subtracting exports by the other countries from total exports. Total exports by European countries were determined as the sum of imports by European countries and exports to outside Europe, the latter of which were limited to the export of 32.2 million eggs to Chile (Sernapesca, 2014), while imports from non-European countries were negligible (pers. comm. Bakke, 2014). When the Norwegian export was known, the Norwegian egg production could be calculated with Eq. 2 and equalled 360 million. The number of eggs used in production in Norway was calculated at 352 million using Eq. 3, which corresponds well to the 370 million eggs used in production in 2013/2014 (Kontali Analyse cited in Hosteland, 2014). The total egg production in Europe was 473 million. 
Table 4 Production and trade of eyed eggs of Atlantic salmon within Europe in 2012.

\begin{tabular}{lcccc}
\hline Country & $\begin{array}{c}\text { Production } \\
\text { (million) }\end{array}$ & $\begin{array}{c}\text { Export } \\
\text { (million) }\end{array}$ & $\begin{array}{c}\text { Import } \\
\text { (million) }\end{array}$ & $\begin{array}{c}\text { Used in domestic } \\
\text { production } \\
\text { (million) }\end{array}$ \\
\hline Norway & $360^{\mathrm{C} 2}$ & $30^{\mathrm{C}}$ & $22^{\mathrm{R} 1}$ & $352^{\mathrm{C} 3}$ \\
Iceland & $55^{\mathrm{R} 2}$ & $54^{\mathrm{R} 2}$ & $0^{\mathrm{C} 2}$ & $1^{\mathrm{C} 3}$ \\
UK-Scotland & $18.5^{\mathrm{R} 3}$ & $0^{\mathrm{R} 3}$ & $44.7^{\mathrm{R} 3}$ & $63.2^{\mathrm{R} 3}$ \\
Ireland & $16.9^{\mathrm{R} 4}$ & $10^{\mathrm{R} 4}$ & $0.6^{\mathrm{R} 4}$ & $7.4^{\mathrm{R} 4}$ \\
Faroe Islands & $12.5^{\mathrm{R} 5}$ & $0^{\mathrm{R} 5}$ & $4.5^{\mathrm{C} 2}$ & $17^{\mathrm{C} 3}$ \\
UK-rest & $10^{\mathrm{R} 3}$ & $10^{\mathrm{R} 3}$ & $0^{\mathrm{R} 6}$ & $0^{\mathrm{R} 6}$ \\
\hline Total Europe & 473 & 104 & $72^{2}$ & 441 \\
\hline
\end{tabular}

$\mathrm{R}=$ Values from references: ${ }^{1}$ pers. comm. Bakke (2014); ${ }^{2}$ pers. comm. Jonasson (2014); ${ }^{3}$ Munro and Wallace (2012); ${ }^{4}$ pers. comm. Robinson (2014); ${ }^{5}$ pers. comm. Patursson (2013); ${ }^{6}$ Poseidon (2008)

$\mathrm{C}=$ Calculated: ${ }^{2}$ using Eq. $2 ;{ }^{3}$ using Eq. 3

\subsubsection{Market share of breeding companies}

The reported egg and juvenile production per breeding program are presented in Table 5. For seabass one company did not produce any eggs or juveniles from its breeding program in 2012. Another seabass breeding company indicated to have sold eggs and larvae, which were estimated to have resulted in the production of an additional 40-60 million juveniles in Europe. 
Table 5 Per species egg or juvenile production from breeding programs and the type of selection performed.

\begin{tabular}{ccccc|ccccc}
\hline BP & Species & $\begin{array}{c}\text { Eggs/ } \\
\text { juveniles }\end{array}$ & Million & Selection & BP & Species & $\begin{array}{c}\text { Eggs/ } \\
\text { juveniles }\end{array}$ & Million & Selection \\
\hline 1 & Trout & eggs & 210 & $\mathrm{f}$ & 20 & & & 17 & $\mathrm{f}$ \\
2 & & & 200 & $\mathrm{f}$ & 21 & & & $10-15$ & $\mathrm{f}$ \\
3 & & & 188 & $\mathrm{f}$ & 22 & & & 10 & $\mathrm{f}$ \\
4 & & & 120 & $\mathrm{~m}$ & 23 & Seabass & juveniles & a $52-72$ & $\mathrm{~m}$ \\
5 & & & 80 & $\mathrm{~m}$ & 24 & & & $40-60$ & $\mathrm{f}$ \\
6 & & & $30-60$ & $\mathrm{f}$ & 25 & & & 30 & $\mathrm{~m}$ \\
7 & & 51 & $\mathrm{f}$ & 26 & & & 16 & $\mathrm{~m}$ \\
8 & & 50 & $\mathrm{f}$ & 27 & & & 0 & $\mathrm{f}$ \\
9 & & & 25 & $\mathrm{f}$ & 28 & Seabream & juveniles & 75 & $\mathrm{f}$ \\
10 & & & 20 & $\mathrm{~m}$ & 29 & & & 70 & $\mathrm{f}$ \\
11 & & & 18 & $\mathrm{f}$ & 30 & & & $40-60$ & $\mathrm{f}$ \\
12 & & & $2-10$ & $\mathrm{f}$ & 31 & & & $30-35$ & $\mathrm{f}$ \\
13 & & 6 & $\mathrm{~m}$ & 32 & & & 20 & $\mathrm{~m}$ \\
14 & & & $\mathrm{~m}$ & 33 & & & 13 & $\mathrm{f}$ \\
15 & & & & $\mathrm{~m}$ & 34 & & & $<2$ & $\mathrm{~m}$ \\
16 & Salmon & eggs & $210-230$ & $\mathrm{f}$ & 35 & Turbot & juveniles & 12 & $\mathrm{f}$ \\
17 & & $100-120$ & $\mathrm{f}$ & 36 & & & 5 & $\mathrm{f}$ \\
18 & & & 111 & $\mathrm{f}$ & 37 & & & 1.3 & $\mathrm{~m}$ \\
19 & & & 55 & $\mathrm{f}$ & & & & & \\
\hline
\end{tabular}

$\mathrm{BP}=$ Breeding program

$\mathrm{f}=$ family selection, $\mathrm{m}=$ mass selection

${ }^{\text {a }}$ Includes estimated juvenile production from egg sales in Europe

The market share of breeding companies per species is presented in Table 6 . The only three companies that reproduced turbot operated breeding programs (pers. comm. Cabaleiro, 2015), hence their combined market share was 100\%. For salmon the combined egg production by the seven breeding companies was 513-558 million, which was 40-85 million higher than the total egg production in Europe. The production of 26-31 million eggs in the UK and the Faroe Islands did not originate from the seven breeding companies. This egg production originated from a few small companies that did not have a breeding program (pers. comm. Tinch, 2014) and from a breeding program that was terminated in 2005 (pers. comm. Patursson, 2015). The market share of breeding companies was, therefore, $93-95 \%$ in 2012. Since 2013 the broodstock in the Faroe Islands was replaced by broodstock of one of the seven breeding companies and the market share of breeding companies has increased accordingly to $96-97 \%$. 
Table 6 Market shares of breeding companies per species.

\begin{tabular}{lccccc}
\hline Item & $\begin{array}{c}\text { Rainbow } \\
\text { trout }\end{array}$ & $\begin{array}{c}\text { Atlantic } \\
\text { salmon }\end{array}$ & $\begin{array}{c}\text { European } \\
\text { seabass }\end{array}$ & $\begin{array}{c}\text { Gilthead } \\
\text { seabream }\end{array}$ & Turbot \\
\hline $\begin{array}{l}\text { Total reported egg/juvenile } \\
\text { production by breeding companies } \\
\text { (million) }\end{array}$ & $1006-1048$ & $513-558$ & ${ }^{\mathrm{a}} 138-178$ & $248-275$ & 18.3 \\
$\begin{array}{l}\text { Total European egg/juvenile } \\
\text { production (million) }\end{array}$ & 1543 & 473 & 319 & 414 & 18.3 \\
Market share (\%) & $65-68$ & ${ }^{\mathrm{b}} 93-95$ & $43-56$ & $60-66$ & 100 \\
\hline
\end{tabular}

${ }^{\mathrm{a}}$ Includes 40-60 million from egg sales to Europe

${ }^{b}$ Estimation based on egg production not originating from breeding programs

The total volume of fish production in Europe that originated from selective breeding was $1653-1706$ thousand tons, corresponding to $80-83 \%$ of the total aquaculture production.

\subsubsection{Characteristics of breeding companies and their programs}

Two types of breeding companies can be distinguished. The first type controls the entire process from reproduction to harvest and has integrated a breeding program in the production process. The second specialized type of breeding company operates a breeding program as its core activity. These companies operate in an international market for egg/ juvenile sales in which they experience a high degree of competition. Most larger scale trout breeding companies, most salmon breeding companies, one medium size seabass breeding company, and one medium size seabream breeding company belonged to this specialized type. Most companies operated a single breeding program. Of the companies that operated a breeding program for seabream, however, four also operated a breeding program for seabass. Only one company operated a breeding program for both trout and salmon.

The combined results of both surveys revealed that for the 37 breeding programs that participated, mass selection was performed in 12 and family selection in 25 breeding programs (Table 5). When family selection was performed, egg or juvenile production tended to be higher than when mass selection was performed. The vast majority of the specialized breeding companies performed family selection. Integrated companies performed mass and family selection about equally often. When mass selection was performed, selected traits were generally limited to growth performance and morphology, whereas in family selection more traits were included (Table 7). 
Table 7 Number of breeding programs that reported to select on a given trait in the first survey $(\mathrm{n}=28)$.

\begin{tabular}{lcccccc}
\hline Selected traits & $\begin{array}{c}\text { Rainbow } \\
\text { trout }\end{array}$ & $\begin{array}{c}\text { Atlantic } \\
\text { salmon }\end{array}$ & $\begin{array}{c}\text { European } \\
\text { seabass }\end{array}$ & $\begin{array}{c}\text { Gilthead } \\
\text { seabream }\end{array}$ & Turbot & Total \\
\hline Growth performance & 9 & 7 & 4 & 5 & 2 & 27 \\
Morphology & 4 & 3 & 3 & 5 & 0 & 15 \\
Disease resistance & 4 & 6 & 2 & 2 & 1 & 15 \\
Product quality & 3 & 6 & 1 & 3 & 0 & 13 \\
Processing yield & 4 & 6 & 2 & 0 & 0 & 12 \\
Reproduction & 5 & 2 & 0 & 0 & 0 & 7 \\
Feed efficiency & 2 & 2 & 1 & 2 & 0 & 7 \\
\hline
\end{tabular}

\subsubsection{Cumulative genetic gain}

For trout the highest reported number of selected generations was 20 in mass selection and 14 in family selection. Considering a three year generation interval, the oldest mass selection program started in the mid 1950's and oldest family selection program started in 1972 (AquaGen, 2015). The reported number of selected generations varied strongly among breeding programs and many of the younger programs were established from strains that had previously been selected, often in a more rudimentary manner. It was, therefore, assumed that most strains used in breeding programs have been selected for at least eight generations. Selection response on harvest weight varies from 7\% (Kause et al., 2005) to 10-13\% (Gjerde, 1986) (Table 8). Four studies were used to estimate TGC of wild trout (Appendix). Martens (2013) reported a TGC of $0.67 \mathrm{~g}^{1 / 3} /($ day degrees $\cdot 1000)$ for juvenile wild trout (Martens, 2013; Martens et al., 2014). Tymchuk and Devlin (2005) reported a bodyweight of $47 \mathrm{~g}$ at 637 days after fertilization at a rearing temperature of $11{ }^{\circ} \mathrm{C}$, corresponding to a TGC around $0.5 \mathrm{~g}^{1 / 3} /($ day degrees $\cdot 1000)$. Devlin et al. (2013) reported a bodyweight of $39 \mathrm{~g}$ at 556 days after fertilization at a rearing temperature of $10{ }^{\circ} \mathrm{C}$, corresponding to a TGC around $0.6 \mathrm{~g}^{1 / 3} /($ day degrees $\cdot 1000)$. Biro et al. (2006) reported a growth from 0.6 to $8.5 \mathrm{~g}$ in 82 days at a temperature of $10^{\circ} \mathrm{C}$, corresponding to a TGC of $1.5 \mathrm{~g}^{1 / 3} /($ day degrees $\cdot 1000)$. Much higher TGCs have been reported for strains from breeding programs. Sae-Lim et al. (2013) reported TGCs of 1.43 to $2.07 \mathrm{~g}^{1 / 3} /($ day degrees - 1000) for a variety of culture systems. Grisdale-Helland et al. (2007) reported TGCs of 2.43 to $2.53 \mathrm{~g}^{1 / 3} /($ day degrees $\cdot 1000)$ for a strain that was grown from 400 to $850 \mathrm{~g}$ in seawater at $11^{\circ} \mathrm{C}$. At the USDA National Center for Cool and Cold Water Aquaculture, strains from three different suppliers to the European market were grown from $6 \mathrm{~g}$ to a final weight of 700-1000 $\mathrm{g}$ at a temperature around $11{ }^{\circ} \mathrm{C}$. They found TGCs of 2.05, 2.09 and $2.40 \mathrm{~g}^{1 / 3} /($ day degrees $\cdot 1000)$ for the three different strains (unpublished results Cleveland, 2015). TGCs of 2.4 and $2.7 \mathrm{~g}^{1 / 3} /($ day degrees $\cdot 1000)$ were also estimated based on 
ongrowing data, provided by two other breeding companies that participated in the survey. Average TGC of wild trout is around $0.8 \mathrm{~g}^{1 / 3} /($ day degrees $\cdot 1000)$ and TGC of selected trout is around $2.2 \mathrm{~g}^{1 / 3} /($ day degrees $\cdot 1000)$, almost 200\% higher (Appendix). Wild trout with a TGC of $0.8 \mathrm{~g}^{1 / 3} /($ day degrees $\cdot 1000)$, stocked at $10 \mathrm{~g}$, and reared at $12{ }^{\circ} \mathrm{C}$, would reach a harvest weight of $300 \mathrm{~g}$ at 473 days. Selected trout with a TGC of $2.2 \mathrm{~g}^{1 / 3} /($ day degrees $\cdot 1000$ ) would after an equal growing period in the same conditions reach a harvest weight over $3 \mathrm{~kg}$ instead. The comparison of TGCs of wild and selected trout suggests that cumulative genetic gain in TGC is about $+200 \%$, and cumulative genetic gain in harvest weight is roughly $+900 \%$.

Table 8 Reported heritabilities $\left(\mathrm{h}^{2}\right)$ and genetic gain on harvest weight $(\Delta \mathrm{G})$ used to predict cumulative genetic gain in growth performance.

\begin{tabular}{lccccc}
\hline Species & $\mathrm{h}^{2}$ & $\begin{array}{c}\Delta \mathrm{G} \text { per } \\
\text { generation }(\%)\end{array}$ & $\begin{array}{c}\Delta \mathrm{G} \text { total } \\
(\%)\end{array}$ & $\begin{array}{c}\text { Selected } \\
\text { generations }\end{array}$ & Reference \\
\hline Trout & - & $10-13$ & $26-30$ & $2-3$ & Gjerde (1986) \\
Trout & $0.26-0.27$ & $4.9-7.9$ & - & 3 & Kause et al. (2005) \\
\hline Salmon & - & - & $121-131$ & $7-8$ & Glover et al. (2009) \\
Salmon & - & - & 196 & $9-10$ & Solberg et al. (2013) \\
\hline Seabass & 0.4 & 26.3 & - & - & Le Boucher et al. (2013) \\
Seabass & $0.52-0.64$ & $25-30$ & - & - & Chatain and Chavanne (2009) \\
Seabass & $0.38-0.44$ & $16-25$ & - & - & Dupont-Nivet et al. (2008) \\
Seabass & 0.44 & - & 65 & 2.6 & Thorland et al. (2015b) \\
Seabass & 0.34 & 23 & - & - & Vandeputte et al. (2009) \\
Seabream & 0.55 & 29 & - & - & Brown (2003) \\
Seabream & - & $5-10$ & - & up to 3 & Knibb (2000) \\
Seabream & 0.34 & - & - & - & Navarro et al. (2009) \\
Seabream & 0.35 & 13 & - & 2.6 & Thorland et al. (2015a) \\
\hline Turbot & - & $10-15$ & - & 3 & Danacher and Garcia-Vazquez \\
& & & & & (2007) \\
Turbot & - & - & 65 & 4 & pers. comm. Johansen (2015) \\
\hline
\end{tabular}

For salmon the total number of selected generations was generally around 10, of which 4 to 11 generations were based on family selection. Except for the AquaGen program, all programs initially performed mass selection. Around the year 2000 family selection became more widely adopted. Glover et al. (2009) performed a common garden experiment with the Mowi strain selected for 7-8 generations and a wild strain of similar origin. Compared to the wild strain fish from the Mowi strain were on average 121-131\% heavier after equal growing periods and the TGC, calculated from their data, was $42-48 \%$ higher. For 7-8 generations these figures correspond to a selection response of $11-12 \%$ on harvest weight or about $5 \%$ on TGC. Solberg et al. (2013) performed a common garden experiment with juveniles of the Mowi strain selected for 9-10 generations and a wild strain. Compared to the wild strain, fish from the Mowi strain were 196\% heavier after equal growing periods 
and the TGC, calculated from their data, was 83\% higher. For 9-10 generations these figures correspond to a selection response of $12 \%$ on harvest weight or $6.6 \%$ on TGC. Assuming similar selection responses across breeding programs, 10 selected generations have resulted in a cumulative genetic gain of about $+200 \%$ on harvest weight or $+80 \%$ on TGC. This improvement is further supported by a reduction in growing period to 2-3 years from egg to harvest and an increase in harvest weight to about $5 \mathrm{~kg}$ (Marine Harvest, 2014), which rather represents an industry average than the even higher actual growth potential (pers. comm. Bakke, 2015).

For seabass the reported number of selected generations varied between two and eight. Vandeputte et al. (2009) compared the growth performance of offspring of wild seabass to the offspring of selected sires and wild dams. Harvest weight was $12 \%$ higher in offspring of selected sires compared to offspring of unselected parents after equal growing periods. When selecting on both males and females, the predicted selection response on harvest weight was $23 \%$. Similar selection responses on harvest weight were predicted by Chatain and Chavanne (2009), Dupont-Nivet et al. (2008) and Le Boucher et al. (2013). Thorland et al. (2015b) reported a selection response on harvest weight of about $25 \%$ in a family selection breeding program, which has resulted in a $65 \%$ improvement on growth performance relative to the base population. The performance of the base population relative to the wild was unclear. Selection responses reported in the above studies were all based on the first few selected generations, which may be inflated due to domestication effects (Vandeputte et al., 2009). Based on two to eight selected generations in current breeding programs, cumulative genetic gain in harvest weight is estimated to range from $+50 \%$ to $+150 \%$. Wild seabass with a TGC of $0.55 \mathrm{~g}^{1 / 3} /($ day degrees $\cdot 1000)$ (based on Vandeputte et al., 2014), stocked at $10 \mathrm{~g}$, and reared at $20^{\circ} \mathrm{C}$, would reach a harvest weight of $350 \mathrm{~g}$ at 449 days. A $50 \%$ higher harvest weight after an equal growing period would correspond to a TGC of $0.66 \mathrm{~g}^{1 / 3} /($ day degrees $\cdot 1000)$, and a $150 \%$ higher harvest weight would correspond to a TGC of $0.83 \mathrm{~g}^{1 / 3} /($ day degrees $\cdot 1000)$. Cumulative genetic gain in TGC is, therefore, estimated to range from $20 \%$ to $50 \%$.

For seabream the reported number of selected generations varied between one and five. A few studies have estimated the selection response in seabream breeding programs. Based on a high heritability of 0.55 (Batargias, 1998 in: Brown, 2003), Brown (2003) estimated a selection response of $29 \%$ on harvest weight. Assuming a moderate heritability of 0.34 
(Navarro et al., 2009), the selection response would be 19\% instead. Knibb (2000) reported a $5-10 \%$ increase in 'growth rate' per generation of seabream selected for up to three generations. Thorland et al. (2015a) reported an average selection response in harvest weight of $13 \%$ over 2.6 selected generations in a family selection breeding program. A selection response in harvest weight of $10 \%$ to $15 \%$ may thus be expected. Because the highest number of selected generations reported by breeding companies was five, cumulative genetic gain in harvest weight is expected to range up to maximally $+100 \%$. Wild seabream with a TGC of $0.39 \mathrm{~g}^{1 / 3} /($ day degrees $\cdot 1000)$ (based on Knibb, 2000), stocked at $10 \mathrm{~g}$, and reared at $20^{\circ} \mathrm{C}$, would reach a harvest weight of $350 \mathrm{~g}$ at 633 days. A $100 \%$ higher harvest weight after an equal growing period would correspond to a TGC of $0.53 \mathrm{~g}^{1 / 3} /($ day degrees $\cdot 1000)$. Cumulative genetic gain in TGC is, therefore, estimated to range up to maximally $40 \%$.

For turbot the reported number of selected generations varied between three and five. Selection responses on harvest weight were 10-15\% for the first generations (Danacher and Garcia-Vazquez, 2007). Based on genetic trend analysis, Johansen (2015, pers. comm.) reported a cumulative genetic gain in harvest weight of $+65 \%$ at the current generation of one of the breeding programs. Wild turbot stocked at $20 \mathrm{~g}$ and reared at $15^{\circ} \mathrm{C}$, reached a weight of $1200 \mathrm{~g}$ after 21.5 months (Imsland et al., 2000), corresponding to a TGC of 0.8 $\mathrm{g}^{1 / 3} /($ day degrees $\cdot 1000)$. A $65 \%$ higher harvest weight after the same growing period would correspond to a TGC of $1.0 \mathrm{~g}^{1 / 3} /($ day degrees $\cdot 1000)$, i.e. a $25 \%$ increase. Genetic gain is expected to be similar across breeding programs and is estimated at $65 \%$ in harvest weight and $25 \%$ in TGC.

A summary of cumulative genetic gains in harvest weight and TGC is presented in Table 9. Most genetic gain has been realized on salmonids, which should largely be attributed to the highest number of selected generations. 
Table 9 Estimated cumulative genetic gain in harvest weight and thermal growth coefficient (TGC) by selective breeding in Europe.

\begin{tabular}{lccccc}
\hline & $\begin{array}{c}\text { Rainbow } \\
\text { Trout }\end{array}$ & $\begin{array}{c}\text { Atlantic } \\
\text { salmon }\end{array}$ & $\begin{array}{c}\text { European } \\
\text { seabass }\end{array}$ & $\begin{array}{c}\text { Gilthead } \\
\text { seabream }\end{array}$ & Turbot \\
\hline Selected generations & $8-20$ & $+/-10$ & $2-8$ & $1-5$ & $3-5$ \\
$\begin{array}{l}\text { Selection response on harvest weight } \\
(\%)\end{array}$ & $7-13$ & 12 & $20-25$ & $10-15$ & $10-15$ \\
$\begin{array}{l}\text { Selection response on TGC (\%) } \\
\text { Cumulative genetic gain in harvest }\end{array}$ & + & 6 & $5-10$ & 7 & 5 \\
weight (\%) & +900 & +200 & $+50-150$ & $<100$ & +65 \\
Cumulative genetic gain in TGC (\%) & +200 & +80 & $+20-50$ & $<40$ & +25 \\
\hline
\end{tabular}

${ }^{\mathrm{a}}$ Only based on selection response in first generation and genetic parameters

\subsection{Discussion}

\subsubsection{Market share of selective breeding}

This is the first study that estimates the proportion of aquaculture production in Europe that originates from selective breeding. This market share is estimated at $80-83 \%$, which is much higher than the previously reported $8.2 \%$ for global aquaculture production (Gjedrem et al., 2012). The market share might even be somewhat underestimated, since it was assumed that yield per egg or juvenile was independent of its origin (selective breeding or not). In reality, yield of selected eggs and juveniles is likely to be higher than yield of unselected eggs and juveniles due to, e.g., improved survival or higher harvest weight. Moreover, there might be some bias due to production cycles that exceed one year. Both in the computation of national egg production data for salmon and trout, and in the estimation of the proportion of fish production that originated from selective breeding, fish production data of 2012 were used. Eggs and juveniles produced in 2012 could not have resulted in fish production in the same year, but it was assumed that production growth in successive years could be ignored.

The market share of salmon breeding companies in Europe (93-95\%) is very similar to the global market share of $97 \%$ (Gjedrem and Baranski, 2009). For trout the market share of breeding companies in Europe (65-68\%) is much higher than the global market share of 27\% (Gjedrem and Baranski, 2009). Global estimates for the other species are not available.

Selective breeding is expected to play an increasingly important role in seabass and seabream, because several smaller companies have initiated breeding programs since 2014 . On a global level, this positive trend is also observed: the proportion of genetically improved stocks worldwide increased from less than 5\% in 2003 (Gjedrem and Baranski, 2009) to $8.2 \%$ in 2010 (Gjedrem et al., 2012). 


\subsubsection{Characteristics of breeding companies and their programs}

Specialized breeding companies play a dominant role in the production of salmonids, while their role in the production of the three Mediterranean species is smaller. This may be partly explained by the way that genetically improved material is distributed. Eggs of salmonids are easily disinfected and shipped over long distances. Juveniles of seabass, seabream, and turbot to the contrary, are less easily transported over long distances and, moreover, transportation may increase the risk to spread diseases. This may be an incentive to companies that produce these species to fully control the reproductive cycle and to operate their own breeding program, which would explain the dominance of integrated companies in seabass, seabream, and turbot production.

Concentration of breeding companies in salmon is high compared to the other species, when the volume of fish production and combined market share of breeding companies are taken into account. It is expected that breeding programs integrated with production can relatively easily coexist with other competing breeding programs, because their existence depends rather on the overall performance of the company they are part of than on results obtained by the breeding program itself. This may explain why there is relatively little concentration of breeding companies in the Mediterranean species. The stronger concentration of breeding companies in salmon than in trout can be explained by a rather uniform salmon farming industry, contrasted by a highly diverse trout farming industry. Uniformity within the salmon farming industry allows benchmarking (Soares et al., 2011) and breeding companies often select on similar traits (Table 7). Diversity among the trout farming industry complicates benchmarking and breeding companies often select on different traits. Both benchmarking (Elmuti and Kathawala, 1997) and similarity in selected traits are expected to have led to a higher degree of concentration in salmon than in trout. Looking towards the future, in salmonids further concentration of breeding companies is expected. This trend has already taken place in livestock (Gura, 2007) and is shown by recent mergers in the salmon breeding industry.

\subsubsection{Cumulative genetic gain}

Genetic gain in TGC is much lower than genetic gain in harvest weight (Table 9), because TGC describes bodyweight as an exponential function of time and temperature. Advantages of describing genetic gain in terms of harvest weight are its easy interpretation and the common use of bodyweight as a selection criterion. The disadvantage is that harvest weight 
is strongly dependent of stocking weight, growing period, and rearing temperature. Harvest weight is, thereby, a management parameter largely determined by non-genetic factors. Harvest weight can, therefore, not be compared across conditions. In contrast, TGC is more difficult to interpret, but it does describe genetic growth potential of a strain and can, with caution (Dumas et al., 2007; Jobling, 2003), be compared across conditions.

Comparison of TGCs of wild and selected trout suggest that cumulative genetic gain is around $+200 \%$ in TGC, or $+900 \%$ in harvest weight. Although environmental conditions differed in the various studies from which TGCs of wild and selected fish were derived, it may be assumed that rearing conditions were conform modern standards. Bias due to environmental effects is, therefore, expected to be small. Comparison of TGC may suffer from bias due to differences in life stage (Dumas et al., 2007); TGCs of wild trout are based on fish up to $50 \mathrm{~g}$, whereas TGCs of selected trout are based on larger individuals. The comparison, therefore, requires verification by, for example, a common garden experiment. For eight generations of selection cumulative genetic gain on harvest weight of $+900 \%$ would correspond to an unrealistically high selection response of 33\%. For 20 generations of selection the selection response on harvest weight would be $12 \%$. The high cumulative genetic gain cannot entirely be explained from the number of selected generations in current breeding programs (up to 20), given that the selection response varies between 7 and 13\% (Gjerde, 1986; Kause et al., 2005). This implies that both domestication and early breeding work have contributed substantially to cumulative genetic gain, which is not surprising considering the long history of domestication and breeding of trout.

Results on trout show that phenotypic differences in TGC may be useful indicators of genetic improvement. The genetic component may, however, be obscured by environmental effects, as has been suggested for seabass and seabream (EAS-EATiP, 2014). In farming practice of both seabass and seabream incidence of diseases has increased (Arechavala-Lopez et al., 2013; Subasinghe, 2009). At the same time higher inclusion levels of alternative ingredients for fishmeal and fish oil in feed (Rana et al., 2009; Tacon et al., 2011) are likely to have had negative effects on growth performance, because the diet may contain anti-nutritional factors and low levels of essential fatty acids, and have an imbalanced amino acid composition (Gatlin et al., 2007; Turchini et al., 2009). Combined with a high variability in performance among farms stocked with the same genetic material, 
trends in on farm performance do not support the high theoretical improvements on growth performance (pers. comm. Coli, 2015).

The selection response on harvest weight was generally in the lower end of the often reported 10-20\% genetic gain per generation (Gjedrem and Baranski, 2009). The reason may be that in most breeding programs family selection is applied with the objective to improve multiple traits. The more emphasis is put on other traits than growth performance, the less genetic gain in growth performance is realized. Based on results presented in this paper, the overall average selection response on harvest weight is $12 \%$. Assuming an average generation interval of four years, this would correspond to an increase of $3 \%$ per year. This is considerable compared to livestock, where annual genetic gain is around $1 \%$ in cows (Hill, 2010) up to 2\% in poultry (Hill and Bünger, 2004).

\subsubsection{Impact of selective breeding}

Gjedrem (2012) showed that selective breeding may play an important role in the future supply of fish, but its impact largely depends on the adoption of selective breeding by the aquaculture sector. Considering that $80-83 \%$ of the European aquaculture production already originates from selective breeding, there is not much room for improvement in terms of adoption. Still, in some species adoption could be considerably increased.

Based on an annual genetic gain in harvest weight of $3 \%$ and given that $80-83 \%$ of the production originates from selective breeding, the sector could grow by $2.4 \%$ per year only due to genetic gain in growth performance. Underlying this prediction are the assumptions that growth rate limits production, and genetic improvement in harvest weight leads to a corresponding reduction in the duration of production cycles. In addition, genetic gain in survival related traits also positively affects production, which would facilitate an even faster growth of the sector.

\subsection{Conclusion}

Of the total European aquaculture production, $80-83 \%$ originates from selective breeding. This is a much higher figure than for global aquaculture production, which is mainly explained by the dominance of salmon farming in European aquaculture and the high combined market share of breeding companies (93-95\%) in salmon. There are 37 breeding programs in Europe of which the majority performs family selection. Cumulative genetic gain in growth performance varies from $+65 \%$ for turbot to $+900 \%$ for trout in terms of 
harvest weight, and from $+25 \%$ for turbot to $+200 \%$ for trout in terms of thermal growth coefficient. It is concluded that selective breeding has a major impact on European aquaculture and will contribute to future growth of the sector.

\subsection{Acknowledgements}

The research leading to these results has received funding from the European Union's Seventh Framework Programme (KBBE.2013.1.2-10) under grant agreement $n^{\circ} 613611$. This work is the result of the collaborative effort of researchers in the FP7 projects 'Aquatrace' and 'FISHBOOST'. We thank Martin Kocour and Martin Prchal for the information they provided on carp production. We gratefully acknowledge the contributions of companies that participated in the surveys. We also acknowledge the contribution of national institutes in several countries that helped us to collect the relevant data on the trade and production of eggs. We thank two anonymous reviewers for their useful comments.

\subsection{Appendix}

Reported thermal growth coefficients (TGC) of rainbow trout from various origin

\begin{tabular}{lcc}
\hline Origin & TGC $\left(\mathrm{g}^{1 / 3} /(\right.$ day degrees $\cdot 1000)$ & Reference \\
\hline Wild & 0.67 & Martens et al. $(2014)$ \\
Wild & 0.5 & Tymchuk and Devlin $(2005)$ \\
Wild & 0.6 & Devlin et al. $(2013)$ \\
Wild & 1.5 & Biro et al. $(2006)$ \\
Selected & $1.43-2.07$ & Sae-Lim et al. $(2013)$ \\
Selected & $2.43-2.53$ & Grisdale-Helland et al. (2007) \\
Selected & $2.05-2.4$ & unpublished results Cleveland \\
& & (2015) \\
Selected & $2.4-2.7$ & unpublished results \\
\hline
\end{tabular}

\subsection{References}

AquaBreeding, 2008. Survey on the breeding practices in the European aquaculture industry. In: AquaBreeding final technical report. FP6 EU project $\mathrm{N}^{\circ} 044424$ cordis.europa.eu/documents/documentlibrary/124722901EN19.doc. Accessed on 4 September 2015.

AquaGen, 2015. http://aquagen.no/en/about-aquagen/history/. Accessed on 13 February 2015.

Arechavala-Lopez, P., Sanchez-Jerez, P., Bayle-Sempere, J.T., Uglem, I., Mladineo, I., 2013. AS WE SEE IT Reared fish, farmed escapees and wild fish stocks-a triangle of pathogen transmission of concern to Mediterranean aquaculture management. Aquacult Env Interac. $3,153-161$.

Aulstad, D., Gjedrem, T., Skjervol, H., 1972. Genetic and Environmental Sources of Variation in Length and Weight of Rainbow-Trout (Salmo-Gairdneri). J Fish Res Board Can. 29, 237241.

Biro, P.A., Abrahams, M.V., Post, J.R., Parkinson, E.A., 2006. Behavioural trade-offs between growth and mortality explain evolution of submaximal growth rates. J Anim Ecol. 75, 1165 1171 . 
Blair, H.T., Pollak, E.J., 1984. Estimation of Genetic Trend in selected Population with and Without the use of Control Population. J Anim Sci. 58, 878-886.

Brown, R.C., 2003. Genetic Management and Selective Breeding in Farmed Populations of Gilthead Seabream (Sparus aurata). PhD Thesis, Universtiy of Stirling.

Chatain, B., Chavanne, H., 2009. Genetics of European seabass (Dicentrarchus labrax L.). Cah Agric. 18, 249-255.

Chavanne, H., Janssen, K., Hofherr, J., Contini, F., Haffray, P., Komen, H., Nielsen, E.E., Bargelloni, L., 2016. A comprehensive survey on selective breeding programs and seed market in the European aquaculture fish industry. Aquacult Int. 24, 1287-1307.

Cho, C.Y., 1992. Feeding systems for rainbow trout and other salmonids with reference to current estimates of energy and protein requirements. Aquaculture. 100, 107-123.

Cleveland, B., 2015. Unpublished data. USDA National Center for Cool and Cold Water Aquaculture

Coves, D., Dewavrin, G., Breuil, G., N., D., 1991. Culture of Sea Bass (Dicentrarchus labrax L.). in: McVey, J.P. (Ed.), Handbook of Mariculture. CRC Press, Boca Raton, Florida, 3-20.

Crawford, S.S., Muir, A.M., 2008. Global introductions of salmon and trout in the genus Oncorhynchus: 1870-2007. Reviews in Fish Biology and Fisheries. 18, 313-344.

Danacher, D., Garcia-Vazquez, E., 2007. Turbot - Scophthalmus maximus. Svåsand, T., Crosetti, D., García-Vázquez, E., Verspoor, E., Genetic impact of aquaculture activities on native populations. Genimpact final scientific report, 55-61.

Devlin, R.H., Sakhrani, D., White, S., Overturf, K., 2013. Effects of domestication and growth hormone transgenesis on mRNA profiles in rainbow trout (Oncorhynchus mykiss). J Anim Sci. 91, 5247-5258.

Divanach, P., Kentouri, M., 2000. Hatchery techniques for specific diversification in Mediterranean finfish larviculture. CIHEAM - Options Mediterraneenes, 75-87.

Donaldson, L.R., Olson, P.R., 1957. Development of Rainbow Trout Brood Stock by Selective Breeding. Transactions of the American Fisheries Society. 85, 93-101.

Dumas, A., France, J., Bureau, D.P., 2007. Evidence of three growth stanzas in rainbow trout (Oncorhynchus mykiss) across life stages and adaptation of the thermal-unit growth coefficient. Aquaculture. 267, 139-146.

Dupont-Nivet, M., Vandeputte, M., Vergnet, A., Merdy, O., Haffray, P., Chavanne, H., Chatain, B., 2008. Heritabilities and GxE interactions for growth in the European sea bass (Dicentrarchus labrax L.) using a marker-based pedigree. Aquaculture. 275, 81-87.

EAS-EATiP, 2014. Performance of the sea bass and sea bream sector in the Mediterranean. Aquaculture Europe, San Sebastian.

Elmuti, D., Kathawala, Y., 1997. An overview of benchmarking process: a tool for continuous improvement and competitive advantage. Benchmarking for Quality Management \& Technology. 4, 229-243.

FAO, 2014. The State of World Fisheries and Aquaculture. FAO, Rome, 2014.

FAO, 2015. Fisheries and aquaculture software. FishStat - software for fishery statistical time series. FAO Fisheries and Aquaculture Department. Rome.

FEAP, 2014a. European Aquaculture Production Report 2004-2013. Dehasque, M., Federation of European Aquaculture Producers, 53.

FEAP, 2014b. Unpublished data.

Gall, G.A.E., 1975. Genetics of Reproduction in Domesticated Rainbow-Trout. J Anim Sci. 40, 1928.

Gall, G.A.E., Crandell, P.A., 1992. The rainbow trout. Aquaculture. 100, 1-10.

Gatlin, D.M., Barrows, F.T., Brown, P., Dabrowski, K., Gaylord, T.G., Hardy, R.W., Herman, E., Hu, G., Krogdahl, Å., Nelson, R., Overturf, K., Rust, M., Sealey, W., Skonberg, D., J Souza, E., Stone, D., Wilson, R., Wurtele, E., 2007. Expanding the utilization of sustainable plant products in aquafeeds: a review. Aquacult Res. 38, 551-579.

Ghosh, A., 2004. Increasing Market Share as a Rationale for Corporate Acquistions. Journal of Business Finance \& Accounting. 31, 209-247.

Gjedrem, T., 1985. Improvement of productivity through breeding schemes. GeoJournal. 10, 233241. 
Gjedrem, T., 2012. Genetic improvement for the development of efficient global aquaculture: A personal opinion review. Aquaculture. 344-349, 12-22.

Gjedrem, T., Baranski, M., 2009. Selective Breeding in Aquaculture: an Introduction. Springer, Dordrecht Heidelberg London New York.

Gjedrem, T., Gjøen, H.M., Gjerde, B., 1991. Genetic origin of Norwegian farmed Atlantic salmon. Aquaculture. 98, 41-50.

Gjedrem, T., Robinson, N., Rye, M., 2012. The importance of selective breeding in aquaculture to meet future demands for animal protein: A review. Aquaculture. 350-353, 117-129.

Gjerde, B., 1986. Growth and reproduction in fish and shellfish. Aquaculture. 57, 37-55.

Glover, K.A., Otterå, H., Olsen, R.E., Slinde, E., Taranger, G.L., Skaala, Ø., 2009. A comparison of farmed, wild and hybrid Atlantic salmon (Salmo salar L.) reared under farming conditions. Aquaculture. 286, 203-210.

Goodman, L.A., 1961. Snowball Sampling. The Annals of Mathematical Statistics. 32, 148-170.

Grisdale-Helland, B., Shearer, K.D., Helland, J., 2007. Energy and nutrient utilization of Atlantic cod, Atlantic salmon and rainbow trout fed diets differing in energy content. Aquacult Nutr. 13, 321-334.

Gross, R., Lulla, P., Paaver, T., 2007. Genetic variability and differentiation of rainbow trout (Oncorhynchus mykiss) strains in northern and Eastern Europe. Aquaculture. 272, S139S146.

Gura, S., 2007. Livestock Genetics Companies. Concentration and proprietary strategies of an emerging power in the global food economy., League for Pastoral Peoples and Endogenous Livestock Development, Ober-Ramstadt.

Guyomard, R., 1981. Electrophoretic Variation in Four French Populations of Domesticated RainbowTrout (Salmo gairdneri). Can J Genet Cytol. 23, 33-47.

Hill, W.G., 2010. Understanding and using quantitative genetic variation. Philos T R Soc B Biol Sci. $365,73-85$.

Hill, W.G., Bünger, L., 2004. Inferences on the genetics of quantitative traits from long-term selection in laboratory and domestic animals. Plant Breeding Reviews. 24, 169-210.

Hosteland, L.T., 2014. Flust av rogn til næringen. NF Xpert Økonomi, 38-39.

Imsland, A.K., Foss, A., Naevdal, G., Cross, T., Bonga, S.W., Ham, E.V., Stefansson, S.O., 2000. Countergradient variation in growth and food conversion efficiency of juvenile turbot. Journal of Fish Biology. 57, 1213-1226.

Iwama, G.K., Tautz, A.F., 1981. A Simple Growth Model for Salmonids in Hatcheries. Can J Fish Aquat Sci. 38, 649-656.

Janssen, K., Prchal, M., Kocour, M., Berentsen, P.B.M., Komen, H., 2015. Common carp - Current status of selective breeding in Europe, http://www.fishboost.eu/reports-on-current-statusof-selective-breeding-in-europe.html. Accessed on 14 September 2015.

Jobling, M., 2003. The thermal growth coefficient (TGC) model of fish growth: a cautionary note. Aquacult Res. 34, 581-584.

Kause, A., Ritola, O., Paananen, T., Wahlroos, H., Mantysaari, E., 2005. Genetic trends in growth, sexual maturity and skeletal deformations, and rate of inbreeding in a breeding programme for rainbow trout (Oncorhynchus mykiss). Aquaculture. 247, 177-187.

Knibb, W., 2000. Genetic improvement of marine fish - which method for industry? Aquacult Res. $31,11-23$.

Knibb, W., Gorshkova, G., Gorshkov, S., 1997. Selection for growth in the gilthead seabream, Sparus aurata L. Israeli Journal of Aquaculture - Bamidgeh. 49, 57-66.

Knibb, W., Gorshkova, G., Gorshkov, S., 1998. Selection and crossbreeding in Mediterranean cultured marine fish. in: Bartley, D.M., Basurco, B. (Eds.), Genetics and breeding of Mediterranean aquaculture species. CIHEAM, Zaragoza, 47-60.

Komen, H., 1990. Clones of common carp, Cyprinus carpio. PhD Thesis, Agricultural University Wageningen, Department of Fish Culture and Fisheries \& Department of Experimental Animal Morphology and Cell Biology.

Le Boucher, R., Vandeputte, M., Dupont-Nivet, M., Quillet, E., Ruelle, F., Vergnet, A., Kaushik, S., Allamellou, J.M., Medale, F., Chatain, B., 2013. Genotype by diet interactions in 
European sea bass (Dicentrarchus labrax L.): Nutritional challenge with totally plant-based diets. J Anim Sci. 91, 44-56.

Marine Harvest, 2014. Salmon Farming Industry Handbook 2014.

Martens, M.T., 2013. The comparative growth and survival of a naturalized and aquaculture strain of rainbow trout (Oncorhynchus mykiss) in laboratory and whole-ecosystem experiments. MSc. Thesis, University of Manitoba, Department of Biological Sciences.

Martens, M.T., Wall, A.J., Pyle, G.G., Wasylenko, B.A., Dew, W.A., Devlin, R.H., Blanchfield, P.J., 2014. Growth and feeding efficiency of wild and aquaculture genotypes of rainbow trout (Oncorhynchus mykiss) common to Lake Huron, Canada. Journal of Great Lakes Research. 40, 377-384.

Millenbach, C., 1950. Rainbow Brood-Stock Selection and Observations on its Application to Fishery Management. The Progressive Fish-Culturist. 12, 151-152.

Ministerio de Agricultura, 2014. Estadísticas pesqueras: Producción de acuitcultura, http://www.magrama.gob.es/en/estadistica/temas/estadisticas-

pesqueras/acuicultura/encuesta-establecimientos-acuicultura/produccion/. Accessed on 28 November 2014.

Moretti, A., Fernandez-Criado, M.P., Cittolin, G., Guidastri, R., 1999. Manual on Hatchery Production of Seabass and Gilthead Seabream - Volume 1. FAO, Rome, 195.

Morkramer, S., Horstgenschwark, G., Langholz, H.J., 1985. Comparison of Different European Rainbow-Trout Populations under Intensive Production Conditions. Aquaculture. 44, 303320.

Munro, L.A., Wallace, I.S., 2012. Scottish Fish Farm production survey - Report 2012. Marine Scotland Science.

Navarro, A., Zamorano, M.J., Hildebrandt, S., Ginés, R., Aguilera, C., Afonso, J.M., 2009. Estimates of heritabilities and genetic correlations for growth and carcass traits in gilthead seabream (Sparus auratus L.), under industrial conditions. Aquaculture. 289, 225-230.

Paisley, L.G., Ariel, E., Lyngstad, T., Jónsson, G., Vennerström, P., Hellström, A., Østergaard, P., 2010. An overview of aquaculture in the nordic countries. Journal of the World Aquaculture Society. 41, 1-17.

Poseidon, 2008. Regulatory Costs and Competitiveness of Scottish Salmon Industry. Poseidon Aquatic Resource Management Ltd, 1.

Rana, K.J., Siriwardena, S., Hasan, M.R., 2009. Impact of rising feed ingredient prices on aquafeeds and aquaculture production. Food and Agriculture Organization of the United Nations (FAO), Rome, 1-63.

Reese, A., 2013. 2011 Survey of aquaculture production of finfish in the UK. Finfish News, Cefas, 22-28.

Rye, M., Gjerde, B., Gjedrem, T., 2010. Genetic Improvement Programs For Aquaculture Species In Developed Countries. In: 9th World Congress on Genetics Applied to Livestock Production. Leipzig, Germany.

Sae-Lim, P., Kause, A., Mulder, H.A., Martin, K.E., Barfoot, A.J., Parsons, J.E., Davidson, J., Rexroad III, C.E., Van Arendonk, J.A.M., Komen, H., 2013. Genotype-by-environment interaction of growth traits in rainbow trout (Oncorhynchus mykiss): A continental scale study. J Anim Sci. 91, 5572-5581.

Sernapesca, 2014. Estadística de Importación de Ovas por origen 2010-2014, http://www.sernapesca.cl/. Accessed on 18 December 2014.

Soares, S., Green, D.M., Turnbull, J.F., Crumlish, M., Murray, A.G., 2011. A baseline method for benchmarking mortality losses in Atlantic salmon (Salmo salar) production. Aquaculture. 314, 7-12.

Solberg, M.F., Skaala, O., Nilsen, F., Glover, K.A., 2013. Does domestication cause changes in growth reaction norms? A study of farmed, wild and hybrid Atlantic salmon families exposed to environmental stress. Plos One. 8, 1-11.

Statistisches Bundesamt, 2012. Erzeugung in Aquakulturbetrieben.

Subasinghe, R., 2009. Disease control in aquaculture and the responsible use of veterinary drugs and vaccines: The issues, prospects and challenges. Options Méditerranéennes. 86, 5-11. 
Tacon, A.G.J., Hasan, M.R., Metian, M., 2011. Demand and supply of feed ingredients for farmed fish and crustaceans: trends and prospects. Food and Agriculture Organization of the United Nations (FAO), Rome, 1-87.

Thorland, I., Papaioannou, N., Kottaras, L., Refstie, T., Papasolomontos, S., Rye, M., 2006. The Kego breeding programs for sea bream (Sparus aurata) and sea bass (Dicentrarchus labrax) in Greece. 8th Hellenic Symposium on Oceanography and Fisheries, Thessaloniki, Greece.

Thorland, I., Kottaras, L., Refstie, S., Dimitroglou, A., Papaharisis, L., Rye, M., 2015a. Response to selection for harvest weight in a family based selection program of gilthead seabream (Sparus aurata). International Symposium of Genetics in Aquaculture XII, Santiago de Compostella, Spain.

Thorland, I., Kottaras, L., Refstie, S., Papanna, K., Papaharisis, L., Rye, M., 2015b. Response to selection for harvest weight in European sea bass (Dicentrarchus labrax) in Greece. International Symposium of Genetics in Aquaculture XII, Santiago de Compostella, Spain.

Trong, T.Q., Mulder, H.A., van Arendonk, J.A.M., Komen, H., 2013. Heritability and genotype by environment interaction estimates for harvest weight, Growth rate, And shape of Nile tilapia (Oreochromis niloticus) grown in river cage and VAC in Vietnam. Aquaculture. 384-387, 119-127.

Turchini, G.M., Torstensen, B.E., Ng, W.-K., 2009. Fish oil replacement in finfish nutrition. Rev Aquac. 1, 10-57.

Tymchuk, W.E., Devlin, R.H., 2005. Growth differences among first and second generation hybrids of domesticated and wild rainbow trout (Oncorhynchus mykiss). Aquaculture. 245, 295300 .

Vandeputte, M., 2003. Selective breeding of quantitative traits in the common carp (Cyprinus carpio): a review. Aquat Living Resour. 16, 399-407.

Vandeputte, M., Dupont-Nivet, M., Haffray, P., Chavanne, H., Cenadelli, S., Parati, K., Vidal, M.O., Vergnet, A., Chatain, B., 2009. Response to domestication and selection for growth in the European sea bass (Dicentrarchus labrax) in separate and mixed tanks. Aquaculture. 286, 20-27.

Vandeputte, M., Garouste, R., Dupont-Nivet, M., Haffray, P., Vergnet, A., Chavanne, H., Laureau, S., Ron, T.B., Pagelson, G., Mazorra, C., Ricoux, R., Marques, P., Gameiro, M., Chatain, B., 2014. Multi-site evaluation of the rearing performances of 5 wild populations of European sea bass (Dicentrarchus labrax). Aquaculture. 424-425, 239-248. 


\title{
3 \\ Derivation of economic values for production traits in aquaculture species
}

\author{
Kasper Janssen ${ }^{1}$, Paul Berentsen ${ }^{2}$, Mathieu Besson ${ }^{1,3}$ and Hans Komen ${ }^{1}$ \\ ${ }^{1}$ Wageningen University, Animal Breeding and Genomics, Droevendaalsesteeg 1, 6708 \\ PB Wageningen, The Netherlands \\ ${ }^{2}$ Wageningen University, Business Economics Group, Hollandseweg 1, 6706 KN \\ Wageningen, The Netherlands \\ ${ }^{3}$ Génétique Animale Biologie Intégrative, INRA, AgroParisTech, Université Paris- \\ Saclay, 78350 Jouy-en-Josas, France
}

Genetics Selection Evolution (2017) 49:5 


\begin{abstract}
Background: In breeding programs for aquaculture species, breeding goal traits are often weighted based on desired gains but economic gain would be higher if economic values were used instead. The objectives of this study were: (1) to develop a bio-economic model to derive economic values for aquaculture species, (2) to apply the model to determine the economic importance and economic values of traits in a case-study on gilthead seabream, and (3) to validate the model by comparison with a profit equation for a simplified production system.
\end{abstract}

Methods: A bio-economic model was developed to simulate a grow-out farm for gilthead seabream, and then used to simulate gross margin at the current levels of the traits and after one genetic standard deviation change in each trait with the other traits remaining unchanged. Economic values were derived for the traits included in the breeding goal: thermal growth coefficient (TGC), thermal feed intake coefficient (TFC), mortality rate (M), and standard deviation of harvest weight $\left(\sigma_{\mathrm{HW}}\right)$. For a simplified production system improvement in TGC was assumed to affect harvest weight instead of growing period. Using the bio-economic model and a profit equation, economic values were derived for harvest weight, cumulative feed intake at harvest, and overall survival.

Results: Changes in gross margin showed that the order of economic importance of the traits was: TGC, TFC, M, and $\sigma_{\mathrm{HW}}$. Economic values in $€\left(\mathrm{~kg}\right.$ production) ${ }^{-1}$ (trait unit) ${ }^{-1}$ were: 0.40 for TGC, -0.45 for TFC, -7.7 for $\mathrm{M}$, and -0.0011 to -0.0010 for $\sigma_{\mathrm{HW}}$. For the simplified production system similar economic values were obtained with the bioeconomic model and the profit equation. The advantage of the profit equation is its simplicity, while that of the bio-economic model is that it can be applied to any aquaculture species, because it can include any limiting factor and/or environmental condition that affects production.

Conclusion: We confirmed the validity of the bio-economic model. TGC is the most important trait to improve, followed by TFC and $\mathrm{M}$, and the effect of $\sigma_{\mathrm{HW}}$ on gross margin is small. 


\subsection{Background}

In Europe, over $80 \%$ of aquaculture production originates from breeding programs, which in most cases apply family selection with the aim of improving multiple traits simultaneously (Janssen et al., 2017). Breeding goal traits are often weighted based on desired gains rather than economic values (Nielsen et al., 2014), which compromises economic gain (Gibson and Kennedy, 1990; Shook, 2006).

In aquaculture species, economic values are available only for a few species, although their importance has repeatedly been underlined (e.g., Gjedrem and Baranski, 2009; Gjedrem and Thodesen, 2005). Profit equations have been used to derive economic values for Nile tilapia (Oreochromis niloticus) (Ponzoni et al., 2007), common carp (Cyprinus carpio) (Ponzoni et al., 2008), Australian abalones (Haliotis rubra and H. laevigata) (Zuniga-Jara and Marin-Riffo, 2014), and crayfish (Cherax tenuimanus) (Henryon et al., 1999). Besson et al. (2014) and Besson et al. (2016a) used a bio-economic model to derive economic values for African catfish (Clarias gariepinus) that were produced in a land-based aquaculture system in which water is treated and recirculated, and for growth rate in European seabass (Dicentrarchus labrax) under varying temperature conditions, respectively.

For livestock species with simple and highly controlled production systems, such as pig production, economic values can be derived from a profit equation (e.g., Knap, 2005). For production systems with a higher degree of complexity partly due to seasonal variation, such as in dairy cattle and sheep farming, profit equations may fail to provide an adequate description of the farming system and bio-economic models are required (Byrne et al., 2010; Hietala et al., 2014; van Middelaar et al., 2014). In general bio-economic models provide a more accurate description of farming systems than profit equations and are, therefore, increasingly used to estimate economic values (Nielsen et al., 2014). Fish farms are complex production systems for two reasons. First, fish are kept outdoors in most farming systems and, thus, are exposed to fluctuating environmental conditions. Seasonal variation in temperature causes variation in growth rate of fish, because of their ectothermic nature. Fish are harvested at a constant weight rather than at a constant age, hence the length of a production cycle depends on the stocking date. Second, production output of a farm is determined by constraints such as oxygen availability (Besson et al., 2016a) and stocking density. Stocking density constrains production output for many important aquaculture 
species, including Atlantic salmon (Salmo salar), European seabass, and gilthead seabream (Sparus aurata). Thus, bio-economic models could prove useful to derive economic values for aquaculture species.

The objectives of this study were: (1) to develop such a bio-economic model, (2) to apply the model to determine the economic importance and economic values for various traits in a case-study on gilthead seabream, and (3) to validate the model by comparison with a profit equation for a simplified production system.

\subsection{Methods}

\subsubsection{Traits}

The breeding goal considered here includes growth rate, feed intake rate, mortality rate, and uniformity in harvest weight. Growth rate affects revenues, feed and juvenile costs; feed intake rate affects feed costs; mortality rate affects feed and juvenile costs. Feed and juveniles are major costs in production (Barazi-Yeroulanos, 2010), thus including growth and feed intake in the breeding goal is common practice in livestock (Emmerson, 1997; Veerkamp et al., 2013). Uniformity, i.e. size variation around the mean harvest weight, determines the distribution of fish over price categories at harvest, and thus affects revenues via the average sales price of fish.

Economic values are specific for the unit in which a trait is expressed (Wolfová and Wolf, 2013). Here, growth rate is expressed in units of thermal growth coefficient (TGC) (Iwama and Tautz, 1981). TGC is a standardized measure of growth in fish that takes stocking weight and temperature variation over the lifespan of a fish into account. TGC is widely used (Jobling, 2003), is more accurate than other measures of growth rate (Cho, 1992), and is relatively robust to differences in temperature regimes (Sae-Lim et al., 2013; Trong et al., 2013). Feed intake is assumed to be determined by the same variables as bodyweight and gain in bodyweight, because energy requirement is largely determined by bodyweight and gain in bodyweight (Lupatsch et al., 2003). In this study feed intake rate is, therefore, expressed in units of thermal feed intake coefficient (TFC), a TGC analogue. TFC takes stocking weight and temperature variation over the lifespan of a fish into account. The TFC model is independent of the TGC model, i.e. a modelled change in growth rate will not affect modelled feed intake rate and vice versa, which is a prerequisite to derive economic values. Mortality rate (M) is expressed as \% of mortality per day. Uniformity is expressed as the standard deviation of harvest weight $\left(\sigma_{\mathrm{HW}}\right)$ in grams. 


\subsubsection{Bio-economic model}

The bio-economic model developed by Besson et al. (2014) was adapted to simulate production systems with seasonal variation in temperature and in which density constrains production output, in this case a typical grow-out farm for gilthead seabream in Greece. The model is a deterministic simulation model that is programmed in $\mathrm{R}$ version 2.12.2. ( $\mathrm{R}$ Core Team, 2015). The model simulates operation of the farm during an average year. The farm consists of 20 cages of $2800 \mathrm{~m}^{3}$ each and produces about 550 tons annually. As shown in Fig. 1, the model consists of three hierarchical parts: a fish model, a cage model, and a farm model. Inputs into the fish model are: stocking date, temperature coefficients, TGC, and TFC. Outputs of the fish model for each stocking date are: bodyweight per day per fish, feed consumption per day per fish, and harvest date. Inputs into the cage model are: outputs of the fish model, M, cage volume, and feed prices. Outputs of the cage model for each stocking date are per production cycle of a cage: fish production, number of juveniles stocked, feed consumption, and feed costs. A production cycle is the period between stocking and harvesting a cage. Inputs of the farm model are: outputs of the cage model, number of cages, price of juveniles, price of packing, and sales prices. Outputs of the farm model are total per year: fish production, number of juveniles stocked, feed consumption, feed costs, juvenile costs, packing costs, revenues from fish sales, and gross margin.

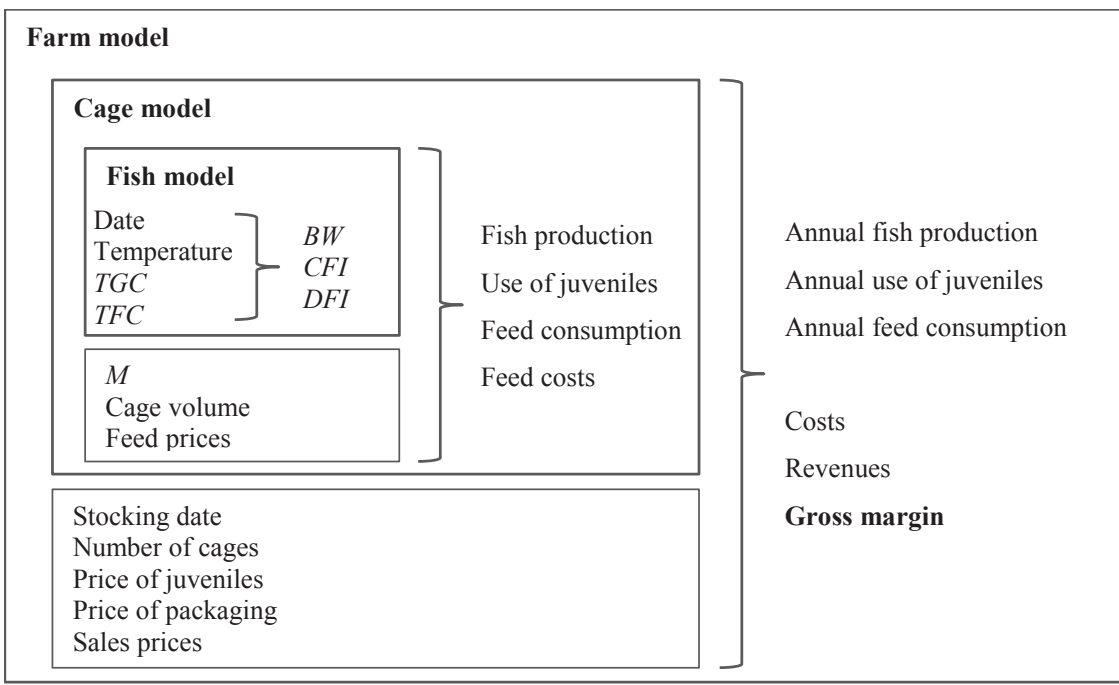

Fig. 1 Schematic overview of the bio-economic model. TGC = thermal growth coefficient, TFC = thermal feed intake coefficient, $\mathrm{BW}=$ bodyweight, $\mathrm{CFI}=$ cumulative feed intake, $\mathrm{DFI}=$ daily feed intake, $\mathrm{M}=$ mortality rate. 
The model was used to derive economic values of the traits mentioned above. Economic values give the expected change in profit from a small change in trait level, keeping the level of all other traits constant. Genetic change does not affect fixed costs, hence change in profit due to genetic change equals change in gross margin. When change in trait level equals the additive genetic standard deviation $\left(\sigma_{\mathrm{A}}\right)$ (van Middelaar et al., 2014), the resulting change in gross margin indicates how important that trait is, because $\sigma_{\mathrm{A}}$ is indicative of the rate at which breeding values can be improved (Houle, 1992). To determine the relative importance of the traits and to derive economic values, the model was run under two situations: first before genetic change and second, after a change of one $\sigma_{\mathrm{A}}$ in one trait with the other traits kept constant. For the trait 'uniformity' minimum and maximum values of the possible range of $\sigma_{\mathrm{A}}$ were used, because the actual value was unknown. Trait levels were changed in the desired direction of the genetic change. Economic values were expressed per $\mathrm{kg}$ of fish produced in the situation before genetic change (Groen, 1989) and were calculated as:

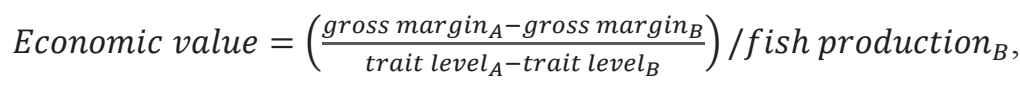

where subscripts indicate before $(B)$ and after $(A)$ genetic change.

\subsubsection{Model equations}

The subsection 'Estimation of model coefficients' describes the derivation of model coefficients from farm data. These coefficients (see Table 1) are used as the equations' coefficients of the bioeconomic model. The three parts of the bio-economic model are described in the following three subsections.

Table 1 Estimated coefficients used in model equations.

\begin{tabular}{lcccc}
\hline Symbol & Meaning & Value & Standard error & Unit \\
\hline TM & Annual mean temperature & 19.57 & 0.0119 & ${ }^{\circ} \mathrm{C}$ \\
TA & Amplitude of temperature & -4.806 & 0.0167 & ${ }^{\circ} \mathrm{C}$ \\
$t_{A}$ & Date at which temperature & -32.49 & 0.2057 & day \\
& $\quad$ equals TM & & & \\
TGC & $\begin{array}{c}\text { Thermal growth coefficient } \\
\text { TFC }\end{array}$ & 12.6 & 0.0847 & $\mathrm{~g}^{2 / 3} /($ day degrees $\cdot 1000)$ \\
$\quad \begin{array}{c}\text { Thermal feed intake } \\
\text { coefficient }\end{array}$ & 8.25 & 0.157 & $\mathrm{~g} \mathrm{~g}^{0.544} /($ day degrees $\cdot 1000)$ \\
$p$ & $\begin{array}{c}\text { Weight exponent to predict } \\
\text { cumulative feed intake }\end{array}$ & 0.544 & 0.00282 & - \\
M & $\quad$ Mortality rate & 0.0300 & 0.000164 & $\% /$ day \\
\hline
\end{tabular}




\subsubsection{Estimation of model coefficients}

Coefficients in the equations to describe temperature, fish growth, feed intake, and number of fish per cage were derived from recent farm data of the company Andromeda S.A., which is hereafter referred to as 'data'. The data included daily records of temperature, feed provided, and mortality, and regular records of bodyweight from 15 cages of a farm located in Vonitsa, Northern Greece during the period 2013 through 2015.

Seasonal variation in daily water temperature throughout the year followed a sinusoidal pattern. Therefore, the equation to describe daily temperature $\left(\mathrm{T}_{t_{s, a}}\right)$ in ${ }^{\circ} \mathrm{C}$ was $(\mathrm{Cacho}$, 1990):

$\mathrm{T}_{t_{s, a}}=\mathrm{TM}-\mathrm{TA} \cdot \sin \left(2 \pi \cdot\left(t_{s, a}-t_{A}\right) / 365\right)$

where TM is the average annual temperature $\left({ }^{\circ} \mathrm{C}\right)$, TA is the range of temperatures around $\mathrm{TM}\left({ }^{\circ} \mathrm{C}\right), t_{A}$ is the time of the year at which $\mathrm{T}_{t_{s, a}}$ equalled $\mathrm{TM}$, and $t_{s, a}$ represents the date defined as:

$t_{s, a}=s+a$,

where stocking date $s(s=1, \ldots, n)$ equals 1 on January 12013 and $a(a=0, \ldots, n)$ is the age of the fish (days). To estimate TM, TA, and $t_{A}$, Eq. 2 was fitted to the data by means of non-linear least-squares regression in $\mathrm{R}$. Table 1 shows the resulting coefficients.

Bodyweight in seabream can be predicted from the stocking weight and the sum of daily effective temperatures. Daily effective temperature is the daily temperature minus $12{ }^{\circ} \mathrm{C}$, where $12^{\circ} \mathrm{C}$ represents the minimum temperature for seabream growth (Mayer et al., 2008). Therefore, the equation to describe bodyweight (in g) at $t_{s, a}\left(\mathrm{BW}_{t_{s, a}}\right)$ was (Mayer et al., 2012):

$\mathrm{BW}_{t_{s, a}}=\left(\mathrm{BW}_{t_{s, 0}}{ }^{2 / 3}+\frac{\mathrm{TGC}}{1000} \cdot \sum_{i=t_{s, 0}}^{\left(t_{s, a}\right)-1}\left(\mathrm{~T}_{i}-12\right)\right)^{3 / 2}$

where $\mathrm{BW}_{t_{s, 0}}$ is bodyweight at stocking (in g), and $\sum_{i=t_{s, 0}}^{\left(t_{s, a}\right)-1}\left(\mathrm{~T}_{i}-12\right)$ represents the sum of effective temperatures (day degrees) over the lifespan of a fish excluding $t_{s, a}$. To estimate TGC, Eq. 4 was fitted to the data by means of non-linear least-squares regression in R. Instead of fixing exponents $2 / 3$ and $3 / 2$, fitting these to the data resulted in values of 
0.612 and $1 / 0.612$, but this barely improved accuracy of the model. Values of $2 / 3$ and $3 / 2$ were preferred, because standardization of growth models allows for a better comparison of growth rate across studies. Analogous to $\mathrm{BW}_{t_{s, a}}$, the model to describe cumulative feed intake (in g) at $t_{s, a}\left(\mathrm{CFI}_{t_{s, a}}\right)$ was:

$\mathrm{CFI}_{t_{s, a}}=\left(\mathrm{BW}_{t_{s, 0}}^{p}+\frac{\mathrm{TFC}}{1000} \cdot \sum_{i=t_{s, 0}}^{t_{s, a}}\left(\mathrm{~T}_{i}-12\right)\right)^{1 / p}-\mathrm{BW}_{t_{s, 0}}$

where $p$ is a weight exponent, and $\sum_{i=t_{s, 0}}^{t_{s, a}}\left(\mathrm{~T}_{i}-12\right)$ represents the sum of effective temperatures (day degrees) over the lifespan of a fish, including $t_{s, a}$. The term $\mathrm{BW}_{t_{s, 0}}$ was subtracted from $\left(\mathrm{BW}_{t_{s, 0}}{ }^{p}+\frac{\mathrm{TFC}}{1000} \cdot \sum_{i=t_{s, 0}}^{t_{s, a}}\left(\mathrm{~T}_{i}-12\right)\right)^{1 / p}$ to force the model through the intercept. To estimate TFC and $p$, Eq. 5 was fitted to the data by means of non-linear leastsquares regression in R. Parameter M (\%/day) was assumed to be constant over time, hence the number of fish alive decreased exponentially in time. The model to describe the number of fish at $t_{s, a}\left(\mathrm{~N}_{t_{s, a}}\right)$ was:

$\mathrm{N}_{t_{s, a}}=\mathrm{N}_{t_{s, 0}} \cdot\left(1-\frac{\mathrm{M}}{100 \%}\right)^{\left(t_{s, a}-t_{s, 0}\right)}$,

where $\mathrm{N}_{t_{s, 0}}$ is the number of fish stocked. To estimate M, Eq. 6 was fitted to the data by means of non-linear least-squares regression in $\mathrm{R}$.

\subsubsection{Fish model}

Date $\left(t_{s, a}\right)$ was modelled as in Eq. 3. Temperature $\left(\mathrm{T}_{t_{s, a}}\right)$ was modelled as in Eq. 2. Bodyweight $\left(\mathrm{BW}_{t_{s, a}}\right)$ was modelled as in Eq. 4, where stocking weight $\left(\mathrm{BW}_{t_{s, 0}}\right)$ was $4.4 \mathrm{~g}$, equal to the average in the data. Eq. 4 was rewritten to calculate the harvest date $\left(t_{s, h}\right)$ as:

$\sum_{i=t_{s, 0}}^{\left(t_{s, h}\right)-1}\left(\mathrm{~T}_{i}-12\right)=\frac{\mathrm{BW}_{t_{s, h}}{ }^{2 / 3}-\mathrm{BW}_{t_{s, 0}}{ }^{2 / 3}}{\mathrm{TGC} / 1000}$

where $\mathrm{BW}_{t_{s, h}}$ is the average harvest weight, here set to the desired market weight of $400 \mathrm{~g}$. Solving the right hand side of the equation, yields $\sum_{i=t_{s, 0}}^{\left(t_{s, h}\right)-1}\left(\mathrm{~T}_{i}-12\right)=4084$ day degrees. Cumulative feed intake $\left(\mathrm{CFI}_{t_{s, a}}\right)$ was modelled as in Eq. 5. $\mathrm{CFI}_{t_{s, h}}$ was set equal to $\mathrm{CFI}_{\left(t_{s, h}\right)-1}$, because fish are not fed on the day that they are harvested. Daily feed intake $\left(\mathrm{DFI}_{t_{s, a}}\right)$ was modelled as: 
$\mathrm{DFI}_{t_{s, a}}=\mathrm{CFI}_{\left(t_{s, a}\right)+1}-\mathrm{CFI}_{t_{s, a}}$.

\subsubsection{Cage model}

To maximize production, standing stock in a cage reaches the maximum allowable density of $15 \mathrm{~kg} / \mathrm{m}^{3}$ at harvest. For the $2800 \mathrm{~m}^{3}$ cages per production cycle fish production is thus $42,000 \mathrm{~kg}$ or 100,500 fish. To compensate for mortality, a larger number of fish is stocked than harvested. The number of fish in a cage at $t_{s, a}\left(\mathrm{~N}_{t_{s, a}}\right)$ was modelled as:

$\mathrm{N}_{t_{s, a}}=100,500 \cdot\left(1-\frac{\mathrm{M}}{100 \%}\right)^{\left(t_{s, a}-t_{s, h}\right)}$

The number of juveniles stocked per cage $\left(\mathrm{N}_{t_{s, 0}}\right)$ was calculated by substituting $t_{s, a}$ for $t_{s, 0}$.

Daily feed intake per cage $(\mathrm{kg})$ at $t_{s, a}\left(\right.$ DFIcage $\left._{t_{s, a}}\right)$ was modelled as:

DFIcage $_{t_{s, a}}=\mathrm{N}_{t_{s, a}} \cdot \mathrm{DFI}_{t_{s, a}} / 1000$

Total feed consumption per cage $(\mathrm{kg})$ stocked at date $t_{s, 0}\left(\right.$ TFIcage $_{t_{s, 0}}$ ) was calculated as:

TFIcage $_{t_{s, 0}}=\sum_{i=t_{s, 0}}^{t_{s, h}}$ DFIcage $_{i}$

Depending on bodyweight, fish are fed different feed types. Daily feed costs per cage (DFCcage $_{t_{s, a}}$ ) were calculated as the product of DFIcage $t_{s, a}$ and feed price per size category. Table 2 shows the prices of feed types for the fish size categories. Total feed costs per cage $(€)$ stocked at date $t_{s, 0}\left(\right.$ TFCcage $\left._{t_{s, 0}}\right)$ were calculated as:

TFCcage $_{t_{s, 0}}=\sum_{i=t_{s, 0}}^{t_{s, h}}$ DFCcage $_{i}$

Table 2 Feed price per fish size category in 2014 (pers. comm. Andromeda S.A., 2015).

\begin{tabular}{cc}
\hline Fish size $(\mathrm{g})$ & Price $(€ / \mathrm{kg})$ \\
\hline$<7$ & 2.21 \\
7 to 13 & 1.97 \\
13 to 30 & 1.65 \\
30 to 80 & 1.26 \\
80 to 300 & 1.12 \\
$>300$ & 1.17 \\
\hline
\end{tabular}




\subsubsection{Farm model}

For the farm model, the cage model was run repeatedly over the whole range of stocking dates, from 1 (January 1th) to 365 days (December 31 th) by one-day steps. Per stocking date, age at harvest $\left(t_{s, h}-t_{s, 0}\right)$, TFIcage $t_{s, 0}$, TFCcage $_{t_{s, 0}}$, and $\mathrm{N}_{t_{s, 0}}$ were calculated. These results were averaged over all stocking dates to compute the average production cycle of a cage. The period between two successive production cycles is three days (pers. comm. Andromeda S.A., 2015). For the 20 cages that are present on the farm the number of production cycles per year was calculated as:

Production cycles per year $=20 \cdot \frac{365}{\operatorname{average}\left(t_{s, h}-t_{s, 0}\right)+3}$.

Average results per production cycle were multiplied by the number of production cycles per year to compute outputs at the farm level per year: fish production, number of juveniles stocked, feed consumption, and feed costs. Juvenile costs at the farm level were calculated by multiplying the number of juveniles stocked by the price of juveniles of $€ 0.20$ per piece. Packing costs at the farm level were calculated by multiplying fish production by the price of packing of $€ 0.33$ per $\mathrm{kg}$ fish. Revenues from fish sales at the farm level were calculated as the product of fish production and average sales price. Average sales price was computed as the proportion of fish of each category in Table 3 multiplied by its corresponding sales price. Three percent of the fish harvested are deformed. The size distribution of the remaining fish was calculated from a normal probability density function with $\mu=400$ and $\sigma_{\mathrm{HW}}=60$ (pers. comm. Andromeda S.A., 2015).

Table 3 Sales price per fish size category in 2014 (pers. comm. Andromeda S.A., 2015).

\begin{tabular}{ll}
\hline Category & Price $(€ / \mathrm{kg})$ \\
\hline$<100 \mathrm{~g}$ & 0 \\
100 to $200 \mathrm{~g}$ & 1.65 \\
200 to $300 \mathrm{~g}$ & 4.15 \\
300 to $400 \mathrm{~g}$ & 4.52 \\
400 to $600 \mathrm{~g}$ & 4.63 \\
$>600 \mathrm{~g}$ & 5.27 \\
Deformed & 2.52 \\
\hline
\end{tabular}

\subsubsection{Additive genetic standard deviation of traits}

The economic importance of each trait in the breeding goal depends on the change in gross margin, which itself depends on the change in trait level of one $\sigma_{\mathrm{A}}$. The genetic coefficient of variation $\left(\mathrm{CV}_{\mathrm{A}}\right)$ can be used to estimate $\sigma_{\mathrm{A}}$ from the mean trait level $(\mu)$ (Houle, 1992): 
$\sigma_{\mathrm{A}}=\frac{\mathrm{CV}_{\mathrm{A}}}{100 \%} \cdot \mu$.

For TGC $\sigma_{\mathrm{A}}$ can be estimated from the genetic variation in $\mathrm{BW}_{t_{s, h}}$. For this study $\mathrm{BW}_{t_{s, h}}$ was set equal to $400 \mathrm{~g}$, and $\sum_{i=t_{s, 0}}^{\left(t_{s, h}\right)-1}\left(\mathrm{~T}_{i}-12\right)$ was 4084 day degrees (Eq. 7). $\mathrm{CV}_{\mathrm{A}}$ of bodyweight was estimated to be $10.6 \%$ based on data from Navarro et al. (2009). For BW $t_{s, h}$ $\sigma_{\mathrm{A}}$ was thus $42.4 \mathrm{~g}$. The distribution of $\mathrm{BW}_{t_{s, h}}$ was simulated in $\mathrm{R}$ as $\mathrm{BW}_{t_{s, h}, n}=\mu+\mathrm{z}_{n}$. $\sigma_{\mathrm{A}}$, where $\mu=400$ and $\sigma_{\mathrm{A}}=42.4$, and $\mathrm{z}_{n}$ is a standard normal distribution $\left(\mathrm{z}_{n} \sim \mathrm{N}(0,1)\right)$ with $n=1, \ldots, 10^{6}$. From this simulation $\sigma_{\mathrm{A}}$ of TGC was estimated as (Appendix 1):

$$
\begin{aligned}
& \sigma_{\mathrm{A}} \text { of TGC } \approx \sqrt{\operatorname{Var}\left(\mathrm{TGC}_{n}\right)} \approx \sqrt{\left(\frac{1000}{4084}\right)^{2} \cdot \operatorname{Var}\left(\mathrm{BW}_{t_{s, h}, n}{ }^{2 / 3}\right)} \\
& =\frac{1000}{4084} \sqrt{\frac{1}{10^{6}-1} \cdot \sum_{i=1}^{n}\left(\mathrm{BW}_{i}^{2 / 3}-400^{2 / 3}\right)^{2}}=0.95 \mathrm{~g}^{2 / 3} /(\text { day degrees } \cdot 1000) .
\end{aligned}
$$

For TFC $\sigma_{\mathrm{A}}$ can be estimated from the genetic variation in both $\mathrm{BW}_{t_{s, 0}}$ and $\mathrm{CFI}_{t_{s, h}}$. For $\mathrm{CFI}_{t_{s, h}} \sigma_{\mathrm{A}}$ can be approximated by (Appendix 2):

$\sigma_{\mathrm{A}}$ of $\mathrm{CFI}_{t_{s, h}} \approx \frac{1.75}{\mathrm{r}_{\mathrm{A}}} \cdot \sigma_{\mathrm{A}}$ of $\mathrm{BW}_{t_{s, h}}$,

where $\mathrm{r}_{\mathrm{A}}$ is the genetic correlation between $\mathrm{BW}_{t_{s, h}}$ and $\mathrm{CFI}_{t_{s, h}}$, which was assumed to be 0.90 (Quinton et al., 2007). Solving Eq. 16, $\sigma_{\mathrm{A}}$ of $\mathrm{CFI}_{t_{s, h}}$ was equal to $82 \mathrm{~g}$. Based on an average $\mathrm{CFI}_{t_{s, h}}$ of $713 \mathrm{~g}$ in our study, the CVA of $\mathrm{CFI}_{t_{s, h}}$ was $12 \%$, which is close to values reported for other species (Kause et al., 2006; Quinton et al., 2007). Genetic variances for $\mathrm{CFI}_{t_{s, h}}$ and $\mathrm{BW}_{t_{s, 0}}$ were simulated to calculate $\sigma_{\mathrm{A}}$ of TFC. In our study the average $\mathrm{BW}_{t_{s, 0}}$ was $4.4 \mathrm{~g}$. Based on a CVA of $10.6 \%$ for bodyweight, $\sigma_{\mathrm{A}}$ of $\mathrm{BW}_{t_{s, 0}}$ was equal to $0.45 \mathrm{~g}$. The distribution of $\mathrm{CFI}_{t_{s, h}}$ was simulated in $\mathrm{R}$ as $\mathrm{CFI}_{t_{s, h}, n}=\mu+\mathrm{z}_{n} \cdot \sigma_{\mathrm{A}}$, where $\mu=713, \sigma_{\mathrm{A}}=$ 82 , and $\mathrm{z}_{n}$ is a standard normal distribution $\left(\mathrm{z}_{n} \sim \mathrm{N}(0,1)\right)$ with $n=1, \ldots, 10^{6}$. The distribution of $\mathrm{BW}_{t_{s, 0}}$ was simulated in $\mathrm{R}$ as $\mathrm{BW}_{t_{s, 0}, n}=\mu+\mathrm{z}_{n} \cdot \sigma_{\mathrm{A}}$, where $\mu=4.4, \sigma_{\mathrm{A}}=$ 0.45 and $\mathrm{z}_{n}$ is a standard normal distribution $\left(\mathrm{z}_{n} \sim \mathrm{N}(0,1)\right)$ with $n=1, \ldots, 10^{6}$. A covariance of zero was assumed between $\mathrm{CFI}_{t_{s, h}}$ and $\mathrm{BW}_{t_{s, 0}}$. Based on the simulations, $\sigma_{\mathrm{A}}$ of TFC was estimated as: 
$\sigma_{\mathrm{A}}$ of $\mathrm{TFC} \approx \sqrt{\operatorname{Var}\left(\mathrm{TFC}_{n}\right)}=\sqrt{\operatorname{Var}\left(1000 \cdot \frac{\left(\mathrm{CFI}_{t_{s, h}, n}+\mathrm{BW}_{t_{s, 0}, n}\right)^{p}-\mathrm{BW}_{t_{s, 0}, n}^{P}}{4084}\right)}$

$=\frac{1000}{4084} \cdot \sqrt{\frac{1}{10^{6}-1} \cdot \sum_{i=1}^{n}\left(\begin{array}{c}\left(\mathrm{CFI}_{i}+\mathrm{BW}_{i}\right)^{0.544}-\mathrm{BW}_{i}^{0.544} \\ -\left((713+4.4)^{0.544}-4.4^{0.544}\right)\end{array}\right)^{2}}$

$=0.55 \mathrm{~g}^{0.544} /($ degree days $\cdot 1000)$.

For $\mathrm{M} \sigma_{\mathrm{A}}$ can be estimated from the genetic variation in cumulative mortality at harvest $\left(\mathrm{CM}_{t_{s, h}}\right)$. The average $\mathrm{CM}_{t_{s, h}}$ was $14.9 \%$. In animal breeding an underlying liability scale is commonly used to analyse mortality and survival (Falconer and Mackay, 1989). Heritability of $\mathrm{CM}_{t_{s, h}}$ on the liability scale was assumed to be 0.17 (Vehvilainen et al., 2008) and by definition $\sigma_{\mathrm{P}}$ is equal to 1 , hence $\sigma_{\mathrm{A}}=\sqrt{\mathrm{h}^{2}}=\sqrt{0.17}$. Before genetic change, the deviation of the threshold from the mean $\left(x_{B}\right)$ was calculated from the quantile function of a normal distribution in $\mathrm{R}$ as $\mathrm{x}_{\mathrm{B}}=-\operatorname{qnorm}(0.149)=1.04$. After genetic change by one $\sigma_{\mathrm{A}}$, the deviation from the threshold from the mean $\left(x_{A}\right)$ becomes: $x_{A}=x_{B}+\sigma_{\mathrm{A}}=$ $1.04+\sqrt{0.17}=1.45$. After genetic change, $\mathrm{CM}_{t_{s, h}}$ was calculated from the distribution function of a normal distribution in $\mathrm{R}$ as:

$\mathrm{CM}_{t_{s, h}}=\left(1-\operatorname{pnorm}\left(x_{A}\right)\right) \cdot 100 \%=(1-$ pnorm $(1.45)) \cdot 100 \%=7.34 \%$

Average age at harvest was equal to 539 days (Table 4). $\mathrm{M}$ after genetic change was calculated as:

$\mathrm{M}=\left(1-\left(\frac{\mathrm{CM}_{t_{s, h}}}{100}\right)^{\frac{1}{539}}\right) \cdot 100=\left(1-\left(\frac{7.34}{100}\right)^{\frac{1}{539}}\right) \cdot 100=0.014 \% /$ day

The difference in $\mathrm{M}$ before and after genetic change was $0.016 \% /$ day, which was treated as the $\sigma_{\mathrm{A}}$ of $\mathrm{M}$.

Genetic improvement of uniformity reduces the environmental variance of bodyweight. For environmental variance of bodyweight $\mathrm{CV}_{\mathrm{A}}$ was calculated as (Mulder et al., 2007):

$\mathrm{CV}_{\mathrm{A}}=\frac{\mathrm{SD}\left(\sigma_{\mathrm{E}}^{2}\right)}{\overline{\sigma_{\mathrm{E}}^{2}}} \cdot 100 \%$ 
where $\mathrm{SD}\left(\sigma_{\mathrm{E}}^{2}\right)$ is the genetic standard deviation of environmental variance and $\overline{\sigma_{\mathrm{E}}^{2}}$ is the mean environmental variance. Environmental variance equals phenotypic variance minus genetic variance (Hazel, 1943). The $\mathrm{CV}_{\mathrm{A}}$ of environmental variance of bodyweight is about $20 \%$ in rainbow trout (Sae-Lim et al., 2015) and 41.7\% in Atlantic salmon (Sonesson et al., 2013). For seabream the actual value was unknown, hence a minimum of $20 \%$ and maximum of $40 \%$ were used to represent both extremes of the possible range of $\sigma_{\mathrm{A}}$. In this study the trait uniformity was expressed on the standard deviation scale instead of the variance scale. On the standard deviation scale, the $\mathrm{CV}_{\mathrm{A}}$ is half as large as on the variance scale (Hill and Mulder, 2010; Sell-Kubiak et al., 2015). For BW $t_{s, h} \overline{\sigma_{\mathrm{E}}}=\sqrt{\sigma_{\mathrm{HW}^{2}-\sigma_{\mathrm{A}}^{2}}}=$ $\sqrt{60^{2}-42.4^{2}}=42.45 \mathrm{~g}$. For the minimum $\mathrm{CV}_{\mathrm{A}}$ of the environmental standard deviation of bodyweight of $10 \% \sigma_{\mathrm{A}}$ equals $4.2 \mathrm{~g}$, and for the maximum $\mathrm{CV}_{\mathrm{A}}$ of the environmental standard deviation of bodyweight of $20 \% \sigma_{\mathrm{A}}$ equals $8.5 \mathrm{~g}$.

\subsubsection{Validation of the bio-economic model}

To validate the bio-economic model, a simplified production system was assumed for which a profit equation can be developed. In this simplified production system fish were harvested at a constant sum of effective temperatures instead of constant bodyweight. The sum of effective temperatures at harvest was assumed to be unaffected by genetic change. This allowed a profit equation to be set up as a function of the traits: harvest weight $\left(\mathrm{BW}_{t_{s, h}}\right)$, cumulative feed intake at harvest $\left(\mathrm{CFI}_{t_{s, h}}\right)$, and survival at harvest $\left(\mathrm{S}_{t_{s, h}}\right)$. In the bio-economic model $\mathrm{S}_{t_{s, h}}=\frac{\mathrm{N}_{t_{s, h}}}{\mathrm{~N}_{t_{s, 0}}} \cdot 100 \%$. The bio-economic model was adapted by changing the harvest criterion from a bodyweight of $400 \mathrm{~g}$ to a sum of effective temperatures of 4084 day degrees. Thus, an increase in TGC resulted in a greater harvest weight instead of a shorter growing period. One $\sigma_{\mathrm{A}}$ change in TGC led to change in $\mathrm{BW}_{t_{s, h}}$; one $\sigma_{\mathrm{A}}$ change in TFC led to change in $\mathrm{CFI}_{t_{s, h}}$; one $\sigma_{\mathrm{A}}$ change in M led to change in $\mathrm{S}_{\mathrm{t}_{\mathrm{s}, \mathrm{h}}}$. Economic values were derived from the bio-economic model using Eq. 1 and trait levels of $\mathrm{BW}_{t_{s, h}}, \mathrm{CFI}_{t_{s, h}}$, and $\mathrm{S}_{t_{s, h}}$. 
In the profit equation, profit at the farm level was described as:

$$
\begin{aligned}
& \text { Profit }=\frac{1000 \cdot \mathrm{Q}}{\mathrm{BW}_{t_{s, h}}} \cdot\left(\mathrm{BW}_{t_{s, h}} \cdot \frac{\text { sales price-packing costs }}{1000}-\mathrm{CFI}_{t_{s, h}} \cdot \frac{1}{0.5+\frac{\mathrm{S}_{t_{s, h}}}{200}} \cdot\left(\frac{\text { feed price }}{1000}\right)-\right. \\
& \left.\frac{\text { juvenile price }}{\mathrm{S}_{t_{s, h}} / 100}\right)- \text { fixed costs, }
\end{aligned}
$$

where $\mathrm{Q}$ represents production output of the farm $(\mathrm{kg})$ and was calculated as the product of maximum stocking density, cage volume, and number of production cycles per year. Q is not affected by genetic change when the harvest criterion is a sum of effective temperatures of 4084 day degrees. Economic values were calculated as partial derivatives of the profit equation and divided by $\mathrm{Q}$ to express them per $\mathrm{kg}$ fish production. For $\mathrm{BW}_{t_{s, h}}$ the economic value $(\mathrm{EV})$ was calculated as:

$\mathrm{EV}_{\mathrm{BW}_{t_{s, h}}}=\frac{\text { DProfit }}{\partial \mathrm{BW}_{t_{s, h}}} \cdot \frac{1}{\mathrm{Q}}=\frac{1000}{\mathrm{BW}_{t_{s, h}{ }^{2}}} \cdot\left(\frac{\mathrm{CFI}_{t_{s, h}} \cdot(\text { feed price } / 1000)}{0.5+\mathrm{S}_{t_{s, h}} / 200}+\frac{\text { juvenile price }}{\mathrm{S}_{t_{s, h}} / 100}\right)$.

For $\mathrm{CFI}_{t_{s, h}}$ the economic value was calculated as:

$$
\mathrm{EV}_{\mathrm{CFI}_{t_{s, h}}}=\frac{\text { PProfit }}{\partial \mathrm{CFI}_{t_{s, h}}} \cdot \frac{1}{\mathrm{Q}}=-\frac{\text { feed price }}{\mathrm{BW}_{t_{s, h}} \cdot\left(0.5+\mathrm{S}_{t_{s, h}} / 200\right)}
$$

For $\mathrm{S}_{t_{s, h}}$ the economic value was calculated as:

$$
\mathrm{EV}_{\mathrm{S}_{t_{s, h}}}=\frac{\text { PProfit }}{\partial \mathrm{S}_{t_{s, h}}} \cdot \frac{1}{\mathrm{Q}}=\frac{\mathrm{CFI}_{t_{s, h}} \cdot \text { feed price }}{\mathrm{BW}_{t_{s, h}} \cdot\left(50+\mathrm{S}_{t_{s, h}}+\mathrm{S}_{t_{s, h}}{ }^{2} / 200\right)}+\frac{100,000 \cdot \text { juvenile price }}{\mathrm{BW}_{t_{s, h}} \cdot \mathrm{S}_{t_{s, h}}{ }^{2}} .
$$

\subsection{Results}

\subsubsection{Production results before genetic change}

Tables 4 and 5 show the results of the model for key production variables and costs, respectively. The annual fish production was about 565 tons and gross margin about $759,000 €$. Average feed costs were $€ 1.18 / \mathrm{kg}$ feed and average sales price was $€ 4.49 / \mathrm{kg}$ fish. 
Table 4 Key production variables of the gilthead seabream farm before genetic change.

\begin{tabular}{lc}
\hline Item & Value \\
\hline Number of juveniles stocked (year $\left.{ }^{-1}\right)$ & $1,659,945$ \\
Feed consumption (kg/year) & $1,070,177$ \\
Fish production (kg/year) & 564,661 \\
Cages stocked (year ${ }^{-1}$ ) & 13.4 \\
Average age at harvest (day) & 539 \\
Survival (\%) & 85.1 \\
Biological FCR (kg feed/kg fish) & 1.80 \\
Economic FCR (kg feed/kg fish) & 1.92 \\
\hline
\end{tabular}

Biological FCR = feed consumption / (fish production + biomass mortality - biomass juveniles)

Economic FCR $=$ feed consumption / fish production

Table 5 Economic results for the gilthead seabream farm before genetic change.

\begin{tabular}{lcc}
\hline Item & Farm level $(€)$ & Fish level $(€ / \mathrm{kg})$ \\
\hline Feed costs & $1,259,917$ & 2.23 \\
Juvenile costs & 331,989 & 0.59 \\
Packing costs & 186,338 & 0.33 \\
Total variable costs & $1,778,244$ & 3.15 \\
Total revenues & $2,537,166$ & 4.49 \\
Gross margin & 758,922 & 1.34 \\
\hline
\end{tabular}

\subsubsection{Production results after genetic change and economic values}

The effect of the genetic change on production results is illustrated in Table 6. Changes in gross margin show that the order of economic importance of traits was: TGC, TFC, M, and $\sigma_{\mathrm{HW}}$. The effect on gross margin of one $\sigma_{\mathrm{A}}$ change for each trait relative to the effect of a $8.5 \mathrm{~g}$ decrease in $\sigma_{\mathrm{HW}}$ was 43 -fold for TGC, 28 -fold for TFC, and 12-fold for M. Nonlinearity was strongest for $\sigma_{\mathrm{HW}}$ (results not presented for TGC, TFC, and M), for which a doubling of change in trait level from $-4.2 \mathrm{~g}$ to $-8.5 \mathrm{~g}$ led to $7.7 \%$ overestimation of the increase in gross margin.

Table 6 Effect of genetic change on production results relative to the situation without genetic change.

\begin{tabular}{lccccc}
\hline Trait & $\begin{array}{c}\text { Genetic change } \\
\text { (trait unit) }\end{array}$ & $\begin{array}{c}\Delta \text { Juveniles } \\
\left.\text { stocked (year }{ }^{-1}\right)\end{array}$ & $\begin{array}{c}\Delta \text { Feed } \\
\text { consumption } \\
\text { (kg/year) }\end{array}$ & $\begin{array}{c}\Delta \text { Fish } \\
\text { production } \\
(\mathrm{kg} / \text { year) }\end{array}$ & $\begin{array}{c}\Delta \text { Gross margin } \\
(€)\end{array}$ \\
\hline TGC & +0.95 & 89,400 & $-68,409$ & 36,309 & 213,131 \\
TFC & -0.55 & 0 & $-120,300$ & 0 & 140,891 \\
M & -0.016 & $-137,294$ & $-34,446$ & 0 & 69,531 \\
$\sigma_{\text {HW }}$ & -4.2 & 0 & 0 & 0 & 2636 \\
$\sigma_{\text {HW }}$ & -8.5 & 0 & 0 & 0 & 4952 \\
\hline
\end{tabular}

TGC $=$ Thermal growth coefficient $\left(\mathrm{g}^{2 / 3} /(\right.$ day degrees $\left.\cdot 1000)\right)$

$\mathrm{TFC}=$ Thermal feed intake coefficient $\left(\mathrm{g}^{0.544} /(\right.$ day degrees $\left.\cdot 1000)\right)$

$\mathrm{M}=$ Mortality rate $(\% /$ day $)$

$\sigma_{\mathrm{HW}}=$ Standard deviation of harvest weight $(\mathrm{g})$

The mechanisms by which changes in trait levels determined changes in gross margin were as follows. An increase in TGC resulted in a lower age at harvest (Eq. 7) and consequently, 
the number of production cycles per year increased (Eq. 13) and at the farm level, the annual number of juveniles stocked and annual fish production increased. An increase in TGC did not affect daily feed consumption (Eq. 4) and consequently, cumulative feed intake at harvest decreased because the sum of effective temperatures at harvest decreased (Eq. 5) and at the farm level, the annual feed consumption decreased. A decrease in TFC decreased total feed consumption per production cycle (Eqs. 5, 11) but the number of juveniles stocked per production cycle and the fish production per production cycle remained unaltered, thus at the farm level, only annual feed consumption decreased. A decrease in $\mathrm{M}$ reduced the number of juveniles stocked per production cycle (Eq. 9) and consequently, daily feed intake per cage decreased because the average number of fish per cage per day was smaller (Eq. 10), but fish production per production cycle was unaltered. Thus at the farm level, the annual number of juveniles stocked and annual feed consumption decreased. The effect of $\sigma_{\mathrm{HW}}$ on the average sales price is illustrated in Fig. 2: less variation led to more sales in size category 300 to $400 \mathrm{~g}(€ 4.52 / \mathrm{kg})$ at the expense of sales in size category 200 to $300 \mathrm{~g}(€ 4.15 / \mathrm{kg})$. Production results were unaltered by a change in $\sigma_{\mathrm{HW}}$.

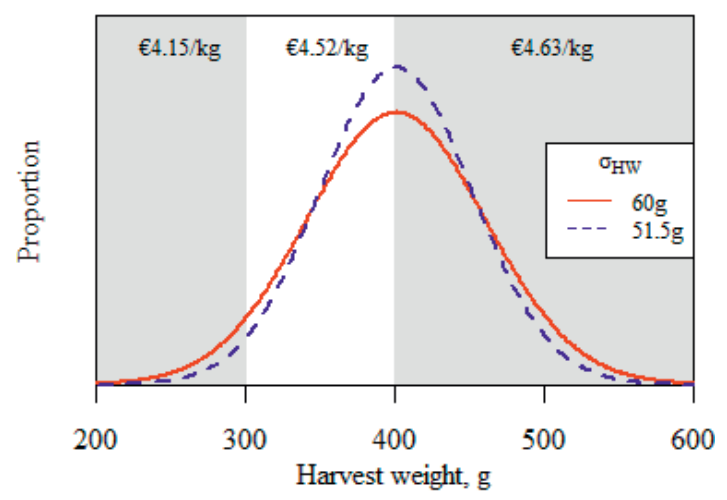

Fig. 2 Distribution of harvest weight over sales price categories at different standard deviations of harvest weight $\left(\sigma_{\mathrm{HW}}\right)$.

Economic values are in Table 7, which shows that the economic value of $\sigma_{\mathrm{HW}}$ was similar for both levels of genetic change. 
Table 7 Economic values of traits for gilthead seabream.

\begin{tabular}{|c|c|c|c|}
\hline Trait & $\begin{array}{l}\text { Baseline trait level } \\
\text { (trait unit) }\end{array}$ & $\begin{array}{l}\text { Genetic change } \\
\text { (trait unit) }\end{array}$ & $\begin{array}{c}\text { Economic value }(€(\mathrm{~kg} \\
\left.\text { production })^{-1}(\text { trait unit })^{-1}\right)\end{array}$ \\
\hline TGC & 12.6 & +0.95 & 0.40 \\
\hline TFC & 8.25 & -0.55 & -0.45 \\
\hline M & 0.0300 & -0.016 & -7.7 \\
\hline$\sigma_{\mathrm{HW}}$ & 60 & -4.2 & -0.0011 \\
\hline$\sigma_{\mathrm{HW}}$ & 60 & -8.5 & -0.0010 \\
\hline
\end{tabular}

TGC $=$ Thermal growth coefficient $\left(\mathrm{g}^{2 / 3} /(\right.$ day degrees $\left.\cdot 1000)\right)$

$\mathrm{TFC}=$ Thermal feed intake coefficient $\left(\mathrm{g}^{0.544} /(\right.$ day degrees $\left.\cdot 1000)\right)$

$\mathrm{M}=$ Mortality rate (\%/day)

$\sigma_{\mathrm{HW}}=$ Standard deviation of harvest weight $(\mathrm{g})$

\subsubsection{Comparison of economic values from the bio-economic model and the profit equation}

Table 8 shows that, for the simplified production system, the economic values derived from the bio-economic model and the profit equation were similar.

Table 8 Economic values derived from the bio-economic model and profit equation.

\begin{tabular}{lcccc}
\hline Trait & $\begin{array}{c}\text { Baseline trait } \\
\text { level (trait unit) }\end{array}$ & $\begin{array}{c}\text { Genetic change } \\
\text { (trait unit) }\end{array}$ & \multicolumn{2}{c}{$\begin{array}{c}\text { Economic value } \\
(€(\mathrm{~kg} \text { production) }\end{array}$} \\
\cline { 3 - 5 } (trait unit) $\left.^{-1}\right)$
\end{tabular}

\subsection{Discussion}

\subsubsection{Validity of the bio-economic model}

For the simplified production system, the profit equation and the bio-economic model return similar economic values, which confirms the validity of the bio-economic model. To further validate the bio-economic model, production results were compared to those of other studies. FCR (Table 4) was within the range of 1.5 to 2 reported by Sola et al. (2007), but considerably lower than the 2.3 value reported by EAS-EATiP (2014). Overall survival was $85 \%$, which is within the range reported by EAS-EATiP (2014). A comparison with a cost-breakdown for large-scale production of gilthead seabream and European seabass (Dicentrarchus labrax) is in Table 9 (Barazi-Yeroulanos, 2010). In the FAO data variable costs are higher, largely because labour, energy, and medicines and veterinary services were not considered to be variable costs in our study. Trends in the increase in productivity per person (University of Stirling, 2004) support the assumption that labour should be 
treated more as a fixed than a variable cost. Medicine costs may vary, but veterinary costs are likely to be fixed per farm. Energy costs are to a larger extent determined by farm layout than by realized production, and thus can be considered as fixed. Altogether, total variable costs may have been slightly underestimated in our study, but FCR and overall survival matched well to current industry standards.

Table 9 Cost-breakdown for gilthead seabream production.

\begin{tabular}{lcc}
\hline Item & \multicolumn{2}{c}{ Proportion of total costs (\%) } \\
\cline { 2 - 3 } & Our study ${ }^{\text {a }}$ & Barazi-Yeroulanos (2010) \\
\hline Feed & 50 & 48 \\
Juveniles & 13 & 11 \\
Marketing (incl. packing) & 7 & 18 \\
Labour & - & 3 \\
Energy & - & 4 \\
Medicines and veterinary services & - & 2 \\
Other & - & 4 \\
Total variable costs & 70 & 89 \\
Total fixed costs & - & 11 \\
\hline
\end{tabular}

${ }^{\mathrm{a}}$ Relative to revenues

\subsubsection{Breeding goal}

In the breeding goal, TGC, TFC, and $\mathrm{M}$ are equivalent to respectively $\mathrm{BW}_{t_{s, h}}, \mathrm{CFI}_{t_{s, h}}$, and $\mathrm{S}_{t_{s, h}}$, when $\mathrm{BW}_{t_{s, 0}}$ is much smaller than $\mathrm{BW}_{t_{s, h}}$ (Appendix 1 and 2). When the sum of effective temperatures is the harvest criterion, one $\sigma_{\mathrm{A}}$ change in TGC, TFC, and M led to changes in $\mathrm{BW}_{t_{s, h}}, \mathrm{CFI}_{t_{s, h}}$, and $\mathrm{S}_{t_{s, h}}$ that were very similar to the $\sigma_{\mathrm{A}}$ of these traits (Table 8), which demonstrates their equivalence. If the economic values of TGC, TFC, and M were calculated for the sum of effective temperatures instead of harvest weight as the harvest criterion, they would be slightly lower for TGC $\left(0.34 €(\mathrm{~kg} \text { production })^{-1}\left(\mathrm{~g}^{0.544} /(\right.\right.$ day degrees 1000) $)^{-1}$ ) and unaltered for TFC and M. In agreement with Wilton and Goddard (1996) economic values were similar for both harvest criteria. Although both sets of traits are equivalent in the breeding goal, there are pros and cons to each one. $\mathrm{BW}_{t_{s, h}}$ is commonly used as a selection criterion and thus its use in the breeding goal is straightforward. However, $\mathrm{BW}_{t_{s, h}}$ is a management parameter that is strongly influenced by the growing period and temperature regime. TGC corrects for heterogeneity in stocking weight, growing period, and temperature regime, and, therefore, allows for a better comparison of breeding values across conditions than $\mathrm{BW}_{t_{s, h}}$ (Besson et al., 2016a; Sae-Lim et al., 2013; Trong et al., 2013). 
FCR could be used as an alternative to TFC in the breeding goal. An advantage of feed intake compared to FCR is that it relates directly to feed costs (Goddard, 1998). An advantage of FCR is that it illustrates the effect of improvement in efficiency on, for example, environmental impacts, as in Besson et al. (2016b). Feed intake is often considered more appropriate as a breeding goal trait than FCR (Emmerson, 1997; Veerkamp et al., 2013), with a common argument that traits expressed as ratio's are disadvantageous in animal breeding (Veerkamp et al., 2013). Selection for a ratio, e.g., FCR, results in a lower selection response than selection for both components of the ratio, e.g., feed intake and growth (Gunsett, 1984). However, in the same way that FCR is a ratio, growth is the ratio of feed intake to FCR, thus a breeding goal that includes both growth and FCR is equivalent to a breeding goal that includes growth and feed intake. The economic value of growth depends on which other trait, feed intake or FCR, is included in the breeding goal (Goddard, 1998).

\subsubsection{Economic values}

Bio-economic models and profit equations are both suitable to derive economic values. An advantage of a profit equation compared to a bio-economic model is its simplicity. However, its applicability is limited to specific situations, because environmental conditions are ignored. For example, the profit equation cannot be used to derive economic values for a range of temperature regimes, as was done in Besson et al. (2016a) by using the bio-economic model. Such properties may be of particular interest for breeding programs that aim to supply many farms. In addition, alternative constraints on production output, such as oxygen availability, cannot be dealt with by the profit equation but can be incorporated in the bio-economic model, as discussed later. Furthermore, the profit equation is rigid in terms of trait definition, which has led to the false assumption that harvest weight changes following genetic improvement, whereas in the bio-economic model genetic improvement of growth rate leads to a reduction in the growing period.

From a profit function economic values can be computed from either its partial derivative with respect to trait level, or from an increase or decrease in trait level relative to the current mean. In this study simulated changes in trait levels correspond to desired directions of genetic change of one genetic standard deviation. However, for a non-linear profit function Goddard (1983) demonstrated that economic values that maximize profit in the next generation may depend on selection responses. Dekkers et al. (1995) showed that economic 
gain is slightly higher when economic values are derived as the partial derivative of a nonlinear profit equation at the genetic level of the next generation than at the genetic level of the current generation. This implies two things:

(1) Economic values are closer to optimum when the simulated change in trait level resembles its expected rather than its desired direction.

(2) Economic values are closer to optimum when the simulated change in trait level equals the difference between trait levels in the current and next generation than when it is the partial derivative at current genetic levels.

In our study, expected and desired directions of change in trait levels were identical, except for TFC, which may increase in practice due to its genetic correlation with TGC (Quinton et al., 2007). A genetic standard deviation generally provides a better proxy for the difference between trait levels in the current and next generation than an infinitesimal change, and hence will result in an economic value that is closer to optimum than the conventional partial derivative at the current trait level.

This is the first time that economic values have been derived for uniformity in aquaculture, here expressed as $\sigma_{\mathrm{HW}}$. In recent years there has been increasing interest to improve uniformity (Khaw et al., 2016; Marjanovic et al., 2016; Mulder et al., 2008; Sae-Lim et al., 2015). Improvement in uniformity affects average sales price and reduces the need for sizegrading. However, for seabream production reducing the need for size-grading would not result in major cost-savings, because seabream is size-graded only once during grow-out. Thus, a potential effect on grading frequency was excluded from the economic value of uniformity. Furthermore, uniformity has been suggested to affect feed intake, growth rate, and mortality (Gilmour et al., 2005; Jobling, 1995). Economic consequences of changes in other traits were accounted for in their respective economic values. By exploiting genetic correlations, selection for uniformity may be used to improve the other traits in the breeding goal.

\subsubsection{Application to other aquaculture species}

In its current form, the bio-economic model can be easily applied for the derivation of economic values for other species produced in systems where stocking density limits production output, such as cages and flow-through tanks. This would require different values for the coefficients of Table 1, maximum stocking density, stocking and harvest weight, and input and output prices. Eqs. 4 and 5 require some species-specific 
modifications, such as alternative values for exponents $2 / 3$ and 3/2 in Eq. 4 (Dumas et al., 2007) or a different minimum temperature for growth.

Adaptations to the model are required for species that are reared in production systems for which constraints on production output are different, such as recirculating aquaculture systems and ponds. When the constraint on production output is different from stocking density, the number of fish stocked per production cycle (Eq. 9) is determined by other parameters. For recirculating aquaculture systems treatment capacity of the biofilter can be a constraint on production output (Besson et al., 2014). In this case daily nitrogen excretion by fish is the parameter that determines the number of fish stocked per production cycle. Daily nitrogen excretion by fish can be predicted from the difference between daily feed consumption and daily gain in bodyweight, as described in Besson et al. (2014). In both cages and ponds oxygen availability can be a constraint on production output. In this case daily oxygen consumption per fish is the parameter that determines the number of fish stocked per production cycle. Daily oxygen consumption per fish can be predicted from daily feed consumption and daily gain in bodyweight, as described in Besson et al. (2016a). With the above modifications the same bio-economic model was applied for the derivation of economic values for African catfish produced in recirculating aquaculture systems (Besson et al., 2014), European seabass produced in cages (Besson et al., 2016a), gilthead seabream produced in cages (this study), turbot produced in tanks (unpublished results), and Nile tilapia produced in ponds (unpublished results).

\subsection{Conclusions}

We developed a bio-economic model to derive economic values for a wide range of aquaculture species. Its validity was confirmed by the comparison to a profit equation for a simplified production system and by comparison of the production results to those of other studies. Application of the bio-economic model to gilthead seabream resulted in economic values for TGC, TFC, $\mathrm{M}$, and $\sigma_{\mathrm{HW}}$. TGC was the most important trait to improve, followed by TFC and M. The effect of $\sigma_{\mathrm{HW}}$ on gross margin was small.

\subsection{Acknowledgements}

We are grateful for the extensive production data provided by Andromeda S.A. and their feedback on model assumptions. We thank Piter Bijma for his help in the computation of genetic standard deviations. 


\subsection{Appendices}

\subsubsection{Appendix 1: Genetic variation in TGC}

Genetic variation in TGC depends on genetic variation both in $\mathrm{BW}_{t_{s, 0}}$ and $\mathrm{BW}_{t_{s, h}}$ :

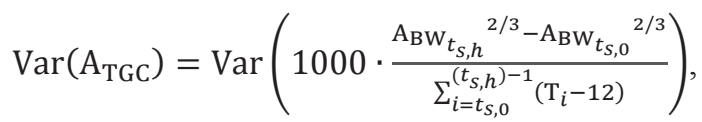

where $\mathrm{A}_{\mathrm{TGC}}$ is the genotype for TGC, $\mathrm{A}_{\mathrm{BW}_{t_{s, h}}}$ is the genotype for harvest weight, and $\mathrm{A}_{\mathrm{BW}}{ }_{t_{s, 0}}$ is the genotype for stocking weight. Eq. 25 can be rewritten as:

$\operatorname{Var}\left(\mathrm{A}_{\mathrm{TGC}}\right)=\left(\frac{1000}{\sum_{i=t_{s, 0}}^{\left(t_{s, h}\right)-1}\left(\mathrm{~T}_{i}-12\right)}\right)^{2} \cdot\left(\operatorname{Var}\left(\mathrm{A}_{\mathrm{BW}_{t_{s, h}}}{ }^{2 / 3}\right)+\operatorname{Var}\left(\mathrm{A}_{\mathrm{BW}_{t_{s, 0}}}{ }^{2 / 3}\right)\right.$

$\left.-2 \cdot \operatorname{cov}\left(\mathrm{A}_{\mathrm{BW}_{t_{s, h}}}{ }^{2 / 3}, \mathrm{~A}_{\mathrm{BW}_{t_{s, 0}}} 2 / 3\right)\right)$.

Because $\mathrm{BW}_{t_{s, 0}}$ is much smaller than $\mathrm{BW}_{t_{s, h}}, \operatorname{Var}\left(\mathrm{A}_{\mathrm{BW}_{t_{s, 0}}} 2 / 3\right)-2$. $\operatorname{cov}\left(\mathrm{A}_{\mathrm{BW}}{ }_{t_{s, h}}{ }^{2 / 3}, \mathrm{~A}_{\mathrm{BW}_{t_{s, 0}}}{ }^{2 / 3}\right)$ is much smaller than $\operatorname{Var}\left(\mathrm{A}_{\mathrm{BW}}{ }_{t_{s, h}}{ }^{2 / 3}\right)$ (Rutten et al., 2005). Thus, Eq. 26 can be reduced to Eq. 15 .

\subsubsection{Appendix 2: Genetic variation in cumulative feed intake at harvest}

The regression coefficient of the genotype for $\mathrm{CFI}_{t_{s, h}}\left(\mathrm{~A}_{\mathrm{CFI}_{t_{s, h}}}\right)$ on the difference between $\mathrm{A}_{\mathrm{BW}_{t_{s, h}}}$ and $\mathrm{A}_{\mathrm{BW}_{t_{s, 0}}}$, can be calculated as:

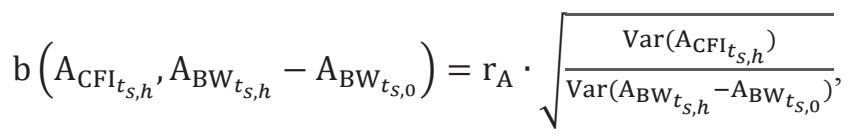

where $\mathrm{b}\left(\mathrm{A}_{\mathrm{CFI}_{t}, h}, \mathrm{~A}_{\mathrm{BW}_{t_{s, h}}}-\mathrm{A}_{\mathrm{BW}_{t_{s, 0}}}\right)$ is the regression coefficient, and $\mathrm{r}_{\mathrm{A}}$ is the genetic correlation coefficient. For the regression of $\mathrm{A}_{\mathrm{CFI}_{t}, h}$ on $\mathrm{A}_{\mathrm{BW}_{t_{s, h}}}-\mathrm{A}_{\mathrm{BW}_{t_{s, 0}}}$ the intercept corresponds to feed consumption to meet maintenance energy requirements $\left(\mathrm{CFI}_{\text {maintenance }}\right)$ at zero growth. Assuming a digestible energy content of the diet of 17 $\mathrm{kJ} / \mathrm{g}, \mathrm{CFI}_{\text {maintenance }}$ is calculated as (Lupatsch et al., 2003):

$\mathrm{CFI}_{\text {maintenance }}=\sum_{i=t_{s, 0}}^{t_{s, h}} 47.89 \cdot\left(\mathrm{BW}_{i} / 1000\right)^{0.80} / 17=20 \mathrm{~g}$. 
For $\mathrm{A}_{\mathrm{BW}_{t_{s, h}}}-\mathrm{A}_{\mathrm{BW}_{t_{s, 0}}}=400-4.4=395.6 \mathrm{~g}, \mathrm{~A}_{\mathrm{CFI}_{t_{s, h}}}$ equals $1.80 \cdot 395.6=713 \mathrm{~g}$, where

1.80 is the biological FCR (Table 4). The regression coefficient can thus be approximated as $(713-20) / 395.6=1.75$ and Eq. 27 can be rewritten as:

$1.75=\mathrm{r}_{\mathrm{A}} \cdot \sqrt{\frac{\operatorname{Var}\left(\mathrm{A}_{\mathrm{CFI}} t_{s, h}\right)}{\operatorname{Var}\left(\mathrm{A}_{\mathrm{BW}} t_{t_{s, h}}\right)+\operatorname{Var}\left(\mathrm{A}_{\mathrm{BW}} t_{t_{s, 0}}\right)-2 \cdot \operatorname{cov}\left(\mathrm{A}_{\mathrm{BW}} t_{t_{s, h}}, \mathrm{~A}_{\mathrm{BW}} \mathrm{t}_{t_{s, 0}}\right)}}$.

Because $\mathrm{BW}_{t_{s, 0}}$ is much smaller than $\mathrm{BW}_{t_{s, h}}, \operatorname{Var}\left(\mathrm{A}_{\mathrm{BW}} t_{s, 0}\right)-2 \cdot \operatorname{cov}\left(\mathrm{A}_{\mathrm{BW}} t_{t_{s, h}}, \mathrm{~A}_{\mathrm{BW}} t_{t_{s, 0}}\right)$ is much smaller than $\operatorname{Var}\left(\mathrm{A}_{\mathrm{BW}_{t_{s, h}}}\right)$ (Rutten et al., 2005). Thus, Eq. 29 can be reduced to Eq. 16.

\subsection{References}

Barazi-Yeroulanos, L., 2010. Synthesis of Mediterranean marine finfish aquaculture - A marketing and promotion strategy. Studies and reviews. General Fisheries Commission for the Mediterranean. No. 88 FAO, Rome, 1-198.

Besson, M., Vandeputte, M., van Arendonk, J.A.M., Aubin, J., de Boer, I.J.M., Quillet, E., Komen, H., 2016a. Influence of water temperature on the economic value of growth rate in fish farming: The case of sea bass (Dicentrarchus labrax) cage farming in the Mediterranean. Aquaculture. 462, 47-55.

Besson, M., Aubin, J., Komen, H., Poelman, M., Quillet, E., Vandeputte, M., van Arendonk, J.A.M., de Boer, I.J.M., 2016b. Environmental impacts of genetic improvement of growth rate and feed conversion ratio in fish farming under rearing density and nitrogen output limitations. J Clean Prod. 116, 100-109.

Besson, M., Komen, H., Aubin, J., De Boer, I.J.M., Poelman, M., Quillet, E., Vancoillie, M., Vandeputte, M., Van Arendonk, J.A.M., 2014. Economic values of growth and feed efficiency for fish farming in recirculating aquaculture system with density and nitrogen output limitations: a case study with African catfish (Clarias gariepinus). J Anim Sci. 92, 5394-5405.

Byrne, T.J., Amer, P.R., Fennessy, P.F., Cromie, A.R., Keady, T.W.J., Hanrahan, J.P., McHugh, M.P., Wickham, B.W., 2010. Breeding objectives for sheep in Ireland: A bio-economic approach. Livest Sci. 132, 135-144.

Cacho, O.J., 1990. Protein and fat dynamics in fish: A bioenergetic model applied to aquaculture. Ecol Model. 50, 33-56.

Cho, C.Y., 1992. Feeding systems for rainbow trout and other salmonids with reference to current estimates of energy and protein requirements. Aquaculture. 100, 107-123.

Dekkers, J.C.M., Birke, P.V., Gibson, J.P., 1995. Optimum Linear Selection Indexes for Multiple Generation Objectives with Nonlinear Profit-Functions. Anim Sci. 61, 165-175.

Dumas, A., France, J., Bureau, D.P., 2007. Evidence of three growth stanzas in rainbow trout (Oncorhynchus mykiss) across life stages and adaptation of the thermal-unit growth coefficient. Aquaculture. 267, 139-146.

EAS-EATiP, 2014. Performance of the sea bass and sea bream sector in the Mediterranean. Aquaculture Europe, San Sebastian.

Emmerson, D.A., 1997. Commercial approaches to genetic selection for growth and feed conversion in domestic poultry. Poult Sci. 76, 1121-1125.

Falconer, D.S., Mackay, T.F.C., 1989. Introduction to quantitative genetics, 3rd ed. Longman, Harlow. 
Gibson, J.P., Kennedy, B.W., 1990. The Use of Constrained Selection Indexes in Breeding for Economic Merit. Theor Appl Genet. 80, 801-805.

Gilmour, K.M., DiBattista, J.D., Thomas, J.B., 2005. Physiological causes and consequences of social status in salmonid fish. Integr Comp Biol. 45, 263-273.

Gjedrem, T., Thodesen, J., 2005. Selection. in: Gjedrem, T. (Ed.), Selection and Breeding Programs in Aquaculture. Springer, Dordrecht, 89-111.

Gjedrem, T., Baranski, M., 2009. Selective Breeding in Aquaculture: an Introduction. Springer, Dordrecht Heidelberg London New York.

Goddard, M.E., 1983. Selection Indices for Non-Linear Profit-Functions. Theor Appl Genet. 64, 339-344.

Goddard, M.E., 1998. Consensus and debate in the definition of breeding objectives. J Dairy Sci. 81, 6-18.

Groen, A.F., 1989. Economic Values in Cattle-Breeding 2. Influences of Production Circumstances in Situations with Output Limitations. Livest Prod Sci. 22, 17-30.

Gunsett, F.C., 1984. Linear Index Selection to Improve Traits Defined as Ratios. J Anim Sci. 59, 1185-1193.

Hazel, L.N., 1943. The genetic basis for constructing selection indexes. Genetics. 28, 476-490.

Henryon, M., Purvis, I.W., Berg, P., 1999. Definition of a breeding objective for commercial production of the freshwater crayfish, marron (Cherax tenuimanus). Aquaculture. 173, 179195.

Hietala, P., Wolfova, M., Wolf, J., Kantanen, J., Juga, J., 2014. Economic values of production and functional traits, including residual feed intake, in Finnish milk production. J Dairy Sci. 97, 1092-1106.

Hill, W.G., Mulder, H.A., 2010. Genetic analysis of environmental variation. Genet Res. 92, 381395.

Houle, D., 1992. Comparing Evolvability and Variability of Quantitative Traits. Genetics. 130, 195 204.

Iwama, G.K., Tautz, A.F., 1981. A Simple Growth Model for Salmonids in Hatcheries. Can J Fish Aquat Sci. 38, 649-656.

Janssen, K., Chavanne, H., Berentsen, P., Komen, H., 2017. Impact of selective breeding on European aquaculture. Aquaculture. 472, 8-16.

Jobling, M., 1995. Simple indices for the assessment of the influences of social environment on growth performance, exemplified by studies on Arctic charr. Aquacult Int. 3, 60-65.

Jobling, M., 2003. The thermal growth coefficient (TGC) model of fish growth: a cautionary note. Aquacult Res. 34, 581-584.

Kause, A., Tobin, D., Dobly, A., Houlihan, D., Martin, S., Mantysaari, E.A., Ritola, O., Ruohonen, K., 2006. Recording strategies and selection potential of feed intake measured using the Xray method in rainbow trout. Genet Sel Evol. 38, 389-409.

Khaw, H.L., Ponzoni, R.W., Yee, H.Y., Aziz, M.A.b., Mulder, H.A., Marjanovic, J., Bijma, P., 2016. Genetic variance for uniformity of harvest weight in Nile tilapia (Oreochromis niloticus). Aquaculture. 451, 113-120.

Knap, P.W., 2005. Breeding robust pigs. Austr J Exp Agric. 45, 763-773.

Lupatsch, I., Kissil, G.W., Sklan, D., 2003. Comparison of energy and protein efficiency among three fish species gilthead sea bream (Sparus aurata), European sea bass (Dicentrarchus labrax) and white grouper (Epinephelus aeneus): energy expenditure for protein and lipid deposition. Aquaculture. 225, 175-189.

Marjanovic, J., Mulder, H.A., Khaw, H.L., Bijma, P., 2016. Genetic parameters for uniformity of harvest weight and body size traits in the GIFT strain of Nile tilapia. Genet Sel Evol. 48.

Mayer, P., Estruch, V.D., Jover, M., 2012. A two-stage growth model for gilthead sea bream (Sparus aurata) based on the thermal growth coefficient. Aquaculture. 358-359, 6-13.

Mayer, P., Estruch, V., Blasco, J., Jover, M., 2008. Predicting the growth of gilthead sea bream (Sparus aurata L.) farmed in marine cages under real production conditions using temperature- and time-dependent models. Aquacult Res. 39, 1046-1052.

Mulder, H.A., Bijma, P., Hill, W.G., 2007. Prediction of breeding values and selection responses with genetic heterogeneity of environmental variance. Genetics. 175, 1895-1910. 
Mulder, H.A., Bijma, P., Hill, W.G., 2008. Selection for uniformity in livestock by exploiting genetic heterogeneity of residual variance. Genet Sel Evol. 40, 37-59.

Navarro, A., Zamorano, M.J., Hildebrandt, S., Ginés, R., Aguilera, C., Afonso, J.M., 2009. Estimates of heritabilities and genetic correlations for growth and carcass traits in gilthead seabream (Sparus auratus L.), under industrial conditions. Aquaculture. 289, 225-230.

Nielsen, H.M., Amer, P.R., Byrne, T.J., 2014. Approaches to formulating practical breeding objectives for animal production systems. Acta Agr Scand A An Sci. 64, 2-12.

Ponzoni, R.W., Nguyen, N.H., Khaw, H.L., 2007. Investment appraisal of genetic improvement programs in Nile tilapia (Oreochromis niloticus). Aquaculture. 269, 187-199.

Ponzoni, R.W., Nguyen, N.H., Khaw, H.L., Ninh, N.H., 2008. Accounting for genotype by environment interaction in economic appraisal of genetic improvement programs in common carp Cyprinus carpio. Aquaculture. 285, 47-55.

Quinton, C.D., Kause, A., Koskela, J., Ritola, O., 2007. Breeding salmonids for feed efficiency in current fishmeal and future plant-based diet environments. Genet Sel Evol. 39, 431-446.

R Core Team, 2015. R: A Language and Environment for Statistical Computing. http://www.Rproject.org/.

Rutten, M.J.M., Komen, H., Bovenhuis, H., 2005. Longitudinal genetic analysis of Nile tilapia (Oreochromis niloticus L.) body weight using a random regression model. Aquaculture. 246, 101-113.

Sae-Lim, P., Kause, A., Janhunen, M., Vehvilainen, H., Koskinen, H., Gjerde, B., Lillehammer, M., Mulder, H.A., 2015. Genetic (co)variance of rainbow trout (Oncorhynchus mykiss) body weight and its uniformity across production environments. Genet Sel Evol. 47, 46.

Sae-Lim, P., Kause, A., Mulder, H.A., Martin, K.E., Barfoot, A.J., Parsons, J.E., Davidson, J., Rexroad III, C.E., Van Arendonk, J.A.M., Komen, H., 2013. Genotype-by-environment interaction of growth traits in rainbow trout (Oncorhynchus mykiss): A continental scale study. J Anim Sci. 91, 5572-5581.

Sell-Kubiak, E., Bijma, P., Knol, E.F., Mulder, H.A., 2015. Comparison of methods to study uniformity of traits: Application to birth weight in pigs. J Anim Sci. 93, 900-911.

Shook, G.E., 2006. Major Advances in Determining Appropriate Selection Goals. J Dairy Sci. 89, 1349-1361.

Sola, L., Moretti, A., Crosetti, D., Karaiskou, N., Magoulas, A., Rossi, A.R., Rye, M., Triantafyllidis, A., Tsigenopoulos, C.S., 2007. Gilthead seabream - Sparus aurata. in: Crossetti, D., Lapègue, S., Olesen, I., Svaasand, T. (Eds.), Genetic effects of domestication, culture and breeding of fish and shellfish, and their impacts on wild populations. Genimpact Final Scientific report, Viterbo, Italy, 47-54.

Sonesson, A.K., Odegard, J., Ronnegard, L., 2013. Genetic heterogeneity of within-family variance of body weight in Atlantic salmon (Salmo salar). Genet Sel Evol. 45.

Trong, T.Q., Mulder, H.A., van Arendonk, J.A.M., Komen, H., 2013. Heritability and genotype by environment interaction estimates for harvest weight, Growth rate, And shape of Nile tilapia (Oreochromis niloticus) grown in river cage and VAC in Vietnam. Aquaculture. 384-387, 119-127.

University of Stirling, 2004. Study of the market for aquaculture produced seabass and seabream species,

http://ec.europa.eu/fisheries/documentation/studies/aquaculture_market_230404_en.pdf. Accessed on 12 April 2016

van Middelaar, C.E., Berentsen, P.B.M., Dijkstra, J., van Arendonk, J.A.M., de Boer, I.J.M., 2014. Methods to determine the relative value of genetic traits in dairy cows to reduce greenhouse gas emissions along the chain. J Dairy Sci. 97, 5191-5205.

Veerkamp, R.F., Pryce, J.E., Spurlock, D., Berry, D., Coffey, M., Løvendahl, P., Linde, R.v.d., Bryant, J., Miglior, F., Wang, Z., Winters, M., Krattenmacher, N., Charfeddine, N., Pedersen, J., Haas, Y.d., 2013. Selection on feed intake or feed efficiency: A position paper from gDMI breeding goal discussions. Interbull Bull. 47, 15-22.

Vehvilainen, H., Kause, A., Quinton, C., Koskinen, H., Paananen, T., 2008. Survival of the currently fittest: Genetics of rainbow trout survival across time and space. Genetics. 180, 507-516. 
Wilton, J.W., Goddard, M.E., 1996. Selection for carcass and feedlot traits considering alternative slaughter end points and optimized management. J Anim Sci. 74, 37-45.

Wolfová, M., Wolf, J., 2013. Strategies for defining traits when calculating economic values for livestock breeding: A review. Animal. 7, 1401-1413.

Zuniga-Jara, S., Marin-Riffo, M.C., 2014. A bioeconomic model of a genetic improvement program of abalone. Aquacult Int. 22, 1533-1562. 


\title{
4
}

\section{Derivation of the economic value of $R_{0}$ for macroparasitic diseases and application to sea lice in salmon}

\author{
Kasper Janssen ${ }^{1}$, Hans Komen ${ }^{1}$, Helmut W. Saatkamp ${ }^{2}$, Mart C.M. de Jong ${ }^{3}$ and \\ Piter Bijma ${ }^{1}$
}

${ }^{1}$ Wageningen University, Animal Breeding and Genomics, Droevendaalsesteeg 1, 6708 PB Wageningen, The Netherlands

${ }^{2}$ Wageningen University, Business Economics, Hollandseweg 1, 6706 KN Wageningen, The Netherlands

${ }^{3}$ Wageningen University and Research, Quantitative Veterinary Epidemiology, P.O. Box 338, 6708 PB Wageningen, The Netherlands.

Genetics Selection Evolution (2018) 50:47 


\begin{abstract}
Background: Macroparasites, such as ticks, lice, and helminths, are a concern in livestock and aquaculture production, and can be controlled by genetic improvement of the host population. Genetic improvement should aim at reducing the rate at which parasites spread across the farmed population. This rate is determined by the basic reproduction ratio, i.e. $\mathrm{R}_{0}$, which is the appropriate breeding goal trait. This study aims at providing a method to derive the economic value of $\mathrm{R}_{0}$.
\end{abstract}

Methods: Costs of a disease are the sum of production losses and expenditures on disease control. Genetic improvement of $\mathrm{R}_{0}$ decreases the loss-expenditure frontier. Its economic effect depends on whether the management strategy is optimized or not. The economic value may be derived either from the reduction in losses with constant expenditures or from the reduction in expenditures with constant losses.

Results: When $\mathrm{R}_{0} \leq 1$, the economic value of a further reduction is zero because there is no risk of a major epidemic. When $\mathrm{R}_{0}>1$ and management is optimized, the economic value increases with decreasing values of $R_{0}$, because both the mean number of parasites per host and frequency of treatments decrease at an increasing rate when $R_{0}$ decreases. When $\mathrm{R}_{0}>1$ and management is not optimized, the economic value depends on whether genetic improvement is used for reducing expenditures or losses. For sea lice in salmon the economic value depends on a reduction in expenditures with constant losses, and is estimated to be $0.065 € /$ unit $\mathrm{R}_{0} / \mathrm{kg}$ production.

Discussion: Response to selection for measures of disease prevalence cannot be predicted from quantitative genetic theory alone. Moreover, many studies fail to address the issue of whether genetic improvement results in reduced losses or expenditures. Using $\mathrm{R}_{0}$ as the breeding goal trait, weighed by its appropriate economic value, avoids these issues.

Conclusion: When management is optimized, the economic value increases with decreasing values of $R_{0}$ (until the threshold of $R_{0}=1$, where it drops to zero). When management is not optimized, the economic value depends on whether genetic improvement is used for reduced expenditures or production losses. For sea lice in salmon the economic value is estimated to be $0.065 € /$ unit $R_{0} / \mathrm{kg}$ production. 


\subsection{Background}

Macroparasites, such as ticks, lice, and helminths, are a concern in livestock and aquaculture production worldwide. Macroparasites may reduce the wellbeing of the animals (Fast et al., 2006), are transmitted from livestock to humans (Roepstorff et al., 2011), impose a threat to wild populations due to pathogen spillover from farmed animals (Graystock et al., 2016; Krkošek et al., 2011), and induce economic costs in farming (Iversen and Hermansen, 2017; Nieuwhof and Bishop, 2005). Free range (outdoor) farming is particularly prone to macroparasites compared to indoor farming, because generally it provides more favourable conditions for parasites to complete their lifecycle, and thus the risk of infection from wild populations may be higher (Lay et al., 2011; Roepstorff et al., 2011). The worldwide trend from free-range farming to indoor farming of monogastrics (Steinfeld et al., 2006) could have reduced parasite prevalence globally, while the opposite trend in farming conditions that occurs in some developed countries (CBS, 2017) might increase parasite prevalence locally. For the same reasons that free-range farming is more prone to macroparasites than indoor farming, outdoor cage and pond aquaculture - the dominant forms of aquaculture - are likely to be more prone to macroparasites than indoor aquaculture.

The prevalence of macroparasites is controlled by (1) preventive measures that minimize the risk of infection, inhibit the rate at which parasites spread, and interrupt the parasitic lifecycle, and (2) by treatment with drugs or other methods. Treatment efficacy tends to deteriorate over time as parasites often evolve drug resistance (Stear et al., 2007). Because of the evolution of drug-resistant parasites and the stringent regulations on maximum residue limits for drugs, control of parasites is increasingly difficult (Mul, 2017). The rate at which parasites evolve drug resistance is expected to increase as the frequency of treatments increases, and when treatment relies only on a few treatment mechanisms compared to a combination of various treatment mechanisms (e.g., drugs and temperature treatment). Based on the same principle, genetic improvement of farm animals may be more sustainable when selection is performed on many underlying loci with small effects compared to selection on a single quantitative trait locus with a large effect (Kemper et al., 2013). Nevertheless, both simulation studies (Kemper et al., 2013) and empirical evidence (Kemper et al., 2010) suggest that parasite evolution will not revert the effect of genetic improvement of livestock in the short term. Thus, genetic improvement of resistance to 
macroparasites in farm animals is a highly desirable addition to the repertoire of control measures.

Genetic improvement should aim at reducing the rate at which parasites spread across the farmed population, and combined with the management strategy, this rate determines prevalence. This rate is determined by the basic reproduction ratio, $\mathrm{R}_{0}$, which was previously proposed as the appropriate breeding goal trait for infectious diseases by Anche et al. (2014). For macroparasitic diseases $\mathrm{R}_{0}$ is defined as "the average number of offspring (female offspring in a dioecious species) produced throughout the reproductive lifespan of a mature parasite that themselves survive to reproductive maturity in the absence of densitydependent constraints on population growth" (Anderson and May, 1992), where densitydependent constraints refer to parasite density. In the absence of density-dependent constraints $\mathrm{R}_{0}$ is an "exponential" per parasite generation growth factor for the number of parasites per host. $\mathrm{R}_{0}$ has a threshold value of 1 . When $\mathrm{R}_{0}>1$ and density-dependent constraints are absent, the parasite population can grow. When $\mathrm{R}_{0}<1$, the parasite population declines after initial infection and no major epidemic can occur. $\mathrm{R}_{0}$ is a widely used parameter in epidemiology to describe macroparasitic infections using the definition above, and to describe microparasitic infections in, e.g., a susceptible-infected-recovered (SIR) model. For both macro- and microparasitic infections $\mathrm{R}_{0}$ combines susceptibility, infectivity, contact rate, and recovery rate in a single parameter (Anderson and May, 1992; Diekmann et al., 1990). Today, selection by breeding companies aims mostly at reducing susceptibility, while methods to estimate infectivity are being developed (Anacleto et al., 2015; Biemans et al., 2017). Other traits of potential interest for genetic improvement include tolerance and resilience, and we discuss their relevance later in the paper.

For optimal implementation in breeding programs, the economic value of $\mathrm{R}_{0}$ should be known. The economic value of a trait is a linear approximation of the change in farm profit due to a one unit change in the trait from its current value (Goddard, 1998). Economic values are needed to maximize economic gain. However, no method has been developed for the derivation of the economic value of $R_{0}$ for macroparasites, or alternatively for the derivation of economic values of susceptibility and infectivity. This study presents a method for the derivation of the economic value of $\mathrm{R}_{0}$ for macroparasitic diseases. The method is specific to macroparasites that are the causative pathogen. It does not apply to macroparasites that act as a vector of microparasitic diseases, such as Lyme disease, 
because the transmission dynamics are different and production losses are determined by the microparasite rather than the macroparasite.

First, we describe the effect of improvement in $\mathrm{R}_{0}$ on farm profit via reduced production losses and/or reduced expenditures. Then, we consider these effects for situations where management is or is not optimized. We determine the effect of improvement of $R_{0}$ when expenditures or losses are kept constant and provide algebra to derive the economic value. A numerical example is provided for illustration, and we apply the method to find the economic value of $\mathrm{R}_{0}$ for sea lice in Atlantic salmon. Finally, we discuss implications and limitations of the method.

\subsection{Methods}

\subsubsection{Effect of $R_{0}$ on farm profit}

The economic value of $R_{0}$ is a linear approximation of the change in farm profit due to a one unit change in $\mathrm{R}_{0}$ from its current value:

$\mathrm{EV}=\frac{\partial \text { Profit }}{\partial \mathrm{R}_{0}}$

To derive the economic value, we are interested in the change in profit per unit change in $\mathrm{R}_{0}$, rather than in its absolute level. Because a reduction in $\mathrm{R}_{0}$ increases farm profit, the economic value is negative. However, for presentation purposes, we shall ignore the minus sign in the economic value throughout the remainder of the text.

Costs of livestock diseases are the sum of production losses (L) and expenditures on control (E) (McInerney et al., 1992). L are reduced revenues, e.g., due to decreased productivity or reduced product quality, and $\mathrm{E}$ are costs of treatment and prevention. The loss-expenditure frontier gives the minimum level of $\mathrm{L}$ for any level of $\mathrm{E}$, both expressed in monetary units. $\mathrm{L}$ decreases when $\mathrm{E}$ increases, because expenditures on disease control reduce production losses. The sum of $\mathrm{L}$ and $\mathrm{E}$ takes a concave shape. Fig. 1a shows the hypothetical lossexpenditure frontiers for two values of $R_{0}$. For any given frontier the value of $R_{0}$ is constant. All farmers operate on or above the loss-expenditure frontier. In economics farmers that operate on the frontier are referred to as "efficient", while farmers that operate above the frontier are not. Different levels of $\mathrm{E}$ reflect differences in disease control management. Some farmers may choose to have a low $\mathrm{E}$ and incur a relatively high $\mathrm{L}$ as a consequence, whereas other farmers may choose for a high $\mathrm{E}$ and incur a relatively low $\mathrm{L}$. 
Farmers that operate at the level of $\mathrm{E}$ at which costs are minimum are at the economic optimum. The economic optimum is reached when the sum of $\mathrm{L}$ and $\mathrm{E}$ is minimal. At this optimum, the sum of $\mathrm{L}$ and $\mathrm{E}$ does not change with a marginal change in $\mathrm{E}: \frac{\partial(\mathrm{L}+\mathrm{E})}{\partial \mathrm{E}}=0$ or equivalently $\frac{\partial \mathrm{L}}{\partial \mathrm{E}}=-1$. Genetic improvement of $\mathrm{R}_{0}$ lowers the loss-expenditure frontier and thereby reduces L, E, or both, for farmers that are efficient both before and after genetic improvement. Here, we focus on the economic value of $\mathrm{R}_{0}$ for efficient farmers; benefits for inefficient farmers depend on how they capitalize on genetic gains.
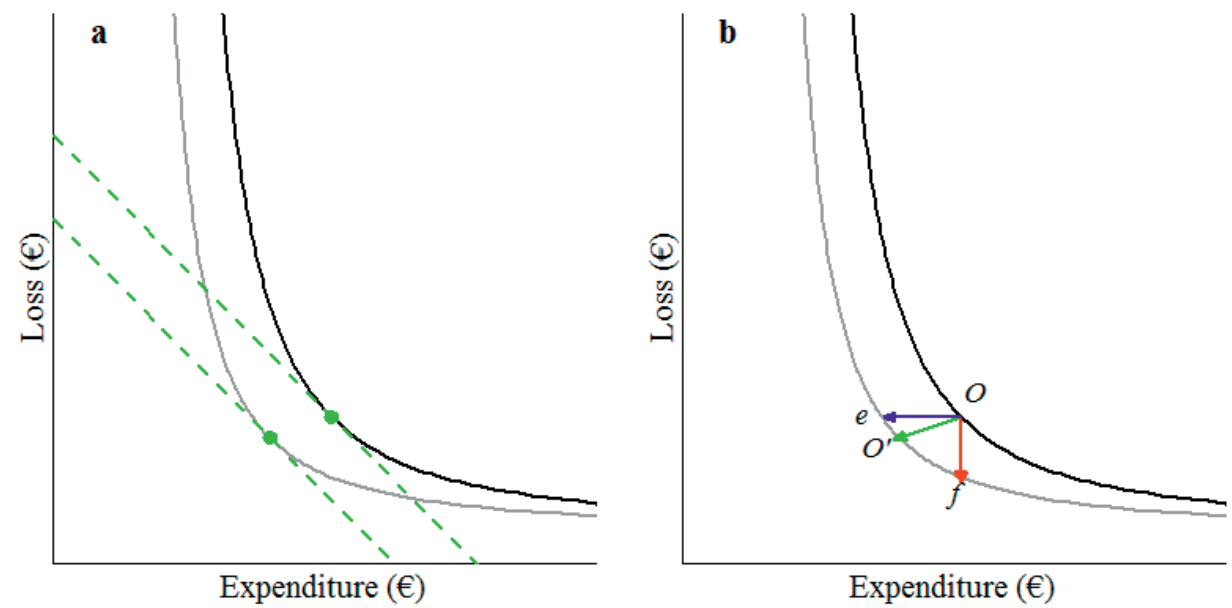

Fig. 1 Loss-expenditure frontiers (solid curves) for two values of $R_{0}$, with the frontier on top having the highest $R_{0}$. a Green dots: economic optima, dashed lines: $\partial$ Loss $\partial$ Expenditure $=-1$ b Reduction in cost due to a reduction in $\mathrm{R}_{0}$. Green arrow: reduction in losses and expenditures when moving from optimum $O$ to optimum $O^{\prime}$, blue arrow ending in $e$ : reduction in expenditures at constant losses, red arrow ending in $f$ : reduction in losses at constant expenditures.

\subsubsection{Optimized management}

In livestock genetic improvement, it is common to derive economic values in the context of optimized management, because improvement of management is generally easier to achieve than genetic improvement. The management variable $\mathrm{E}$ is a function of $\mathrm{R}_{0}$, and $\mathrm{E}$ and $\mathrm{R}_{0}$ together determine $\mathrm{L}$. Thus, $\mathrm{E}$ should be at the economic optimum before genetic improvement (Goddard, 1983), which results in the optimum level of L. The optimum before genetic improvement is at point $O$ in Fig. 1b. Following improvement of $\mathrm{R}_{0}$, the initial optimum $O$ will move to a new optimum $O^{\prime}$ between points $e$ and $f$. For a small (infinitesimal) improvement in $\mathrm{R}_{0}$ the new loss-expenditure frontier between points $e$ and 
$f$ can be approximated linearly by $\partial \mathrm{L} / \partial \mathrm{E}=-1$. Thus, the sum of $\partial \mathrm{L}$ and $\partial \mathrm{E}$ when moving from the initial optimum $O$ to any point on the lower frontier between $e$ and $f$ is constant. Moving to any point between $e$ and $f$ on the lower frontier, therefore, gives the same cost reduction. When $\mathrm{E}$ is optimized before genetic improvement, the economic value (EV) may be derived either as the partial derivative of $\mathrm{L}$ with respect to $\mathrm{R}_{0}$ while $\mathrm{E}$ is held constant:

$\mathrm{EV}=\frac{\partial \mathrm{L}}{\partial \mathrm{R}_{0}}$

or as the partial derivative of $E$ with respect to $R_{0}$ while $L$ is held constant:

$\mathrm{EV}=\frac{\partial \mathrm{E}}{\partial \mathrm{R}_{0}}$

For an infinitesimal change in $\mathrm{R}_{0}$, both methods give the same result as when moving from the optimum level of expenditures (point $O$ ) before genetic improvement to the optimum level of expenditures (point $O^{\prime}$ ) after genetic improvement.

\subsubsection{Non-optimized management}

According to neoclassical economic theory, with no constraints on either L or E, farm management converges to the economic optimum strategy. However, in reality farmers may constrain either $\mathrm{L}$ or $\mathrm{E}$ for non-economic reasons or for economic reasons that are not apparent from the costs of the disease. For example, farmers may keep E at a constant level below its optimum, because of restrictions on the use of antibiotics. Conversely, farmers may keep $\mathrm{E}$ above its optimum, because a minimum frequency of treatments is enforced by legislation. Similarly, farmers may keep L below its optimum for animal welfare reasons. Thus, it may be relevant to derive the economic value for a situation where management is not optimized, and where the deviation from the optimum originates from constraints on either L or E. In other words, constraints on either L or E may push farmers to operate at a suboptimum level of E. Here, we assume that these constraints will remain after genetic improvement.

When $\mathrm{E}$ is constrained either below or above its optimum, genetic improvement of $\mathrm{R}_{0}$ will reduce $\mathrm{L}$ while $\mathrm{E}$ is kept constant. For this scenario the economic value can thus be derived as the reduction in $\mathrm{L}$ per unit change in $\mathrm{R}_{0}$ while $\mathrm{E}$ is kept constant (Eq. 1), denoted by the red arrow in Fig. 1b. 
When $\mathrm{L}$ is constrained below its economic optimum, as in the animal welfare example, genetic improvement of $\mathrm{R}_{0}$ will reduce $\mathrm{E}$ while $\mathrm{L}$ is kept constant. For this scenario the economic value can thus be derived as the reduction in $E$ per unit change in $R_{0}$ while $L$ is kept constant (Eq. 2), denoted by the blue arrow in Fig. 1b. We consider situations where $\mathrm{L}$ is constrained above its optimum as irrelevant, because we cannot think of a realistic example. Note that in the antibiotics example, the level of $\mathrm{L}$ is above its optimum, but this follows from a constraint on $\mathrm{E}$ rather than $\mathrm{L}$, and improvement of $\mathrm{R}_{0}$ will reduce $\mathrm{L}$ with constant E.

\subsubsection{Derivation of the economic value when expenditures are kept constant}

When expenditures are kept constant, the economic value follows from Eq. 1. Thus, in this case we need to express $L$ as a function of $R_{0}$. $L$ has been broadly defined as production losses, but is defined more specifically as lost production due to parasites, which equals the deviation of the actual production in the presence of parasites relative to the production that would have been achieved in the absence of parasites. In our definition $\mathrm{L}$ is independent of the production level itself. Here, we assume that $\mathrm{L}$ is linearly related to the mean number of parasites per host (Anderson and May, 1978). Hence, production losses per host per parasite are assumed constant. This assumption implies that given the mean, variation in the number of parasites per host within the herd and over time can be ignored when deriving the economic value. Thus, to define $\mathrm{L}$ as a function of $\mathrm{R}_{0}$, we need to define the mean number of parasites per host as a function of $R_{0}$.

We assume that minimum and maximum numbers of parasites in animal production are controlled within such a narrow range that the growth of the number of parasites per host within this range is exponential and can be described by the growth factor per parasite generation, $\mathrm{R}_{0}$. Thus, when $\mathrm{R}_{0}>1$, the number of parasites per host grows exponentially over time until treatment is applied. We assume that treatment reduces the number of parasites per host to a fixed minimum, i.e. $I_{\min }$. Because a single treatment involves a fixed expenditure, the interval between treatments remains constant when $\mathrm{E}$ is kept constant, such that the number of parasite generations between two treatments also remains constant. This implies that, for a given $\mathrm{I}_{\min }$ and a given number of parasite generations between treatments, the mean number of parasites per host between treatments is determined by $R_{0}$. The transition of one production cycle to the next may affect the number of parasites per host. The relative importance of this effect is diluted when the length of a production cycle 
is long compared to the period between treatments. Here, we assume that the mean number of parasites per host over the total length of a production cycle can be approximated by the mean number of parasites per host between two treatments. Because $\mathrm{L}$ is proportional to the mean number of parasites per host over the length of a production cycle, L can be expressed as a function of $\mathrm{R}_{0}$. The corresponding algebra is provided below.

Let $I_{\min }$ be the minimum number of parasites per host and $\tau$ the number of parasite generations between two treatments. The number of parasites per host (I) over parasite generations $(\mathrm{t})$ is a function of $\mathrm{R}_{0}$ as:

$\mathrm{I}\left(\mathrm{R}_{0}, \mathrm{t}\right)=\mathrm{I}_{\min } \cdot \mathrm{R}_{0}^{\mathrm{t}}$

The mean number of parasites per host over a period of $\tau$ generations between treatments is:

$\bar{I}\left(R_{0}, \tau\right)=\frac{\int_{0}^{\tau} I\left(R_{0}, t\right) d t}{\tau}=\left(\frac{I_{\min } \cdot R_{0}^{\tau}}{\ln \left(R_{0}\right)}-\frac{I_{\min } \cdot R_{0}{ }^{0}}{\ln \left(R_{0}\right)}\right) \cdot \frac{1}{\tau}=\frac{I_{\min } \cdot\left(R_{0}{ }^{\tau}-1\right)}{\tau \cdot \ln \left(R_{0}\right)}$,

which increases with $\mathrm{R}_{0}$ and $\tau$. Note that $\tau \neq t$. Let $\mathrm{T}$ be the length of a production cycle in parasite generations, and $\overline{\mathrm{I}}\left(\mathrm{R}_{0}, \mathrm{~T}\right)$ the mean number of parasites per host over period $\mathrm{T}$. We assume that $\mathrm{T} \gg \tau$, which allows us to ignore the effect of the transition from one production cycle to the next. Thus, $\overline{\mathrm{I}}\left(\mathrm{R}_{0}, T\right)$ is approximated by $\overline{\mathrm{I}}\left(\mathrm{R}_{0}, \tau\right)$.

Let $\mathrm{L}_{\text {par }}$ be the production losses (e.g., in euro) per host per parasite present over a period of $\mathrm{T}$ parasite generations. The change in the level of a production trait per parasite is known as tolerance or the slope of a reaction norm, and is the linear regression of the production trait on the number of parasites per host (Råberg et al., 2009). Thus, $\mathrm{L}_{\text {par }}$ is defined as:

$\mathrm{L}_{\text {par }}=\frac{\partial \text { profit }}{\partial \overline{\mathrm{I}}\left(\mathrm{R}_{0}\right)}=\sum_{i=1}^{n}\left(\frac{\partial \text { trait }_{i}}{\partial \overline{\mathrm{I}}\left(\mathrm{R}_{0}, \mathrm{~T}\right)} \cdot \frac{\partial \text { profit }}{\partial \text { trait }_{i}}\right)$,

where $\frac{\partial \text { trait }_{i}}{\partial \overline{\mathrm{I}}\left(\mathrm{R}_{0}, \mathrm{~T}\right)}$ is the slope of the reaction norm of production trait $i$, and $\frac{\partial \text { profit }}{\partial \text { trait }_{i}}$ is the economic value of production trait $i$. Under these assumptions, $\mathrm{L}$ per host is a function of $\mathrm{R}_{0}$ :

$\mathrm{L}\left(\mathrm{R}_{0}\right)=\overline{\mathrm{I}}\left(\mathrm{R}_{0}, \mathrm{~T}\right) \cdot \mathrm{L}_{\mathrm{par}}$

From Eqs. 1 and 6 it follows that: 
$\mathrm{EV}=\frac{\partial \mathrm{L}}{\partial \mathrm{R}_{0}}=\frac{\partial\left(\overline{\mathrm{I}}\left(\mathrm{R}_{0}, \mathrm{~T}\right) \cdot \mathrm{L}_{\mathrm{par}}\right)}{\partial \mathrm{R}_{0}}=\mathrm{L}_{\mathrm{par}} \cdot \frac{\partial \overline{\mathrm{I}}\left(\mathrm{R}_{0}, \mathrm{~T}\right)}{\partial \mathrm{R}_{0}}$, where

$\frac{\partial \overline{\mathrm{I}}\left(\mathrm{R}_{0}, \mathrm{~T}\right)}{\partial \mathrm{R}_{0}}=\mathrm{I}_{\min } \cdot \frac{\tau \cdot \mathrm{R}_{0}{ }^{\tau} \cdot \ln \left(\mathrm{R}_{0}\right)-\mathrm{R}_{0}{ }^{\tau}+1}{\mathrm{R}_{0} \cdot \tau \cdot \ln \left(\mathrm{R}_{0}\right)^{2}}$.

Eqs. 7 and 8 give the economic value of $\mathrm{R}_{0}$ when expenditures are kept constant.

\subsubsection{Derivation of the economic value when losses are kept constant}

When losses are kept constant, the economic value follows from Eq. 2. Thus, in this case we need to express $\mathrm{E}$ as a function of $\mathrm{R}_{0}$. Here, we assume that the only expenditures on disease control that change with $\mathrm{R}_{0}$ consist of treatment costs. In the Discussion section we show that partitioning $\mathrm{E}$ into costs of treatment and prevention is irrelevant for the outcome. Thus, in the remainder of the paper E will refer to expenditures on treatment.

We assume that $\mathrm{E}$ is linearly related to the number of treatments per production cycle with constant expenditures per treatment. The number of treatments per production cycle equals the length of a production cycle divided by the period between treatments. To keep L constant, treatment must be applied when the number of parasites per host reaches a fixed maximum value. Thus, the period between treatments equals the time needed for the number of parasites per host to grow from its minimum just after treatment to the value at which treatment is applied. This means that the period between treatments is no longer fixed but has become a function of parasite growth rate, i.e. $\mathrm{R}_{0}$. In other words, improvement of $\mathrm{R}_{0}$ increases the period between treatments and decreases $\mathrm{E}$. The corresponding algebra is provided below.

Let $\mathrm{E}_{\text {treat }}$ be expenditures per treatment and $\mathrm{I}_{\max }$ the number of parasites per host when treatment is applied. From Eq. 3 it follows that, for given values of $I_{\max }$ and $I_{\min }$, the period between treatments $(\tau)$ in parasite generations is:

$\tau\left(\mathrm{R}_{0}\right)=\frac{\ln \left(\mathrm{I}_{\max } / \mathrm{I}_{\min }\right)}{\ln \left(\mathrm{R}_{0}\right)}$

The number of treatments per production cycle of T parasite generations equals $T / \tau\left(R_{0}\right)$, from which it follows that:

$\mathrm{E}\left(\mathrm{R}_{0}\right)=\frac{\mathrm{T}}{\tau\left(\mathrm{R}_{0}\right)} \cdot \mathrm{E}_{\text {treat }}=\mathrm{T} \cdot \mathrm{E}_{\text {treat }} \cdot \frac{\ln \left(\mathrm{R}_{0}\right)}{\ln \left(\mathrm{I}_{\max } / \mathrm{I}_{\min }\right)}$, 
which gives $\mathrm{E}$ as function of $\mathrm{R}_{0}$. From Eqs. 2 and 10 it follows that:

$\mathrm{EV}=\frac{\partial \mathrm{E}}{\partial \mathrm{R}_{0}}=\frac{\partial\left(\mathrm{T} \cdot \mathrm{E}_{\text {treat }} \cdot \frac{\ln \left(\mathrm{R}_{0}\right)}{\ln \left(\mathrm{I}_{\max } / \mathrm{I}_{\min }\right)}\right)}{\partial \mathrm{R}_{0}}=\frac{\mathrm{T} \cdot \mathrm{E}_{\text {treat. }}}{\ln \left(\mathrm{I}_{\max } / \mathrm{I}_{\min }\right)} \cdot \frac{\partial \ln \left(\mathrm{R}_{0}\right)}{\partial \mathrm{R}_{0}}=\frac{\mathrm{T} \cdot \mathrm{E}_{\text {treat. }}}{\ln \left(\mathrm{I}_{\max } / \mathrm{I}_{\min }\right)} \cdot \frac{1}{\mathrm{R}_{0}}$,

which gives the economic value of $\mathrm{R}_{0}$ when losses are kept constant.

\subsection{Results}

\subsubsection{Numerical example}

A numerical example with hypothetical loss-expenditure frontiers is provided to illustrate the economic effect of genetic improvement of $\mathrm{R}_{0}$ (Fig. 2). The loss-expenditure curves are created by calculating E from Eq. 10 and L from Eq. 6 using the input parameters in Table 1. Red arrows (pointing downwards) illustrate reductions in L with constant $\mathrm{E}$, and blue arrows (pointing leftwards) illustrate reductions in E with constant L.

Table 1 Input parameters for hypothetical loss-expenditure frontiers.

\begin{tabular}{|c|c|c|c|}
\hline Item & Symbol & Value & Unit \\
\hline Minimum number of parasites per host & $\mathrm{I}_{\min }$ & 1 & Parasites/host \\
\hline Length of a production cycle & $\mathrm{T}$ & 12 & $\begin{array}{c}\text { Parasite } \\
\text { generations }\end{array}$ \\
\hline Time between two treatments & $\tau$ & 0 to 120 & $\begin{array}{l}\text { Parasite } \\
\text { generations }\end{array}$ \\
\hline $\begin{array}{l}\text { Losses per host per parasite present over } \\
\text { a period of } \mathrm{T} \text { parasite generations }\end{array}$ & $\mathrm{L}_{\text {par }}$ & 1 & $€ /$ parasite/host \\
\hline Expenditures per treatment & $E_{\text {treat }}$ & 5 & $€ /$ treatment \\
\hline $\mathrm{R}_{0}$ & $\mathrm{R}_{0}$ & $1.3,1.4,1.5$, and 1.6 & \\
\hline
\end{tabular}




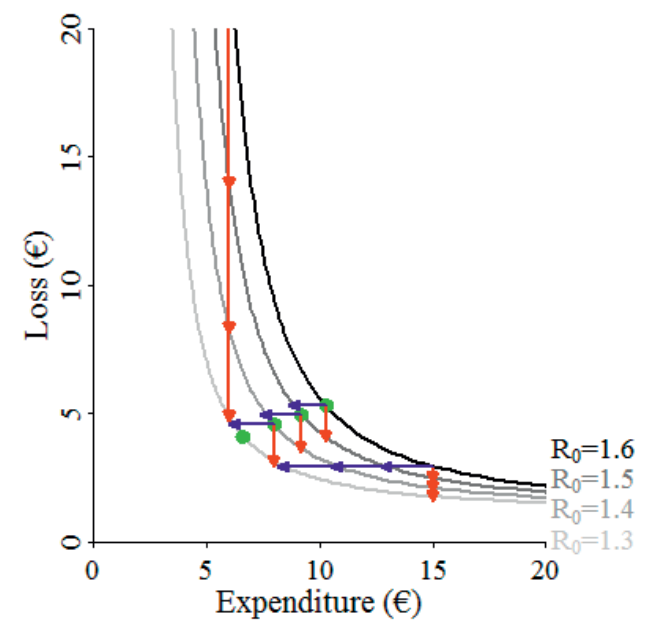

Fig. 2 Loss-expenditure frontiers used in the numerical example. Red arrows (pointing downwards): reductions in losses with constant expenditures, blue arrows (pointing leftwards): reductions in expenditures with constant losses, green dots: optimum levels of expenditures.

Fig. 2 shows that when the level of $\mathrm{E}$ is optimized before genetic improvement, the lengths of the red and blue arrows are similar. Those lengths are identical for a marginal change in $\mathrm{R}_{0}$. For the loss-expenditure frontier where $\mathrm{R}_{0}=1.6$ the optimum frequency of treatment is once per 5.84 parasite generations $(\tau=5.84)$. The economic value may be calculated either from the reduction in $\mathrm{L}$ with constant $\mathrm{E}$ (Eqs. 7 and 8):

$\mathrm{EV}=\frac{\partial \mathrm{L}}{\partial \mathrm{R}_{0}}=\mathrm{L}_{\mathrm{par}} \cdot \mathrm{I}_{\min } \cdot \frac{\tau \cdot \mathrm{R}_{0}{ }^{\tau} \cdot \ln \left(\mathrm{R}_{0}\right)-\mathrm{R}_{0}{ }^{\tau}+1}{\mathrm{R}_{0} \cdot \tau \cdot \ln \left(\mathrm{R}_{0}\right)^{2}}=1 \cdot 1 \cdot \frac{5.84 \cdot 1.6^{5.84} \cdot \ln (1.6)-1.6^{5.84}+1}{1.6 \cdot 5.84 \cdot \ln (1.6)^{2}}$

$=€ 13.7 /$ unit $\mathrm{R}_{0}{ }^{1}$,

or from the reduction in $\mathrm{E}$ with constant $\mathrm{L}$ (Eq. 11):

$\mathrm{EV}=\frac{\partial \mathrm{E}}{\partial \mathrm{R}_{0}}=\frac{\mathrm{T} \cdot \mathrm{E}_{\text {treat. }}}{\ln \left(\mathrm{I}_{\max } / \mathrm{I}_{\min }\right)} \cdot \frac{1}{\mathrm{R}_{0}}=\frac{12 \cdot 10}{\ln \left(1 \cdot 1.6^{5.84} / 1\right)} \cdot \frac{1}{1.6}=€ 13.7 /$ unit $\mathrm{R}_{0}$

As expected, both methods give identical results.

Relative differences in the lengths of the arrows in Fig. 2 are proportionate to relative differences in economic values, and depend on the value of $\mathrm{R}_{0}$ and the management

${ }^{1}$ Throughout the text the minus sign in the economic value is ignored for presentation purposes. 
strategy. The management strategy may be to adopt the optimum level of $\mathrm{E}$, or to reduce $\mathrm{L}$ while $\mathrm{E}$ is kept constant, or to reduce $\mathrm{E}$ while $\mathrm{L}$ is kept constant. When the level of $\mathrm{E}$ is optimized before genetic improvement, the lengths of the red and blue arrows increase when $\mathrm{R}_{0}$ decreases, thus the economic value increases when $\mathrm{R}_{0}$ decreases. When $\mathrm{E}$ is kept constant, the length of the red arrows decreases when $\mathrm{R}_{0}$ decreases, thus the economic value decreases when $R_{0}$ decreases. When $L$ is kept constant, the length of the blue arrows increases when $R_{0}$ decreases, thus the economic value decreases when $R_{0}$ decreases. To illustrate these patterns, the economic value of $R_{0}$ is plotted as a function of the value of $\mathrm{R}_{0}$ for the different management strategies (Fig. 3). Note that the economic value itself does not completely determine economic gain. Economic gain due to genetic improvement is the product of the economic value and genetic gain in $\mathrm{R}_{0}$. The latter is expected to decrease with decreasing $\mathrm{R}_{0}$.

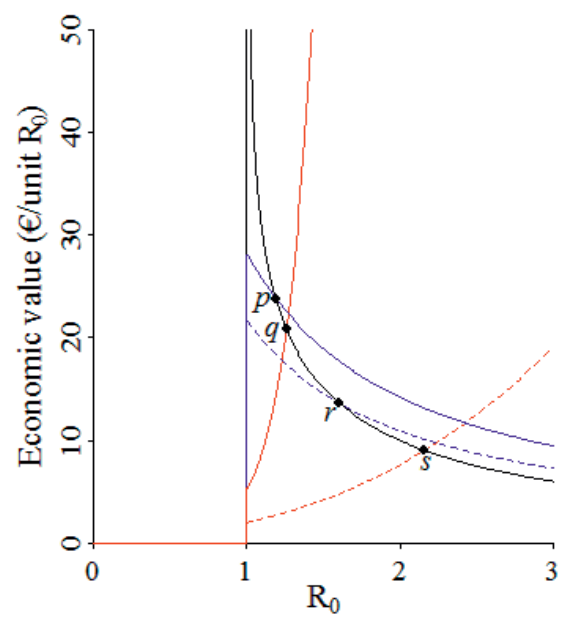

Fig. 3 Economic values for a range of values for $\mathrm{R}_{0}$ for different management strategies in the numerical example. Black line: optimized expenditures, red line: constant expenditures of $€ 6$, dashed red line: constant expenditures of $€ 15$, solid blue line: constant losses of $€ 3$.4, dashed blue line: constant losses of $€ 5.3$. Points $p, q, r$, and $s$ are where a strategy with optimized expenditures results in the same economic value as strategies with constant expenditures or constant losses. Note that the minus sign in the economic value is ignored for presentation purposes.

The black line in Fig. 3 gives the economic value when $\mathrm{E}$ is optimized, and shows that the economic value increases when the value of $R_{0}$ decreases. The economic value increases because both the mean number of parasites per host and the frequency of treatments decrease at an increasing rate when $\mathrm{R}_{0}$ decreases (Appendix). 
The solid red line in Fig. 3 gives the economic value when $\mathrm{E}$ is held constant at a level of $€ 6$, corresponding to the three red arrows on the left in Fig. 2. The dashed red line gives the economic value when $\mathrm{E}$ is held constant at a level of $€ 15$, corresponding to the three red arrows on the right in Fig. 2. Both red lines show that, when E is kept constant, the economic value decreases as $\mathrm{R}_{0}$ decreases. Note that when $\mathrm{E}$ is kept constant, the economic value is higher at lower levels of $E$ and decreases faster with decreasing values of $\mathrm{R}_{0}$. The solid red line intersects the black line at point $q$ where $\mathrm{R}_{0}=1.26$. At point $q$ both economic values are equal, which implies that a level of $E$ at $€ 6$ is optimum for a $R_{0}$ value of 1.26. Because the optimum level of $E$ decreases when the value of $R_{0}$ decreases (Fig. 1a), the given level of $\mathrm{E}(€ 6)$ is above the optimum for $\mathrm{R}_{0}<1.26$, whereas it is below the optimum for $\mathrm{R}_{0}>1.26$. Similarly, the dashed red line intersects the black line at point $s$ where $\mathrm{R}_{0}=$ 2.16, thus a level of $E$ at $€ 15$ is optimum for a $R_{0}$ value of 2.16. Thus, the given level of $E$ $(€ 15)$ is above the optimum for $\mathrm{R}_{0}<2.16$, whereas it is below the optimum for $\mathrm{R}_{0}>2.16$. The economic value when $\mathrm{E}$ is kept constant below its optimum is higher than the economic value when $\mathrm{E}$ is optimized, while the economic value is lower when $\mathrm{E}$ is kept constant above its optimum.

The solid blue line in Fig. 3 gives the economic value when $L$ is held constant at a level of $€ 3.4$, corresponding to the three blue arrows at the bottom of Fig. 2. The dashed blue line gives the economic value when $\mathrm{L}$ is held constant at a level of $€ 5$.3. Both blue lines show that, when $\mathrm{L}$ is kept constant, the economic value increases when the value of $R_{0}$ decreases. The solid blue line intersects the black line at point $p$ where $\mathrm{R}_{0}=1.19$. At point $p$, both economic values are equal, which implies that a level of $L$ at $€ 3.4$ is optimum for a $R_{0}$ value of 1.19. Because the optimum level of $L$ decreases when the value of $R_{0}$ decreases (Fig. 1a), the given level of $L(€ 3.4)$ is above the optimum for $R_{0}<1.19$, whereas it is below the optimum for $\mathrm{R}_{0}>1$ 1.19. Similarly, the dashed blue line intersects the black line at point $r$ where $\mathrm{R}_{0}=1.60$, thus a level of $\mathrm{L}$ at $€ 5.3$ is optimum for a $\mathrm{R}_{0}$ value of 1.60 . Thus, the given level of $E(€ 5.3)$ is above the optimum for $\mathrm{R}_{0}<1.60$, whereas it is below the optimum for $\mathrm{R}_{0}>1.60$. We consider the parts of the blue lines that are below the black line as irrelevant, because for these situations the economic value should follow from the reduction in $\mathrm{L}$ with constant $\mathrm{E}$ instead. The economic value when $\mathrm{L}$ is kept constant below its optimum is higher than the economic value when $\mathrm{E}$ is optimized. 
To summarize the above, we can consider the following scenarios. When management is optimized, the economic value increases as $\mathrm{R}_{0}$ decreases (black line). When $\mathrm{E}$ is held constant above its optimum, the economic value is lower than when management is optimized. When $\mathrm{E}$ is held constant below its optimum, the economic value is higher than when management is optimized. When $\mathrm{L}$ is held constant below its optimum, the economic value is higher than when management is optimized.

A practical implication for continued genetic improvement may be that the management strategy shifts from a strategy where either L or E is held constant (red or blue lines) to the optimum strategy (black line). For example, management may operate under a constraint on $\mathrm{E}$, due to which $\mathrm{E}$ cannot exceed $€ 6$. At first when $\mathrm{R}_{0}$ is larger than 1.26 (right of point $q$ ), management may reduce $\mathrm{L}$ while $\mathrm{E}$ is kept constant in response to genetic improvement. At some point (left of point $q$ ), $\mathrm{R}_{0}$ may become smaller than 1.26, and management can adopt the optimum level of $\mathrm{E}$, which will be below $€ 6$. Thus, in this example the economic value would first decrease following the solid red line in Fig. 3. As from when $\mathrm{R}_{0} \leq 1.26$ (point $q$ ), it would increase following the black line. Similarly, management may operate under a constraint on $\mathrm{L}$, due to which $\mathrm{L}$ cannot exceed $€ 3$.4. In this case the economic value would first increase following the blue line. As from when $\mathrm{R}_{0} \leq 1.19$ (point $p$ ), it would increase following the black line.

\subsubsection{Example: sea lice in Norwegian salmon aquaculture}

Sea lice are one of the major challenges in Norwegian salmon aquaculture. To protect wild salmon populations from infection by farmed salmon, sea lice numbers on farmed salmon are controlled by legislation. Treatment is obligatory when juvenile or adult female lice numbers exceed a threshold. Expenditures on treatment have been estimated at $€ 0.087 /$ treatment/kg production (Iversen and Hermansen, 2017). Ironically, treatment also induces production losses, which may even exceed production losses induced by lice themselves. Production losses induced by treatment include an elevated mortality and increased feed conversion ratio during and shortly after treatment. Total production losses induced by treatment have been estimated at $€ 0.040 /$ treatment $/ \mathrm{kg}$ production (Iversen and Hermansen, 2017). Thus, each treatment involves a cost of $€ 0.127 /$ treatment $/ \mathrm{kg}$ production. Moreover, current sea lice problems limit the expansion of the salmon farming industry in Norway. Solving these problems by genetic improvement of $\mathrm{R}_{0}$ might increase production 
in the long run, which would further increase benefits of selection for $\mathrm{R}_{0}$. However, a detailed treatment of this issue is outside the scope of this paper.

To derive the economic value, we assume that the level of expenditures is above the economic optimum and that genetic improvement of $\mathrm{R}_{0}$ reduces the frequency of treatments while losses induced by lice are kept constant. For simplicity, a threshold for treatment on only adult female lice is considered here. Treatment efficacy is $95 \%$ (Revie et al., 2005), hence $I_{\max } / I_{\min }$ is 20 . On average, salmon are treated 2.4 times per year (Iversen and Hermansen, 2017). A production cycle lasts about 500 days followed by a 60-day fallowing period. Thus, the average number of treatments per production cycle is $560 / 365 \cdot 2.4=3.7$. The generation interval of sea lice is about 70 days (Revie et al., 2005), hence $\mathrm{T}=500 / 70=7.1$ generations, $\tau=T / 3.7=1.9$ generations, and $\mathrm{R}_{0}=$ $\left(\frac{I_{\max }}{I_{\min }}\right)^{1 / \tau}=4.7$ (Eq. 9). $E_{\text {treat }}$ is $€ 0.127 /$ treatment $/ \mathrm{kg}$ production. The economic value is (Eq. 11):

$\mathrm{EV}=\frac{\mathrm{T} \cdot \mathrm{E}_{\text {treat }}}{\ln \left(\mathrm{I}_{\max } / \mathrm{I}_{\min }\right)} \cdot \frac{1}{\mathrm{R}_{0}}=\frac{7.1 \cdot 0.127}{\ln (20)} \cdot \frac{1}{4.7}=0.065 € /$ unit $/ \mathrm{kg}_{\text {production. }}{ }^{2}$

We can use this value to quantify the economic importance of genetic improvement of $R_{0}$ for sea lice to the Norwegian salmon aquaculture industry. Consider, for example, the effect of one genetic standard deviation reduction in $\mathrm{R}_{0}$. Selection against sea lice is generally based on dedicated and controlled challenge tests. Challenge tests are preferred over natural infections, because they allow standardization of testing protocols and avoid confounding affects when a subset of the challenged population have already acquired some degree of immunity due to prior exposure (Kolstad et al., 2005). In a challenge test fish are exposed to a high dose of copepodids (juvenile sea lice) and lice count per fish is recorded shortly after lice attachment. Part of the variation in lice count is determined by variation in skin surface area, which can be corrected for by using the allometric relation between body weight and skin surface area. The resulting trait is termed lice density (Gjerde et al., 2011).

${ }^{2}$ Throughout the text the minus sign in the economic value is ignored for presentation purposes. 
Remaining variation in lice density is assumed to be explained by variation in susceptibility among individuals.

First, consider the case with genetic variation in susceptibility only. In this case genetic variation in $R_{0}$ is proportional to genetic variation in susceptibility, which in turn is proportional to genetic variation in lice density. Thus, in this case breeding values for $\mathrm{R}_{0}$ can be inferred directly from a challenge test. The genetic coefficient of variation of lice density is about 0.35 (Gjerde et al., 2011). Thus, one genetic standard deviation improvement gives a $35 \%$ improvement in $\mathrm{R}_{0}$, corresponding to $0.35 \cdot 4.7=1.6$ units $\mathrm{R}_{0}$. Using the economic value of $\mathrm{R}_{0}$ derived above, this improvement is expected to reduce expenditures on treatment by $1.6 \cdot 0.065=0.11 € / \mathrm{kg}$ production. For comparison, in 2017 the farm gate price of salmon was about $€ 6.30 / \mathrm{kg}$ (Akvafakta, 2018). For the whole of Norway with a salmon production of 1.23 million tons (Directorate of Fisheries, 2017) one standard deviation improvement in $\mathrm{R}_{0}$ corresponds to a cost reduction of about 130 million $€$. In comparison, the expenditures on treatment and production losses induced by treatment combined are 380 million $€$ (Iversen and Hermansen, 2017).

The above analysis ignored genetic variation in infectivity among individuals. However, the result changes only when infectivity and susceptibility are genetically correlated; in the absence of such a correlation, selection for lice density does not yield a correlated response in infectivity. We might hypothesize that susceptibility and infectivity are positively correlated, because the same host-defence mechanisms may underlie these traits. For worm infections in sheep, for example, Kemper et al. (2010) found that worm fecundity was reduced in sheep selected for low faecal egg count compared to a control line, where worm fecundity may be interpreted as a proxy for infectivity. A positive genetic correlation implies that selection for lower susceptibility via a challenge test induces a favourable correlated response in infectivity. Because susceptibility and infectivity have multiplicative effects on $\mathrm{R}_{0}$ (Anche et al., 2014), the response in $\mathrm{R}_{0}$ will then be more than proportionate to the response in susceptibility, and the benefits for industry will be larger than the figures presented above. To fully benefit from genetic variation in infectivity, breeding value estimation could be extended to include also infectivity, and estimated breeding values (EBV) of $\mathrm{R}_{0}$ can be obtained by combining EBV for susceptibility and infectivity (Anche et al., 2014). Estimation of breeding values for infectivity is challenging, but methods for that purpose have been developed (Anacleto et al., 2015; Biemans et al., 2017). 


\subsection{Discussion}

This study presents a method for the derivation of the economic value of $\mathrm{R}_{0}$ for macroparasitic diseases. Economic values, even when imperfect (Smith, 1983), would improve the economic effectiveness of breeding programs. When $\mathrm{R}_{0} \leq 1$, there is no risk for a major epidemic thus the economic value is zero. When $\mathrm{R}_{0}>1$ and management is optimized, the economic value increases when $\mathrm{R}_{0}$ decreases, because both the mean number of parasites per host and the frequency of treatments decrease at an increasing rate when $R_{0}$ decreases. Such an increase in economic value when $R_{0}$ decreases may be counter intuitive, because a decrease in $\mathrm{R}_{0}$ will lower the sum of production losses and expenditures. However, the total costs of a disease are not a good proxy for the avoidable costs per unit genetic improvement of $R_{0}$. In line with these results it is well-known in epidemiology that the effectiveness of vaccination programs increases when $R_{0}$ decreases (Fine, 1993). When $\mathrm{R}_{0}>1$ and management is not optimized, the economic value depends on whether genetic improvement is used for a reduction in expenditures or a reduction in production losses. When management is not optimized and E or L is held constant below its optimum, the economic value is higher than in optimized management. When management is not optimized and $\mathrm{E}$ is held constant above its optimum, the economic value is lower than in optimized management. Because the relation between $\mathrm{R}_{0}$ and farm profit is non-linear (Fig. 3), the economic value should be updated regularly for its actual value of $\mathrm{R}_{0}$ (Groen et al., 1994). For practical implementation in breeding programs some directions are provided in the example on sea lice and in Anche et al. (2014).

Although the aim of genetic improvement should not be to compensate for management inefficiencies (Goddard, 1983), farmers may not always be able to operate under optimized management. For example, strict regulations on drug use apply in organic production (Kaufmann et al., 2011). Such regulations may constrain expenditures, forcing farmers to operate at a below optimum level of expenditures with relatively high losses. Genetic improvement would then reduce losses while expenditures are kept constant. In the example of sea lice in Norwegian salmon aquaculture parasite numbers per host are constrained below the optimum, forcing farmers to operate at an above optimum level of expenditures with relatively low losses. In this case genetic improvement reduces expenditures while losses are kept constant. The example also illustrates that genetic improvement is unlikely to reduce the infective pressure of sea lice on wild fish stocks in 
the short term, because mean lice numbers will not decrease when genetic improvement leads to a reduction in expenditures on treatment.

When losses are kept constant, the economic value of $\mathrm{R}_{0}$ is derived from the reduction in expenditures. We assumed that expenditures for disease control consist of treatment costs only, but in reality they may also include preventive measures. In case of sea lice preventive measures that reduce the overall infective pressure of lice may include the use of cleaner fish, lice skirts, and lasers. Here, we will show that the reduction in expenditures on treatment is equal to the reduction in the sum of expenditures on treatment and expenditures on preventive measures. Let $E^{\prime}$ be the sum of expenditures on treatment $\left(E_{T}^{\prime}\right)$ and expenditures on preventive measures $\left(\mathrm{E}_{\mathrm{P}}^{\prime}\right)$. On the loss-expenditure frontier, the balance between $\mathrm{E}_{\mathrm{T}}^{\prime}$ and $\mathrm{E}_{\mathrm{P}}^{\prime}$ is optimum by definition, otherwise the level of $\mathrm{E}^{\prime}$ would be above the frontier. For any $\mathrm{L}$ we could hypothesize an underlying $\mathrm{E}_{\mathrm{T}}^{\prime} \mathrm{E}_{\mathrm{P}}^{\prime}$ frontier. The level of $\mathrm{E}^{\prime}$ on the loss-expenditure frontier equals the sum of $E_{T}^{\prime}$ and $E_{P}^{\prime}$ at the point on the $E_{T}^{\prime}-E_{P}^{\prime}$ frontier where $\partial \mathrm{E}_{\mathrm{T}}^{\prime} / \partial \mathrm{E}_{\mathrm{P}}^{\prime}=-1$. Starting at this point, improvement of $\mathrm{R}_{0}$ may reduce $\mathrm{E}_{\mathrm{T}}^{\prime}$ while $\mathrm{E}_{\mathrm{P}}^{\prime}$ and $\mathrm{L}$ are kept constant, or it may reduce $\mathrm{E}_{\mathrm{P}}^{\prime}$ while $\mathrm{E}_{\mathrm{T}}^{\prime}$ and $\mathrm{L}$ are kept constant. For an infinitesimal improvement in $\mathrm{R}_{0}$ the new $\mathrm{E}_{\mathrm{T}}^{\prime}-\mathrm{E}_{\mathrm{P}}^{\prime}$ frontier between these points can be approximated linearly by $\partial \mathrm{E}_{\mathrm{T}}^{\prime} / \partial \mathrm{E}_{\mathrm{P}}^{\prime}=-1$, hence $\partial \mathrm{E}^{\prime}$ is constant between these points. Thus, based on the same reasoning as before, the economic value may be derived as the partial derivative of $\mathrm{E}_{T}^{\prime}$ with respect to $\mathrm{R}_{0}$ while $\mathrm{E}_{\mathrm{P}}^{\prime}$ and $\mathrm{L}$ are held constant. This mathematical argument allows us to ignore the complex relation between expenditures on preventive measures and $\mathrm{R}_{0}$. Another way to approach the issue is by considering a threedimensional loss-expenditure frontier, where one axis represents production losses, one axis represents expenditures on treatment, and the third axis represents expenditures on preventive measures. We have ignored the axis on preventive measures based on the mathematical grounds given before, but we expect that the surface of the frontier is rather flat in this direction. We expect preventive measures to be a relative attractive control option compared to treatment, such that expenditures on preventive measures are not so responsive to genetic improvement of $\mathrm{R}_{0}$. For example, in case of sea lice we would expect farmers to reduce rather the number of treatments than the use of cleaner fish. Still, genetic improvement may lead to changes in expenditures on preventive measures that affect the value of $R_{0}$. Because in this study the method to derive the economic value ignores the effect of genetic improvement on preventive measures that affect $R_{0}$, the value of $R_{0}$ may 
not improve as much as expected. The estimated value of $R_{0}$ should, therefore, be evaluated regularly and the economic value should be updated accordingly.

In this study, the economic value of $\mathrm{R}_{0}$ includes production losses due to disease. However, the breeding goal usually also includes yield as a trait. This introduces the risk of doublecounting of production losses due to disease, which occurs when they are counted via the products of economic values and EBV of both $\mathrm{R}_{0}$ and yield. To avoid double-counting, one might restrict the economic value of $\mathrm{R}_{0}$ to expenditures on disease control, and include production losses due to disease in the economic value of yield. However, the economic value of yield would then include a non-linear component for production losses due to changing dynamics of disease transmission (Eq. 7) and a linear component for yield independent of production losses, which seems non-trivial. Furthermore, the effect of genetic improvement on management via reduction in losses or expenditures becomes unclear. These issues are resolved in the current study, where the economic value of $\mathrm{R}_{0}$ includes production losses. As a consequence, we have to define yield to refer to individuals experiencing equal production losses due to disease (e.g., in the absence of disease). For the derivation of selection index weights and for prediction of the response to selection it is essential that trait definitions agree between the breeding goal, the selection index, and the breeding value estimation. Thus, if the breeding goal includes $\mathrm{R}_{0}$ (including production losses) and yield at equal production losses, then the selection-index weights and EBV should also refer to those same traits. Ideally, this is achieved by separate recording of phenotypes for production traits on animals that have equal production losses while phenotypes to estimate breeding values for $\mathrm{R}_{0}$ are recorded on a different group of animals. This situation is common in salmon breeding programs, where production traits are recorded in commercial conditions with small (and, therefore, similar) numbers of lice per fish while susceptibility to sea lice is recorded in dedicated challenge tests. When phenotypes for production traits and phenotypes to estimate breeding values for $\mathrm{R}_{0}$ are recorded instead on the same animals, phenotypes for production traits will include production losses. In sheep, for example, faecal egg count is recorded together with live weight on sheep maintained on infected pastures. Susceptible sheep have a relatively high faecal egg count and thus a lower live weight. To avoid double-counting of production losses in such a situation, the number of parasites per host may be included as a covariate in the linear model used for breeding value estimation for production traits. Using this 
approach, Bishop et al. (2004) estimated the slope of the regression of live weight on logtransformed faecal egg count to be $-1.28 \mathrm{~kg} / \mathrm{ln}$ (faecal egg count).

In addition to $\mathrm{R}_{0}$, other disease-related traits of potential interest for genetic improvement include tolerance and resilience. Tolerance is defined as an animal's ability to cope with the effects of infection (Bishop, 2012). The economic importance of tolerance depends highly on disease status, which is determined by the value of $R_{0}$. Tolerance may be included in the breeding goal in addition to $\mathrm{R}_{0}$, but the derivation of its economic value is beyond the scope of this study. Resilience is defined as an animal's productivity in the face of infection (Bishop, 2012), which is some sort of aggregate measure of $\mathrm{R}_{0}$, tolerance, and production traits. As explained above, it does not seem wise to combine such different traits in a single measure.

A few other studies have attempted to derive economic values for macroparasitic disease traits, and some principles were discussed in general terms by Woolaston and Baker (1996). Woolaston and Baker (1996) consider frequency of treatments and production losses as two separate and mutually exclusive breeding goal traits for macroparasitic diseases. Instead, we consider frequency of treatments and production losses as different management strategies that result from the underlying trait $R_{0}$. We have shown that both frequency of treatments (expenditures) and production losses may decrease in response to genetic improvement of $\mathrm{R}_{0}$ when management is optimized. Including only one of these management variables as a trait in the breeding goal excludes the relevant scenario of optimized management. Bishop and Stear (1997) demonstrated that the selection response for measures of disease prevalence cannot be predicted from quantitative genetic theory alone, because quantitative genetic theory disregards the underlying dynamics of disease transmission determined by $\mathrm{R}_{0}$. Their findings are in agreement with the non-linear relations between $\mathrm{R}_{0}$ and the number of parasites at any given time (Eq. 3), and between $\mathrm{R}_{0}$ and the mean number of parasites between treatments (Eq. 4). Similarly, the response in frequency of treatments cannot be predicted from quantitative genetic theory alone, due to the non-linear relation between $R_{0}$ and frequency of treatments (Eq. 9 and 10). The economic value may compensate for this bias in the predicted selection response resulting in the appropriate emphasis on the breeding goal trait, as in Amer et al. (1999) for faecal egg count in sheep. In contrast, when $\mathrm{R}_{0}$ is the breeding goal trait the response to selection can be predicted from quantitative genetic theory only (Anche et al., 2014), such that the 
product of the response in units $\mathrm{R}_{0}$ combined with the economic value of $\mathrm{R}_{0}$ gives a direct prediction of the economic response to selection. Gharbi et al. (2015) used an epidemiological model to describe the relation between genetic improvement and frequency of treatments for sea lice in salmon, but we have not been able to replicate their results. Lobo et al. (2011) derived the economic value of the number of anthelmintic doses used per year for sheep. Bishop et al. (2004) derived the economic value of faecal egg count for sheep from its negative effect on live weight. Neither Lobo et al. (2011) nor Bishop et al. (2004) explicitly considered whether genetic improvement would reduce production losses, expenditures, or both and neither of these studies considered that quantitative genetic theory fails to predict the response to selection for these traits. These issues would be resolved if $\mathrm{R}_{0}$ was used as the breeding goal trait for which the economic value can be derived with the method outlined in this paper.

\subsection{Conclusions}

This study presents a method for the derivation of the economic value of $\mathrm{R}_{0}$ for macroparasitic diseases. When management is optimized, the economic value increases with decreasing values of $R_{0}$ (until the threshold of $R_{0}=1$, where it drops to zero). When management is not optimized, the economic value depends on whether genetic improvement is used for reduced expenditures or production losses. For sea lice in salmon the economic value is estimated to be $0.065 € /$ unit $R_{0} / \mathrm{kg}$ production.

\subsection{Appendix}

When the level of expenditures is optimized for the value of $R_{0}$ in the numerical example, the frequency of treatments and the mean number of parasites per host both decrease at an increasing rate as $\mathrm{R}_{0}$ decreases (Fig. A1). As a result, $\mathrm{E}$ and $\mathrm{L}$ both decrease at an increasing rate as $R_{0}$ decreases, hence the economic value increases as $R_{0}$ decreases. 

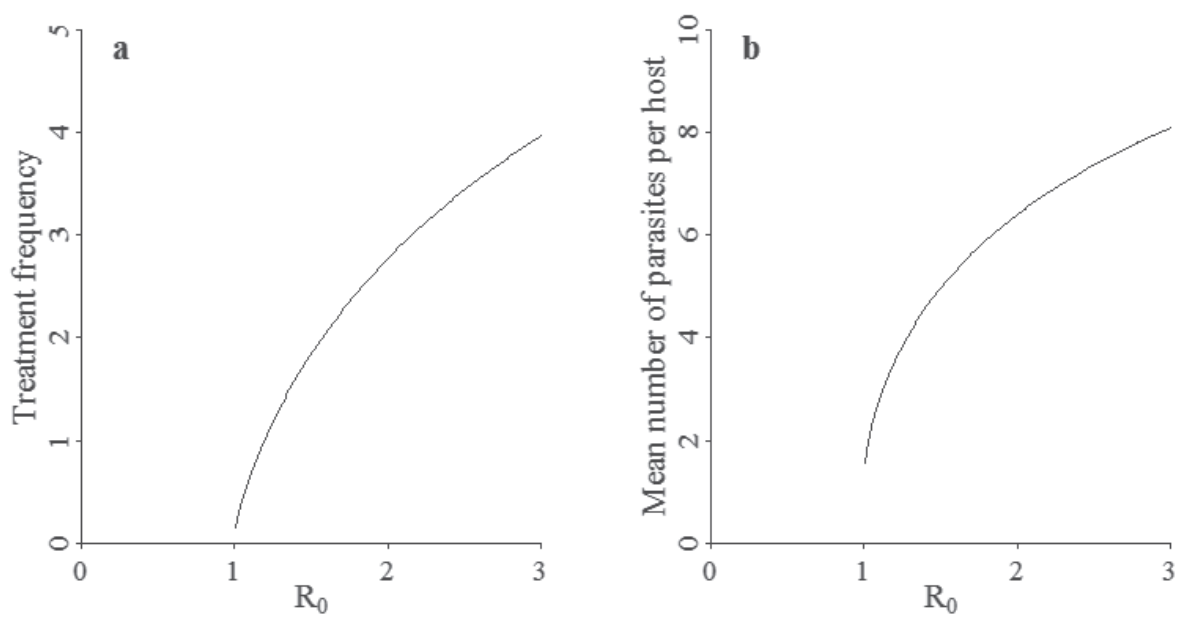

Fig. A1 Frequency of treatments $\mathbf{a}$ and the mean number of parasites per host $\mathbf{b}$ when the level of expenditures is optimized for the value of $\mathrm{R}_{0}$ in the numerical example.

\subsection{References}

Akvafakta, 2018. Akvafakta.fhl.no. Accessed on 15 May 2018.

Amer, P., Woolaston, R.R., Eady, S.J., McEwan, J.C., 1999. Economic values for sheep internal parasite resistance traits in New Zealand and Australia. Proc. Assoc. Advmt. Anim. Breed. Genet. 504-507.

Anacleto, O., Garcia-Cortéz, L.A., Lipschutz-Powell, D., Woolliams, J., Doeschl-Wilson, A., 2015. A Novel Statistical Model to Estimate Host Genetic Effects Affecting Disease Transmission. Genetics.

Anche, M.T., de Jong, M.C.M., Bijma, P., 2014. On the definition and utilization of heritable variation among hosts in reproduction ratio R0 for infectious diseases. Heredity (Edinb). 113,364 .

Anderson, R.M., May, R.M., 1978. Regulation and Stability of Host-Parasite Population Interactions: I. Regulatory Processes. J Anim Ecol. 47, 219-247.

Anderson, R.M., May, R.M., 1992. Infectious Diseases of Humans. Dynamics and Control. Oxford University Press, Oxford, UK.

Biemans, F., de Jong, M.C.M., Bijma, P., 2017. A model to estimate effects of SNPs on host susceptibility and infectivity for an endemic infectious disease. Genet Sel Evol. 49, 53.

Bishop, S., 2012. A consideration of resistance and tolerance for ruminant nematode infections. Front Genet. 3.

Bishop, S.C., Stear, M.J., 1997. Modelling responses to selection for resistance to gastro-intestinal parasites in sheep. Anim Sci. 64, 469-478.

Bishop, S.C., Jackson, F., Coop, R.L., Stear, M.J., 2004. Genetic parameters for resistance to nematode infections in Texel lambs and their utility in breeding programmes. Anim Sci. 78, 185-194.

CBS, 2017. StatLine: Landbouw; biologisch en/of in omschakeling, gewassen, dieren, nationaal, http://statline.cbs.nl/Statweb/publication/?DM=SLNL\&PA=81517NED\&D1=361,368,37 9,397\&D2=a\&D3=a\&HDR=G2,G1\&STB=T\&VW=T. Accessed on 12 December 2017.

Diekmann, O., Heesterbeek, J.A.P., Metz, J.A.J., 1990. On the Definition and the Computation of the Basic Reproduction Ratio R0 in Models for Infectious-Diseases in Heterogeneous Populations. J Math Biol. 28, 365-382. 
Directorate of Fisheries, 2017. Atlantic salmon, rainbow trout and trout - Grow out production, http://www.fiskeridir.no/Akvakultur/Statistikk-akvakultur/Biomassestatistikk. Accessed on 2-1-2017 2017.

Fast, M.D., Muise, D.M., Easy, R.E., Ross, N.W., Johnson, S.C., 2006. The effects of Lepeophtheirus salmonis infections on the stress response and immunological status of Atlantic salmon (Salmo salar). Fish Shellfish Immun. 21, 228-241.

Fine, P.E.M., 1993. Herd-Immunity - History, Theory, Practice. Epidemiol Rev. 15, 265-302.

Gharbi, K., Matthews, L., Bron, J., Roberts, R., Tinch, A., Stear, M.J., 2015. The control of sea lice in Atlantic salmon by selective breeding. J R Soc Interface. 12.

Gjerde, B., Ødegård, J., Thorland, I., 2011. Estimates of genetic variation in the susceptibility of Atlantic salmon (Salmo salar) to the salmon louse Lepeophtheirus salmonis. Aquaculture. 314, 66-72.

Goddard, M.E., 1983. Selection Indices for Non-Linear Profit-Functions. Theor Appl Genet. 64, 339-344.

Goddard, M.E., 1998. Consensus and debate in the definition of breeding objectives. J Dairy Sci. 81, 6-18.

Graystock, P., Blane, E.J., McFrederick, Q.S., Goulson, D., Hughes, W.O.H., 2016. Do managed bees drive parasite spread and emergence in wild bees? Int J Parasitol Parasites Wildl. 5, 64-75.

Groen, A.F., Meuwissen, T.H.E., Vollema, A.R., Brascamp, E.W., 1994. A comparison of alternative index procedures for multiple generation selection on non-linear profit. Anim Prod. 59, 1-9.

Iversen, A., Hermansen, Ø., 2017. Cost development in farming of Norwegian Salmon. Nofima, 46.

Kaufmann, F., Daş, G., Sohnrey, B., Gauly, M., 2011. Helminth infections in laying hens kept in organic free range systems in Germany. Livest Sci. 141, 182-187.

Kemper, K.E., Goddard, M.E., Bishop, S.C., 2013. Adaptation of gastrointestinal nematode parasites to host genotype: single locus simulation models. Genet Sel Evol. 45, 14.

Kemper, K.E., Palmer, D.G., Liu, S.M., Greeff, J.C., Bishop, S.C., Karlsson, L.J.E., 2010. Reduction of faecal worm egg count, worm numbers and worm fecundity in sheep selected for worm resistance following artificial infection with Teladorsagia circumcincta and Trichostrongylus colubriformis. Vet Parasitol. 171, 238-246.

Kolstad, K., Heuch, P.A., Gjerde, B., Gjedrem, T., Salte, R., 2005. Genetic variation in resistance of Atlantic salmon (Salmo salar) to the salmon louse Lepeophtheirus salmonis. Aquaculture. 247, 145-151.

Krkošek, M., Connors, B.M., Morton, A., Lewis, M.A., Dill, L.M., Hilborn, R., 2011. Effects of parasites from salmon farms on productivity of wild salmon. Proceedings of the National Academy of Sciences. 108, 14700-14704.

Lay, J.D.C., Fulton, R.M., Hester, P.Y., Karcher, D.M., Kjaer, J.B., Mench, J.A., Mullens, B.A., Newberry, R.C., Nicol, C.J., O’Sullivan, N.P., Porter, R.E., 2011. Hen welfare in different housing systems 1. Poult Sci. 90, 278-294.

Lobo, R.N.B., Pereira, I.D.C., Faco, O., McManus, C.M., 2011. Economic values for production traits of Morada Nova meat sheep in a pasture based production system in semi-arid Brazil. Small Rumin Res. 96, 93-100.

McInerney, J.P., Howe, K.S., Schepers, J.A., 1992. A Framework for the Economic-Analysis of Disease in Farm Livestock. Prev Vet Med. 13, 137-154.

Mul, M.F., 2017. Advancing Integrated Pest Management for Dermanyssus gallinae in laying hen facilities. Wageningen University.

Nieuwhof, G.J., Bishop, S.C., 2005. Costs of the major endemic diseases of sheep in Great Britain and the potential benefits of reduction in disease impact. Anim Sci. 81, 23-29.

Råberg, L., Graham, A.L., Read, A.F., 2009. Decomposing health: tolerance and resistance to parasites in animals. Philos T R Soc B Biol Sci. 364, 37-49.

Revie, C.W., Robbins, C., Gettinby, G., Kelly, L., Treasurer, J.W., 2005. A mathematical model of the growth of sea lice, Lepeophtheirus salmonis, populations on farmed Atlantic salmon, 
Salmo salar L., in Scotland and its use in the assessment of treatment strategies. J Fish Dis. 28, 603-613.

Roepstorff, A., Mejer, H., Nejsum, P., Thamsborg, S.M., 2011. Helminth parasites in pigs: New challenges in pig production and current research highlights. Vet Parasitol. 180, 72-81.

Smith, C., 1983. Effects of changes in economic weights on the efficiency of index selection. J Anim Sci. 56, 1057-1064.

Stear, M.J., Doligalska, M., Donskow-Schmelter, K., 2007. Alternatives to anthelmintics for the control of nematodes in livestock. Parasitology. 134, 139-151.

Steinfeld, H., Wassenaar, T., Jutzi, S., 2006. Livestock production systems in developing countries: status, drivers, trends. Rev Sci Tech Oie. 25, 505-516.

Woolaston, R.R., Baker, R.L., 1996. Prospects of breeding small ruminants for resistance to internal parasites. Int J Parasitol. 26, 845-855. 



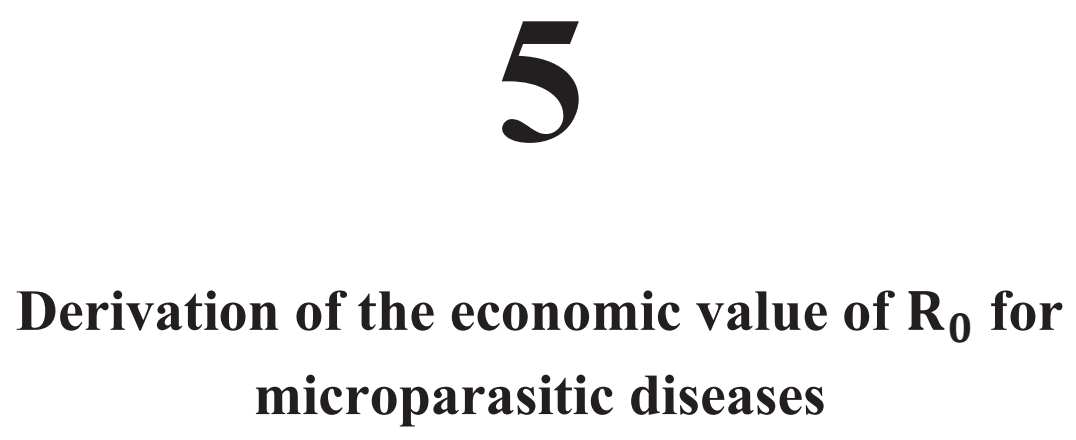

Kasper Janssen ${ }^{1}$ and Piter Bijma ${ }^{1}$

${ }^{1}$ Wageningen University, Animal Breeding and Genomics, Droevendaalsesteeg 1, 6708 PB Wageningen, The Netherlands

To be submitted 


\begin{abstract}
Background: Microparasitic diseases are caused by bacteria and viruses. Genetic improvement of resistance to microparasitic diseases in breeding programs is desirable, and should aim to reduce the basic reproduction ratio, $\mathrm{R}_{0}$. Recently a method for the derivation of the economic value of $\mathrm{R}_{0}$ for macroparasitic diseases was developed. Building on that method, this study aims to develop a method to derive the economic value of $R_{0}$ for microparasitic diseases.
\end{abstract}

Methods: Genetic improvement of $\mathrm{R}_{0}$ for microparasitic diseases is assumed to reduce production losses while expenditures on disease control are unaffected. Microparasitic diseases are classified as epidemic when there are incidental outbreaks, and as endemic when the disease is virtually always present and the infected fraction of the population varies around its endemic equilibrium. For both types of disease the economic value depends on the value of $\mathrm{R}_{0}$, production losses per infected animal, and the size of the population. Additionally, for epidemic diseases the economic value depends on the frequency of infection from an outside source.

Results: For epidemic diseases, the probability and size of major epidemics increase asymptotically with $\mathrm{R}_{0}$. For endemic diseases the infected faction of the population at the endemic equilibrium increases asymptotically with $\mathrm{R}_{0}$. For both epidemic and endemic diseases the economic value is relatively high at intermediate values of $\mathrm{R}_{0}$. The economic value approaches zero when $R_{0}$ increases to large values. When $R_{0} \leq 1$, the economic value is zero, because the disease is very rare.

Discussion: Opportunities for genetic improvement of resistance to epidemic diseases are limited when phenotyping strategies conflict directly with disease control measures, as is often the case in livestock. This is no issue in aquaculture where controlled challenge tests are performed in dedicated facilities.

Conclusion: For both epidemic and endemic microparasitic diseases, the economic value is highest at intermediate values of $\mathrm{R}_{0}$, it approaches zero when $\mathrm{R}_{0}$ increases to large values, and it is zero when $\mathrm{R}_{0} \leq 1$. Data availability has so far been a bottleneck to apply the method. 


\subsection{Introduction}

Microparasitic diseases are diseases caused by bacteria and viruses. Genetic improvement of resistance to microparasitic diseases in breeding programs for livestock and aquaculture species is of interest for the same reasons as for macroparasitic diseases, as recently discussed in Janssen et al. (2018). Genetic improvement should aim to reduce the risk and severity of disease outbreaks. Both are determined by the basic reproduction ratio, $\mathrm{R}_{0}$ (Anche et al., 2014). The definition of $\mathrm{R}_{0}$ for microparasitic diseases is, however, different from macroparasitic diseases, because the disease status of animals is classified differently. For most macroparasitic diseases the number of parasites per host can be counted, and the severity of clinical symptoms increases with the number of parasites (Anderson and May, 1978). In epidemiological models for macroparasitic diseases an animal's disease status is, therefore, given by the number of macroparasites it carries (e.g., Gharbi et al., 2015). For most microparasitic diseases the number of parasites per host cannot be recorded. In epidemiological models for microparasitic diseases an animal's disease status is classified as infected or not infected, without any differentiation in the degree of infection. $\mathrm{R}_{0}$ is, therefore, defined as "the expected number of secondary cases produced by a typical infected individual during its entire period of infectiousness in a completely susceptible population" (Diekmann et al., 1990).

We distinguish two types of microparasitic diseases: epidemic and endemic diseases. In epidemic diseases animals become immune after infection, so that an outbreak can occur only once per production cycle. In endemic diseases animals do not become immune after infection and can thus be infected multiple times during a production cycle. Therefore, we classify epidemic diseases as those that lead to incidental outbreaks, and endemic diseases as those that are virtually always present and the infected fraction of the population varies around its endemic equilibrium. For epidemic diseases the risk and size of major epidemics are determined by $\mathrm{R}_{0}$. For endemic diseases the level of the endemic equilibrium is determined by $\mathrm{R}_{0}$. Just as in macroparasitic diseases, $\mathrm{R}_{0}$ is, therefore, considered the appropriate breeding goal trait for both epidemic and endemic microparasitic diseases (Anche et al., 2014).

The economic value of $R_{0}$ needs to be derived to optimize its relative emphasis in the breeding goal. Janssen et al. (2018) recently presented a method for the derivation of the 
economic value of $\mathrm{R}_{0}$ for macroparasitic diseases. Here, we aim to extend the method for the derivation of the economic value of $\mathrm{R}_{0}$ for microparasitic diseases.

\subsection{Methods}

To derive the economic value of $R_{0}$, the relation between costs and $R_{0}$ needs to be known. Here, we assume that genetic improvement of $\mathrm{R}_{0}$ for microparasitic diseases will mainly reduce production losses (L) while expenditures (E) on disease control will be largely unaffected. Thus, the economic value can be derived as the partial derivative of $\mathrm{L}$ with respect to $R_{0}$ while $E$ is assumed to be constant (Janssen et al., 2018):

$\mathrm{EV}=\partial \mathrm{L} / \partial \mathrm{R}_{0}$

Because a reduction in $\mathrm{R}_{0}$ increases farm profit, the economic value is negative. However, for presentation purposes, we ignore the minus sign in the economic value throughout the remainder of the text.

\subsubsection{Epidemic diseases}

Epidemic diseases are commonly modelled in a SIR-model, where a population is classified according to three mutually exclusive states: susceptible, infected, and recovered (Britton, 2010). In this model all animals are susceptible before a first epidemic. Susceptible animals can become infected, and infected animals can recover. Neither infected or recovered animals can become susceptible again, hence recovered animals have acquired full immunity. The term 'removed' is sometimes used instead of recovered, for example, when infection leads to death.

We assume that $\mathrm{L}$ is proportional to the average proportion of the population that gets infected during a production cycle. In other words, we assume constant losses per infected animal. The average proportion of the population that gets infected during a production cycle equals the product of the probability of an epidemic in a production cycle and the fraction of the population that gets infected in case of an epidemic. An epidemic can only occur after infection from an outside source. Therefore, the probability of an epidemic increases with the frequency of infections from an outside source in a production cycle. After infection from an outside source, there are two options: the infection leads to a minor or a major epidemic. 
Following infection from an outside source, the probability for a minor epidemic equals $1 / R_{0}$ (Britton, 2010). During a minor epidemic a negligible proportion of the population gets infected, and the epidemic dies out quickly. Minor epidemics occur even when $\mathrm{R}_{0}>$ 1. After a minor epidemic, the probability of a (next) epidemic remains virtually unchanged, because the susceptible proportion of the population remains largely unaltered. Since relatively few animals get infected during minor epidemics, we ignore their effect on L.

Following infection from an outside source, the probability for a major epidemic equals $1-1 / R_{0}$ (Britton, 2010). During a major epidemic a large proportion of the population gets infected. The final fraction of the population that has been infected by the end of a major epidemic increases with $\mathrm{R}_{0}$ to an asymptote of one (Britton, 2010). The final fraction of the population that is still susceptible after a major epidemic is too small for a second major epidemic to occur. The corresponding algebra is provided below.

$\mathrm{L}$ is a function of the probability of a major epidemic in a production cycle, the final fraction of the population that has been infected by the end of a major epidemic, the population size, and production losses per infected individual. Let $m$ be the frequency of infections by an outside source per production cycle. The probability that a single infection by an outside source results in a minor epidemic is $1 / \mathrm{R}_{0}$; hence the probability that $m$ infections from an outside source each result in minor epidemics is $\left(\frac{1}{\mathrm{R}_{0}}\right)^{m}$. Following Britton (2010), the probability $(p)$ of a major epidemic during a production cycle equals:

$\left.p\left(\mathrm{R}_{0}\right)\right|_{\mathrm{R}_{0}>1}=1-\left(\frac{1}{\mathrm{R}_{0}}\right)^{m}$

which increases with $\mathrm{R}_{0}$ and $m$ to an asymptote of 1 (Fig. 1a). When $\mathrm{R}_{0} \leq 1$ or $m=0$, $p\left(\mathrm{R}_{0}\right)=0$ and major epidemics do not occur. The final fraction of the population that has been infected by the end of a major epidemic is denoted by $1-S_{\infty}$, where $S_{\infty}$ is the fraction of the population that remains susceptible after the epidemic has ended, i.e. that escapes infection. Following Britton (2010):

$1-S_{\infty}=-\ln \left(S_{\infty}\right) / R_{0}$

which increases with $\mathrm{R}_{0}$ to an asymptote of 1 (Fig. 1b). Let $\mathrm{N}$ be the population size and $\mathrm{L}_{\text {ind }}$ production losses per infected animal. In a SIR-model animals can get infected only 
once, hence losses can be incurred only once per animal. Under these assumptions, L is a function of $\mathrm{R}_{0}$ as:

$\mathrm{L}\left(\mathrm{R}_{0}\right)=p\left(\mathrm{R}_{0}\right) \cdot\left(1-\mathrm{S}_{\infty}\right) \cdot \mathrm{N} \cdot \mathrm{L}_{\text {ind }} \cdot$
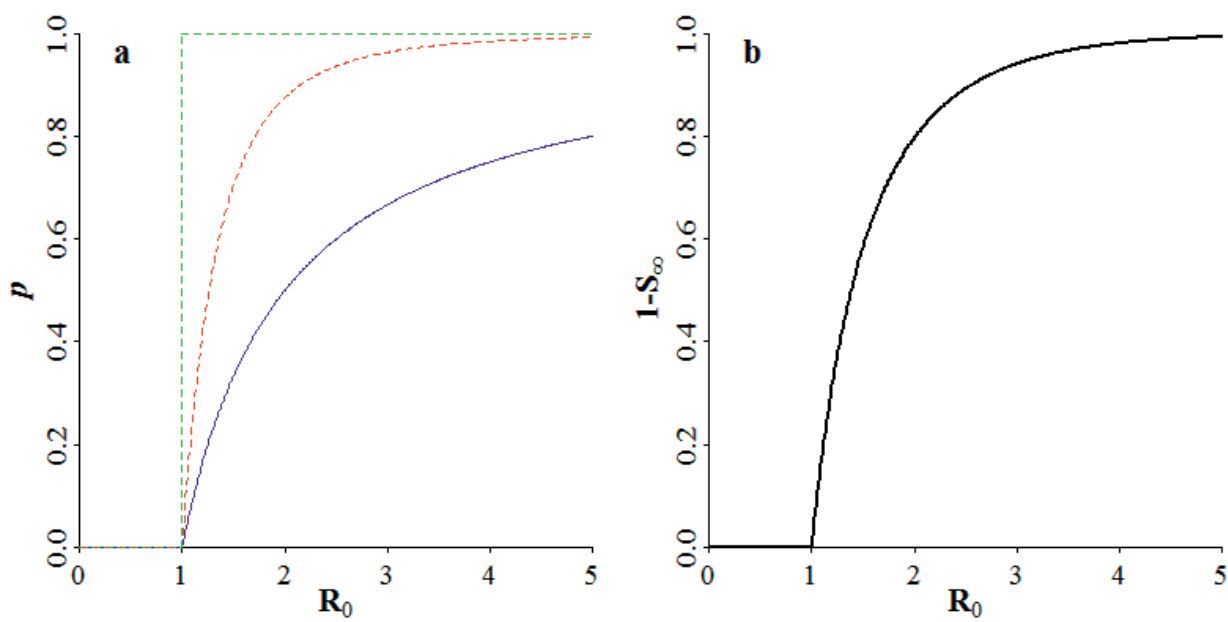

Fig. 1 The relation between $\mathrm{R}_{0}$ and a the probability $(p)$ of a major epidemic during a production cycle for different frequencies of infection from an outside source $(m)$, $\mathbf{b}$ the final fraction of the population that has been infected by the end of a major epidemic $\left(1-S_{\infty}\right)$ in epidemic microparasitic diseases. Solid blue line: $m=1$, dashed red line: $m=3$, green dotted line: $m=\infty$.

From Eqs. 1 and 4 it follows that:

$\mathrm{EV}=\frac{\partial \mathrm{L}}{\partial \mathrm{R}_{0}}=\frac{\partial\left(p\left(\mathrm{R}_{0}\right) \cdot\left(1-\mathrm{S}_{\infty}\right) \cdot \mathrm{N} \cdot \mathrm{L}_{\text {ind }}\right)}{\partial \mathrm{R}_{0}}$

$=\mathrm{N} \cdot \mathrm{L}_{\text {ind. }} \cdot\left(\frac{\partial p\left(\mathrm{R}_{0}\right)}{\partial \mathrm{R}_{0}} \cdot\left(1-\mathrm{S}_{\infty}\right)+\frac{\partial\left(1-\mathrm{S}_{\infty}\right)}{\partial \mathrm{R}_{0}} \cdot p\left(\mathrm{R}_{0}\right)\right)$, where:

$\frac{\partial p\left(\mathrm{R}_{0}\right)}{\partial \mathrm{R}_{0}}=\frac{m}{\mathrm{R}_{0}{ }^{m+1}}$, and

$\frac{\partial\left(1-S_{\infty}\right)}{\partial R_{0}}=-\frac{\partial S_{\infty}}{\partial R_{0}}=\frac{-1}{\partial R_{0} / \partial S_{\infty}}=\frac{\left(S_{\infty}-1\right)^{2}}{1 / S_{\infty}+\ln \left(S_{\infty}\right)-1}$,

which gives the economic value for epidemic microparasitic diseases. This expression cannot be simplified further. 


\subsubsection{Endemic diseases}

Endemic diseases are commonly modelled in a SIS-model, where recovered animals become susceptible again. This model assumes that animals do not acquire immunity, such that the population consists of susceptible and infected animals only. When the disease is present and $\mathrm{R}_{0}>1$, the fractions of susceptible and infected animals tend towards an endemic equilibrium. The proportion of infected animals at the endemic equilibrium increases with $\mathrm{R}_{0}$ to an asymptote of 1 . We assume that $\mathrm{L}$ is proportional to the average fraction of the population that is infected at the endemic equilibrium. The corresponding algebra is provided below.

$\mathrm{L}$ is a function of the fraction of infected animals at the endemic equilibrium, the population size, and the production losses per infected animal. The endemic equilibrium is reached when the infected fraction of the population $\left(1-S_{\infty}\right)$ equals (Britton, 2010):

$1-\mathrm{S}_{\infty}=1-\frac{1}{\mathrm{R}_{0}}$

which increases with $\mathrm{R}_{0}$ to an asymptote of 1 (Fig. 2). Let $\mathrm{N}$ again be the population size and $\mathrm{L}_{\mathrm{ind}}$ production losses per infected animal that is infected during the entire length of a production cycle. Production losses per day are assumed equal for all infected individuals, hence $L$ remains unaltered when a susceptible and infected animal change state at the same point in time. In other words, $L$ is determined by the average infected fraction of the population during the length of a production cycle, irrespective of which individuals are infected. Under these assumptions, $\mathrm{L}$ is a function of $\mathrm{R}_{0}$ as:

$\mathrm{L}\left(\mathrm{R}_{0}\right)=\left(1-\mathrm{S}_{\infty}\right) \cdot \mathrm{N} \cdot \mathrm{L}_{\text {ind }}$

From Eqs. 1 and 9 it follows that:

$\mathrm{EV}=\frac{\partial \mathrm{L}}{\partial \mathrm{R}_{0}}=\frac{\partial\left(\left(1-\mathrm{S}_{\infty}\right) \cdot \mathrm{N} \cdot \mathrm{L}_{\text {ind }}\right)}{\partial \mathrm{R}_{0}}=\mathrm{N} \cdot \mathrm{L}_{\text {ind }} \cdot \frac{\partial\left(1-\mathrm{S}_{\infty}\right)}{\partial \mathrm{R}_{0}}=\frac{\mathrm{N} \cdot \mathrm{L}_{\text {ind }}}{\mathrm{R}_{0}{ }^{2}}$,

which gives the economic value for endemic microparasitic diseases. 


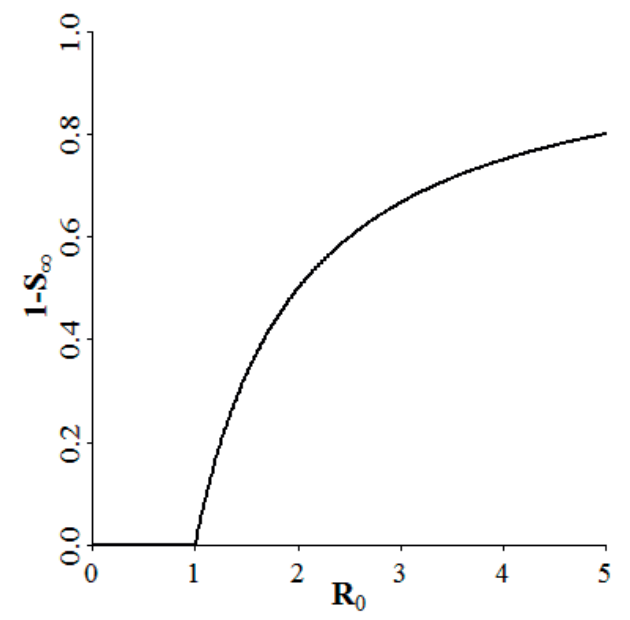

Fig. 2 The relation between $R_{0}$ and the infected fraction of the population $\left(1-S_{\infty}\right)$ in endemic microparasitic diseases.

\subsection{Results}

\subsubsection{Epidemic diseases}

The relation between $R_{0}$ and $L$ is in Fig. $3 a$, and the relation between $R_{0}$ and its economic value is in Fig. 3b. Actual units are omitted from the y-axis, because these depend on the number of animals in the population and production losses per infected animal. $\mathrm{L}$ decreases when $R_{0}$ decreases, up to the point where $R_{0} \leq 1$ at which no major epidemic can occur and $L$ is zero. Thus when $R_{0} \leq 1$, the economic value is zero. At intermediate values of $R_{0}$ $\left(\mathrm{R}_{0}>1\right.$ and smaller than, say, 3$) \mathrm{L}$ decreases rapidly with $\mathrm{R}_{0}$, so that the economic value is relatively high. When $R_{0}$ is large and there are frequent infections from an outside source, a major epidemic occurs in most production cycles (Fig. 1a) during which virtually the entire population is infected (Fig. 1b). Thus for such cases, $\mathrm{L}$ is rather constant with respect to $R_{0}$ and the economic value is relatively small. When $R_{0}$ increases to large values, its economic value approaches zero. 

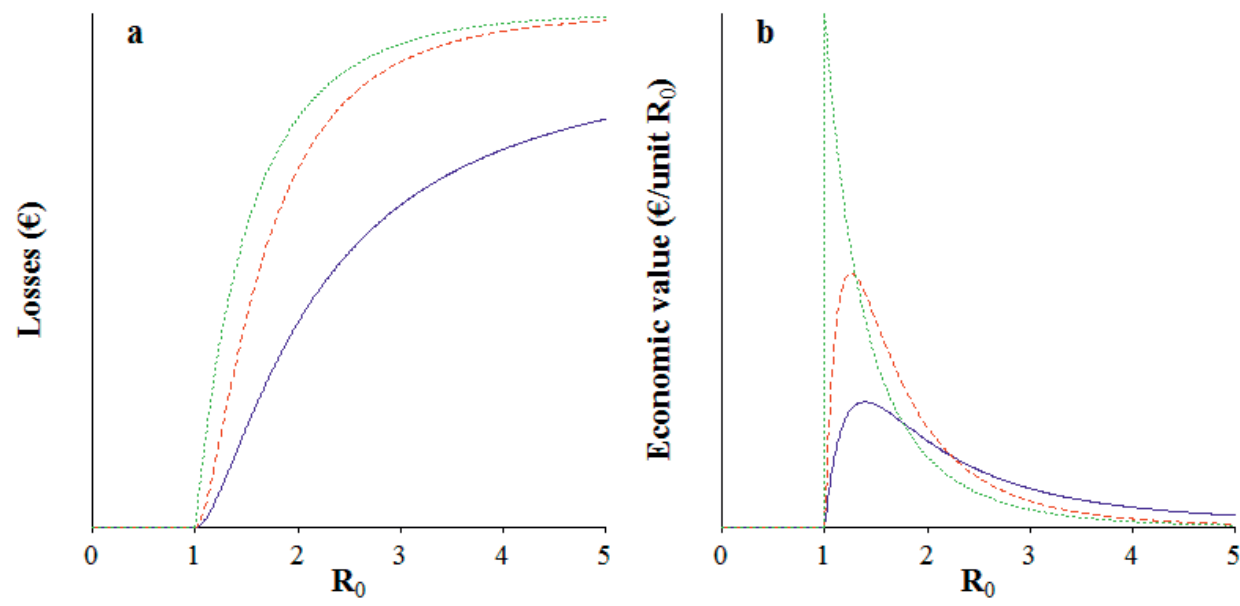

Fig. 3 The relation between $R_{0}$ and a production losses and $\mathbf{b}$ the economic value of $R_{0}$ for epidemic microparasitic diseases for different frequencies of infection from an outside source $(m)$. Solid blue line: $m=1$, dashed red line: $m=3$, green dotted line: $m=\infty$. Note that the minus sign in the economic value is ignored for presentation purposes.

The relation between the probability of a major epidemic during a production cycle and the frequency of infection from an outside source $(m)$ (Fig. 1a) explains the relations between $\mathrm{L}$ and $m$ and between the economic value of $\mathrm{R}_{0}$ and $m$. L increases asymptotically with $m$, because the probability of a major epidemic increases asymptotically with $m$. When $R_{0}$ is close to 1 , the probability of a major epidemic increases at a higher rate for higher values of $m$. As a result, the economic value increases with $m$ when $\mathrm{R}_{0}$ is close to 1 . When $\mathrm{R}_{0}$ is large, the probability of a major epidemic increases at a lower rate for higher values of $m$. As a result, the economic value decreases with $m$ when $\mathrm{R}_{0}$ is large.

\subsubsection{Endemic diseases}

The relation between $R_{0}$ and $L$ is in Fig. $4 a$, and the relation between $R_{0}$ and its economic value is in Fig. 4b. Actual units are omitted from the y-axis, because these depend on the number of animals in the population and production losses per infected animal. L decreases when $\mathrm{R}_{0}$ decreases, up to the point where $\mathrm{R}_{0} \leq 1$ at which the disease will disappear from the population. Thus when $\mathrm{R}_{0} \leq 1$, the economic value is zero. At intermediate values of $\mathrm{R}_{0}\left(\mathrm{R}_{0}>1\right.$ and smaller than, say, 3$) \mathrm{L}$ decreases rapidly with $\mathrm{R}_{0}$, so that the economic value is relatively high. When $\mathrm{R}_{0}$ is large, virtually the entire population is infected. Thus for such cases, $L$ is rather constant with respect to $R_{0}$ and the economic value is relatively small. When $\mathrm{R}_{0}$ increases to large values, its economic value approaches zero. 

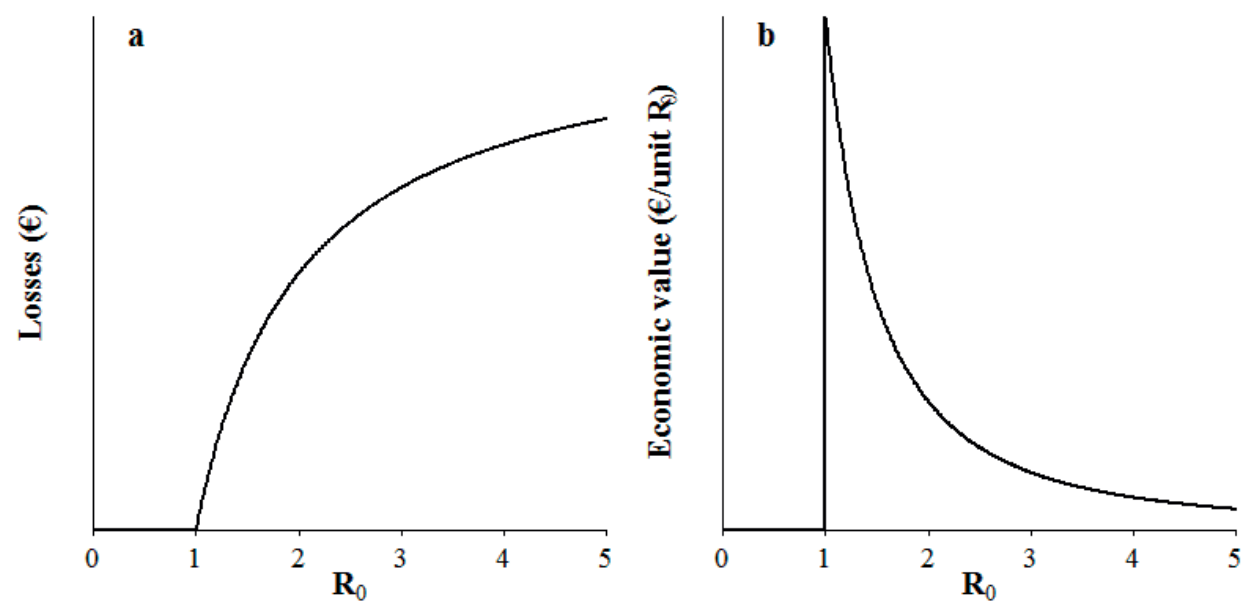

Fig. 4 The relation between $R_{0}$ and a production losses and $\mathbf{b}$ the economic value of $R_{0}$ for endemic microparasitic diseases. Note that the minus sign in the economic value is ignored for presentation purposes.

\subsection{Discussion}

For epidemic and endemic microparasitic diseases we have shown that the average proportion of the population that gets infected during a production cycle increases asymptotically with $\mathrm{R}_{0}$. Resulting production losses increase asymptotically with $\mathrm{R}_{0}$ (Fig. $3 \mathrm{a}$ and $4 \mathrm{a}$ ), hence the economic value is relatively high at intermediate values of $\mathrm{R}_{0}$ (Fig. $3 b$ and $4 b$ ). When $R_{0}$ is large, production losses are relatively constant with respect to $R_{0}$, hence the economic value is relatively low. These results are in agreement with previous studies. For an epidemic microparasitic disease MacKenzie and Bishop (1999) predicted the final fraction of the population that has been infected by the end of a major epidemic to decrease at an increasing rate with decreasing values of $\mathrm{R}_{0}$, just as in Fig. 1b. Similarly, Nieuwhof et al. (2009) predicted a substantially higher response in prevalence for an endemic microparasitic disease when using epidemiological models than when using prevalence itself as a predictor in a threshold model. These studies emphasize the need to account for the dynamics of disease transmission in the derivation of the economic value of disease resistance. For microparasitic diseases the above method as an extension of the method of Janssen et al. (2018) may be a useful starting point for the derivation of the economic value of $\mathrm{R}_{0}$. Although only few parameters are required, i.e. $\mathrm{L}_{\text {ind., }} m$ and $\mathrm{R}_{0}$ for epidemic diseases and $L_{\text {ind. }}$ and $R_{0}$ for endemic diseases, data availability has so far been a bottleneck to apply the method. 
Janssen et al. (2018) argued that genetic improvement of $\mathrm{R}_{0}$ may reduce production losses, expenditures on control, or both. Here, only a reduction in production losses was considered. In reality, expenditures on control can be reduced when genetic improvement reduces the vaccination rate, or when genetic improvement reduces treatment frequency. When vaccination is used to induce herd immunity, i.e. the objective is disease eradication, the critical vaccination coverage decreases with $\mathrm{R}_{0}$ (Britton, 2010). The critical vaccination coverage is the minimum proportion of the population that needs to be vaccinated in order to induce herd immunity. If costs of vaccination are constant per animal, the economic value of $\mathrm{R}_{0}$ can be derived from the reduction in critical vaccination coverage. The extent to which genetic improvement can reduce expenditures on treatment is likely to differ between livestock and aquaculture. In livestock treatment can be applied at the level of the individual animal when infection is detected, e.g., from clinical signs. These expenditures are proportionate to the average number of infected animals, hence can be included in production losses as part of $\mathrm{L}_{\text {ind }}$ (Eqs. 4 and 9). In aquaculture treatment can only be applied at a population (cage, tank, pond, ...) level. Expenditures on treatment for endemic diseases in aquaculture will largely be aimed at reducing the value of $\mathrm{R}_{0}$, and are, therefore, expected to be rather insensitive to genetic improvement. Expenditures on treatment for epidemic diseases in aquaculture are expected to be largely proportionate to the probability of major epidemics, hence these can decrease as $\mathrm{R}_{0}$ decreases (Fig. 1a).

For epidemic diseases opportunities for genetic improvement are limited when phenotyping strategies conflict directly with disease control measures (Bishop et al., 2010). This applies to livestock diseases where drastic control measures are taken at a regional level upon detection of infection (Saatkamp et al., 2016). Thus, genetic improvement of $R_{0}$ is not feasible for many epidemic microparasitic diseases in livestock. For microparasitic diseases in aquaculture phenotyping is no issue when controlled challenge tests can be performed in dedicated facilities. In a challenge test naive fish are exposed to the pathogen, and after some incubation time, phenotypes are recorded as dead or alive. Dead fish are considered susceptible, and surviving fish as resistant (Robinson et al., 2017). To maximize phenotypic variation, the endpoint of the challenge test may be chosen such that survival is $50 \%$ (Odegard et al., 2006). There are, however, two issues with this dead-or-alive phenotype. First, as already pointed out by Robinson et al. (2017), incomplete exposure obscures the phenotypic expression of susceptibility. In any epidemic some animals may not get infected because they escaped infection, e.g., due to luck, rather than because they were less 
susceptible. When the endpoint of the challenge test is set retrospectively to the point at which survival was $50 \%$, the number of obscured phenotypes increases. Second, with a dead-or-alive phenotype, susceptibility and tolerance are confounded, while only susceptibility is of interest for the objective to improve $\mathrm{R}_{0}$. An intuitive but not necessarily correct interpretation of dead-or-alive phenotypes is that surviving fish are less susceptible, while they might be more tolerant instead. The economic effect of improved tolerance is excluded from the economic value of $\mathrm{R}_{0}$. Phenotypes in a challenge test would be more informative when they include information on whether or not a fish has been infected at some point during the challenge test, and whether or not it has recovered from the infection. When using a binary trait definition, dead, infected, and recovered fish should all be considered susceptible, while uninfected fish should be treated as resistant. More sophisticated methods as proposed by Anche et al. (2014), Anacleto et al. (2015), and Biemans et al. (2017) can further improve the accuracy of estimated breeding values for $\mathrm{R}_{0}$.

\subsection{Conclusion}

This study presents a method for the derivation of the economic value of $\mathrm{R}_{0}$ for epidemic and endemic microparasitic diseases. For both disease types the economic value is highest at intermediate values of $R_{0}$, it approaches zero when $R_{0}$ increases to large values, and it is zero when $\mathrm{R}_{0} \leq 1$. Data availability has so far been a bottleneck to apply the method.

\subsection{References}

Anacleto, O., Garcia-Cortéz, L.A., Lipschutz-Powell, D., Woolliams, J., Doeschl-Wilson, A., 2015. A Novel Statistical Model to Estimate Host Genetic Effects Affecting Disease Transmission. Genetics.

Anche, M.T., de Jong, M.C.M., Bijma, P., 2014. On the definition and utilization of heritable variation among hosts in reproduction ratio R0 for infectious diseases. Heredity (Edinb). $113,364$.

Anderson, R.M., May, R.M., 1978. Regulation and Stability of Host-Parasite Population Interactions: I. Regulatory Processes. J Anim Ecol. 47, 219-247.

Biemans, F., de Jong, M.C.M., Bijma, P., 2017. A model to estimate effects of SNPs on host susceptibility and infectivity for an endemic infectious disease. Genet Sel Evol. 49, 53.

Bishop, S.C., Axford, R.F.E., Nicholas, F.W., Owen, J.M., 2010. Breeding For Disease Resistance In Farm Animals, 3rd Edition. CABI, Wallingford, UK.

Britton, T., 2010. Stochastic epidemic models: a survey. Math Biosci. 225, 24-35.

Diekmann, O., Heesterbeek, J.A.P., Metz, J.A.J., 1990. On the Definition and the Computation of the Basic Reproduction Ratio R0 in Models for Infectious-Diseases in Heterogeneous Populations. J Math Biol. 28, 365-382.

Gharbi, K., Matthews, L., Bron, J., Roberts, R., Tinch, A., Stear, M.J., 2015. The control of sea lice in Atlantic salmon by selective breeding. J R Soc Interface. 12. 
Janssen, K., Komen, H., Saatkamp, H.W., de Jong, M.C.M., Bijma, P., 2018. Derivation of the economic value of R0 for macroparasitic diseases and application to sea lice in salmon. Genet Sel Evol. 50, 47.

MacKenzie, K., Bishop, S.C., 1999. A discrete-time epidemiological model to quantify selection for disease resistance. Anim Sci. 69, 543-551.

Nieuwhof, G.J., Conington, J., Bishop, S.C., 2009. A genetic epidemiological model to describe resistance to an endemic bacterial disease in livestock: application to footrot in sheep. Genet Sel Evol. 41.

Odegard, J., Olesen, I., Gjerde, B., Klemetsdal, G., 2006. Evaluation of statistical models for genetic analysis of challenge test data on furunculosis resistance in Atlantic salmon (Salmo salar): Prediction of field survival. Aquaculture. 259, 116-123.

Robinson, N.A., Gjedrem, T., Quillet, E., 2017. Chapter 2 - Improvement of Disease Resistance by Genetic Methods. in: Jeney, G. (Ed.), Fish Diseases. Academic Press, 21-50.

Saatkamp, H.W., Mourits, M.C.M., Howe, K.S., 2016. A Framework for Categorization of the Economic Impacts of Outbreaks of Highly Contagious Livestock Diseases. Transbound Emerg Dis. 63, 422-434. 



\title{
6
}

\section{Cost-benefit analysis of aquaculture breeding programs}

\author{
Kasper Janssen ${ }^{1}$, Helmut W. Saatkamp ${ }^{2}$ and Hans Komen ${ }^{1}$
}

\footnotetext{
${ }^{1}$ Wageningen University, Animal Breeding and Genomics, Droevendaalsesteeg 1, 6708 PB Wageningen, The Netherlands

${ }^{2}$ Wageningen University, Business Economics Group, Hollandseweg 1, $6706 \mathrm{KN}$ Wageningen, The Netherlands
}

Genetics Selection Evolution (2018) 50:2 


\begin{abstract}
Background: Profitability of breeding programs is a key determinant in the adoption of selective breeding, and can be evaluated using cost-benefit analyses. There are many options to design breeding programs, with or without a multiplier tier. Our objectives were to evaluate different breeding program designs for aquaculture and to optimize the number of selection candidates for these programs.
\end{abstract}

Methods: The baseline was based on an existing breeding program for gilthead seabream, where improvement of the nucleus had priority over improvement of the multiplier tier, which was partly replaced once every three years. Alternative breeding programs considered were: annual multiplier tier replacement, annual multiplier tier replacement with priority on improvement of the multiplier tier, and a program without a multiplier tier. Costbenefit analyses were performed to compare breeding programs. The outcomes were used to describe relationships between profitability and the number of selection candidates, length of the time horizon, and production output, and to estimate the optimum numbers of selection candidates.

Results: The baseline breeding program was profitable after five years and reached a net present value of 2.9 million euro in year 10. All alternative programs were more profitable up to year 17. The program without a multiplier tier was the most profitable one up to year 22 , followed by the program with annual multiplier tier replacement and nucleus priority. The optimum number of selection candidates increased with the length of the time horizon and production output.

Conclusions: The baseline breeding program was profitable after five years. For a short time horizon putting priority on improvement of the multiplier tier over the nucleus is more profitable than putting priority on nucleus improvement, and vice versa for a long time horizon. Use of a multiplier tier increases the delay between costs made for selection and resulting benefits. Thus, avoiding the use of a multiplier tier will increase the profitability of the breeding program in the short term. The optimum number of selection candidates increases with the length of the time horizon and production output. Using too many selection candidates relative to the optimum leads to less reduction in profitability than using too few selection candidates. 


\subsection{Background}

In European aquaculture, most breeding programs are operated by private companies, i.e. the governments' involvement is limited (Chavanne et al., 2016; Janssen et al., 2017a). Profitability of breeding programs, therefore, is a key determinant in the adoption of selective breeding (EAS-EATiP, 2014). Cost-benefit analysis can be used to evaluate the effectiveness of an investment, to find its optimal scale, and to identify its constraints (Mishan and Quah, 2007). The theory for cost-benefit analysis of breeding programs, in particular for livestock species, was developed by Hill (1971), Moav (1973), Weller (1994), and Wilton et al. (2013). The general concept is that benefits and costs of a breeding program are expressed relative to a baseline scenario without genetic improvement. Costs include investments for husbandry and testing facilities, rearing of selection candidates, trait recording, and genetic analysis. Benefits follow from the increase in genetic levels of traits, the economic values of these traits, and production output of the company, market, or industry. Benefits are permanent and cumulative, but delayed relative to the costs incurred to implement selection. To account for differences in timing of benefits and costs, these are discounted to their present values. The difference in present values of benefits and costs - the net present value - for a given time horizon is a measure of the profitability of the breeding program.

Genetic improvement increases farm profit, either via cost reduction per unit product, increased production output, or a combination of both. When breeding is a highly specialized and concentrated activity, such as in salmonids and livestock (Gura, 2007; Janssen et al., 2017a), genetic progress is not necessarily reflected in the market price of eggs, young animals, or parent stock (De Vries, 1989). Instead, the benefits of the breeding program are distributed between the breeding company and its clients, such that the minimum proportion of benefits accrued by the breeding company covers its costs. Integrated companies accrue all benefits from genetic progress generated by the breeding program.

Genetic progress can be disseminated with or without a multiplier tier. Generally, pig and poultry breeding programs consist of a nucleus and one or more multiplier tiers. The nucleus consists of various pure lines that are differentially selected. For example, a sire line may be selected for lean tissue growth and a dam line for reproduction. In the multiplier tier crossbreeding is performed to exploit heterosis, and market-specific crosses are made 
to meet needs of different markets. Because of the limited reproductive ability of pigs and poultry, multiplier tiers are required to disseminate genetic progress (Dekkers et al., 2011; Visscher et al., 2000). In aquaculture breeding programs with and without a multiplier tier exist. Specialized breeding companies for salmonids usually make use of a multiplier tier, partly because the fecundity of salmonids is insufficient to supply the entire market directly from the nucleus. Integrated breeding companies control the entire process from reproduction to harvest and operate a breeding program as an integrated part of the process (Janssen et al., 2017a). Some integrated companies use a multiplier tier, while others do not. When a multiplier tier is used, the highest ranking animals may be used for nucleus replacement and the next tier for multiplier tier replacement, or vice versa. It is unclear which strategy is most profitable. Integrated companies that do not use a multiplier tier use the nucleus to supply production. A multiplier tier can result in delay between genetic progress and its dissemination (Bichard, 1971) and may thereby negatively affect profitability of a breeding program. Thus, studying the economic consequences of implementing a multiplier tier is relevant in aquaculture breeding programs.

For integrated companies, the general objective of investing in a breeding program is maximization of the net present value. Benefits are proportional to the selection intensity and production output of the company, while costs are largely proportional to the number of selection candidates. Therefore, there is an optimum number of selection candidates that maximizes net present value.

The first objective of this study was to evaluate the effectiveness of investing in a breeding program by an integrated aquaculture company. The second objective was to evaluate the profitability of alternative breeding program designs. The third objective was to describe the relationship between net present value and the number of selection candidates, length of the time horizon, and production output, and to estimate the optimum number of selection candidates.

\subsection{Methods}

The baseline for the analyses was based on an existing breeding program for gilthead seabream. Improvement of the nucleus had priority over the multiplier tier, which was partly replaced once every three years. Alternative breeding programs were: annual multiplier tier replacement, annual multiplier tier replacement with priority on improvement of the multiplier tier, and a breeding program without a multiplier tier. In all 
breeding programs the number of parents per selection round and the number of selection candidates were equal to those in the baseline program, hence the selection intensity and selection index remained the same over breeding programs.

\subsubsection{Structure of the baseline breeding program}

The baseline breeding program was based on the existing breeding program of the integrated company Andromeda S.A., one of the largest producers of gilthead seabream. A schematic overview of this breeding program is in Fig. 1. It consists of a nucleus of 320 fish, comprised of four year classes, with an overall male to female ratio of 1:1. Because seabream is a protandrous hermaphrodite, younger year classes consist primarily of males and older year classes primarily of females. Thus, broodstock may initially contribute to offspring as males and later as females, which explains the relatively large size of the nucleus. Every year, 80 males and 80 females are selected from the nucleus and distributed over eight spawning tanks according to a mating design that manages contributions of parents. Seabream is a batch spawning species that can produce 20,000 to 80,000 eggs per day for a period of up to three months (Sola et al., 2007). Equal quantities of fertilized eggs from all spawning tanks are collected on the same day, pooled, and larvae are reared communally. After weaning, 2500 juveniles are selected at random, tagged, fin clipped, and transferred to a sea cage. Microsatellite analyses are used for pedigree reconstruction. Selection is performed after 18 months when the fish reach $400 \mathrm{~g}$. Every selection round, 2215 selection candidates survive of which the 80 fish highest ranking fish based on aggregate genotype are selected as replacements for the oldest year class in the nucleus. Once every three years, an additional 350 fish of the next tier are selected to replace half of the multiplier tier, which is used to produce juveniles for production.

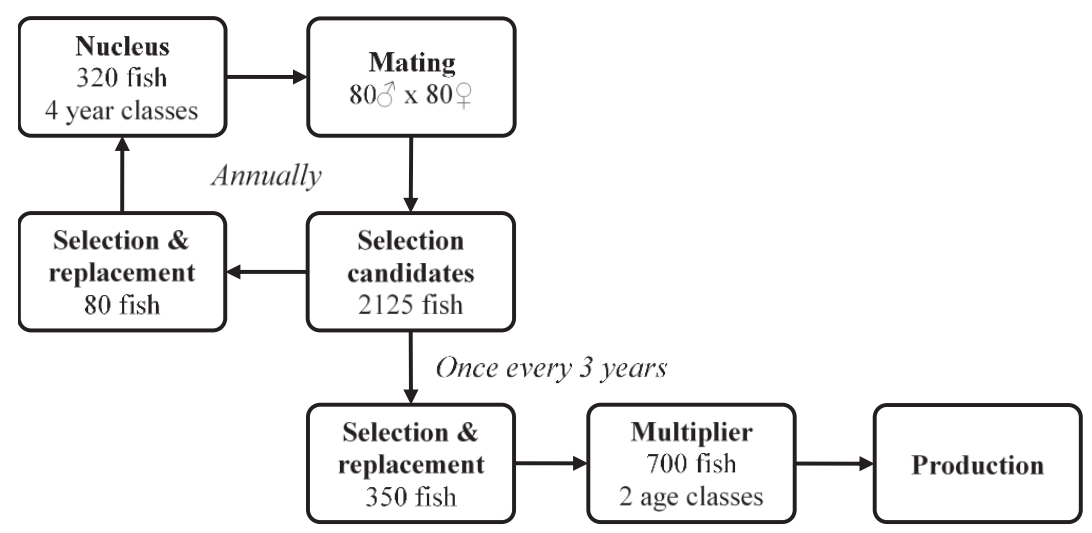

Fig. 1 Schematic overview of the baseline breeding program. 


\subsubsection{Genetic selection differential}

The genetic selection differential, i.e. the difference in the mean value of the aggregate genotype of selected individuals relative to the mean of all selection candidates, was first predicted from the sum of products of genetic gain per trait per selection round and economic values. The breeding goal included three traits: thermal growth coefficient (TGC), thermal feed intake coefficient (TFC), and mortality rate (M) (Janssen et al., 2017b). TGC is a measure of growth rate corrected for initial bodyweight and the sum of lifetime daily temperatures. TFC is a measure of feed intake rate corrected for initial bodyweight and the sum of lifetime daily temperatures. $\mathrm{M}$ is mortality rate in percent per day. Baseline trait levels, genetic parameters, and economic values are in Table 1. Estimation of genetic parameters for TGC and TFC is described in Appendix 1. Genetic and phenotypic correlations between TGC and TFC were assumed to be equal to 0.8 and 0.9 , respectively (Appendix 1). M was assumed to be uncorrelated to TGC and TFC.

Table 1 Traits, trait levels, genetic parameters, and economic values of traits used in the breeding program.

\begin{tabular}{lcccc}
\hline Trait & $\begin{array}{c}\text { Baseline trait } \\
\text { level (trait unit) }\end{array}$ & $\begin{array}{c}\text { Phenotypic variance } \\
\left.\text { (trait unit }^{2}\right)\end{array}$ & Heritability & $\begin{array}{c}\text { Economic value }^{\mathrm{a}} \\
\left(€ \text { (trait unit) }^{-1}{\left.\text { (ton production })^{-1}\right)}^{-1}\right.\end{array}$ \\
\hline TGC & 12.6 & 2.64 & 0.34 & 400 \\
TFC & 8.25 & 1.17 & 0.26 & -450 \\
M & 0.030 & & ${ }^{\mathrm{b}} 0.17$ & -7700 \\
\hline
\end{tabular}

TGC $=$ Thermal growth coefficient $\left(\mathrm{g}^{2 / 3} /(\right.$ day degrees $\left.\cdot 1000)\right)$

$\mathrm{TFC}=$ Thermal feed intake coefficient $\left(\mathrm{g}^{0.544} /(\right.$ day degrees $\left.\cdot 1000)\right)$

$\mathrm{M}=$ Mortality rate $(\% /$ day $)$

a (Janssen et al., 2017b)

${ }^{\mathrm{b}}$ Liability scale (Vehvilainen et al., 2008)

Genetic gains in TGC and TFC in the nucleus were predicted using SelAction (Rutten et al., 2002), applying 1-stage truncation selection on estimated breeding values. Common environmental effects were set to zero. Genetic gain was predicted as if 80 males and 81 females produce offspring (SelAction does not allow half-sibs groups with equal numbers of males and females). The number of surviving selection candidates was 2125 . The number of full-sib and half-sib records per selection candidate were estimated from stochastic simulation. With eight spawning tanks each holding 10 males and 10 females, there were 800 possible combinations of parental pairs. A total of 2125 offspring were simulated with each parental pair having an equal chance to contribute offspring. Over 1000 simulations, per selection candidate the mean number of full-sibs was 2.7 and the mean number of half-sibs was 50. The average number of dams of half-sibs was 8.4. In SelAction a full-sib group of 3 and a half-sib group of 50 originating from eight dams were thus 
included. Although in reality younger year classes consist primarily of males and older year classes primarily of females, here an abrupt sex change from all male to all female was assumed at the age of four years. Thus, selected proportions $(p)$ were set to 0.0376 for both sexes. The selection index contained records of TGC based on own performance, best linear unbiased predictions (BLUP) of breeding values of the parents, and records of TGC on three full-sibs and 50 half-sibs. No phenotypes for TFC were recorded. Genetic gain in M was predicted based on mass selection on cumulative mortality, where the selected proportion equalled the surviving fraction of selection candidates and genetic correlations with other traits were assumed to be zero (Appendix 2).

The genetic selection differential as predicted here does not account for non-linear relationships between trait levels and change in farm profit nor for interactions between traits. To account for these, the genetic selection differential was also predicted using the bio-economic model described in Janssen et al. (2017b) by using baseline trait levels and trait levels after one round of selection as inputs. The genetic selection differential was calculated as the increase in gross margin between the baseline and after one round of selection, divided by the volume of fish production before genetic improvement.

\subsubsection{Gene flow}

Gene flow (Dekkers et al., 2004; Hill, 1974) was used to simulate increases in the genetic level of each age class of the nucleus and multiplier tier over time. In the nucleus the fiveyear old female year class was replaced every year by 80 two-year old selected males. All year classes in the nucleus were assumed to have equal contributions to selected males, hence mortality in year classes was ignored. A vector $\mathbf{n}_{(t)}$ was defined to simulate the flow of genes between age classes over time. The elements in $\mathbf{n}_{(t)}$ defined the genetic level in each year class of the nucleus at time $t$ (years). The length of $\mathbf{n}_{(t)}$ was five: one for oneyear old selection candidates and four for the four-year classes.

We defined a matrix $\mathbf{P}$ that described the flow of genes due to reproduction and aging, and a vector $\mathbf{s}$ that described the increase in breeding values due to selection, such that:

$$
\mathbf{n}_{(t)}=\mathbf{P} \cdot \mathbf{n}_{(t-1)}+\mathbf{s}
$$


$\mathbf{P}=\left[\begin{array}{ccccc}0 & 0.25 & 0.25 & 0.25 & 0.25 \\ 1 & 0 & 0 & 0 & 0 \\ 0 & 1 & 0 & 0 & 0 \\ 0 & 0 & 1 & 0 & 0 \\ 0 & 0 & 0 & 1 & 0\end{array}\right]$, and

$\mathbf{s}^{\prime}=\left[\begin{array}{lllll}S & 0 & 0 & 0 & 0\end{array}\right]$

where $\mathbf{n}_{(0)}^{\prime}=\left[\begin{array}{lllll}0 & 0 & 0 & 0 & 0\end{array}\right]$, element $P_{i j}$ of matrix $\mathbf{P}$ is the proportion of genes in age class $i$ at time $t$ that came from age class $j$ at time $t-1$, and element $S$ of vector $\mathbf{s}$ denotes the genetic selection differential.

The multiplier tier was treated as two age classes with a 1:1 sex ratio, originating from two different selection rounds. Both age classes were assumed to contribute equally to juvenile production, hence the genetic level of fish in production facilities was determined by the average genetic level in the multiplier tier. The genetic selection differential for the 350 fish selected for multiplier tier replacement was lower than that for the 80 fish selected for nucleus replacement. For the nucleus $p=\frac{80}{2125}=0.0376$, hence selection intensity $(i)$ was 2.18. For the $80+350=430$ fish used for replacement of both the nucleus and multiplier tier $p=\frac{430}{2125}=0.202$, hence $i$ was 1.39. For the 350 fish selected for the multiplier tier $i$ was thus $\frac{430 \cdot 1.39-80 \cdot 2.18}{350}=1.21$. Genetic gains in TGC and TFC were proportional to $i$, but genetic gain in $\mathrm{M}$ was not because $i$ for $\mathrm{M}$ depended on the surviving proportion. Thus, the genetic selection differential $S$ was split between the genetic selection differential due to improvement of TGC and TFC $\left(S_{\mathrm{TGC}, \mathrm{TFC}}\right)$ and the selection differential due to improvement of $\mathrm{M}\left(S_{\mathrm{M}}\right)$. The genetic selection differential in the multiplier tier was expressed relative to $S_{\mathrm{TGC}, \mathrm{TFC}}$ and $S_{\mathrm{M}}$ in the nucleus. A vector $\mathbf{m}_{(t)}$ was defined to simulate the flow of genes towards and within the multiplier tier. The elements in $\mathbf{m}_{(t)}$ defined the genetic level in each age class at time $t$ (year). The length of $\mathbf{m}_{(t)}$ was two: the two age classes of the multiplier tier. For years without replacement $(t=1,3,4,6,7$, etc.) average breeding values did not change, hence:

$\mathbf{m}_{(t)}=\mathbf{m}_{(t-1)}$

The oldest age class in the multiplier tier was replaced at $t=2,5,8,11$, etc. For these years we defined a matrix $\mathbf{R}$ that described the flow of genes from the nucleus to the multiplier tier, a matrix $\mathbf{Q}$ that described the flow of genes in age classes of the multiplier tier due to 
aging, and a vector $\mathbf{r}$ that described the increase in average breeding values due to selection, such that:

$\mathbf{m}_{(t)}=\mathbf{R} \cdot \mathbf{n}_{(t-2)}+\mathbf{Q} \cdot \mathbf{m}_{(t-3)}+\mathbf{r}$

$\mathbf{R}=\left[\begin{array}{ccccc}0 & 0.25 & 0.25 & 0.25 & 0.25 \\ 0 & 0 & 0 & 0 & 0\end{array}\right]$

$\mathbf{Q}=\left[\begin{array}{ll}0 & 0 \\ 1 & 0\end{array}\right]$, and

$\mathbf{r}^{\prime}=\left[\frac{1.21}{2.18} \cdot S_{\mathrm{TGC}, \mathrm{TFC}}+S_{\mathrm{M}} 0\right]$

where $\mathbf{m}^{\prime}(0)=\left[\begin{array}{ll}0 & 0\end{array}\right]$, element $R_{i j}$ of matrix $\mathbf{R}$ is the proportion of genes in each age class $i$ of $\mathbf{m}$ at time $t$ that came from age class $j$ of $\mathbf{n}$ at time $t-2$.

\subsubsection{Breeding program with annual multiplier tier replacement}

In this breeding program, part of the multiplier tier was replaced annually. Vector $\mathbf{n}_{(t)}$ was defined as before (Eq. 1). The multiplier tier was made up of four year classes of 175 fish, hence the length of vector $\mathbf{m}_{(t)}$ was four. For the $80+175=255$ fish used for replacement of both the nucleus and multiplier tier $p=\frac{255}{2125}=0.120$ and $i=1.67$. For the 175 fish selected for the multiplier tier $i$ was thus $\frac{255 \cdot 1.67-80 \cdot 2.18}{175}=1.43$. The genetic selection differential was expressed relative to $S_{\mathrm{TGC}, \mathrm{TFC}}$ and $S_{\mathrm{M}}$ in the nucleus in the baseline. Vectors and matrices $\mathbf{m}_{(t)}, \mathbf{R}, \mathbf{Q}$, and $\mathbf{r}$ were redefined as:

$\mathbf{m}_{(t)}=\mathbf{R} \cdot \mathbf{n}_{(t-2)}+\mathbf{Q} \cdot \mathbf{m}_{(t-1)}+\mathbf{r}$

$\mathbf{R}=\left[\begin{array}{ccccc}0 & 0.25 & 0.25 & 0.25 & 0.25 \\ 0 & 0 & 0 & 0 & 0 \\ 0 & 0 & 0 & 0 & 0 \\ 0 & 0 & 0 & 0 & 0\end{array}\right]$

$\mathbf{Q}=\left[\begin{array}{llll}0 & 0 & 0 & 0 \\ 1 & 0 & 0 & 0 \\ 0 & 1 & 0 & 0 \\ 0 & 0 & 1 & 0\end{array}\right]$, and

$\mathbf{r}^{\prime}=\left[\frac{1.43}{2.18} \cdot S_{\mathrm{TGC}, \mathrm{TFC}}+S_{\mathrm{M}} 0000\right]$ 
where $\mathbf{m}_{(0)}^{\prime}=\mathbf{m}_{(1)}^{\prime}=\left[\begin{array}{llll}0 & 0 & 0 & 0\end{array}\right]$.

\subsubsection{Breeding program with priority on improvement of the multiplier tier}

In this breeding program part of the multiplier tier was replaced annually but priority was put on improvement of the multiplier tier over the nucleus. For the multiplier tier $p=$ $\frac{175}{2125}=0.082, i=1.85$. For the nucleus $i=\frac{255 \cdot 1.67-175 \cdot 1.85}{80}=1.28$. Genetic selection differentials were expressed relative to $S_{\mathrm{TGC}, \mathrm{TFC}}$ and $S_{\mathrm{M}}$ in the nucleus in the baseline. Vector $\mathbf{n}_{(t)}$ was defined as in Eq. 1, where vector $\mathbf{s}$ was defined as:

$\mathbf{s}^{\prime}=\left[\frac{1.85}{2.18} \cdot S_{\mathrm{TGC}, \mathrm{TFC}}+S_{\mathrm{M}} \begin{array}{llll}0 & 0 & 0 & 0\end{array}\right]$.

Vector $\mathbf{m}_{(t)}$ was defined as in Eq. 9, where vector $\mathbf{r}$ was defined as:

$\mathbf{r}^{\prime}=\left[\frac{1.28}{2.18} \cdot S_{\mathrm{TGC}, \mathrm{TFC}}+S_{\mathrm{M}} 0000\right]$

\subsubsection{Breeding program without a multiplier tier}

This was a breeding program without a multiplier tier. We assumed that in the baseline breeding program the size of the nucleus was too small to supply production year round and expansion of the nucleus would relieve this constraint. Thus, the nucleus was expanded to 700 fish, consisting of four year classes of 175 fish each. Thus, $p=\frac{175}{2125}=0.082$ and $i$ $=1.85$. The number of parents per selection round was kept at 160 , hence some fish would not be used to produce selection candidates but only to supply production. The genetic selection differential was expressed relative to $S_{\mathrm{TGC}, \mathrm{TFC}}$ and $S_{\mathrm{M}}$ in the nucleus in the baseline. Vector $\mathbf{n}_{(t)}$ was defined as in Eq. 1, where vector $\mathbf{s}$ was defined as:

$\mathbf{s}^{\prime}=\left[\frac{1.85}{2.18} \cdot S_{\mathrm{TGC}, \mathrm{TFC}}+S_{\mathrm{M}} \begin{array}{llll}0 & 0 & 0 & 0\end{array}\right]$.

\subsubsection{Benefits and costs}

For breeding programs with a multiplier tier, benefits in year $t$ were calculated as the average of vector $\mathbf{m}_{(t-1)}$ multiplied by 5000 tons per year. For the breeding program without a multiplier tier benefits in year $t$ were calculated as the average of the last four elements of vector $\mathbf{n}_{(t-1)}$ multiplied by 5000 tons per year. For all breeding programs annual benefits were delayed by one extra year, which is approximately halfway between the total duration of larval rearing and grow out. 
Instead of considering initial investment and operational expenses separately, as in conventional cost-benefit analysis (e.g., Hill, 1971), all costs were converted to annual costs. By using annual costs, irregular investment costs were smoothed over time and the issue of financing is circumvented. The investment pattern and the way of financing are highly specific to individual companies, hence using annual costs instead of cash-flows improves general applicability of the analyses. Costs were estimated from bookkeeping records of Andromeda S.A.. Only costs specifically required for the breeding program were included, hence costs for reproduction that would also be necessary without a breeding program were excluded. For investments in buildings and tanks an annuity was calculated based on a lifetime of 20 years and an interest rate of 4.5\% (Moore et al., 2004). Buildings and tanks had salvage values of zero. Costs for husbandry of the nucleus included feed, daily care, and management of the breeding program. Costs for rearing selection candidates included separate rearing, tagging, handling, and quarantine of selected fish. Costs of separate rearing were calculated as the opportunity costs of selling selection candidates minus revenues from selling unselected fish at a discount. Costs of trait recording included all activities required to measure bodyweight. Costs of external services included genetic analysis with microsatellites for parentage assignment and consultancy. For the breeding program without a multiplier tier annual costs were reduced due to savings on broodstock facilities and husbandry costs. Costs were on average incurred halfway through the twoyear period required for rearing selection candidates, hence costs were incurred for the first time one year after initiation of a breeding program and every year thereafter.

\subsubsection{Cost-benefit analyses}

First, cost-benefit analyses were based on annual benefits and costs as of the start of the breeding program. The net present value was calculated as (Debertin, 2012):

$$
\operatorname{NPV}(t)=\sum_{j=0}^{t}\left(\left(\mathrm{~B}_{j}-\mathrm{C}\right) \cdot r^{j}\right)
$$

where $\mathrm{B}_{j}$ are benefits in year $j, \mathrm{C}$ are annual costs, which are constant over time, and $r$ is a discount factor calculated as $r=\frac{1}{1+d}$ where $d$ is the discount rate. Thus, NPV $(t)$ gives the sum of all discounted benefits minus the sum of all discounted costs as of the start of a breeding program up to a time horizon of $t$ years. The discount rate was set equal to a riskfree rate of return on private investment of $4.5 \%$ per year (Moore et al., 2004) plus a risk 
premium of $2 \%$ per year, summing to $6.5 \%$ per year (Bird and Mitchell, 1980). The NPV( $t$ ) was calculated up to a time horizon of 20 years.

Second, with the aim of explaining differences between breeding programs and for their later optimization, NPV was approximated algebraically as (based on Hill, 1971):

$$
\operatorname{NPV}_{\mathrm{appr}}(t)=\overline{\mathrm{B}} \cdot\left(\frac{r \cdot\left(r^{y}-r^{t}\right)}{(1-r)^{2}}-\frac{(t-y) \cdot r^{t+1}}{1-r}\right)-\mathrm{C} \cdot \frac{r-r^{t+1}}{1-r}
$$

where $\overline{\mathrm{B}}$ is the average increase in benefits per year and $y$ is the average delay between costs made for a selection round and resulting benefits. However, when the benefits of a selection round were incurred exactly was not self-evident. For breeding programs with a multiplier tier part of the benefits followed from the genetic selection differential in the multiplier tier and another part followed from the genetic selection differential in the nucleus, which was gradually transmitted to the multiplier tier in successive years. Furthermore, in the baseline breeding program, benefits increased only once every three years, instead of annually. To find $y$, Eq. 17 was solved for $\mathrm{NPV}_{\mathrm{appr}}(100)$, estimated by simulating the increase in genetic level to $\mathbf{n}_{(99)}$ and $\mathbf{m}_{(99)}$ using the gene flow model described above.

\subsubsection{Optimum number of selection candidates}

Results of the cost-benefit analyses were used to describe the relationship between profitability and number of selection candidates, length of the time horizon, and production output, and to estimate the optimum numbers of selection candidates. For the given index, breeding goal, and number of selected individuals, annual benefits were proportional to production output, genetic gain in TGC and TFC was proportional to $i$, and annual costs were assumed to be proportional to the number of selection candidates $(s c)$. The accuracy of selection increases when the number of full- and half-sib records increases, but this effect was ignored because it was of minor importance: doubling the number of full- and half-sib records increased the accuracy by less than $2 \%$. Genetic gain in $\mathrm{M}$ was independent of the number of selection candidates, because it was determined by the surviving proportion (Appendix 2). Rewriting Eq. 17 as a function of production output $P$ (tons/year), $i$, and $s c$, gives: 
$\mathrm{NPV}_{\mathrm{appr}}(t, P, i, s c)=\frac{P}{5000} \cdot\left(i \cdot \overline{\mathrm{B}}^{\prime}{ }_{\mathrm{TGC}, \mathrm{TFC}}+\overline{\mathrm{B}}_{\mathrm{M}}\right) \cdot\left(\frac{r \cdot\left(r^{y}-r^{t}\right)}{(1-r)^{2}}-\frac{(t-y) \cdot r^{t+1}}{1-r}\right)-s c \cdot \mathrm{C}^{\prime} \cdot$

$\frac{r-r^{t+1}}{1-r}$

where $\overline{\mathrm{B}}^{\prime}{ }_{\mathrm{TGC}, \mathrm{TFC}}$ is the average increase in annual benefits from genetic gain in TGC and TFC per unit of selection intensity $i, \overline{\mathrm{B}}_{\mathrm{M}}$ is the average increase in annual benefits from genetic gain in $\mathrm{M}$, and $\mathrm{C}^{\prime}$ are average annual costs per surviving selection candidate. From $s c, i$ can be approximated algebraically as (Smith, 1969):

$i=0.80+0.41 \cdot \ln (s c /$ sel -1$)$

where sel is 80 selected animals for breeding programs with multiplier tier and 175 for the breeding program without a multiplier tier. For simplicity, effects of $i$ on genetic variation were ignored. $\mathrm{NPV}_{\text {appr }}(t, P, i, s c)$ was calculated for a time horizon of 10 years, a production output of 5000 tons, and a range of selection candidates.

Investment was optimum when $\partial \mathrm{NPV}_{\mathrm{appr}}(t, P, i, s c) / \partial s c=0$ (Hill, 1971). From Eqs. 18 and 19 and $\partial \operatorname{NPV}_{\text {appr }}(t, P, i, s c) / \partial s c=0$ at optimum investment, optimum $s c\left(s c_{o p t}\right)$ was calculated (based on Hill, 1971):

$s c_{\text {opt }}=\frac{P}{5000} \cdot 0.41 \cdot \overline{\mathrm{B}}^{\prime}{ }_{\mathrm{TGC}, \mathrm{TFC}} \cdot\left(\frac{r \cdot\left(r^{y}-r^{t}\right)}{(1-r)^{2}}-\frac{(t-y) \cdot r^{t+1}}{1-r}\right) /\left(\mathrm{C}^{\prime} \cdot \frac{r-r^{t+1}}{1-r}\right)+$ sel.

The number of selection candidates was optimized for a production output of 5000 tons per year at varying time horizon lengths, and for varying production outputs at a time horizon of 10 years. Using these estimated optimum numbers of selection candidates, $\mathrm{NPV}_{\text {appr }}(t, P, i, s c)$ was estimated from Eq. 18, where $i$ was approximated from Eq. 19.

\subsection{Results}

\subsubsection{Genetic level over time}

For the nucleus in the baseline breeding program, genetic gain for each trait due to a single selection round is in Table 2 . The selection differential $(S)$ was $€ 198 /$ ton production, of which $€ 180 /$ ton was due to improvements in TGC and TFC $\left(S_{\mathrm{TGC}, \mathrm{TFC}}\right)$ and $€ 18 /$ ton was due to improvement in $\mathrm{M}\left(S_{\mathrm{M}}\right)$. Simulations in the bio-economic model resulted in a selection differential of $€ 197 /$ ton production, indicating that non-linearity and trait interactions were 
negligible. For comparison, the product price received by the fish farming company was $€ 4500 /$ ton.

Table 2 Genetic gain per trait due to a single selection round in the nucleus of the baseline breeding program.

\begin{tabular}{lcc}
\hline Trait & Genetic gain (trait units) & Genetic gain $(€ /$ ton production) \\
\hline TGC & 1.089 & 436 \\
TFC & 0.568 & -256 \\
M & -0.0023 & 18 \\
Total & & 198
\end{tabular}

TGC $=$ Thermal growth coefficient $\left(\mathrm{g}^{2 / 3} /(\right.$ day degrees $\left.\cdot 1000)\right)$

$\mathrm{TFC}=$ Thermal feed intake coefficient $\left(\mathrm{g}^{0.544} /(\right.$ day degrees $\left.\cdot 1000)\right)$

$\mathrm{M}=$ Mortality rate $(\% /$ day $)$

Mean genetic levels of the nucleus and multiplier tier over 10 years from the start of breeding programs are in Fig. 2. In the baseline breeding program the mean genetic level of the nucleus increased at a more or less constant rate, while the mean genetic level of the multiplier tier increased stepwise once every three years. For longer time horizons the increase in mean genetic levels approached $€ 56.5 /$ ton production per year in the nucleus and $€ 169 /$ ton production per three years in the multiplier tier. 

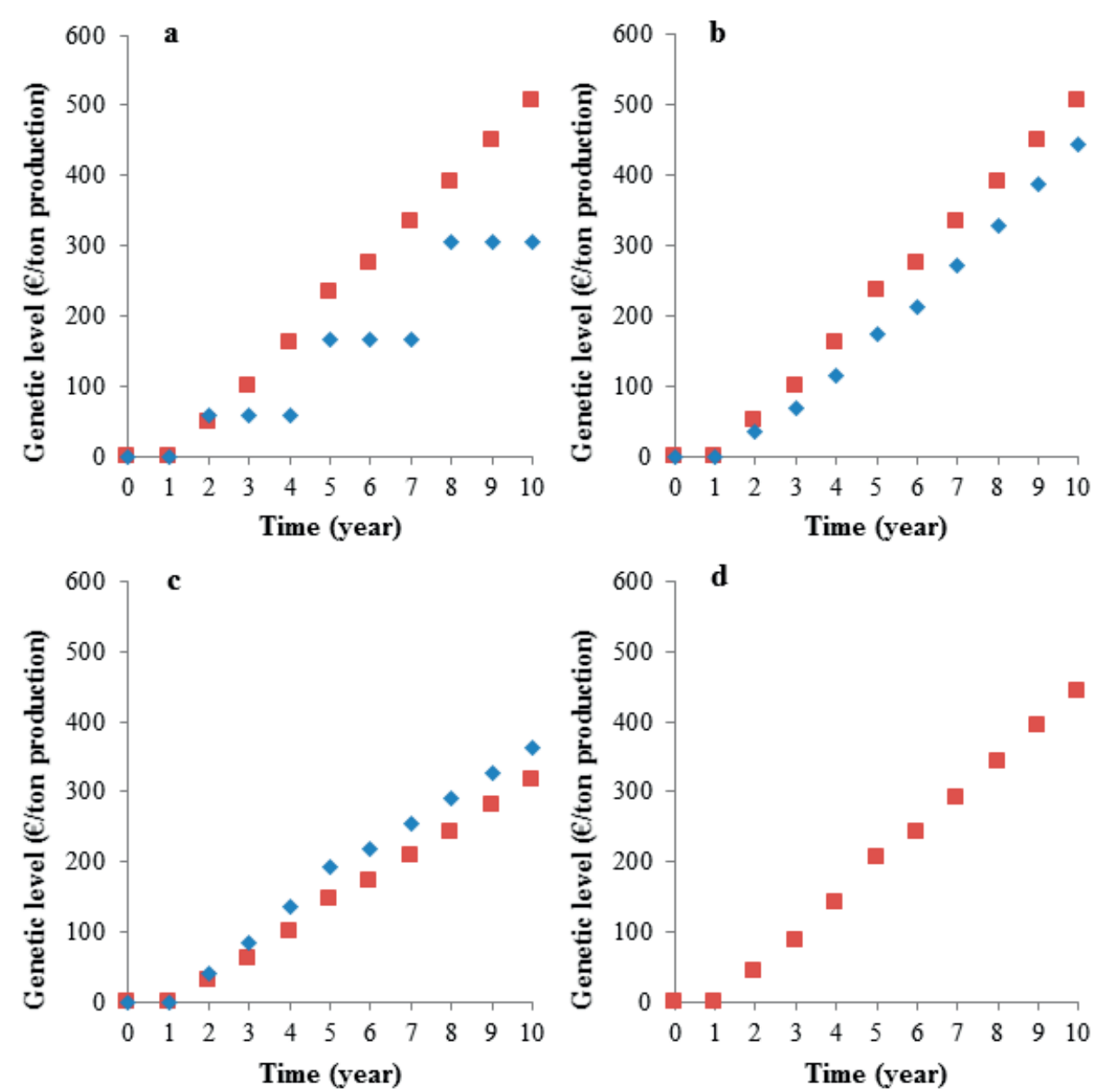

Fig. 2 The genetic level in the nucleus (red square) and multiplier tier (blue diamond) for the four breeding programs over time. a Baseline breeding program, b breeding program with annual multiplier tier replacement, $\mathbf{c}$ breeding program with priority on improvement of the multiplier tier, d breeding program without a multiplier tier.

Genetic levels of animals used in production over 20 years from the start of breeding programs are in Fig. 3. The genetic level of animals used in production was highest up to year 10 in the breeding program without a multiplier tier. Thereafter, the genetic level of the breeding program with annual multiplier tier replacement was highest. The genetic level of animals used in production was higher up to year 7 for the breeding program with priority on improvement of the multiplier tier than for both the baseline breeding program and the breeding program with annual multiplier tier replacement (with nucleus priority). 


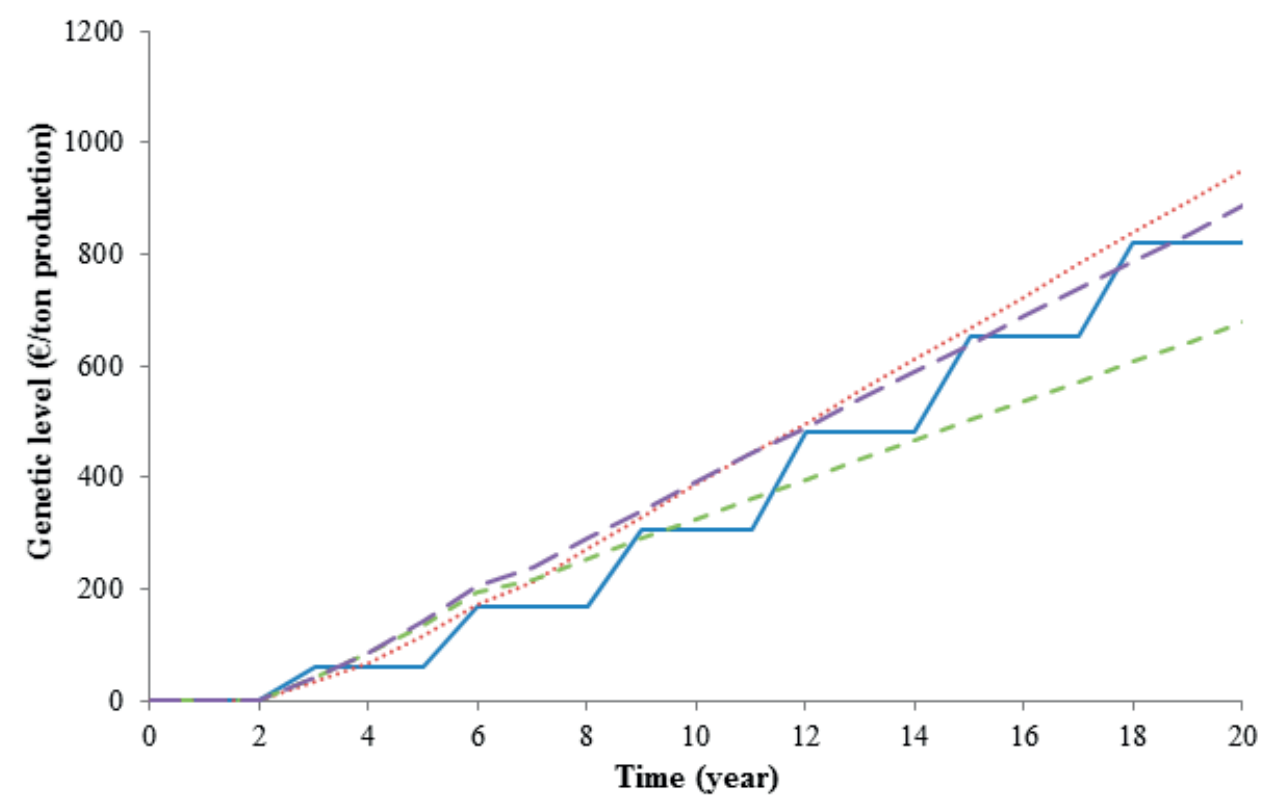

Fig. 3 The genetic level of animals used in production for the four breeding programs over time. Blue line: baseline breeding program, red dotted line: breeding program with annual multiplier tier replacement, green dashed line: breeding program with priority on improvement of the multiplier tier, violet dashed line: breeding program without a multiplier tier.

\subsubsection{Cost-benefit analyses}

Annual costs of the breeding programs are in Table 3, totalling €149,556/year for the breeding programs with a multiplier tier and $€ 127,845 /$ year for the breeding program without a multiplier tier.

Table 3. Annual costs of breeding programs

\begin{tabular}{lcc}
\hline Item & With multiplier tier $(€ /$ year) & Without a multiplier tier $(€ /$ year $)$ \\
\hline Buildings and tanks & 9844 & 3411 \\
Energy, oxygen, fuel & 16,658 & 16,658 \\
Husbandry nucleus & 23,442 & 10,000 \\
Rearing selection candidates & 10,916 & 9081 \\
Trait recording & 4196 & 4196 \\
External services & 84,500 & 84,500 \\
Total & 149,556 & 127,845 \\
\hline
\end{tabular}

For the baseline breeding program NPV became positive after five years, reached 2.9 million $€$ in year 10, and 13.6 million $€$ in year 20 (Fig. 4). The baseline breeding program had the lowest NPV up to year 17. After year 17 the breeding program with priority on improvement of the multiplier tier had the lowest NPV. The breeding program without a 
multiplier tier had the highest NPV up to year 22. After year 22 the breeding program with annual multiplier tier replacement had the highest NPV.

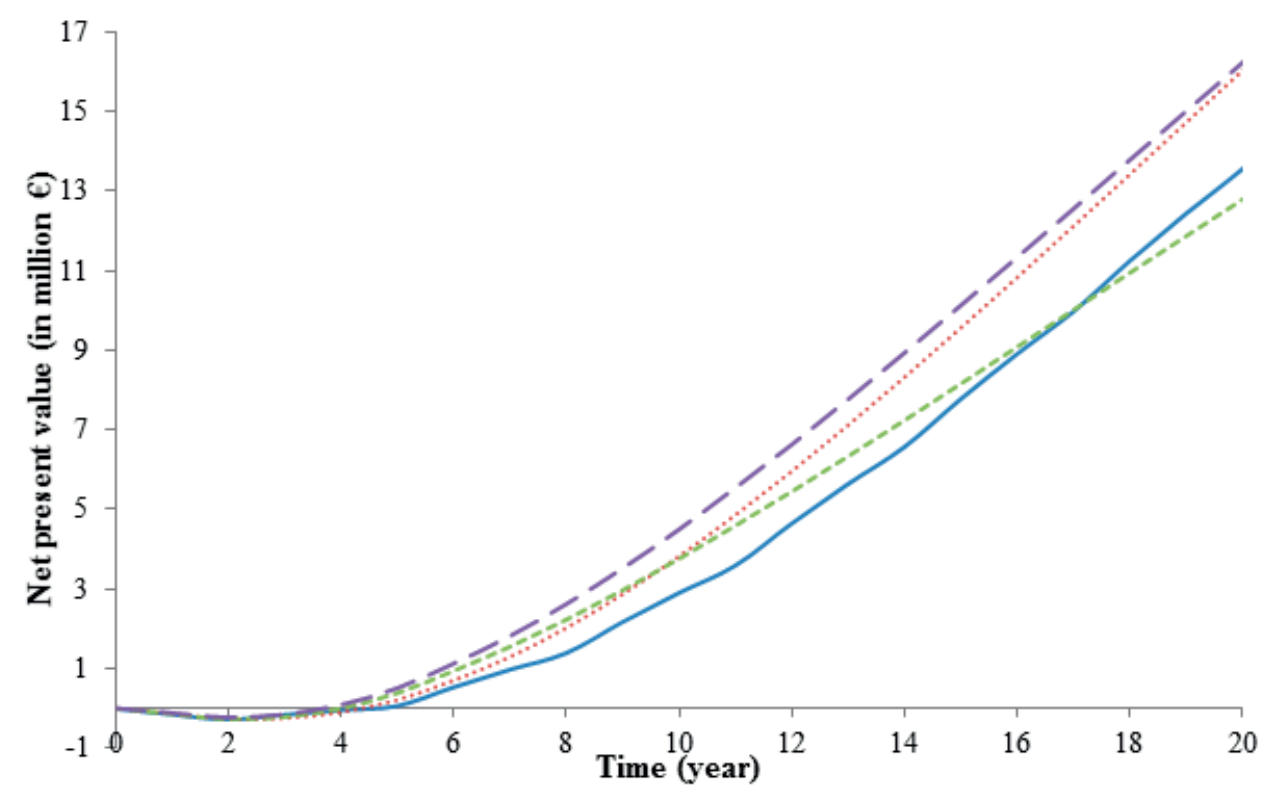

Fig. 4 Net present value of the four breeding programs over time. Blue line: baseline breeding program, red dotted line: breeding program with annual multiplier tier replacement, green dashed line: breeding program with priority on improvement of the multiplier tier, violet dashed line: breeding program without a multiplier tier.

For the baseline breeding program the average increase in annual benefits $(\overline{\mathrm{B}})$ over time approached $56.5 \cdot 5000=€ 282,000$ per year. The average delay $(y)$ between costs made for a selection round and resulting benefits was 4.2 years. $\operatorname{NPV}_{\mathrm{appr}}(t)$ could thus be calculated from Eq. 17 as:

$\mathrm{NPV}_{\text {appr }}(t)=282,000 \cdot\left(\frac{0.94 \cdot\left(0.76-0.94^{t}\right)}{0.0037}-\frac{(t-4.2) \cdot 0.94^{t+1}}{0.061}\right)-149,556 \cdot \frac{0.94-0.94^{t+1}}{0.061}$

For the breeding program with annual multiplier tier replacement, $y$ was 2.5 years and $\overline{\mathrm{B}}$ was $€ 282,000$ per year. For the breeding program with priority on improvement of the multiplier tier, $y$ was 0.4 years and $\overline{\mathrm{B}}$ was $€ 176,000$ per year. For the breeding program without a multiplier tier, $y$ was 2.1 years and $\bar{B}$ was $€ 247,000$ per year. 


\subsubsection{Optimum number of selection candidates}

For a 10-year time horizon and a production output of 5000 tons, $\operatorname{NPV}_{\text {appr }}(t, P, i, s c)$ increased with the number of selection candidates up to an optimum, after which it gradually decreased (Fig. 5). Optimum numbers of selection candidates were: 1218 in the baseline breeding program, 2015 in the breeding program with annual multiplier tier replacement, 1970 in the breeding program with priority on improvement of the multiplier tier, and 2756 in the breeding program without a multiplier tier. Any deviation from the optimum number of selection candidates was at the expense of NPV, although using too many selection candidates relative to the optimum led to a lower reduction of NPV than using too few selection candidates.

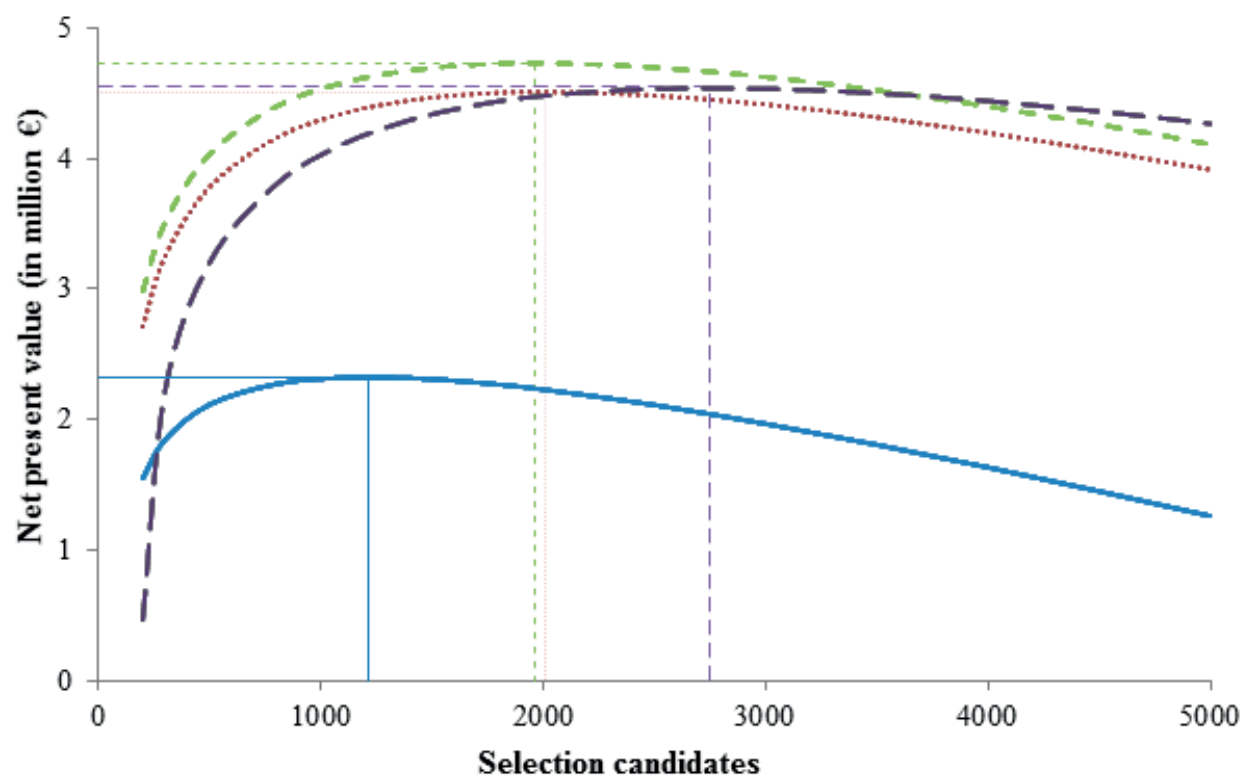

Fig. 5 Net present value for the four breeding programs as a function of the number of selection candidates for a time horizon of 10 years and production of 5000 tons/year. Horizontal and vertical line segments indicate optima. Blue line: baseline breeding program, red dotted line: breeding program with annual multiplier tier replacement, green dashed line: breeding program with priority on improvement of the multiplier tier, violet dashed line: breeding program without a multiplier tier. 
The optimum number of selection candidates increased with time horizon and production output, as presented in Fig. 6. Optimum numbers differed between breeding programs. The 2125 selection candidates in the baseline breeding program was optimum for a 14-year time horizon.
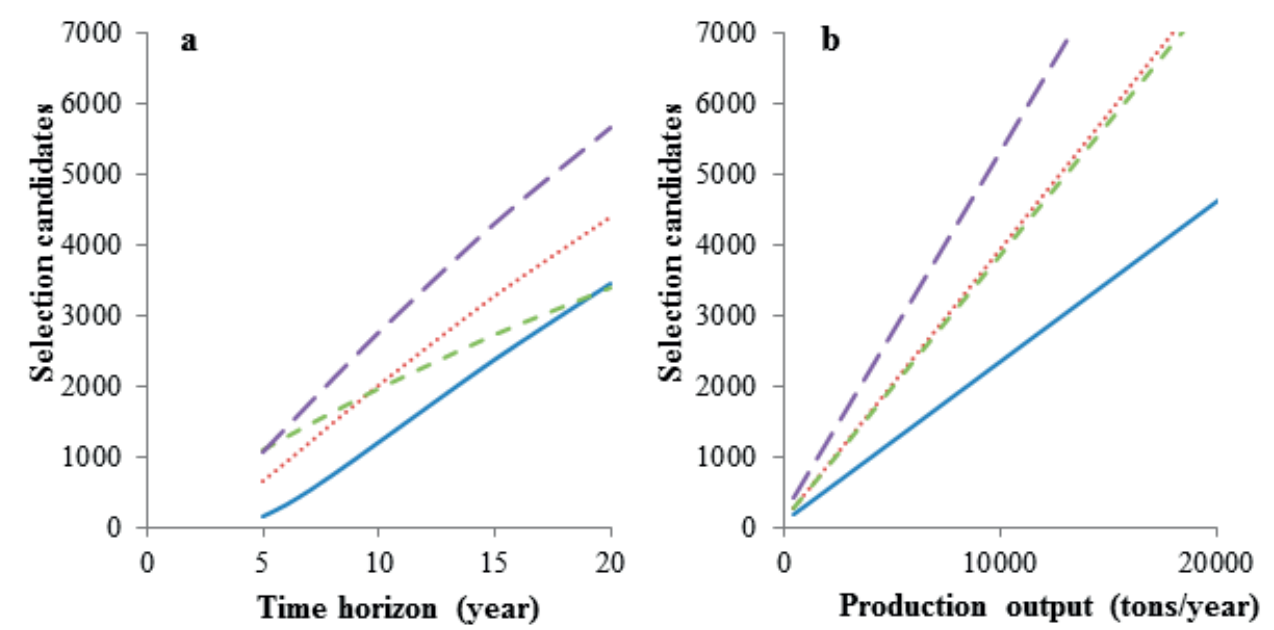

Fig. 6 Optimum number of selection candidates for the four breeding programs. a As function of length of the time horizon for a production of 5000 tons/year, $\mathbf{b}$ as function of production output for a time horizon of 10 years. Blue line: baseline breeding program, red dotted line: breeding program with annual multiplier tier replacement, green dashed line: breeding program with priority on improvement of the multiplier tier, violet dashed line: breeding program without a multiplier tier.

The NPV per breeding program for optimum numbers of selection candidates are in Fig. 7. With optimum numbers of selection candidates and a production output of 5000 tons (Fig. 7a), the breeding program with priority on improvement of the multiplier tier had the highest NPV up to year 10. Thereafter the breeding programs with annual multiplier tier replacement and without a multiplier tier were superior. With optimum numbers of selection candidates and a time horizon of 10 years (Fig. 7b), NPV was similar across breeding programs for any production output, except for the baseline breeding program, which had a much lower NPV. 

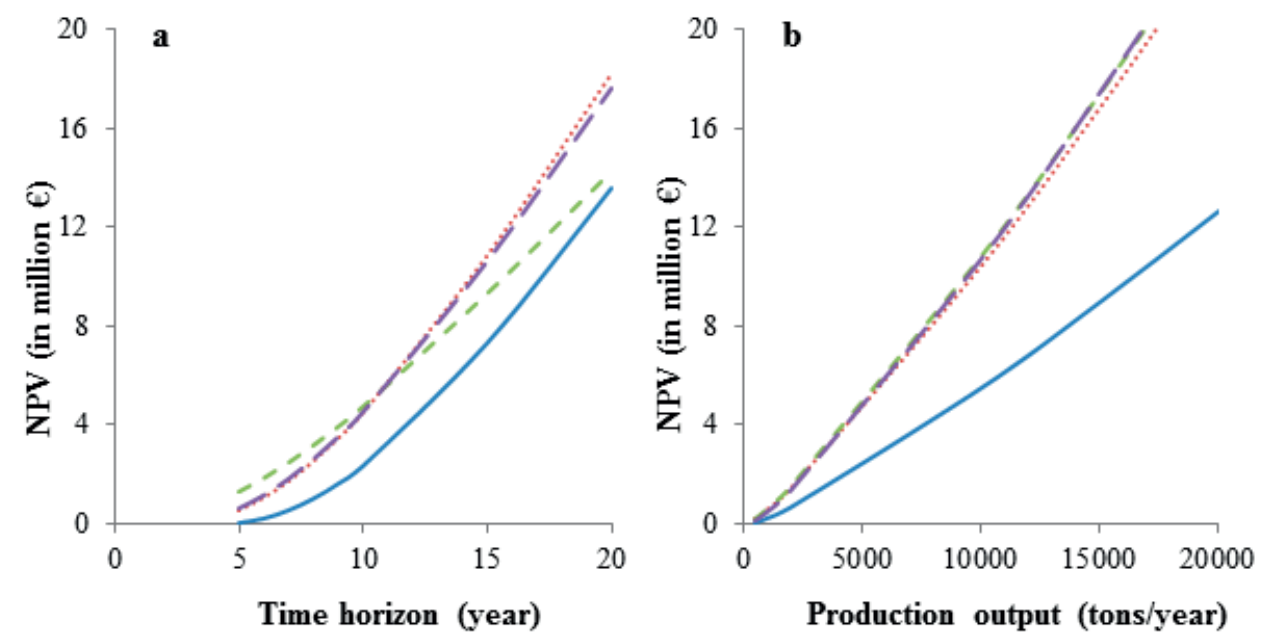

Fig. 7 Net present value (NPV) for the optimum number of selection candidates in the four breeding programs. a As function of length of the time horizon for a production of 5000 tons/year, $\mathbf{b}$ as function of production output for a time horizon of 10 years. Blue line: baseline breeding program, red dotted line: breeding program with annual multiplier tier replacement, green dashed line: breeding program with priority on improvement of the multiplier tier, violet dashed line: breeding program without a multiplier tier.

\subsection{Discussion}

\subsubsection{Cost-benefit analyses}

In the baseline breeding program, part of the multiplier tier was replaced only once every three years. Annual multiplier tier replacement results in a consistently higher NPV, because the average delay between costs made for a selection round and resulting benefits is shorter. In the short term putting priority on improvement of the multiplier tier over the nucleus resulted in a relatively fast increase in the average breeding value of animals used in production. This explained the higher NPV of the breeding program with priority on improvement of the multiplier tier for the first 9 years relative to the breeding program with annual multiplier tier replacement (with nucleus priority). In the long term however, the genetic level of animals used in production is determined by the genetic selection differential in the nucleus and putting priority on improvement of the multiplier tier is at the expense of the genetic selection differential in the nucleus. This explains the lower NPV in the long term of the breeding program with priority on improvement of the multiplier tier relative to the breeding program with annual multiplier tier replacement (with nucleus priority). 
A multiplier tier causes substantial delay in benefits from genetic improvement. Compared to the baseline breeding program and the breeding program with annual multiplier tier replacement, the breeding program without a multiplier tier had a lower genetic selection differential, but the average delay between costs made for a selection round and resulting benefits was shorter. The shorter delay more than compensated for the reduction in genetic selection differential, resulting in a higher NPV for the first 22 years. This has important implications for the design of breeding programs. In livestock species a multiplier tier is used to disseminate genetic progress, to exploit heterosis, and to create market-specific crosses. In aquaculture breeding programs selection in multiple pure lines is not common, except for carp (Chavanne et al., 2016), hence a multiplier tier does not offer any advantage with respect to heterosis or creation of specific line crosses. For most fish species, except salmonids, a multiplication tier is also not required to disseminate genetic progress, because, generally, fish have a high fecundity rate (Skagemo et al., 2010). Nevertheless, some integrated breeding companies use a multiplier tier, for example, to maintain a high level of biosecurity in the nucleus, and for flexibility in juvenile production. Such advantages should be weighed against the loss in NPV of having a multiplier tier.

Results for the optimum number of selection candidates illustrate the importance of production output and time horizon as design parameters for breeding programs. A higher production output and a longer time horizon generate higher benefits, which, in turn, warrant higher annual costs. When the number of selection candidates was optimized, the breeding program with priority on improvement of the multiplier tier had the highest NPV during the first 10 years but for time periods beyond this, other breeding programs were superior. These results demonstrate that re-ranking of breeding programs can occur with increasing time horizon. For the breeding programs considered no re-ranking occurred with increasing production output, regardless of the time horizon.

Our results apply specifically to integrated breeding companies. Nevertheless, investments in a breeding program must be cost effective also for specialized breeding companies, because budgets are always limited and competitiveness of a breeding company is determined by the genetic level of its products. On the one hand, specialized breeding companies often supply a relatively large proportion of the market compared to integrated breeding companies (Janssen et al., 2017a), which warrants relatively large investments in the breeding program. On the other hand, specialized breeding companies accrue only a 
proportion of benefits obtained from genetic improvement. Thus, for a given production output, the optimum level of investment in a breeding program by a specialized breeding company may be lower than for an integrated company. Ultimately, investment in a breeding program by specialized breeding companies is driven by the expected outcome of the complex dynamics between the genetic level of its products relative to the competition, market shares, and the extent to which premium products fetch premium prices (Dekkers et al., 1996).

For aquaculture breeding programs, only a few cost-benefit analyses have been performed (Ponzoni et al., 2007; Ponzoni et al., 2008; Zuniga-Jara and Marin-Riffo, 2014). In all these studies the profit equation that was used to derive economic values of traits did not provide an adequate description of the farming system (Janssen et al., 2017b). Thus, the resulting economic values led to biased estimates of gains in farm profit after genetic improvement, and benefits could not be accurately estimated. Ponzoni et al. (2007) and Ponzoni et al. (2008) performed cost-benefit analyses of national breeding programs for Nile tilapia and common carp, respectively. Because benefits of these programs were distributed nationwide, they were highly profitable. When genetic improvement is disseminated nationwide, most benefits will accrue to consumers, because in an open and competitive market, lower production costs will be followed by lower market prices of fish. This is different from our study, where genetic improvement affects only production costs of a single company. Zuniga-Jara and Marin-Riffo (2014) performed a cost-benefit analysis of a breeding program for abalone for an integrated company and their results were much less favourable than ours, largely because investments to expand production capacity were considered to be costs of the breeding program. The profitability of breeding programs in aquaculture has, in multiple occasions, been reviewed based on the (discounted) benefitcost ratio (e.g., Gjedrem, 1985; Gjedrem and Baranski, 2009; Rye et al., 2010). Although this ratio is appealing, it may not be an appropriate evaluation criterion for breeding programs, because it favours underinvestment. For example, decreasing the optimum number of selection candidates by $10 \%$ results in a higher benefit-cost ratio, whereas it is at the expense of NPV by definition.

\subsubsection{Genetic selection differential and rate of inbreeding}

Economic values used in this study were derived for a situation in which production output of a farm is limited by stocking density (Janssen et al., 2017b). Consequently, the genetic 
selection differential resulted from both a cost reduction per unit product and an increase in production output. Throughout Europe, different regulations apply that constrain production output of farms, and economic values depend on these quota (Besson et al., 2017). If the quota was on production output instead of stocking density, improvement of TGC would not increase production output. Consequently, the economic value of TGC and the genetic selection differential would be lower than in the current study. We also assumed that the increased production output due to genetic improvement did not affect the market price of fish. This assumption is justified when the relative increase in supply is small and slow, and is absorbed by increasing demand (FAO, 2016), i.e. when the company produces only a small fraction of the total supply. Moreover, any price effect would be similar for all alternative breeding programs compared, i.e. would have only a limited impact on their relative performance. Thus, in our view, this assumption is justified.

Estimation of the genetic selection differential was subject to some simplifications. Equal contributions of year classes in the nucleus were assumed, whereas skewed contributions could be expected because average breeding values of older year classes were lower than those of younger year classes. The rate of genetic gain would benefit from a larger contribution of parents from younger year classes with higher average breeding values. For example, the extreme case with maximal contributions from age classes 2 (males) and 4 (females) of the nucleus, such that $P_{1, j}=R_{1, j}=\left[\begin{array}{llll}0 & 0.5 & 0 & 0.5\end{array}\right]$ (top rows of Eqs. 2 and 6) resulted in a $2.6 \%$ higher NPV in year 10 . However, this would also result in an increase in the rate of inbreeding, but this could be controlled by balancing contributions of year classes. Thus, taking unequal contributions of year classes into account would make the prediction of the genetic selection differential unnecessarily complex.

The assumed genetic parameters imply that feed conversion ratio (FCR) improves as a correlated response to selection on TGC. However, there is some debate about the effect of selection on growth on FCR in fish, see review in (de Verdal et al., 2017). Although a reduction in FCR is expected, it is useful to predict the genetic selection differential when there is no correlated response in FCR. For the predicted genetic gain in TGC of 1.089 $\mathrm{g}^{2 / 3} /($ day degrees $\cdot 1000)$ (Table 2$)$ genetic gain in TFC was increased in the bio-economic model (Janssen et al., 2017b) up to the level that the resulting value of FCR was equal to FCR at levels of TGC and TFC before genetic improvement. The resulting value for genetic gain in TFC was $0.70 \mathrm{~g}^{0.544} /($ day degrees $\cdot 1000)$, which was higher than genetic gain in the 
baseline breeding program. Thus, this value for genetic gain in TFC may be considered the maximum correlated response for the predicted genetic gain in TGC. If there is no correlated response in FCR, the selection differential in the baseline breeding program would be $€ 137 /$ ton production, i.e. a reduction of $31 \%$.

For genetic gain in $\mathrm{M}$, we assumed own performance selection on binomial records (dead or alive), such that all surviving selection candidates had equal estimated breeding values for M. Genetic gain would be higher when family information would be used. With family information, all surviving selection candidates within a family would have equal estimated breeding values allowing for between family selection only. A possible correlated response in M from selection on TGC was ignored, leading to a conservative estimate of benefits due to improvement of $\mathrm{M}$. Traits that are genetically correlated to survival could be used in the index for within-family selection. Several studies have reported positive genetic correlations between growth rate and survival, indicating that growth rate can be used as a selection criterion to improve survival (Gitterle et al., 2005; Rye et al., 1990; Sae-Lim et al., 2013; Vehviläinen et al., 2012). These studies analysed only direct genetic effects and ignored indirect genetic effects on group mates, although these may explain a substantial part of the heritable variation (Bijma et al., 2007). A negative correlation of -0.79 between the direct genetic effect of survival and indirect genetic effect of growth rate in a competitive environment suggests that an individual that has a high breeding value for survival will have a negative effect on the growth rate of its group mates (Khaw et al., 2016). Similarly, competition may also lead to a negative correlation between the direct genetic effect of growth rate and the indirect genetic effect of survival, but as far as we know, this correlation has not been studied in fish. A negative correlation between the direct genetic effect of growth and indirect genetic effect of survival would imply that faster growth in one fish may be at the expense of survival of its group mates. In case of competition this correlation may be antagonistic to the correlation between the direct genetic effects of growth and survival. Thus, when indirect genetic effects are ignored, correlated response in survival when selecting on growth rate may be overestimated. Because we ignored a potential negative correlation between the direct genetic effect of growth and indirect genetic effect of survival, we also ignored the positive correlation between the direct genetic effects of growth and survival. 
The breeding program of Andromeda S.A. is used to supply many different production sites across the Mediterranean. Thus, conditions for rearing selection candidates differ from those in production, which may cause genotype-by-environment interactions. Differences in the temperature regime at different sites can affect economic values of traits (Besson et al., 2016) and absolute changes in economic values directly affect the genetic selection differential. Both genotype-by-environment interaction and changes in relative economic values would lead to re-ranking of selection candidates, which would decrease the genetic selection differential. Furthermore, the genetic selection differential was assumed to be constant over generations. In reality, this is unlikely, because both genetic gain in individual traits and economic values may be non-linear over multiple generations. On the one hand, genetic gains in TGC and TFC were based on equilibrium genetic parameters, based on the Bulmer effect, hence the genetic selection differential we used is conservative for the first generations. On the other hand, genetic gain in $\mathrm{M}$ is assumed to be constant, whereas constant genetic gain on the liability scale of cumulative mortality results in exponentially decreasing genetic gain on the observed scale for $\mathrm{M}$. Thus, the genetic selection differential due to improvement of $\mathrm{M}$ would decrease over generations.

Each parental pair was assumed to have the same chance to produce offspring. In reality, the numbers of offspring per parent are skewed, which would increase the rate of inbreeding. Rate of inbreeding is managed by a mating design that controls parental contributions to replacement stock. Measures to control the rate of inbreeding may reduce the genetic selection differential. Compared to the baseline breeding program, all alternative breeding programs had an equal number of parents per selection round, an equal number of selection candidates, and an equal or lower selection intensity. Thus, each breeding program evaluated had similar or lower rates of inbreeding than the baseline breeding program. 


\subsection{Conclusions}

The baseline breeding program had a positive net present value after five years and was highly profitable thereafter. For a short time horizon putting priority on improvement of the multiplier tier over the nucleus is more profitable than putting priority on nucleus improvement, and vice versa for a long time horizon. Use of a multiplier tier increases the delay between costs made for selection and resulting benefits. Thus, avoiding the use of a multiplier tier will increase the profitability of the breeding program in the short term. The number of selection candidates can be optimized to maximize net present value of a breeding program and this optimum increases with the length of the time horizon and production output. Using too many selection candidates relative to the optimum leads to less reduction in profitability than using too few selection candidates.

\subsection{Acknowledgements}

We are grateful for the information and data provided by Andromeda S.A.. We thank the reviewers for the thorough review and constructive comments.

\subsection{Appendices}

\subsubsection{Appendix 1: Genetic parameters of TGC and TFC}

Coefficients and calculations are based on Janssen et al. (2017b). For TGC genetic variance $\left(\sigma_{\mathrm{A}, \mathrm{TGC}}^{2}\right)$ and phenotypic variance $\left(\sigma_{\mathrm{P}, \mathrm{TGC}}^{2}\right)$ were estimated from variation in harvest weight (HW) and sum of effective temperatures at harvest, which was 4084 day degrees. For bodyweight a genetic coefficient of variation of $10.6 \%$ and heritability of 0.34 were assumed (Navarro et al., 2009). Mean harvest weight $\left(\mu_{\mathrm{HW}}\right)$ was $400 \mathrm{~g}$, hence genetic variance $\left(\sigma_{\mathrm{A}, \mathrm{HW}}^{2}\right)$ was $1798 \mathrm{~g}^{2}$ and phenotypic variance $\left(\sigma_{\mathrm{P}, \mathrm{HW}}^{2}\right)$ was $5288 \mathrm{~g}^{2}$. Genetic and phenotypic distributions of $\mathrm{HW}$ were simulated in $\mathrm{R}$ as $\mathrm{HW}_{\mathrm{A}, n}=\mu_{\mathrm{HW}}+z_{n} \cdot \sigma_{\mathrm{A}, \mathrm{HW}}$ and $\mathrm{HW}_{\mathrm{P}, n}=\mu_{\mathrm{HW}}+z_{n} \cdot \sigma_{\mathrm{P}, \mathrm{HW}}$, where subscripts $\mathrm{A}$ and $\mathrm{P}$ indicate genetic and phenotypic, and $z_{n}$ was a random number drawn from a standard normal distribution $\left(z_{n} \sim \mathrm{N}(0,1)\right)$ with $n=1, \ldots, 10^{6}$. From these distributions $\sigma_{\mathrm{A}, \mathrm{TGC}}^{2}$ and $\sigma_{\mathrm{P}, \mathrm{TGC}}^{2}$ were estimated as:

$$
\begin{aligned}
& \sigma_{\mathrm{A}, \mathrm{TGC}}^{2} \approx \operatorname{Var}\left(\mathrm{TGC}_{\mathrm{A}, n}\right) \approx\left(\frac{1000}{4084}\right)^{2} \cdot \operatorname{Var}\left(\mathrm{HW}_{\mathrm{A}, n}{ }^{2 / 3}\right)=\left(\frac{1000}{4084}\right)^{2} \cdot \frac{1}{10^{6}-1} \cdot \sum_{i=1}^{10^{6}}\left(\mathrm{HW}_{\mathrm{A}, i}{ }^{2 / 3}-\right. \\
& \left.400^{2 / 3}\right)^{2}=0.887\left(\mathrm{~g}^{2 / 3} /(\text { day degrees } \cdot 1000)\right)^{2}, \text { and } \\
& \sigma_{\mathrm{P}, \mathrm{TGC}}^{2} \approx \operatorname{Var}\left(\mathrm{TGC}_{\mathrm{P}, n}\right) \approx\left(\frac{1000}{4084}\right)^{2} \cdot \operatorname{Var}\left(\mathrm{HW}_{\mathrm{P}, n}{ }^{2 / 3}\right)=\left(\frac{1000}{4084}\right)^{2} \cdot \frac{1}{10^{6}-1} \cdot \sum_{i=1}^{10^{6}}\left(\mathrm{HW}_{\mathrm{P}, i}{ }^{2 / 3}-\right. \\
& \left.400^{2 / 3}\right)^{2}=2.64\left(\mathrm{~g}^{2 / 3} /(\text { day degrees } \cdot 1000)\right)^{2} .
\end{aligned}
$$


For TFC genetic variance $\left(\sigma_{\mathrm{A}, \mathrm{TGC}}^{2}\right)$ and phenotypic variance $\left(\sigma_{\mathrm{P}, \mathrm{TGC}}^{2}\right)$ were estimated from variation in stocking weight (SW) and variation in cumulative feed intake (CFI). Mean stocking weight $\left(\mu_{\mathrm{SW}}\right)$ was $4.4 \mathrm{~g}$, hence genetic variance $\left(\sigma_{\mathrm{A}, \mathrm{SW}}^{2}\right)$ was $0.22 \mathrm{~g}^{2}$ and phenotypic variance $\left(\sigma_{\mathrm{P}, \mathrm{SW}}^{2}\right)$ was $0.64 \mathrm{~g}^{2}$. Genetic and phenotypic distributions of SW were simulated in $\mathrm{R}$ as $\mathrm{SW}_{\mathrm{A}, n}=\mu_{\mathrm{SW}}+z_{n} \cdot \sigma_{\mathrm{A}, \mathrm{SW}}$ and $\mathrm{SW}_{\mathrm{P}, n}=\mu_{\mathrm{SW}}+z_{n} \cdot \sigma_{\mathrm{P}, \mathrm{HW}}$, where subscripts $\mathrm{A}$ and $\mathrm{P}$ indicate genetic and phenotypic, and $z_{n}$ was a random number drawn from a standard normal distribution $\left(z_{n} \sim \mathrm{N}(0,1)\right)$ with $n=1, \ldots, 10^{6}$. Genetic and phenotypic correlations between SW and HW were assumed to be zero (Rutten et al., 2005). Between HW and CFI, a genetic correlation $\left(r_{\mathrm{A}}\right)$ of 0.9 and phenotypic correlation $\left(r_{\mathrm{P}}\right)$ of 0.8 were assumed (Kause et al., 2006; Quinton et al., 2007). The regression of CFI on gain in bodyweight $\left(b_{\mathrm{CFI}, \mathrm{HW}-\mathrm{SW}}\right)$ had a coefficient of $1.75 \mathrm{~g}$ feed/g gain and an intercept of $20 \mathrm{~g}$ feed. For CFI genetic variance $\left(\sigma_{\mathrm{A}, \mathrm{CFI}}^{2}\right)$ and phenotypic variance $\left(\sigma_{\mathrm{P}, \mathrm{CFI}}^{2}\right)$ were calculated as:

$$
\begin{aligned}
& \sigma_{\mathrm{A}, \mathrm{CFI}}^{2} \approx\left(\frac{b_{\mathrm{CFI}, \mathrm{HW}-\mathrm{SW}}}{r_{\mathrm{A}}}\right)^{2} \cdot \sigma_{\mathrm{A}, \mathrm{HW}}^{2}=\left(\frac{1.75}{0.9}\right)^{2} \cdot 1798=6797 \mathrm{~g}^{2}, \text { and } \\
& \sigma_{\mathrm{P}, \mathrm{CFI}}^{2} \approx\left(\frac{b_{\mathrm{CFI}, \mathrm{HW}-\mathrm{SW}}}{r_{\mathrm{P}}}\right)^{2} \cdot \sigma_{\mathrm{P}, \mathrm{HW}}^{2}=\left(\frac{1.75}{0.8}\right)^{2} \cdot 5288=25,301 \mathrm{~g}^{2} .
\end{aligned}
$$

Genetic and phenotypic distributions of CFI were simulated in R as:

$$
\begin{aligned}
& \mathrm{CFI}_{\mathrm{A}, n}=1.75 \cdot\left(\mathrm{HW}_{\mathrm{A}, n}-\mathrm{SW}_{\mathrm{A}, n}\right)+20+z_{n} \cdot \sigma_{\mathrm{A}, \mathrm{CFI}} \cdot \sqrt{1-r_{\mathrm{A}}^{2}}, \text { and } \\
& \mathrm{CFI}_{\mathrm{P}, n}=1.75 \cdot\left(\mathrm{HW}_{\mathrm{P}, n}-\mathrm{SW}_{\mathrm{P}, n}\right)+20+z_{n} \cdot \sigma_{\mathrm{P}, \mathrm{CFI}} \cdot \sqrt{1-r_{\mathrm{P}}^{2}},
\end{aligned}
$$

where $z_{n}$ was a random number drawn from a standard normal distribution $\left(z_{n} \sim \mathrm{N}(0,1)\right)$ with $n=1, \ldots, 10^{6}$. Negative values of $\mathrm{CFI}_{\mathrm{P}, n}$ were removed $(n=3)$. From these distributions $\sigma_{\mathrm{A}, \mathrm{TFC}}^{2}$ and $\sigma_{\mathrm{P}, \mathrm{TFC}}^{2}$ were estimated as:

$$
\begin{aligned}
& \sigma_{\mathrm{A}, \mathrm{TFC}}^{2} \approx \operatorname{Var}\left(\mathrm{TFC}_{\mathrm{A}, n}\right)=\operatorname{Var}\left(1000 \cdot \frac{\left(\mathrm{CFI}_{\mathrm{A}, n}+\mathrm{SW}_{\mathrm{A}, n}\right)^{0.544}-\mathrm{SW}_{\mathrm{A}, n}{ }^{0.544}}{4084}\right) \\
& =\left(\frac{1000}{4084}\right)^{2} \cdot \frac{1}{10^{6}-1} \cdot \sum_{i=1}^{10^{6}}\left(\left(\mathrm{CFI}_{\mathrm{A}, i}+\mathrm{SW}_{\mathrm{A}, i}\right)^{0.544}-\mathrm{SW}_{\mathrm{A}, i}{ }^{0.544}-\left((713+4.4)^{0.544}-\right.\right. \\
& \left.\left.4.4^{0.544}\right)\right)^{2}=0.304\left(\mathrm{~g}^{0.544} /\left(1000^{\circ} \mathrm{C} \text { days }\right)\right)^{2}, \text { and }
\end{aligned}
$$




$$
\begin{aligned}
& \sigma_{\mathrm{P}, \mathrm{TFC}}^{2} \approx \operatorname{Var}\left(\mathrm{TFC}_{\mathrm{P}, n}\right)=\operatorname{Var}\left(1000 \cdot \frac{\left(\mathrm{CFI}_{\mathrm{P}, n}+\mathrm{SW}_{\mathrm{P}, n}\right)^{0.544}-\mathrm{SW}_{\mathrm{P}, n}{ }^{0.544}}{4084}\right) \\
& =\left(\frac{1000}{4084}\right)^{2} \cdot \frac{1}{10^{6}-4} \cdot \sum_{i=1}^{10^{6}-3}\left(\left(\mathrm{CFI}_{\mathrm{P}, i}+\mathrm{SW}_{\mathrm{P}, i}\right)^{0.544}-\mathrm{SW}_{\mathrm{A}, i}{ }^{0.544}-\left((713+4.4)^{0.544}-\right.\right. \\
& \left.\left.4.4^{0.544}\right)\right)^{2}=1.17\left(\mathrm{~g}^{0.544} /\left(1000^{\circ} \mathrm{C} \text { days }\right)\right)^{2} .
\end{aligned}
$$

Heritabilities of TGC and TFC were calculated as $h^{2}=\frac{\sigma_{\mathrm{A}}^{2}}{\sigma_{\mathrm{P}}^{2}}$. Genetic and phenotypic correlations between TGC and TFC were confirmed to be equal to $r_{\mathrm{A}}$ and $r_{\mathrm{P}}$ between HW and CFI.

\subsubsection{Appendix 2: Selection response in $M$}

On the underlying liability scale of cumulative mortality (CM), heritability $\left(h^{2}\right)$ was assumed to be 0.17 (Vehvilainen et al., 2008), hence the genetic standard deviation $\left(\sigma_{\mathrm{A}}\right)$ was equal to $\sqrt{0.17}$. Before genetic improvement, the deviation of the threshold from the mean $\left(x_{B}\right)$ was calculated from the quantile function of a normal distribution in $\mathrm{R}$ as:

$x_{B}=\operatorname{qnorm}(0.149)=-1.04$.

For mass selection on $\mathrm{CM}, p=\frac{2125}{2500}=0.85$, hence $i=-0.27$. The deviation of the threshold from the mean after one generation of selection $\left(x_{A}\right)$ was equal to:

$x_{A}=x_{B}+i \cdot r_{I H} \cdot \sigma_{A}=-1.04-0.27 \cdot \sqrt{0.17} \cdot \sqrt{0.17}=-1.08$.

On the observed scale, CM after selection was calculated from the distribution function of a normal distribution in $\mathrm{R}$ as:

$\mathrm{CM}=\operatorname{pnorm}\left(x_{A}\right) \cdot 100 \%=\operatorname{pnorm}(-1.08) \cdot 100 \%=13.9 \%$,

hence $\mathrm{M}$ after one generation of selection was equal to:

$M=\left(1-\left(1-\frac{13.9}{100}\right)^{\frac{1}{540-1}}\right) \cdot 100=0.0278 \% /$ day

Thus, for the first selected generation, the response to selection on $\mathrm{M}$ was equal to $0.0278-0.0301=-0.0023 \%$ day. For simplicity, the same response was assumed for successive generations. 


\subsubsection{List of abbreviations}

\begin{tabular}{|c|c|}
\hline Abbreviation & Definition \\
\hline $\mathrm{B}$ & Benefits in a given year $(€)$ \\
\hline$\overline{\mathrm{B}}$ & Average increase in annual benefits ( $€ /$ year) \\
\hline$\overline{\mathrm{B}}^{\prime}{ }_{\mathrm{TGC}, \mathrm{TFC}}$ & $\begin{array}{l}\text { Average increase in annual benefits from genetic gain in TGC and TFC per unit } \\
\text { of } i(€ / \text { year) }\end{array}$ \\
\hline$\overline{\mathrm{B}}_{\mathrm{M}}$ & Average increase in annual benefits from genetic gain in $\mathrm{M}(€ /$ year $)$ \\
\hline $\mathrm{C}^{\prime}$ & Average annual costs per surviving selection candidate (€/year) \\
\hline$d$ & Discount rate $(\% /$ year $)$ \\
\hline$i$ & Selection intensity \\
\hline M & Mortality rate (\%/day) \\
\hline NPV & Net present value $(€)$ \\
\hline $\mathrm{NPV}_{\mathrm{appr}}$ & Algebraically approximated NPV $(€)$ \\
\hline$p$ & Selected proportion \\
\hline $\mathrm{P}$ & Production output (tons/year) \\
\hline$r$ & Discount factor \\
\hline$s c$ & Selection candidates \\
\hline$s c_{\text {opt }}$ & Optimum number of selection candidates \\
\hline sel & Number of selected animals \\
\hline$S$ & Genetic selection differential ( $€ /$ selection round) \\
\hline$S_{\mathrm{M}}$ & Genetic selection differential due to improvement of $\mathrm{M}(€ /$ selection round) \\
\hline$S_{\mathrm{TGC}, \mathrm{TFC}}$ & $\begin{array}{l}\text { Genetic selection differential due to improvement of TGC and TFC ( } € / \text { selection } \\
\text { round) }\end{array}$ \\
\hline$t$ & Time (year) \\
\hline TGC & Thermal growth coefficient $\left(\mathrm{g}^{2 / 3} /(\right.$ day degrees $\left.\cdot 1000)\right)$ \\
\hline TFC & Thermal feed intake coefficient $\left(\mathrm{g}^{0.544} /(\right.$ day degrees $\left.\cdot 1000)\right)$ \\
\hline$y$ & $\begin{array}{l}\text { Average delay between costs made for a selection round and resulting benefits } \\
\text { (year) }\end{array}$ \\
\hline
\end{tabular}




\subsection{References}

Besson, M., Vandeputte, M., van Arendonk, J.A.M., Aubin, J., de Boer, I.J.M., Quillet, E., Komen, H., 2016. Influence of water temperature on the economic value of growth rate in fish farming: The case of sea bass (Dicentrarchus labrax) cage farming in the Mediterranean. Aquaculture. 462, 47-55.

Besson, M., de Boer, I.J.M., Vandeputte, M., van Arendonk, J.A.M., Quillet, E., Komen, H., Aubin, J., 2017. Effect of production quotas on economic and environmental values of growth rate and feed efficiency in sea cage fish farming. Plos One. 12.

Bichard, M., 1971. Dissemination of genetic improvement through a livestock industry. Anim Prod. 13, 401-411.

Bijma, P., Muir, W.M., Ellen, E.D., Wolf, J.B., Van Arendonk, J.A.M., 2007. Multilevel Selection 2: Estimating the Genetic Parameters Determining Inheritance and Response to Selection. Genetics. 175, 289-299.

Bird, P.J.W.N., Mitchell, G., 1980. The choice of discount rate in animal breeding investment appraisal. Anim Breed Abstr. 48, 499-505.

Chavanne, H., Janssen, K., Hofherr, J., Contini, F., Haffray, P., Komen, H., Nielsen, E.E., Bargelloni, L., 2016. A comprehensive survey on selective breeding programs and seed market in the European aquaculture fish industry. Aquacult Int. 24, 1287-1307.

de Verdal, H., Komen, H., Quillet, E., Chatain, B., Allal, F., Benzie, J.A.H., Vandeputte, M., 2017. Improving feed efficiency in fish using selective breeding: a review. Rev Aquac. 10, 1-19.

De Vries, A.G., 1989. A method to incorporate competitive position in the breeding goal. Anim Prod. 48, 221-227.

Debertin, D.L., 2012. Agricultural Production Economics.

Dekkers, J., Mathur, P.K., Knol, E.F., 2011. Genetic improvement of the pig. in: Rothschild, M.F., Ruvinsky, A. (Eds.), The genetics of the pig, 390-425.

Dekkers, J., Gibson, J.P., Bijma, P., Van Arendonk, J.A.M., 2004. Gene Flow, Discounting and Investment Appraisal. Design and optimization of animal breeding programmes. In: Proceeding of animal breeding strategies course. Wageningen, The Netherlands.

Dekkers, J.C.M., Vandervoort, G.E., Burnside, E.B., 1996. Optimal Size of Progeny Groups for Progeny-Testing Programs by Artificial Insemination Firms. J Dairy Sci. 79, 2056-2070.

EAS-EATiP, 2014. Performance of the sea bass and sea bream sector in the Mediterranean. Aquaculture Europe, San Sebastian.

FAO, 2016. The State of World Fisheries and Aquaculture. FAO, Rome, 200.

Gitterle, T., Rye, M., Salte, R., Cock, J., Johansen, H., Lozano, C., Arturo Suárez, J., Gjerde, B., 2005. Genetic (co)variation in harvest body weight and survival in Penaeus (Litopenaeus) vannamei under standard commercial conditions. Aquaculture. 243, 83-92.

Gjedrem, T., 1985. Improvement of productivity through breeding schemes. GeoJournal. 10, 233241.

Gjedrem, T., Baranski, M., 2009. Selective Breeding in Aquaculture: an Introduction. Springer, Dordrecht Heidelberg London New York.

Gura, S., 2007. Livestock Genetics Companies. Concentration and proprietary strategies of an emerging power in the global food economy., League for Pastoral Peoples and Endogenous Livestock Development, Ober-Ramstadt.

Hill, W.G., 1971. Investment appraisal for national breeding programmes. Anim Prod. 13, 37-50.

Hill, W.G., 1974. Prediction and evaluation of response to selection with overlapping generations. Anim Prod. 18, 117-139.

Janssen, K., Chavanne, H., Berentsen, P., Komen, H., 2017a. Impact of selective breeding on European aquaculture. Aquaculture. 472, 8-16.

Janssen, K., Berentsen, P., Besson, M., Komen, H., 2017b. Derivation of economic values for production traits in aquaculture species. Genet Sel Evol. 49, 5.

Kause, A., Tobin, D., Houlihan, D.F., Martin, S.A.M., Mäntysaari, E.A., Ritola, O., Ruohonen, K., 2006. Feed efficiency of rainbow trout can be improved through selection: Different genetic potential on alternative diets. J Anim Sci. 84, 807-817. 
Khaw, H.L., Ponzoni, R.W., Yee, H.Y., Aziz, M.A.b., Bijma, P., 2016. Genetic and non-genetic indirect effects for harvest weight in the GIFT strain of Nile tilapia (Oreochromis niloticus). Aquaculture. 450, 154-161.

Mishan, E.J., Quah, E., 2007. Cost Benefit Analysis - Fifth Edition. Routledge.

Moav, R., 1973. Economic evaluation of genetic differences. in: Moav, R. (Ed.), Agricultural Genetics, 319-352.

Moore, M.A., Boardman, A.E., Vining, A.R., Weimer, D.L., Greenberg, D.H., 2004. "Just give me a number!" Practical values for the social discount rate. J. Pol. Anal. Manage. 23, 789-812.

Navarro, A., Zamorano, M.J., Hildebrandt, S., Ginés, R., Aguilera, C., Afonso, J.M., 2009. Estimates of heritabilities and genetic correlations for growth and carcass traits in gilthead seabream (Sparus auratus L.), under industrial conditions. Aquaculture. 289, 225-230.

Ponzoni, R.W., Nguyen, N.H., Khaw, H.L., 2007. Investment appraisal of genetic improvement programs in Nile tilapia (Oreochromis niloticus). Aquaculture. 269, 187-199.

Ponzoni, R.W., Nguyen, N.H., Khaw, H.L., Ninh, N.H., 2008. Accounting for genotype by environment interaction in economic appraisal of genetic improvement programs in common carp Cyprinus carpio. Aquaculture. 285, 47-55.

Quinton, C.D., Kause, A., Koskela, J., Ritola, O., 2007. Breeding salmonids for feed efficiency in current fishmeal and future plant-based diet environments. Genet Sel Evol. 39, 431-446.

Rutten, M.J.M., Komen, H., Bovenhuis, H., 2005. Longitudinal genetic analysis of Nile tilapia (Oreochromis niloticus L.) body weight using a random regression model. Aquaculture. 246, 101-113.

Rutten, M.J.M., Bijma, P., Woolliams, J.A., van Arendonk, J.A.M., 2002. SelAction: Software to predict selection response and rate of inbreeding in livestock breeding programs. J Hered. 93, 456-458.

Rye, M., Lillevik, K.M., Gjerde, B., 1990. Survival in early life of Atlantic salmon and rainbow trout: estimates of heritabilities and genetic correlations. Aquaculture. 89, 209-216.

Rye, M., Gjerde, B., Gjedrem, T., 2010. Genetic Improvement Programs For Aquaculture Species In Developed Countries. In: 9th World Congress on Genetics Applied to Livestock Production. Leipzig, Germany.

Sae-Lim, P., Komen, H., Kause, A., Martin, K.E., Crooijmans, R., van Arendonk, J.A.M., Parsons, J.E., 2013. Enhancing selective breeding for growth, slaughter traits and overall survival in rainbow trout (Oncorhynchus mykiss). Aquaculture. 372-375, 89-96.

Skagemo, V., Sonesson, A.K., Meuwissen, T.H.E., Rye, M., 2010. Increased profits in aquaculture through optimised dissemination schemes. Aquaculture. 300, 65-72.

Smith, C., 1969. Optimum Selection Procedures in Animal Breeding. Anim Prod. 11, 433-442.

Sola, L., Moretti, A., Crosetti, D., Karaiskou, N., Magoulas, A., Rossi, A.R., Rye, M., Triantafyllidis, A., Tsigenopoulos, C.S., 2007. Gilthead seabream - Sparus aurata. in: Crossetti, D., Lapègue, S., Olesen, I., Svaasand, T. (Eds.), Genetic effects of domestication, culture and breeding of fish and shellfish, and their impacts on wild populations. Genimpact Final Scientific report, Viterbo, Italy, 47-54.

Vehvilainen, H., Kause, A., Quinton, C., Koskinen, H., Paananen, T., 2008. Survival of the currently fittest: Genetics of rainbow trout survival across time and space. Genetics. 180, 507-516.

Vehviläinen, H., Kause, A., Kuukka-Anttila, H., Koskinen, H., Paananen, T., 2012. Untangling the positive genetic correlation between rainbow trout growth and survival. Evol Appl. 5, 732745.

Visscher, P., Pong-Wong, R., Whittemore, C., Haley, C., 2000. Impact of biotechnology on (cross)breeding programmes in pigs. Livest Prod Sci. 65, 57-70.

Weller, J.I., 1994. Economic aspects of animal breeding. Chapman \& Hall, London.

Wilton, J.W., Quinton, V.M., Quinton, C.D., 2013. Optimizing Animal Genetic Improvement. Centre for Genetic Improvement of Livestock, Guelph.

Zuniga-Jara, S., Marin-Riffo, M.C., 2014. A bioeconomic model of a genetic improvement program of abalone. Aquacult Int. 22, 1533-1562. 



\title{
7
}

\section{Economic optimization of full-sib test group size and genotyping effort in a breeding program for Atlantic salmon}

\author{
Kasper Janssen ${ }^{1}$, Helmut W. Saatkamp ${ }^{2}$ and Hans Komen ${ }^{1}$ \\ ${ }^{1}$ Wageningen University, Animal Breeding and Genomics, Droevendaalsesteeg 1, 6708 \\ PB Wageningen, The Netherlands \\ ${ }^{2}$ Wageningen University, Business Economics Group, Hollandseweg 1, 6706 KN \\ Wageningen, The Netherlands
}

Submitted to Genetics Selection Evolution 


\begin{abstract}
Background: Breeding companies may aim to maximize the rate of genetic gain from their breeding program with a limited budget. In salmon breeding programs full-sibs of selection candidates are exposed to dedicated performance tests for traits that cannot be recorded on selection candidates. Marginal gains in the aggregate genotype from phenotyping and genotyping more full-sibs per candidate decrease, while costs increase linearly. This suggests there is an optimum allocation of budget over these activities. Our objective is to study how the budget allocation over numbers of phenotyped and numbers of genotyped test individuals in performance tests can be optimized in a breeding program for Atlantic salmon.
\end{abstract}

Methods: We defined gain in the aggregate genotype as a function of the numbers of fullsibs of selection candidates that were phenotyped in a challenge test for sea lice resistance, phenotyped in a slaughter test, genotyped in the challenge test, and genotyped in the slaughter test. These activities were subject to a constraint on budget. Using grid search, we optimized the allocation of budget over activities to maximize gain in the aggregate genotype. We performed sensitivity analyses on the maximum gain in the aggregate genotype and on the relative allocation of budget over activities at the optimum.

Results: Gain in the aggregate genotype at the optimum was $€ 367 /$ ton per generation. The optimum was rather flat, but close to the extremes gain in the aggregate genotype was compromised. Maximum gain in the aggregate genotype was sensitive to the budget and the relative emphasis on breeding goal traits, and less so to the cost of phenotyping in the challenge test and the cost of genotyping. The relative allocation of budget over activities at the optimum was sensitive to the cost of genotyping and the relative emphasis on breeding goal traits, and less so to the budget and the cost of phenotyping.

Conclusion: There exists an optimum allocation of budget to the numbers of full-sibs of selection candidates that are phenotyped and genotyped in performance tests that maximizes gain in the aggregate genotype. Although potential gains from optimizing group sizes and genotyping effort may be small, they come at no extra cost. 


\subsection{Introduction}

When the genetic level of breeding stock from a breeding company is superior to its competitors, the breeding company may incur a premium on the sales price of its products or may increase its market share (De Vries, 1989; Dekkers et al., 1996). Since genetic gain is cumulative, even small differences in the rate of genetic gain among breeding companies become meaningful over time. In Atlantic salmon breeding sales prices of eggs do not vary much among breeding companies. This may either be because differences in genetic levels of eggs are small, or because differences in genetic levels are not reflected in the sales price of eggs. In contrast to sales prices of eggs, market shares among salmon breeding companies vary a lot (Janssen et al., 2017a). The turnover of a breeding company increases with its market share. If a breeding program involves a fixed cost, a larger turnover will generate higher profits. Assuming that a breeding company's market share is at least partly related to the genetic level of its products, there is thus a clear incentive to maximize the rate of genetic gain from the breeding program. This objective needs to be met with a limited annual budget available for the breeding program.

Salmon breeding programs often use nested mating designs to create both full- and half-sib groups. Family sizes are large, so that part of each family is used as selection candidate, while another part is used in dedicated performance tests for traits that cannot be recorded on selection candidates, such as disease resistance and slaughter traits. The large family sizes in Atlantic salmon allow for within-family genomic selection with relatively few markers. In within-family genomic selection pedigree information is used to predict family means, while genomic information is used to exploit within family variation (Lillehammer et al., 2013). In pedigree selection the accuracy increases asymptotically with the number of phenotyped test individuals, such that marginal gains in aggregate genotype decrease. Similarly, in genomic selection the accuracy increases asymptotically with the number of genotyped test individuals (Lillehammer et al., 2013; Toro et al., 2017), such that marginal gains in the aggregate genotype decrease. In contrast, costs of a performance test increase (more or less) linearly with the number of phenotyped and the number of genotyped test individuals. When a breeding company's annual budget for its breeding program is limited, budget allocated to phenotyping and genotyping individuals in one performance test is at the expense of the budget available for an alternative performance test. In other words, a limited budget has to be allocated over multiple competing activities. Since each activity 
has decreasing marginal returns, we hypothesize that there is an optimum allocation of budget.

Our objective is to study how the budget allocation over numbers of phenotyped and numbers of genotyped test individuals in performance tests can be optimized in a breeding program for Atlantic salmon. Furthermore, we evaluate the sensitivity of maximum gain in the aggregate genotype and the sensitivity of the relative allocation of budget over activities at the optimum to: the cost of phenotyping in a performance test, the cost of genotyping, the budget, and the relative emphasis on breeding goal traits. In the Discussion we elaborate on the underlying mechanisms that have implications for any breeding program that uses performance tests on sibs of selection candidates.

The nucleus breeding program was based on a simplified version of the breeding program of SalmoBreed as it was up to 2016. The breeding program in our analyses used two performance tests: one challenge test for resistance to sea lice, and one slaughter test. We aimed to maximize gain in the aggregate genotype $(\Delta \mathrm{H})$ by optimizing the budget allocated over phenotyping and genotyping in each performance test. First, we describe the optimization and sensitivity analyses. Then, we provide a detailed description of the prediction of $\Delta \mathrm{H}$.

\subsection{Methods}

\subsubsection{Optimization}

$\Delta \mathrm{H}$ was a function of the number phenotyped full-sibs per family in the challenge test $\left(n_{1}\right)$, the number of phenotyped full-sibs per family in the slaughter test $\left(n_{2}\right)$, the number of genotyped full-sibs per family in the challenge test $\left(n_{3}\right)$, and the number of genotyped fullsibs per family in the slaughter test $\left(n_{4}\right)$. The number of families used for phenotyping $\left(n_{1}\right.$ and $n_{2}$ ) was 300 . Females were selected based on estimated breeding values (EBVs) derived from pedigree relations only. Males were selected in two stages, where the first was based on pedigree EBVs and the second on genomic EBVs. Males from only 120 families were selected in the first stage, such that the number of families used for genotyping $\left(n_{3}\right.$ and $n_{4}$ ) was 120 . Costs were assumed to be linearly related to the number of records. Costs of $n_{1}$ were $€ 15 /$ fish, costs of $n_{2}$ were $€ 60 /$ fish, and costs of genotyping ( $n_{3}$ and $n_{4}$ ) were $€ 20 /$ fish. The annual budget for performance tests was $€ 444,000$, which was based on the budget requirement to phenotype (300 families) and genotype (120 families) 20 full-sibs 
per family in the challenge test and 15 full-sibs per family in the slaughter test. Using formal notation, the optimization problem was defined as:

$$
\max \Delta \mathrm{H}(\mathbf{n})
$$

subject to

$$
\begin{aligned}
& n_{i} \in \mathbb{Z}_{\geq 0}, i=1,2,3,4 \\
& 300 \cdot\left(15 n_{1}+60 n_{2}\right)+120 \cdot 20 \cdot\left(n_{3}+n_{4}\right) \leq 444,000 \\
& n_{1} \geq n_{3} \\
& n_{2} \geq n_{4}
\end{aligned}
$$

where $\mathbf{n}$ is a vector with elements $n_{i}(i=1,2,3,4), 300$ is the number of full-sib families that was phenotyped, and 120 is the number of full-sib families that was genotyped. To solve the optimization problem, we performed a grid search. We first computed all possible $\mathbf{n}$ at which the budget was exhausted, i.e. insufficient budget remained to increase any of the activities by one unit. This was done by first generating the sequence $n_{1, i}$, where $i=$ $0, \ldots, i_{\max }$ with $i_{\max }$ being the maximum within the budget constraint. For each $n_{1, i}$ a sequence $n_{2, i j}$ was generated where $j=0, \ldots, j_{\max }$ with $j_{\max }$ being the maximum for the remaining budget. For each $n_{1, i}$ and $n_{2, i j}$ a sequence $n_{3, i j k}$ was generated where $k=$ $0, \ldots, k_{\max }$ with $k_{\max }$ being the maximum for the remaining budget provided that it was no greater than $n_{1, i}$. Finally, for $n_{1, i}, n_{2, i j}$, and $n_{3, i j k}$ a sequence $n_{4, i j k l}$ was generated where $l=0, \ldots, l_{\max }$ with $l_{\max }$ being the maximum for the remaining budget provided that it was no greater than $n_{2, i j}$. Any $\mathbf{n}$ for which the budget was not exhausted was removed. We predicted $\Delta \mathrm{H}$ for each remaining $\mathbf{n}$. The point where $\Delta \mathrm{H}$ was maximum returned the solution for $\mathbf{n}$. The maximum of $\Delta \mathrm{H}$, and the solutions for $\mathbf{n}$ and $n_{i}$ were indicated by an asterisk as: $\Delta \mathrm{H}^{*}, \mathbf{n}^{*}$, and $n_{i}^{*}$.

First, as a simple example, we performed the optimization for pedigree selection. In this case only $n_{1}$ and $n_{2}$ were allowed to vary, while $n_{3}$ and $n_{4}$ were set to zero, and $\Delta \mathrm{H}$ was predicted for one-stage truncation selection on EBVs. Then, we performed the optimization for genomic selection, where $n_{1}, n_{2}, n_{3}$ and $n_{4}$ were allowed to vary. When the allocation of budget was optimized for genomic selection, we estimated the shadow value of the budget constraint. The shadow value was defined as gain in the objective function $\Delta \mathrm{H}$ from a marginal relaxation of the budget constraint. Since solutions for $n_{3}$ and $n_{4}$ were fixed at the boundary, that is $n_{3}^{*}=n_{1}^{*}$ and $n_{4}^{*}=n_{2}^{*}$, the shadow value was estimated as the increase in $\Delta \mathrm{H}$ per euro costs of a simultaneous increase by one unit of either $n_{1}^{*}$ and $n_{3}^{*}$, or $n_{2}^{*}$ and $n_{4}^{*}$. 
In sensitivity analyses we evaluated the sensitivity of $\Delta \mathrm{H}^{*}$ and the relative allocation of budget over activities at $\mathbf{n}^{*}$ to: the cost of phenotyping in the challenge test, the cost of genotyping, the budget, and the relative emphasis on breeding goal traits. Sensitivity to the costs of phenotyping in the challenge test was evaluated by increasing the costs of $n_{1}$ from half to double the original costs ( $€ 15 /$ fish) by steps of $€ 7.5 /$ fish. Sensitivity to the costs of genotyping was evaluated by increasing the costs of $n_{3}$ and $n_{4}$ from half to double the original costs (€20/fish) by steps of $€ 5 /$ fish. Sensitivity to the budget was evaluated by increasing the budget from half to double the original budget $(€ 444,000)$ by steps of $€ 111,000$. Sensitivity to the relative emphasis on breeding goal traits was evaluated by increasing the economic value of sea lice resistance $\left(\mathrm{R}_{0}\right)$ by a factor $2,3,4$, or 5 . Furthermore, in an additional scenario we used desired gains (Gibson and Kennedy, 1990) to maintain fillet fat content (FilletFat) close to its current level. For the index corresponding to $\mathbf{n}^{\prime}=\left[\begin{array}{lll}15 & 20 & 15\end{array}\right.$ 20] we derived the breeding goal weight for FilletFat to maintain its current level constant by iteration. This weight was used in the breeding goal to find $\Delta \mathrm{H}^{*}$ in the grid search as before.

To speed up the optimizations, we excluded any $\mathbf{n}$ from the grid search that was, based on previous results, unlikely to be $\mathbf{n}^{*}$. For example, when the original budget was doubled, there were $>10^{5}$ possible $\mathbf{n}$ that exhausted the budget, but we expected any new $n_{i}^{*}$ to be at least as high as in the solution for the original budget. This reduced the possible $\mathbf{n}$ to only 3017 options, and thereby reduced computation time substantially.

\subsubsection{Prediction of gain in the aggregate genotype}

The breeding program of SalmoBreed was more complex than what we describe in this paper. In this section we describe only those aspects of the breeding program that were relevant to the prediction of $\Delta \mathrm{H}$ in the context of this study. The breeding goal included thermal growth coefficient (TGC), thermal feed intake coefficient (TFC), fillet yield (FY), and $\mathrm{R}_{0}$ for sea lice. TGC is a measure of growth rate that accounts for heterogeneity in smolt weight, rearing period and temperature. TFC is a TGC-analogue for feed intake (Janssen et al., 2017b). Economic values for TGC and TFC were derived using an adapted version of the bio-economic model described in Janssen et al. (2017b). The bio-economic model accounted for quota on the number of smolts stocked per cage, and quota on biomass at farm level. The number of smolts stocked per cage was optimized before and after simulated changes in trait levels. FY is the ratio of fillet weight to whole round weight in 
\%. The economic value of FY was derived by substituting FY/100\% · fillet price for the price of fish in the profit equation in Janssen et al. (2017b), such that the economic value equalled the ratio of the sales price of fish over FY. $\mathrm{R}_{0}$ for sea lice is the rate at which sea lice (L. salmonis) spread across the farmed population, and together with management determines disease prevalence (Janssen et al., 2018b). Survival was ignored in the breeding goal, because the response is hard to predict accurately while its economic effect was expected to be small (Janssen et al., 2018a). Inputs per trait used to predict $\Delta \mathrm{H}$ are in Table 1.

Table 1 Inputs per trait used to predict the gain in the aggregate genotype.

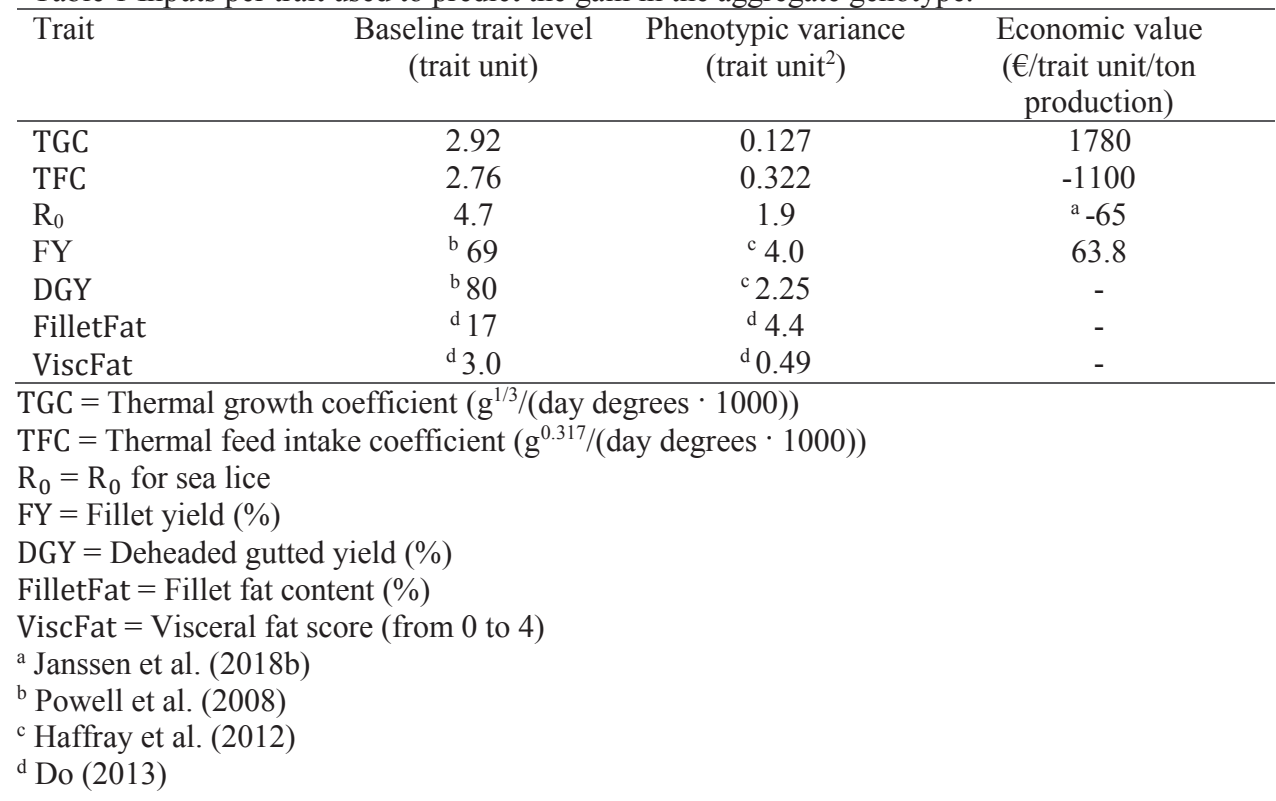

We predicted $\Delta \mathrm{H}$ per year class, assuming that the four year classes in the nucleus were discrete. An overview of the annual selection procedure is in Fig. 1. Each year class consisted of 150 males and 300 females. Every male was mated to two females so that 300 full-sib families were produced. Families were reared in separate conditions until tagging. After tagging, every full-sib family was divided into three groups. From every family a group of 170 fish were reared as selection candidates, a group of $n_{1}$ full-sibs was exposed to a challenge test for sea lice resistance, and a group of $n_{2}$ full-sibs was exposed to a slaughter test. All selection candidates had a phenotypic record for TGC. In the challenge test lice density (Gjerde et al., 2011) was recorded to estimate breeding values for $\mathrm{R}_{0}$. In the slaughter test TGC, deheaded gutted yield (DGY), fillet fat content (FilletFat), and visceral fat score (ViscFat) were recorded. DGY was the ratio of deheaded gutted weight to 
whole round weight in \%, and was used to predict FY. FilletFat and ViscFat were used to predict TGC and TFC. From the challenge test a group of $n_{3}$ full-sibs per family was genotyped. From the slaughter test a group of $n_{4}$ full-sibs per family was genotyped. Genotyping was performed on a custom-made 55k SNP array. At the time of selection, 120 candidates per full-sib family had survived and reached sexual maturity. Their sex ratio was 1:1. Females were selected in a single stage based on pedigree EBVs using best linear unbiased prediction (BLUP). Males were selected in two stages. The first was based on pedigree EBVs using BLUP, and the second was based on genomic EBVs using withinfamily genomic selection as described in Lillehammer et al. (2013). Genomic selection was applied only in males and not in females, because there its impact will be largest as males were also used to fertilize females in the multiplier tier.

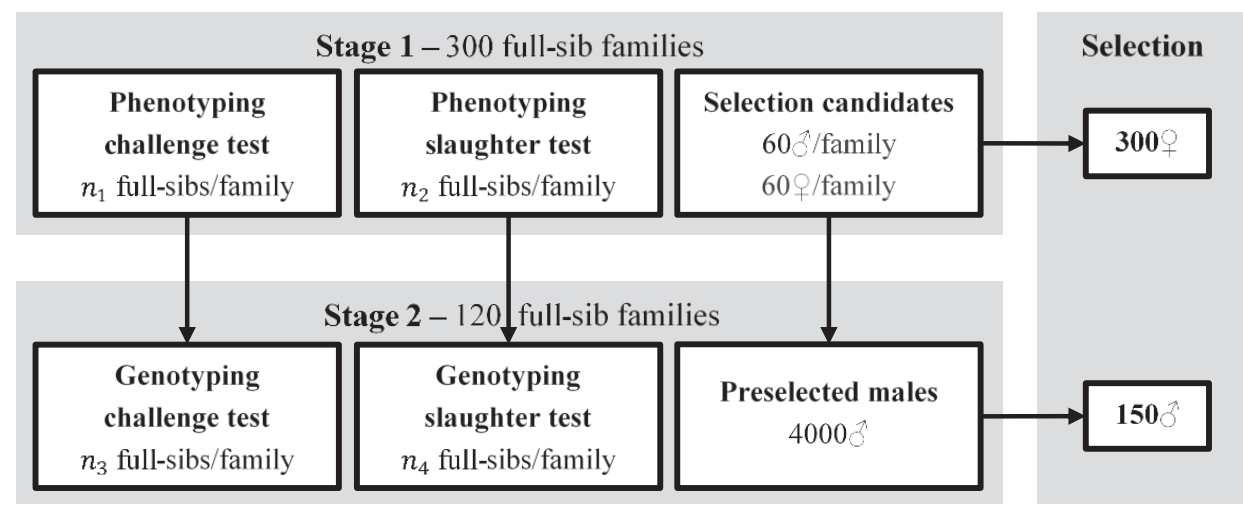

Fig. 1 Schematic overview of selection of parents in the nucleus.

Heritabilities $\left(h^{2}\right)$, and genetic and phenotypic correlations are in Table 2. Genetic parameters for TGC and TFC were estimated as in Janssen et al. (2018a). Underlying assumptions were a genetic coefficient of variation of bodyweight of 0.15 and $h^{2}=0.36$ (Sonesson et al., 2013). For the regression of cumulative feed intake at harvest on gain in bodyweight a slope of $1.17 \mathrm{~g}$ feed/g gain, an intercept of $145 \mathrm{~g}$ feed, a genetic correlation of 0.70 , and phenotypic correlation of 0.60 were assumed. For $\mathrm{R}_{0}$ genetic parameters are unknown, but we assumed that a change in the estimated breeding value for lice density in a challenge test would give a proportional change in $\mathrm{R}_{0}$ (Janssen et al., 2018b). We, therefore, used the same phenotypic coefficient of variation and heritability as for lice density (Gjerde et al., 2011). This is equivalent to including lice density in the selection index and $\mathrm{R}_{0}$ in the breeding goal while assuming a genetic correlation of unity between both traits. 
Table 2 Genetic correlations (below diagonal), phenotypic correlations (above diagonal), and heritabilities (diagonal) of traits.

\begin{tabular}{lccccccc}
\hline & ${ }^{\mathrm{a}}$ TGC & ${ }^{\mathrm{b}}$ TFC & ${ }^{\mathrm{c}} \mathrm{R}_{0}$ & ${ }^{\mathrm{d}}$ FY & ${ }^{\mathrm{e}}$ DGY & ${ }^{\mathrm{f}}$ FilletFat & ${ }^{\mathrm{g}}$ ViscFat \\
\hline TGC & 0.34 & 0.56 & 0 & 0 & 0 & ${ }^{\mathrm{a}} 0.07$ & ${ }^{\mathrm{a}} 0.13$ \\
TFC & 0.69 & 0.23 & 0 & 0 & 0 & ${ }^{\mathrm{a}} 0.06$ & ${ }^{\mathrm{a}} 0.09$ \\
$\mathrm{R}_{0}$ & 0 & 0 & ${ }^{\mathrm{b}} 0.30$ & 0 & 0 & 0 & 0 \\
FY & 0 & 0 & 0 & ${ }^{\mathrm{c}} 0.35$ & ${ }^{\mathrm{c}} 0.71$ & 0 & 0 \\
DGY & 0 & 0 & 0 & ${ }^{\mathrm{c}} 0.97$ & ${ }^{\mathrm{c}} 0.54$ & 0 & 0 \\
FilletFat & ${ }^{\mathrm{a}}-0.26$ & ${ }^{\mathrm{a}} 0.41$ & 0 & 0 & 0 & ${ }^{\mathrm{d}} 0.42$ & ${ }^{\mathrm{d}} 0.01$ \\
ViscFat & ${ }^{\mathrm{a}} 0.29$ & ${ }^{\mathrm{a}} 0.09$ & 0 & 0 & 0 & ${ }^{\mathrm{d}} 0.01$ & ${ }^{\mathrm{d}} 0.23$ \\
\hline
\end{tabular}

$\mathrm{TGC}=$ Thermal growth coefficient $\left(\mathrm{g}^{1 / 3} /(\right.$ day degrees $\left.\cdot 1000)\right)$

$\mathrm{TFC}=$ Thermal feed intake coefficient $\left(\mathrm{g}^{0.317} /(\right.$ day degrees $\left.\cdot 1000)\right)$

$\mathrm{R}_{0}=\mathrm{R}_{0}$ for sea lice

$\mathrm{FY}=$ Fillet yield $(\%)$

DGY $=$ Deheaded gutted yield $(\%)$

FilletFat $=$ Fillet fat content $(\%)$

ViscFat $=$ Visceral fat score (from 0 to 4$)$

${ }^{a}$ Kause et al. (2016)

${ }^{\mathrm{b}}$ Gjerde et al. (2011)

${ }^{\mathrm{c}}$ Haffray et al. (2012)

${ }^{\mathrm{d}}$ Do (2013)

Breeding programs using genomic selection can be simulated deterministically using extended selection index theory as outlined by Dekkers (2007). For each trait for which phenotypes were recorded (TGC, $\mathrm{R}_{0}$, DGY, FilletFat, ViscFat) an extra genomic trait was added to the selection index. Each of these genomic traits had $h^{2}=1$, a phenotypic variance of one, and a genetic correlation with the corresponding breeding goal trait equal to the expected accuracy of genomic selection for that trait $\left(r_{G S}\right)$. Hayes et al. (2009) developed deterministic equations to estimate the accuracy of genomic prediction from fulland half-sib records, but here we ignored information from half-sib records, because halfsib records were not available for some of the preselected males. The genomic prediction accuracy for $m$ full-sib records was estimated as (Hayes et al., 2009):

$r_{G S}=\sqrt{\frac{0.5 \cdot m}{m-1+2 / h^{2}}+\frac{0.5 \cdot m}{m+4 \cdot M_{e} / h^{2}}}$

were $M_{e}$ was the effective number of chromosome segments that segregate independently in the population. $M_{e}$ was estimated from variation among full-sibs $\left(V\left(P_{F S}\right)\right)$ as in Hayes et al. (2009),

$M_{e}=\frac{1}{8 \cdot V\left(P_{F S}\right)}$, 
where $V\left(P_{F S}\right)$ was estimated as in Hill (1993) assuming that chromosomes are of equal length:

$V\left(P_{F S}\right)=\frac{4 \cdot L-N_{c h r}+N_{c h r} \cdot e^{-4 \cdot L / N_{c h r}}}{64 \cdot L^{2}}$,

where $L$ was the length of the genome in Morgan, and $N_{c h r}$. was the number of chromosomes. $L$ is a measure of recombination rate rather than physical length. For Atlantic salmon $L=3.9$ Morgan in males and $L=19.83$ Morgan in females and $N_{c h r}$. is 29 (Moen et al., 2008). $M_{e}$ was calculated separately per sex and averaged, resulting in $M_{e}=47.3$. To compute $r_{G S}$ for TGC, we made the simplifying assumption that the number of preselected male selection candidates was equal for each of the 120 remaining families, so that the number of genotyped selection candidates per family was 33, i.e. 32 full-sibs per candidate. An additional $n_{4}$ full-sibs per family from the slaughter test had records for TGC, hence $r_{G S}$ was computed for $32+n_{4}$ full-sibs per family. For $\mathrm{R}_{0} r_{G S}$ was based on records on $n_{3}$ full-sibs per family. For DGY, FilletFat, and ViscFat $r_{G S}$ was based on records on $n_{4}$ full-sibs per family. Correlations of genomic traits with other traits were derived using path coefficients (Dekkers, 2007). A table with all correlations for the optimum index in genomic selection is in the Appendix. As an example for DGY with $n_{3}=20, r_{G S}=$ $\sqrt{\frac{0.5 \cdot 20}{20-1+2 / 0.54^{2}}+\frac{0.5 \cdot 20}{20+4 \cdot 47.3 / 0.54^{2}}}=0.684$ (Eq. 1). Thus, the corresponding index would include a genomic trait with $h^{2}=1$, phenotypic variance of 1 , genetic correlation with DGY of 0.684 , phenotypic correlation with DGY of $0.684 \cdot \sqrt{0.54}=0.50$, genetic correlation with FY of $0.684 \cdot 0.97=0.663$, and phenotypic correlation with FY of $0.663 \cdot \sqrt{0.35}=0.39$.

$\Delta \mathrm{H}$ was predicted by deterministic simulation in SelAction (Rutten et al., 2002). For each prediction SelAction was run twice: once to predict $\Delta \mathrm{H}$ in females in one-stage truncation selection on EBVs, and once to predict $\Delta \mathrm{H}$ in males in two-stage truncation selection on EBVs. In one-stage selection the selected proportion $(p)$ for males was $p=\frac{150}{18,000}=$ 0.0083 and for females $p=\frac{300}{18,000}=0.017$. In two-stage selection for males $p=\frac{4000}{18,000}=$ 0.22 in the first stage and $p=\frac{150}{4000}=0.038$ in the second stage, and for females $p=$ 0.017 in the first stage and $p=1$ in the second stage. For all non-genomic traits the proportion of phenotypic variance explained by environmental effects common to full-sibs 
$\left(c^{2}\right)$ was set to 0.05 . Selection indices are in Table 3 . The rate of inbreeding was not evaluated, because it is not computed by SelAction for two-stage selection, and because generations overlapped in reality.

Table 3. Selection indices used in the nucleus breeding program.

\begin{tabular}{|c|c|c|c|}
\hline Trait & Records & $\begin{array}{c}\text { Females and 1st stage } \\
\text { males }\end{array}$ & 2nd Stage males \\
\hline \multirow{5}{*}{ TGC } & Own performance & $\checkmark$ & $\sqrt{ }$ \\
\hline & BLUP & $\checkmark$ & $\checkmark$ \\
\hline & 119 full-sibs & $\checkmark$ & $\checkmark$ \\
\hline & 120 half-sib & $\checkmark$ & $\checkmark$ \\
\hline & GEBV for $32+n_{4}$ full-sibs & & $\checkmark$ \\
\hline \multirow{4}{*}{$\mathrm{R}_{0}$} & BLUP & $\sqrt{ }$ & $\checkmark$ \\
\hline & $n_{1}$ full-sibs & $\checkmark$ & $\checkmark$ \\
\hline & $n_{1}$ half-sibs & $\checkmark$ & $\checkmark$ \\
\hline & GEBV for $n_{3}$ full-sibs & & $\checkmark$ \\
\hline \multirow{4}{*}{$\begin{array}{l}\text { TGC, DGY, } \\
\text { FilletFat, } \\
\text { and ViscFat }\end{array}$} & BLUP & $\checkmark$ & $\checkmark$ \\
\hline & $n_{2}$ full-sibs & $\checkmark$ & $\checkmark$ \\
\hline & $n_{2}$ half-sibs & $\checkmark$ & $\checkmark$ \\
\hline & GEBV for $n_{4}$ full-sibs & & $\checkmark$ \\
\hline
\end{tabular}

\subsection{Results}

\subsubsection{Pedigree selection}

For the objective to maximize $\Delta \mathrm{H}$ in pedigree selection, the optimum numbers of phenotyped full-sibs per family were 10 in the challenge test $\left(n_{1}^{*}\right)$ and 22 in the slaughter test $\left(n_{2}^{*}\right)$. Genetic gain per generation for the optimized breeding program is in Table 4 . $\Delta \mathrm{H}^{*}$ was $€ 333 /$ ton, of which $90 \%$ was due to improvement of TGC and TFC. The combined effect of gains in TGC and TFC would reduce feed conversion ratio (FCR) from 1.20 to 1.08 (results from bio-economic model). Gain in $\mathrm{R}_{0}$ corresponds to an expected reduction in treatment frequency from 3.7 to 3.6 treatments per production cycle while average lice numbers would remain unaltered. 
Table 4 Genetic gain per generation in the optimized breeding program for Atlantic salmon using pedigree information only.

\begin{tabular}{lcc}
\hline Trait & $\begin{array}{c}\text { Genetic gain } \\
\left(\sigma_{\mathrm{A}}\right)\end{array}$ & $\begin{array}{c}\text { Genetic gain } \\
\text { (€/ton production) }\end{array}$ \\
\hline TGC & 0.95 & 349.7 \\
TFC & 0.16 & -47.9 \\
$\mathrm{R}_{0}$ & -0.17 & 8.2 \\
FY & 0.31 & 23.1 \\
DGY & 0.31 & \\
FilletFat & -0.98 & \\
ViscFat & 0.38 & 333 \\
Total & & \\
\hline
\end{tabular}

TGC $=$ Thermal growth coefficient $\left(\mathrm{g}^{1 / 3} /(\right.$ day degrees $\left.\cdot 1000)\right)$

$\mathrm{TFC}=$ Thermal feed intake coefficient $\left(\mathrm{g}^{0.317} /\right.$ (day degrees $\left.\left.\cdot 1000\right)\right)$

$\mathrm{R}_{0}=\mathrm{R}_{0}$ for sea lice

$\mathrm{FY}=$ Fillet yield $(\%)$

DGY $=$ Deheaded gutted yield $(\%)$

FilletFat $=$ Fillet fat content $(\%)$

ViscFat $=$ Visceral fat score (from 0 to 4$)$

$\Delta \mathrm{H}$ for any combination of $n_{1}$ and $n_{2}$ that exhausted the budget is in Fig. 2. The optimum was relatively flat, such that $\Delta \mathrm{H}$ was rather robust to changes in budget allocation over $n_{1}$ and $n_{2}$ around the optimum. At both extremes and particularly with few full-sibs per family in the slaughter test, however, $\Delta \mathrm{H}$ was compromised. Marginal gains of an extra phenotyped full-sib per family were relatively high when its number was low, and decreased as its number increased. The selection intensity was constant for any combination of $n_{1}$ and $n_{2}$, and differences in $\Delta \mathrm{H}$ were largely due to differences in the accuracy of the index, and to a minor extent due to differences in genetic variation in the breeding goal caused by the Bulmer-effect (results from SelAction output). 


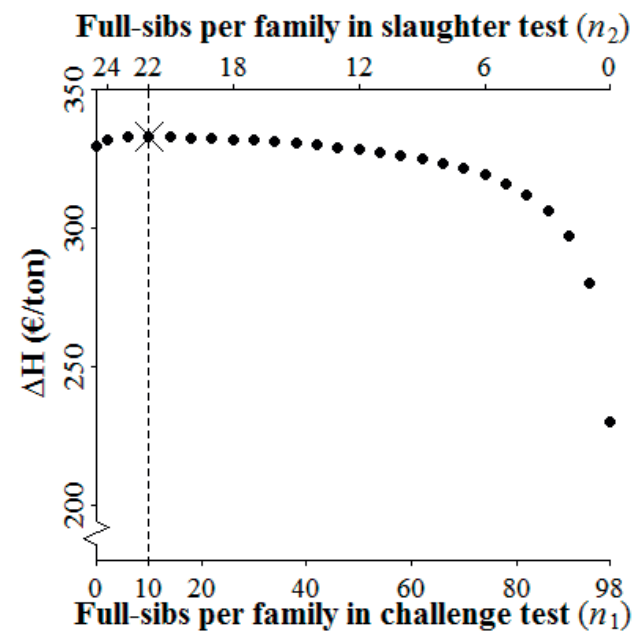

Fig. 2 Gain in the aggregate genotype $(\Delta \mathrm{H})$ for varying numbers of phenotyped full-sibs per family used in performance tests. The vertical dashed line indicates the optimum and the cross is at $\Delta \mathrm{H}^{*}$.

\subsubsection{Genomic selection}

For the objective to maximize $\Delta \mathrm{H}$ in genomic selection, the optimum numbers of phenotyped and genotyped full-sibs per family were 5 in the challenge test $\left(n_{1}^{*}\right.$ and $\left.n_{3}^{*}\right)$ and

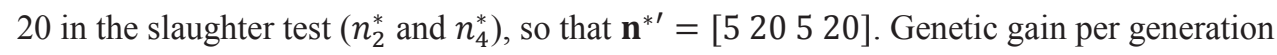
for the optimized breeding program is in Table 5. $\Delta \mathrm{H}^{*}$ was $€ 367 /$ ton, which was an increase of $10 \%$ relative to pedigree selection. Most of this increase was due to extra gain in TGC. Costs of phenotyping and genotyping in the challenge test accounted for $8 \%$ of the budget, whereas in pedigree selection costs of phenotyping in the challenge test accounted for $11 \%$ of the budget. As a result, the relative contribution of $\mathrm{R}_{0}$ to $\Delta \mathrm{H}^{*}$ decreased relative to pedigree selection, although the decrease was less marked in absolute terms. The shadow value of the budget constraint was $€ 3.1 \cdot 10^{-5}$ /ton per euro costs when estimated from a one unit increase of $n_{1}^{*}$ and $n_{3}^{*}$, and it was $€ 2.8 \cdot 10^{-5} /$ ton per euro costs when estimated from a one unit increase of $n_{2}^{*}$ and $n_{4}^{*}$. 
Table 5 Genetic gain per generation in males and females in the optimized breeding program for Atlantic salmon using genomic selection.

\begin{tabular}{lcc}
\hline Trait & $\begin{array}{c}\text { Genetic gain } \\
\left(\sigma_{\mathrm{A}}\right)\end{array}$ & $\begin{array}{c}\text { Genetic gain } \\
(€ / \text { ton production })\end{array}$ \\
\hline TGC & 1.01 & 374.9 \\
TFC & 0.14 & -41.7 \\
$\mathrm{R}_{0}$ & -0.16 & 7.7 \\
FY & 0.35 & 26.1 \\
DGY & 0.36 & \\
FilletFat & -1.09 & \\
ViscFat & 0.42 & 367 \\
Total & & \\
\hline
\end{tabular}

TGC $=$ Thermal growth coefficient $\left(\mathrm{g}^{1 / 3} /(\right.$ day degrees $\left.\cdot 1000)\right)$

$\mathrm{TFC}=$ Thermal feed intake coefficient $\left(\mathrm{g}^{0.317} /(\right.$ day degrees $\left.\cdot 1000)\right)$

$\mathrm{R}_{0}=\mathrm{R}_{0}$ for sea lice

$\mathrm{FY}=$ Fillet yield $(\%)$

DGY $=$ Deheaded gutted yield $(\%)$

FilletFat $=$ Fillet fat content $(\%)$

ViscFat $=$ Visceral fat score (from 0 to 4$)$

Fig. 3 gives the maximum $\Delta \mathrm{H}$ for varying numbers of full-sibs per family in each one of the four activities. At any of these maxima, the numbers of full-sibs per family in the other three activities was optimum for the given value of the activity. Just as in pedigree selection, the optimum was relatively flat such that $\Delta \mathrm{H}$ was rather robust to changes in budget allocation over $\mathbf{n}$ around the optimum. Starting at zero full-sibs per family in any of the activities, $\Delta \mathrm{H}$ increased with the number of full-sibs per family up to the point where it was maximum, i.e. $\Delta \mathrm{H}^{*}$. Since marginal gains in $\Delta \mathrm{H}$ decreased with an increasing number of full-sibs per family, $\Delta \mathrm{H}$ decreased when the number of full-sibs per family increased beyond the optimum, i.e. $n_{i}{ }^{*}$. 

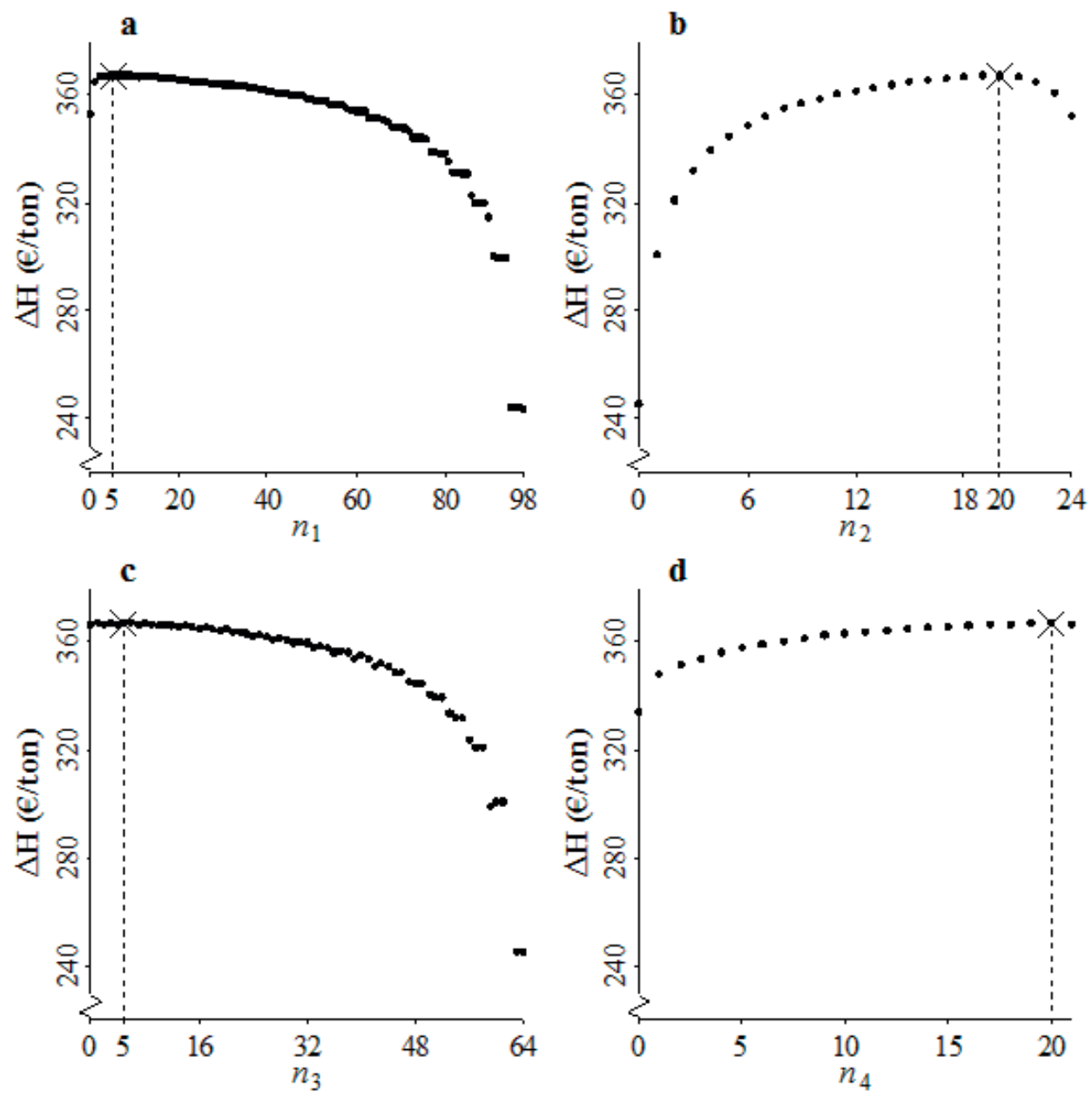

Fig. 3 Maximum gain in the aggregate genotype $(\Delta \mathrm{H})$ for varying numbers of a phenotyped fullsibs per family in the challenge test $\left(n_{1}\right)$, b phenotyped full-sibs per family in the slaughter test $\left(n_{2}\right)$, $\mathbf{c}$ genotyped full-sibs per family in the challenge test $\left(n_{3}\right)$, $\mathbf{d}$ genotyped full-sibs per family in the slaughter test $\left(n_{4}\right)$. The vertical dashed lines and crosses indicate the optima.

\subsubsection{Sensitivity analyses}

Fig. 4 gives the relation between $\Delta \mathrm{H}^{*}$ and the parameters evaluated in the sensitivity analysis. $\Delta \mathrm{H}^{*}$ decreased when the cost of the challenge test increased (Fig. 4a), and when the cost of genotyping increased (Fig. $4 \mathrm{~b}$ ). $\Delta \mathrm{H}^{*}$ increased at a decreasing rate when the budget increased (Fig. 4c). The slope of the relation between $\Delta \mathrm{H}^{*}$ and the budget at a budget of $€ 444,000$ equalled the average shadow value of the budget constraint. Furthermore, $\Delta \mathrm{H}^{*}$ itself became more sensitive to changes in budget allocation over $\mathbf{n}$ around the optimum when the budget decreased, and more robust when the budget 
increased. $\Delta \mathrm{H}^{*}$ increased at an increasing rate when the economic value of $\mathrm{R}_{0}$ increased (Fig. 4d). Note that if the actual economic value would remain constant while only the emphasis on $\mathrm{R}_{0}$ is increased, $\Delta \mathrm{H}^{*}$ would decrease instead.
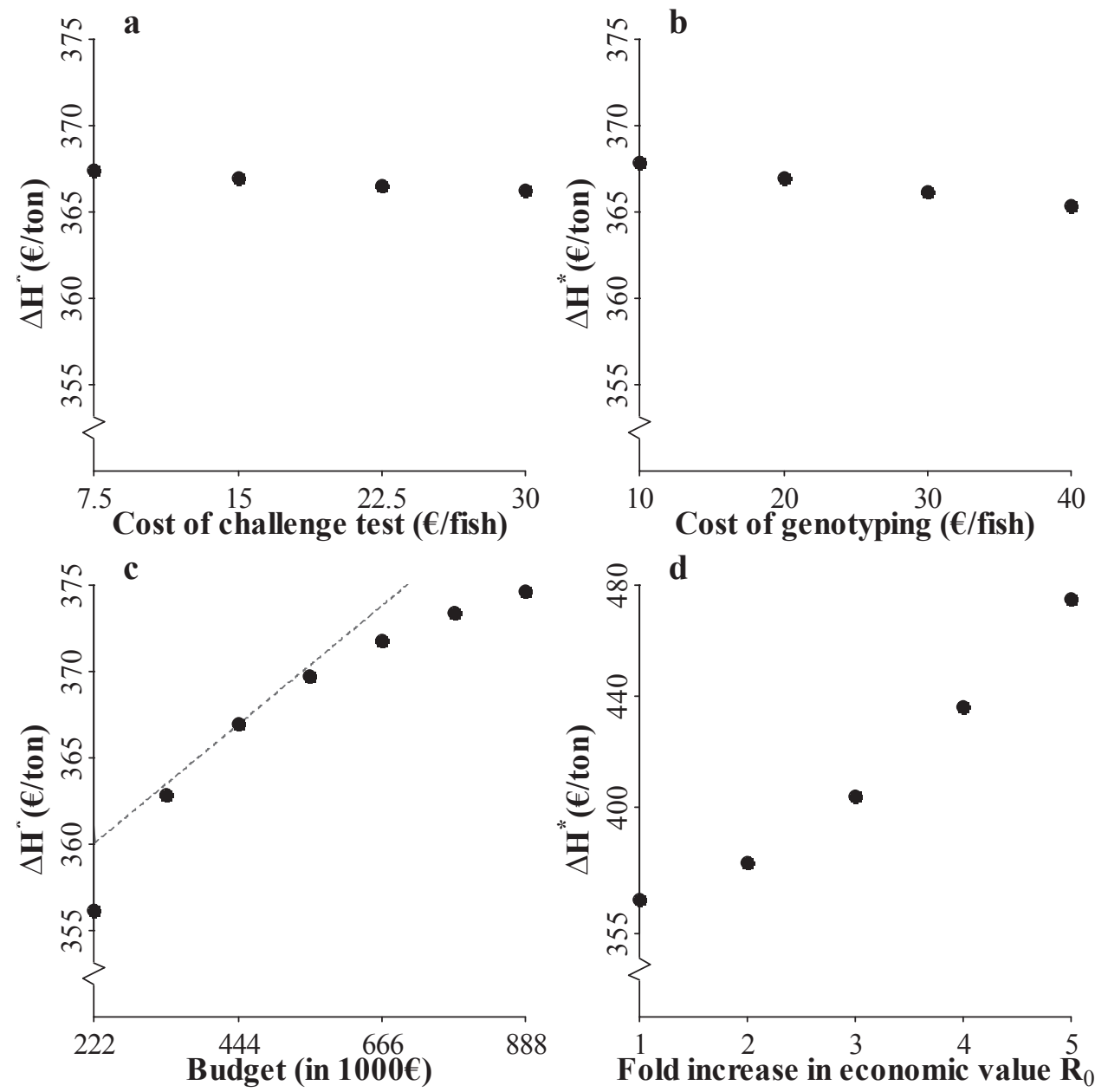

Fig. 4 Sensitivity of gain in the aggregate genotype at the optimum $\left(\Delta \mathrm{H}^{*}\right)$ to a the cost of the challenge test, $\mathbf{b}$ the cost of genotyping, $\mathbf{c}$ the budget, where the slope of the dashed line is equal to the shadow value of the budget constraint, $\mathbf{d}$ the economic value of $\mathrm{R}_{0}$ (note the different scale on the $y$-axis here).

Fig. 5 gives the relation between the relative allocation of budget over activities at $\mathbf{n}^{*}$ and the parameters evaluated in the sensitivity analysis. When the cost of phenotyping in the challenge test halved relative to the original cost (€15/fish), $n_{1}^{*}$ doubled and the proportion of budget allocated to each activity remained constant (Fig. 5a). When the cost of 
phenotyping in the challenge test increased relative to the original cost, a larger proportion of the budget was spend on $n_{1}^{*}$. When the costs of genotyping increased, the proportion of budget spend on $n_{4}^{*}$ increased (Fig. 5b). When the costs of genotyping increased from $€ 10$ /fish to $€ 40 /$ fish, $n_{4}^{*}$ dropped from 21 to 18 , which is only small relative to the fourfold change in costs. In contrast, $n_{1}^{*}$ dropped from 7 to 1 for the same increase in costs. When the budget increased, the relative allocation of budget over activities remained rather constant (Fig. 5c). Note that there were two optima with equal $\Delta \mathrm{H}^{*}$ for a budget of $€ 777,000$. When the economic value of $R_{0}$ increased, the proportion of budget spend on the challenge test $\left(n_{1}^{*}\right.$ and $\left.n_{3}^{*}\right)$ increased at the expense of the slaughter test $\left(n_{2}^{*}\right.$ and $\left.n_{4}^{*}\right)$ (Fig. 5d). 

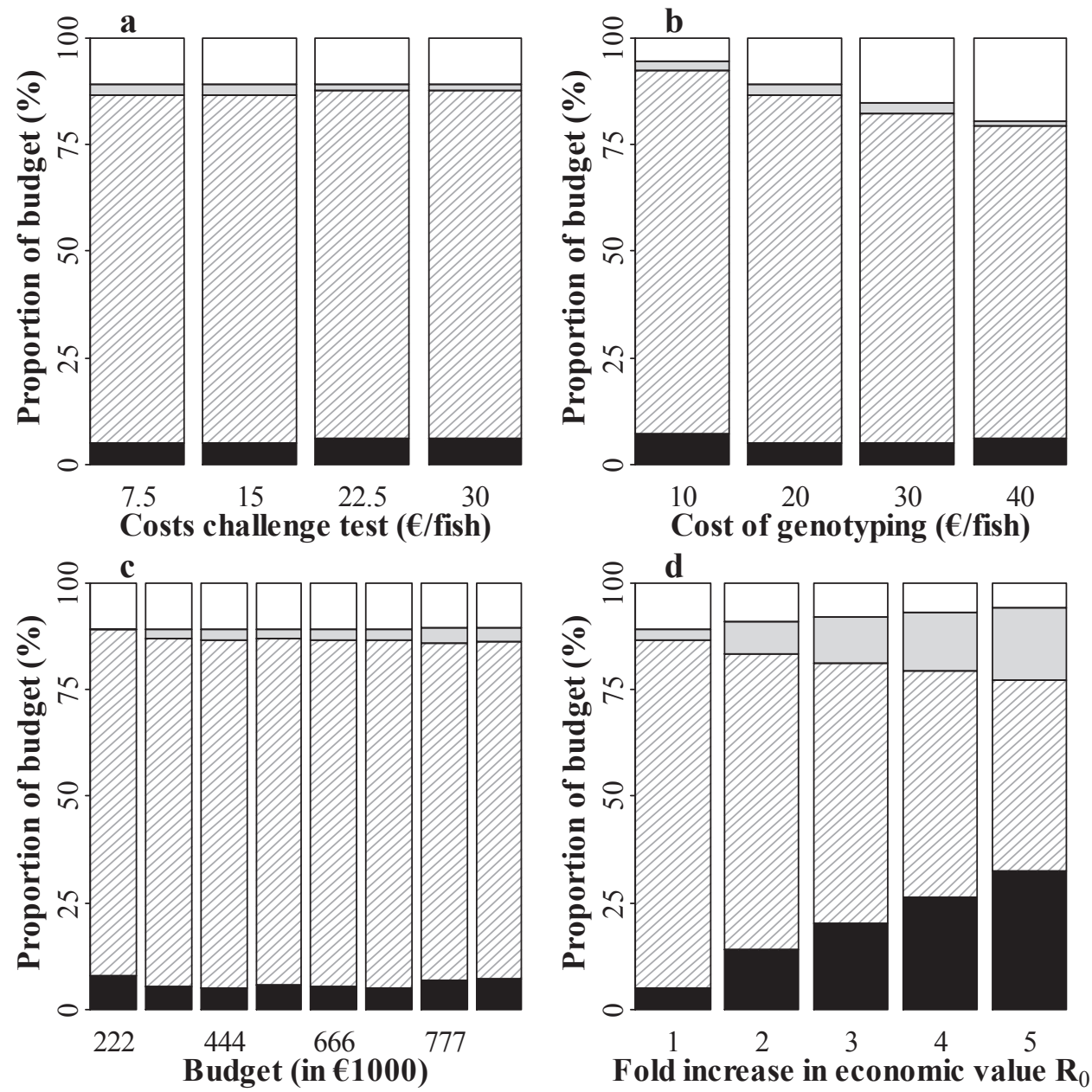

Fig. 5 The proportion of budget allocated to activities $\left(n_{1}^{*}=\right.$ black, $n_{2}^{*}=$ grey stripes, $n_{3}^{*}=$ grey, $n_{4}^{*}=$ white) when the allocation of budget has been optimized. a for increasing costs of the challenge test, $\mathbf{b}$ for increasing costs of genotyping, $\mathbf{c}$ for an increasing budget, $\mathbf{d}$ for an increasing economic value of $\mathrm{R}_{0}$.

In the desired gains index, the weight given to FilletFat was $€ 170 / \% /$ ton production. $\Delta \mathrm{H}^{*}$ was $€ 207 /$ ton, which was a decrease of $43 \%$ relative to the baseline. The relative contributions of TGC and TFC to $\Delta \mathrm{H}^{*}$ decreased to $70 \%$ compared to $90 \%$ in the baseline, while relative contributions of $\mathrm{R}_{0}$ and $\mathrm{FY}$ increased. The combined effect of gains in TGC and TFC would no longer reduce FCR (results from bio-economic model). More budget was allocated to the challenge test at the expense of the slaughter test, so that $\mathbf{n}^{* \prime}=$ $\left[\begin{array}{llll}14 & 17 & 14 & 17\end{array}\right]$. 


\subsection{Discussion}

The results on the optimization of the breeding program show that there exists an optimum allocation of budget to group size and genotyping effort in performance tests that maximizes gain in the aggregate genotype. Optima were rather flat for the scenarios evaluated, hence gains in the aggregate genotype were relatively robust to changes in budget allocation over activities around the optimum. Close to the extremes, i.e. a very low or high number of full-sibs per family in one of the activities, gains were substantially lower than close to the optimum. Although potential gains from optimizing group sizes and genotyping effort may be small, they come at no extra cost (except for the optimization itself), because the budget can be kept constant. The sensitivity analysis showed that maximum gain in the aggregate genotype was sensitive to the budget and the relative emphasis on breeding goal traits, and less so to the cost of phenotyping in the challenge test and the cost of genotyping. Furthermore, the relative allocation of budget over activities at the optimum was sensitive to the cost of genotyping and the relative emphasis on breeding goal traits, and less so to the budget and the cost of phenotyping.

The results of this study may be better understood from its underlying mechanism. The accuracy increases asymptotically with any of the four activities. Any increase in accuracy increases gain in the aggregate genotype. Thus, gain in the aggregate genotype is maximum at some point where the budget is exhausted. When the budget is exhausted, a further increase in one of the activities should coincide with a decrease in other activities to meet the budget constraint. At the optimum, marginal gains in the aggregate genotype per unit cost are approximately equal for all activities bound by the same constraints, and any deviation thereof is due to the non-continuous nature of the objective function. Since marginal gains per unit cost of genotyping were higher than those of phenotyping in both performance tests but the genotyped number was bound by the phenotyped number, optimum numbers of genotyped full-sibs per family equalled the optimum numbers that were phenotyped. With equal numbers of phenotyped and genotyped full-sibs per family per performance test $\left(n_{1}=n_{3}\right.$ and $\left.n_{2}=n_{4}\right)$, gain in the aggregate genotype is a function of only two variables that are only bound by the budget constraint. At the optimum, marginal gains per unit costs of these two variables are approximately equal, as evidenced by the similar shadow values calculated from a simultaneous increase by one unit of either $n_{1}^{*}$ and $n_{3}^{*}$, or $n_{2}^{*}$ and $n_{4}^{*}$. When marginal gains per unit costs are equal, moving budget from one activity to the other has no effect on gain in the aggregate genotype: what is lost by 
decreasing the budget for one activity is gained by increasing the budget for the other activity. Since marginal gains per unit cost converge for all activities (bound by the same constraints) when approaching the optimum, moving budget from one activity to the other has little effect on gain in the aggregate genotype around the optimum. Thus when costs of phenotyping or genotyping change, budget can be reallocated over activities (Fig. 5a and b) so that gain in the aggregate genotype does not change much (Fig. $4 \mathrm{a}$ and b). It also explains why the optimum is rather flat (Fig. 2 and 3). This result is consistent with the few other studies that focused on the economic optimization of test group sizes. Some of the older studies dealing with the optimization of cattle and pig breeding programs have been reviewed by Cunningham (1973) and Lindhé and Holmquist-Arbrandt (1977), respectively. More recently, De Vries and Van Der Steen (1990) evaluated the distribution of testing capacity over a sire and dam line in pig breeding for a fixed total testing capacity. In their optimizations they did not compute the full-range of possible solutions, hence their solutions may have been somewhat off the actual optimum. However, differences in the objective function (the selection response) were small among scenarios close to the optimum. Dekkers et al. (1996) optimized the size of progeny groups in a dairy cattle breeding program. In their optimizations they computed several points on the response surface which they interpolated. For a large range of options such an approach may be more efficient than the grid search in our study. However, we managed to keep the feasible region of the solution relatively small by using previous results, so that the grid search was not so computation intensive. Similar to our study, De Vries and Van Der Steen (1990) and Dekkers et al. (1996) found that marginal gains in the objective function decreased with increasing group size, and the objective function was relatively flat around the optimum. Yet, in the study of Dekkers et al. (1996) potential gains from the optimization were substantial.

The objective of the optimization was to maximize gain in the aggregate genotype averaged over males and females. This objective maximizes the rate of genetic gain in the nucleus. Since males are also used in the multiplier tier, the strategy of genotyping males shortens the genetic lag and allows the breeding company to produce lines selected on quantitative trait loci for specific disease resistance. For the objective, however, it would be relevant to test how much extra gain could be achieved by also genotyping female selection candidates instead of males only. Similar to selection of males, two-stage selection could be used to select females, where the second step could be based on within-family genomic selection. 
Such two-stage selection would increase the genetic selection differential in females relative to pedigree selection, although somewhat less than in males due to the lower selection intensity in females. When preselected females are taken from the same full-sib families as preselected males, the increase in costs could be limited to the costs of genotyping preselected females while making better use of genotyped full-sibs in performance tests. Such a strategy would accelerate the rate of inbreeding, because the first selection step would force preselected females to belong to the same families as preselected males. The rate of inbreeding, however, may be controlled by other measures such as optimum contribution selection (Meuwissen, 1997). Thus, genotyping a preselected fraction of female selection candidates may be a cost-effective option to accelerate genetic gain in the nucleus.

The optimization of full-sib test group size and genotyping effort is not restricted to breeding objectives based on economic values, but may also be used for any desired gains index. In the desired gains index used here the weight given to FilletFat may be perceived as its shadow price (Melton et al., 1994). This shadow price indicates the maximum amount that producers can afford to pay for a marginal change in FilletFat, i.e. the value of $1 \%$ increase with other traits held constant. In other words, the weight given to FilletFat implies that producers would expect the sales price of fish to decrease by $€ 170 /$ ton when FilletFat decreases by $1 \%$. Underlying this shadow price is the assumption of a negative genetic correlation between TGC and FilletFat. This genetic correlation is negative when genetic improvement of TGC leads to a shorter time to reach a constant harvest weight, but it is positive when genetic improvement of TGC would lead to a higher harvest weight in a constant growing period instead (Gjedrem, 1997; Kause et al., 2016; Kristjansson et al., 2015). If the positive genetic correlation would be more appropriate, FilletFat would increase when its economic value is zero and a negative weight would be required to keep its current level constant. The shadow price of FilletFat thus strongly depends on the genetic correlation of FilletFat with TGC.

In our predictions, the transition from pedigree to genomic selection increased the rate of genetic gain by $10 \%$ per generation. This increase is only moderate, because TGC contributed most to gain in the aggregate genotype and its accuracy was already high in pedigree selection. Still, most extra gains from genomic selection were due to extra gain in TGC. Thus, although genomic selection may be particularly useful for traits that cannot be 
recorded on selection candidates, most extra gain may follow from a slightly higher accuracy on a trait that already dominates gain in the aggregate genotype in pedigree selection, such as TGC in this study. For the optimized genomic selection program gain in the aggregate genotype averaged over males and females was $€ 367 /$ ton per generation. This is an optimistic estimate of the increase in benefits from genetic improvement, because it was computed as if economic values were used to balance the emphasis on breeding goal traits in the optimum way. In reality, for example, FilletFat is held constant. For the optimized desired gains index that controls FilletFat, gain in the aggregate genotype averaged over males and females was $€ 207 /$ ton per generation. For a generation interval of 3.7 years, as in SalmoBreed's breeding program, this would correspond to an increase in benefits of about $€ 55 /$ ton each year. This estimate is only slightly higher than a previous estimate of $€ 50 /$ ton per year by Gjerde et al. (2007), which was a crude estimate based on realized gains in growth and feed conversion ratio. If we assume a yield per egg of $3.7 \mathrm{~kg}$, i.e. the fish production per egg is $3.7 \mathrm{~kg}$, the genetic potential of an egg increases by about $€ 0.20$ per year. In contrast, the sales price of eggs is about $€ 0.18 /$ egg and has increased by only $\_0.01$ per year over the last couple of years. This suggest that only a minor proportion of the benefits of genetic improvement are accrued by the breeding company, while the majority is passed on to fish producers and consumers. In the short term benefits from genetic improvement may be accrued by fish producers when genetic improvement generates a competitive advantage. These benefits may be passed on to the consumer in the long term when competition pushes profit margins downwards (Amer and Fox, 1992). The uneven distribution of benefits from genetic improvement among the breeding company and fish producers causes underinvestment in genetic improvement. If the breeding company would receive a premium of $€ 0.01 /$ egg for its annual sales of 120 million eggs, it would accrue an extra 1.2 million euro. The shadow value of the budget constraint on performance tests was about $€ 3.0 \cdot 10^{-5} /$ ton per euro costs. This means that if gain in the aggregate genotype would increase linearly with the budget, it would increase by $€ 3.0 /$ ton per $€ 100,000$ costs. Thus assuming linearity, a premium of $€ 0.01 /$ egg that is used to increase the budget for performance tests could increase gain in the aggregate genotype by $€ 36 /$ ton each generation. Using the same assumptions as before, a premium of $€ 0.01 /$ egg would increase the genetic potential of an egg by an extra $€ 0.036$ per year. Such higher genetic gains would improve the competitive position of the breeding company while at the same time increasing the benefits to producers. As long as discounted benefits from extra 
genetic gain exceed the discounted costs, such a premium on genetic superiority would be profitable for both parties.

\subsection{Conclusion}

There exists an optimum allocation of budget to group size and genotyping effort in performance tests that maximizes gain in the aggregate genotype. The maximum gain in the aggregate genotype was sensitive to the budget and the relative emphasis on breeding goal traits, and less so to the cost of phenotyping in the challenge test and the cost of genotyping. The relative allocation of budget over activities at the optimum was sensitive to the cost of genotyping and the relative emphasis on breeding goal traits, and less so to the budget and the cost of phenotyping. Although potential gains from optimizing group sizes and genotyping effort may be small, they come at no extra cost.

\subsection{Acknowledgements}

We are grateful to Havard Bakke for providing information about SalmoBreed's breeding program and his input to the study. 


\subsection{Appendix}

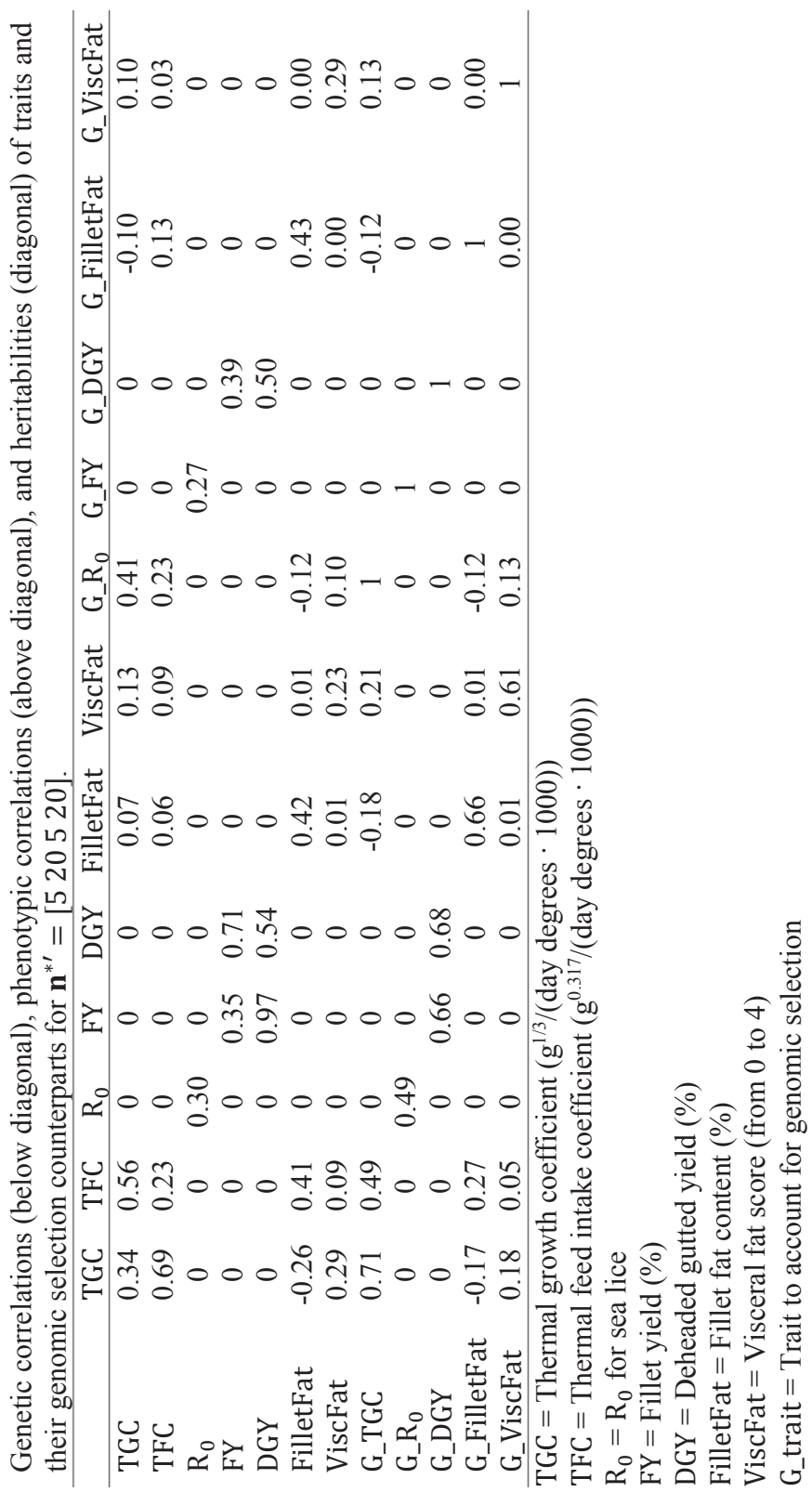




\subsection{References}

Amer, P.R., Fox, G.C., 1992. Estimation of Economic Weights in Genetic-Improvement Using Neoclassical Production Theory - an Alternative to Rescaling. Anim Prod. 54, 341-350.

Cunningham, E., 1973. Cost-effectiveness and population structure in cattle breeding programmes. Ann Genet Sel Anim. 5, 239-256.

De Vries, A.G., 1989. A method to incorporate competitive position in the breeding goal. Anim Prod. 48, 221-227.

De Vries, A.G., Van Der Steen, H.A.M., 1990. Optimal use of nucleus and testing capacity in a pig breeding system with sire and dam lines. Livest Prod Sci. 25, 217-229.

Dekkers, J.C.M., 2007. Prediction of response to marker-assisted and genomic selection using selection index theory. J Anim Breed Genet. 124, 331-341.

Dekkers, J.C.M., Vandervoort, G.E., Burnside, E.B., 1996. Optimal Size of Progeny Groups for Progeny-Testing Programs by Artificial Insemination Firms. J Dairy Sci. 79, 2056-2070.

Do, A., 2013. Genetic improvement of Atlantic salmon in Tasmania. PhD thesis, University of Sydney, Faculty of Veterinary Science.

Gibson, J.P., Kennedy, B.W., 1990. The Use of Constrained Selection Indexes in Breeding for Economic Merit. Theor Appl Genet. 80, 801-805.

Gjedrem, T., 1997. Flesh quality improvement in fish through breeding. Aquacult Int. 5, 197-206.

Gjerde, B., Ødegård, J., Thorland, I., 2011. Estimates of genetic variation in the susceptibility of Atlantic salmon (Salmo salar) to the salmon louse Lepeophtheirus salmonis. Aquaculture. $314,66-72$.

Gjerde, B., Sonesson, A., Storset, A., Rye, M., 2007. Selective breeding and genetics - Atlantic Salmon. in: Thomassen, M., Gudding, R., Norberg, B., Jørgensen, L. (Eds.), Aquaculture Research: From Cage to Consumption. The Research Counsil of Norway, Oslo, 268-301.

Haffray, P., Bugeon, J., Pincent, C., Chapuis, H., Mazeiraud, E., Rossignol, M.-N., Chatain, B., Vandeputte, M., Dupont-Nivet, M., 2012. Negative genetic correlations between production traits and head or bony tissues in large all-female rainbow trout (Oncorhynchus mykiss). Aquaculture. 368-369, 145-152.

Hayes, B.J., Visscher, P.M., Goddard, M.E., 2009. Increased accuracy of artificial selection by using the realized relationship matrix. Genet Res. 91, 47-60.

Hill, W.G., 1993. Variation in Genetic Identity within Kinships. Heredity. 71, 652-653.

Janssen, K., Saatkamp, H., Komen, H., 2018a. Cost-benefit analysis of aquaculture breeding programs. Genet Sel Evol. 50, 2.

Janssen, K., Chavanne, H., Berentsen, P., Komen, H., 2017a. Impact of selective breeding on European aquaculture. Aquaculture. 472, 8-16.

Janssen, K., Berentsen, P., Besson, M., Komen, H., 2017b. Derivation of economic values for production traits in aquaculture species. Genet Sel Evol. 49, 5.

Janssen, K., Komen, H., Saatkamp, H.W., de Jong, M.C.M., Bijma, P., 2018b. Derivation of the economic value of R0 for macroparasitic diseases and application to sea lice in salmon. Genet Sel Evol. 50, 47.

Kause, A., Kiessling, A., Martin, S.A.M., Houlihan, D., Ruohonen, K., 2016. Genetic improvement of feed conversion ratio via indirect selection against lipid deposition in farmed rainbow trout (Oncorhynchus mykiss Walbaum). Brit J Nutr. 116, 1656-1665.

Kristjansson, O., Gjerde, B., Lillehammer, M., Jonasson, J., 2015. Genetic Parameters in Atlantic Salmon for Growth Rate and Carcass Quality Traits Recorded at the Same Body Weight or the Same Age. International Symposium of Genetics in Aquaculture XII, Santiago de Compostela.

Lillehammer, M., Meuwissen, T.H.E., Sonesson, A.K., 2013. A low-marker density implementation of genomic selection in aquaculture using within-family genomic breeding values. Genet Sel Evol. 45.

Lindhé, B., Holmquist-Arbrandt, L., 1977. Economic efficiency of pig breeding schemes: Aspects of a national two-breed programme. Livest Prod Sci. 4, 225-243.

Melton, B.E., Willham, R.L., Heady, E.O., 1994. A note on the estimation of economic values for selection indices: a response. Anim Sci. 59, 455-459. 
Meuwissen, T.H.E., 1997. Maximizing the response of selection with a predefined rate of inbreeding. J Anim Sci. 75, 934-940.

Moen, T., Hayes, B., Baranski, M., Berg, P.R., Kjøglum, S., Koop, B.F., Davidson, W.S., Omholt, S.W., Lien, S., 2008. A linkage map of the Atlantic salmon (Salmo salar) based on ESTderived SNP markers. BMC Genomics. 9, 223.

Powell, J., White, I., Guy, D., Brotherstone, S., 2008. Genetic parameters of production traits in Atlantic salmon (Salmo salar). Aquaculture. 274, 225-231.

Rutten, M.J.M., Bijma, P., Woolliams, J.A., van Arendonk, J.A.M., 2002. SelAction: Software to predict selection response and rate of inbreeding in livestock breeding programs. J Hered. 93, 456-458.

Sonesson, A.K., Odegard, J., Ronnegard, L., 2013. Genetic heterogeneity of within-family variance of body weight in Atlantic salmon (Salmo salar). Genet Sel Evol. 45.

Toro, M.A., Saura, M., Fernandez, J., Villanueva, B., 2017. Accuracy of genomic within-family selection in aquaculture breeding programmes. J Anim Breed Genet. 134, 256-263. 


\section{8}

General discussion 


\subsection{Introduction}

The overall aim of this thesis was to study the economic optimization of breeding programs in aquaculture. Sub-objectives were:

1) To evaluate the impact of selective breeding on European aquaculture

2) To develop methods for the derivation of economic values in aquaculture species

3) To study the optimization of breeding program design

To reach the first sub-objective, a survey was conducted among breeding companies of the main species, i.e. Atlantic salmon, rainbow trout, gilthead seabream, European seabass, and turbot. The impact was assessed by estimating market shares of breeding companies in aquaculture production and realized genetic gain in growth performance.

To reach the second sub-objective, a bio-economic model for the derivation of economic values of production traits was developed. The model was used to derive economic values for gilthead seabream aquaculture. Methods for the derivation of the economic value of $R_{0}$ for macro- and microparasitic diseases were developed. The method for macroparasitic diseases was used to derive the economic value of $\mathrm{R}_{0}$ for sea lice in Atlantic salmon aquaculture in Norway.

To reach the third sub-objective, cost-benefit analysis was used to evaluate alternative breeding program designs for an integrated breeding company, with and without multiplier tier. For each design the number of selection candidates was optimized with the objective to maximize the net present value (NPV). Relations between the optimum number of selection candidates, the length of the time horizon, and production output were described. For a specialized breeding company the allocation of budget over the numbers of phenotyped and genotyped full-sibs of selection candidates in performance tests was optimized with the objective to maximize gain in the aggregate genotype $(\Delta \mathrm{H})$. Sensitivity analyses were performed on the maximum $\Delta \mathrm{H}$ and the relative allocation of budget over activities at the optimum.

Results on the impact of selective breeding on European aquaculture (chapter 2) were not conclusive on the economic impact, because economic benefits of breeding programs were unclear. The economic impact depends on the combined market share of breeding companies in total production and the rate of economic gain, i.e. $\Delta \mathrm{H}$. Some estimates of $\Delta \mathrm{H}$ have already been reported in this thesis, but not for all species. Towards the future, the 
market share of some breeding companies may increase at the expense of companies that produce strains of inferior genetic merit, including unselected strains. Such concentration would increase the economic impact of selective breeding, but depends on the extent to which genetic merit is and can be benchmarked. Furthermore, technological developments may increase $\Delta \mathrm{H}$, and thereby increase the future economic impact of selective breeding. In the first part of this General discussion estimates of $\Delta \mathrm{H}$ per species are provided. These estimates are combined with 2012 market shares to evaluate the current economic impact of selective breeding. Then, the role of benchmarking as a driver of concentration in the aquaculture breeding industry is discussed. Finally, the potential economic impact of main findings from the project FISHBOOST on production efficiency, including disease resistance, is discussed.

The potential to accelerate genetic gain becomes increasingly large when moving further away from the optimum (chapter 6 and 7). To improve a breeding program, one should, therefore, first focus on its weakest part. As weaknesses are removed, the potential for improvement becomes smaller. Yet, small differences in genetic merit matter for the competitive position of breeding companies, hence optimization can provide the extra edge. The first step in the economic optimization of a breeding program is to optimize the relative emphasis on breeding goal traits. Second, the design of the breeding program can be optimized. So far in this thesis, optimization has focussed on only one or few variables at a time. To optimize a breeding program as a whole, its objective should be defined as a function of all activities simultaneously, which poses a multidimensional optimization problem. Differences in the predicted rate of inbreeding $(\Delta \mathrm{F})$ between designs have so far been ignored, while these might affect the ranking of alternative designs. In the second part of this General discussion the definition of the breeding goal is discussed using results of chapters 3, 4, and 5. Methods to solve the multidimensional optimization problem of optimizing a breeding program as a whole are discussed. A method is proposed to account for differences in predicted $\Delta \mathrm{F}$ in the optimization of breeding program design.

In the final part of this General discussion, main findings and conclusions of the thesis are summarized. 


\subsection{Economic impact of selective breeding}

\subsubsection{Economic gain}

To estimate the economic gain from selective breeding on a European level, estimates of $\Delta \mathrm{H}$ are compiled per species. These estimates are extrapolated to a European level using market shares of breeding companies for each of the five main species. For gilthead seabream $\Delta \mathrm{H}$ was predicted at $198 € /$ ton production per generation (chapter 6). Given the average generation interval of 3.5 years, $\Delta \mathrm{H}$ corresponds to $56.5 € /$ ton per year. For Atlantic salmon benefits were predicted to increase by $55 € /$ ton per year (chapter 7 ). To provide estimates of economic gain for European seabass and turbot, the same approach was followed as for gilthead seabream and Atlantic salmon. First, the bio-economic model was used to derive economic values of production traits (chapter 3). Production data from Andromeda S.A. were used for European seabass, and production data from Cluster de la Acuicultura de Galicia (CETGA) were used for turbot. Second, for hypothetical breeding programs $\Delta H$ was predicted in SelAction (Rutten et al., 2002). The structure of these breeding programs was similar as for gilthead seabream (chapter 6), but in contrast to gilthead seabream, European seabass and turbot do not change sex. Genetic parameters for European seabass were based on Dupont-Nivet et al. (2008) and for turbot on Mas-Muñoz et al. (2013) and Liu et al. (2011). For European seabass $\Delta \mathrm{H}$ is predicted at $408 € /$ ton per generation. Given the average generation interval of three years, $\Delta \mathrm{H}$ corresponds to 136 $€ /$ ton per year. For turbot $\Delta \mathrm{H}$ is predicted at $502 € /$ ton per generation. Given the average generation interval of four years, $\Delta \mathrm{H}$ corresponds to $126 € /$ ton per year. For rainbow trout estimates for $\Delta \mathrm{H}$ range from 200 up to $400 € /$ ton per generation, depending on whether a simple index (body weight at harvest) or a more complex index (measures of lipid content and quality traits) is used (Kause, 2019). The generation interval in rainbow trout is three years, hence these estimate for $\Delta \mathrm{H}$ correspond to about $100 € /$ ton per year.

The NPV of a breeding program for an integrated company is determined by $\Delta \mathrm{H}$, the genetic lag, production output, the length of the time horizon, and the costs of the breeding program (chapter 6). When everything else is equal, NPV will be highest for the species with the highest $\Delta \mathrm{H}$ per year. Here, breeding programs for turbot and European seabass are predicted to generate the highest $\Delta \mathrm{H}$ per year (Table 1). The predicted $\Delta \mathrm{H}$ per generation, however, was much higher in European seabass than in gilthead seabream due to more favourable assumptions for genetic parameters. In reality, $\Delta \mathrm{H}$ per generation is expected to be similar for both species, because the production systems and costs of production are very 
similar. $\Delta \mathrm{H}$ per year will still be higher in European seabass than in gilthead seabream, due to its shorter generation interval. The predictions of $\Delta \mathrm{H}$ are optimistic, because the emphasis on breeding goal traits is generally not based on economic values, and selection intensities tend to be lower in practise than in theory.

Table 1 Economic impact of selective breeding in European aquaculture in 2012.

\begin{tabular}{lcccc}
\hline Species & $\begin{array}{c}\Delta \mathrm{H} \\
(€ / \text { ton/year) }\end{array}$ & $\begin{array}{c}\text { Market share } \\
\text { breeding } \\
\text { programs (\%) }\end{array}$ & $\begin{array}{c}\text { Production from } \\
\text { breeding programs } \\
\text { (in 1000 tons) }\end{array}$ & $\begin{array}{c}\text { Increase in annual } \\
\text { benefits } \\
\text { (in million } € / \text { year) }\end{array}$ \\
\hline $\begin{array}{l}\text { Gilthead } \\
\text { seabream }\end{array}$ & 56.5 & $60-66$ & 66 & 3.7 \\
$\begin{array}{l}\text { Atlantic salmon } \\
\begin{array}{l}\text { European } \\
\text { seabass }\end{array}\end{array}$ & 55 & $93-95$ & 1400 & 77 \\
$\begin{array}{l}\text { Turbot } \\
\text { Rainbow trout }\end{array}$ & 136 & $43-56$ & 35 & 4.8 \\
Total & 126 & 100 & 13 & 1.6 \\
\hline
\end{tabular}

$\Delta \mathrm{H}=$ Gain in the aggregate genotype

Assuming that estimates of $\Delta \mathrm{H}$ are representative for the industry, benefits of genetic improvement can be estimated as the product of $\Delta \mathrm{H}$ and the production from breeding programs. Table 1 presents a per species overview of the economic impact of selective breeding in European aquaculture. For Atlantic salmon the increase in annual benefits is highest, because, despite a relatively low $\Delta \mathrm{H}$ per year, the production from breeding programs is by far the highest. For turbot the increase in annual benefits is lowest, because, despite a relatively high $\Delta \mathrm{H}$ per year, the production from breeding programs is lowest. Note that the increase in annual benefits is cumulative, so that total benefits are 104 million euro in year one, 208 million euro in year two, etcetera. For comparison, the total value of the total European aquaculture production of these five species was 8.5 billion euro in 2012 (FAO, 2015), hence benefits increase by $1.2 \%$ of the value per year. These results provide ballpark figures only, because estimates of $\Delta \mathrm{H}$ are optimistic, they are highly sensitive to assumed genetic parameters, and $\Delta \mathrm{H}$ will differ among breeding companies.

\subsubsection{Benchmarking as a driver of concentration}

Benchmarking on genetic merit by producers is expected to be the main driver of concentration of specialized breeding companies. A specialized breeding company that produces a strain of superior genetic merit may increase its market share. A larger market share allows for a higher budget for the breeding program, accelerating genetic gain. This creates a positive feedback loop that stimulates mergers and acquisition of specialised breeding companies. For integrated companies benchmarking provides a measure of the 
performance of one's own breeding program relative to the competition. Underperformance may stimulate additional investment in the breeding program, or its termination when a much superior strain from a specialized breeding company is available. The extent to which benchmarking can be performed, however, will differ among species, companies, and traits.

Among species and companies the extent to which benchmarking is performed depends on culture practices and the scale of operations. Some farmers will not keep a sufficiently detailed administration to allow for benchmarking. For some others differences in genetic merit are obscured by culture practices. For example, some farmers deliberately let their fish grow slowly to let them get a slender and elongated shape. With such practises differences in genetic merit among strains may become irrelevant. For the majority of producers, however, differences in genetic merit are relevant, but the extent to which these can be benchmarked depends on the scale of production. In contrast to large scale producers, small-scale producers may not have the capacity to adequately benchmark the performance of strains from different breeding companies. Small-scale producers account for a relatively large part of the total production in rainbow trout, a smaller part in European seabass and gilthead seabream, and a minor part in Atlantic salmon. As the degree of concentration in production increases, the importance of benchmarking is expected to increase as well. In the presence of genotype by environment interaction benchmarking in different environments can give contrasting results on strain superiority (Sae-Lim et al., 2013). Aquaculture is a relatively young industry with much diversity in production systems and culture practices. Practices are particularly diverse for rainbow trout, but they are more standardized for European seabass, gilthead seabream, and Atlantic salmon. Over time, however, production practises tend to become increasingly standardized (Klepper, 1996), so that benchmarking provides more consistent results across producers. With more standardized production practices, fewer strains are needed to meet the diversity in requirements.

Genetic merit can be benchmarked relatively easily for production and quality traits such as growth rate, feed conversion ratio, and fillet yield. Genetic merit for disease resistance, i.e. $\mathrm{R}_{0}$, however, is much harder to benchmark, because the frequency of disease outbreaks and incidence during an outbreak are for a large part determined by random events (Tsairidou et al., 2019). When benchmarking on production and quality traits is the only criterion for producers, genetic improvement of $R_{0}$ provides a competitive advantage only 
to the extent that it influences these traits. Genetic improvement of $R_{0}$ can reduce production losses and thereby indirectly improve production and quality traits (chapter 4 and 5). For macroparasitic diseases, however, production losses can also be kept constant by management, so that genetic superiority in $\mathrm{R}_{0}$ does not affect production and quality traits. In the latter case genetic improvement of $\mathrm{R}_{0}$ does not provide any competitive advantage, except for what can be achieved by marketing. Instead, improvement of $\mathrm{R}_{0}$ may worsen a breeding company's competitive position, because the emphasis on $R_{0}$ in the breeding goal is at the expense of gain in other traits. When genetic gain in $R_{0}$ is invisible to producers, genetic merits of simple and advanced breeding companies may appear to be similar, allowing them to coexist.

Summarizing the above, benchmarking is expected to drive concentration of the breeding industry, in particular for species dominated by specialized breeding companies, such as Atlantic salmon and rainbow trout. Since the 2012 survey, there has been further concentration of the breeding industry in Atlantic salmon, leaving effectively three dominant players in Europe, hence further concentration is unlikely. For rainbow trout further concentration is expected. Benchmarking tends to favour strains that excel in production traits, while genetic merit for $\mathrm{R}_{0}$ may not be a criterion. Concentration would increase market shares of companies with strains of superior genetic merit at the expense of strains of inferior genetic merit, including unselected strains. The economic impact of selective breeding may thus be expected to increase after further concentration of the breeding industry.

\subsubsection{Production efficiency}

The economic efficiency of aquaculture production is largely determined by the production efficiency. Production efficiency may be defined as the ratio of edible product relative to the total input of feed, and is determined by feed conversion ratio (FCR), fillet yield, and disease resistance, hence genetic improvement of these traits is of interest. In FISHBOOST the potential for genetic improvement of these traits has been studied extensively. Here, the major findings are shortly summarized and their implications for future economic benefits of selective breeding are discussed.

Variation in feed intake (TFC) can be explained by body weight gain (TGC) and fat content. Remaining unexplained variation, e.g., due to variation in maintenance requirements, may be defined as residual feed intake. For aquaculture species residual feed intake has been 
hypothesized to explain little of the variation in feed intake, because the energy requirement for maintenance relative to the intake is low in fish relative to livestock species (Knap and Kause, 2018). Costs to record residual feed intake are high, because it requires the recording of individual feed intake per fish, which is very challenging (de Verdal et al., 2017). Thus, to improve FCR one should increase TGC while decreasing fat content (Knap and Kause, 2018). In the breeding program for Atlantic salmon $\Delta H$ was $99 € /$ ton per year when fillet fat content was allowed to change, while it was only $55 € /$ ton per year when fillet fat content was held constant (chapter 7 ). This $43 \%$ reduction in $\Delta \mathrm{H}$ was largely due to lower genetic gain in FCR. Similarly, for gilthead seabream and European seabass, $\Delta H$ would increase by about $25 \%$ when fat content is included in the index (results not shown). For turbot, however, records of fat content in the index would contribute little to $\Delta \mathrm{H}$, because the economic response in TFC already accounts for only a minor part of $\Delta \mathrm{H}$ (results not shown). This is explained by the relatively low costs of feed ( $20 \%$ of the turnover) and an already low FCR (0.95 g feed/ g gain).

Fillet yield is defined as the ratio of fillet weight to body weight, expressed in $\%$. Phenotypic and genetic correlations between the numerator (fillet weight) and denominator (body weight) of this trait are close to unity, which has been suggested to introduce statistical difficulties. Direct selection on the ratio, however, yields similar results to alternative selection indices, e.g., a linearized index or residual fillet yield (Fraslin et al., 2018). Fillet yield cannot be recorded on selection candidates, but instead morphological records on selection candidates may be used as predictors. The accuracy, however, tends to be low (Haffray et al., 2013; Vandeputte et al., 2017). Alternatively, fillet yield can be recorded on full-sibs of selection candidates. Filleting, however, tends to be inconsistent and introduces residual variation, resulting in a low heritability. Instead, deheaded gutted yield is much easier to record accurately and can be used in the index as a predictor of fillet yield, because both traits are highly correlated (Haffray et al., 2012; Vandeputte et al., 2017). Advantages of morphological records on selection candidates are relatively low costs and the ability to perform within-family selection, while records on sibs tend to give a higher accuracy but require genomic selection to exploit within-family variation. The economic value of fillet yield can be calculated as the ratio of the sales price of fish (in $€$ per $\mathrm{kg}$ ) to fillet yield (in \%) (chapter 7). This economic value is appropriate for species that are mostly marketed as fillets, such as Atlantic salmon and large rainbow trout. When only a proportion is marketed as fillets, the economic value should be multiplied by that 
proportion. This would be appropriate for European seabass and gilthead seabream, which are mostly marketed as whole round fish, hence the economic value of fillet yield in these species is substantially lower than in salmonids. Economic benefits of genetic improvement of fillet yield in Atlantic salmon have been estimated at $24 € /$ ton per generation, accounting for $7.1 \%$ of $\Delta \mathrm{H}$ (chapter 7 ). Here, fillet yield was predicted to increase by $0.41 \%$ per generation by recording deheaded gutted yield on sibs of selection candidates. Given that the economic value of fillet yield will be lower in European seabass and gilthead seabream, economic benefits will also be lower.

Disease resistance is heritable for almost all diseases, with heritability estimates ranging from moderate to high across species (Houston, 2017; Yáñez et al., 2014). An appealing example of genetic improvement of disease resistance is the case of infectious pancreatic necrosis virus (IPN) in Atlantic salmon. In the few years after the identification of a major quantitative trait locus (QTL) that explained over $80 \%$ of the genetic variation, genetic improvement has successfully reduced IPN incidence by $75 \%$. Production losses due to mortality have thereby been reduced substantially (Moen et al., 2015). There is, however, no reason to believe that the case of IPN is representative for other diseases, and the economic impact of genetic improvement of disease resistance is far from evident. For most diseases resistance is a highly polygenic trait, which makes genetic improvement more difficult than selection on a single QTL (Houston, 2017). Furthermore, the potential economic impact depends strongly on the value of $\mathrm{R}_{0}$ and the management strategy (chapter 4 and 5). Since economic values are unknown, the potential economic impact of improved disease resistance is also unknown.

Out of the above options to improve production efficiency, improvement of FCR by reducing fat content has most potential to increase the economic benefits of selective breeding. Although diseases are a major problem in aquaculture, it is currently unknown for most diseases whether genetic improvement has a meaningful economic impact.

\subsection{Optimization of breeding programs}

\subsubsection{The breeding goal}

Inappropriate emphasis on breeding goal traits compromises $\Delta \mathrm{H}$, in particular when too little (much) emphasis is put on (un)important traits or when the sign of the weight is reversed (Smith, 1983). In the absence of economic values, intuition may guide decisions 
on the desired direction for genetic improvement. Intuition may work for some traits, but not for others.

Intuition might do a reasonable job to balance the relative emphasis on production traits. The relative importance of production traits (TGC, TFC, M, and $\sigma_{\mathrm{HW}}$ ), measured by the change in gross margin from one genetic standard deviation improvement (Table 6, chapter 3), may be more or less as expected. On the other hand, the weight on fillet fat content (FilletFat) required to maintain its level constant in a desired gains index depends strongly on the expected genetic correlation between FilletFat and TGC (chapter 7). Both positive (Gjedrem, 1997) and negative (Kause et al., 2016; Kristjansson et al., 2015) genetic correlations have been reported, and these require opposite signs for the weight on FilletFat to maintain its level constant. The desired gains index reduced $\Delta \mathrm{H}$ by $43 \%$ relative to a breeding goal were FilletFat was allowed to change. Although this desired gains index might have been appropriate, these results illustrate how much genetic gain can be forgone by changing the emphasis between breeding goal traits. It also shows that a desired gains index bears the risk of inappropriate emphasis on breeding goal traits when genetic correlations are uncertain. In this case the need of a desired gains index could be overcome by the derivation of the economic value of FilletFat. The economic value could, for example, be obtained by asking fish processors how much they would be willing to pay for fish with a $1 \%$ lower or higher FilletFat.

The relation between $\mathrm{R}_{0}$ and its economic value has been described for macro- and microparasitic diseases (chapters 4 and 5, respectively). It may be intuitive to put more emphasis on improvement of $\mathrm{R}_{0}$ for a disease that involves high costs than for a disease that involves low costs. The potential for economic gain, however, does not depend on the total costs of a disease, but only on the extent to which these costs can be avoided (McInerney et al., 1992). For any given disease total costs will decrease with the value of $\mathrm{R}_{0}$. When $\mathrm{R}_{0}$ becomes smaller than 1 , e.g., due to genetic improvement, the disease disappears from the population and there is no potential for further economic gain. In other cases the potential for economic gain depends on the genetic selection differential in units $\mathrm{R}_{0}$ and its economic value. Here, the genetic selection differential is assumed to be proportional to $R_{0}$ itself (chapter 7), so that the genetic selection differential decreases over generations. This is in line with the study and Tsairidou et al. (2019), who predicted the genetic selection differential over multiple generations to be more or less proportional to 
$\mathrm{R}_{0}$. For macroparasitic diseases where management is optimized, the economic value increases when $R_{0}$ decreases (Fig. 3, chapter 4). For decreasing values of $R_{0}$ the increase in economic value exceeds the decrease in genetic selection differential, so that the potential for economic gain increases with decreasing costs of the disease. For macroparasitic diseases where production losses are kept constant the economic value increases when $\mathrm{R}_{0}$ decreases (Fig. 3, chapter 4). The economic value is proportionate to $1 / R_{0}$ (Eq. 11, chapter 4), so that when $R_{0}$ decreases the increase in economic value is exactly offset by the decrease in genetic selection differential. The potential for economic gain is thus independent of the costs of the disease. For epidemic microparasitic diseases for which there is a high frequency of infections by an outside source per production cycle, the economic value increases when $\mathrm{R}_{0}$ decreases (Fig. 1b, chapter 5). For decreasing values of $\mathrm{R}_{0}$ the increase in economic value exceeds the decrease in genetic selection differential, so that the potential for economic gain increases with decreasing costs of the disease. This is illustrated in Fig. 1a of chapter 5, where the reduction in losses is lower when $\mathrm{R}_{0}$ improves from 4 to 3 than when $R_{0}$ improves from 3 to 2.25. For endemic microparasitic diseases the economic value increases when $\mathrm{R}_{0}$ decreases (Fig. 2b, chapter 5). For decreasing values of $\mathrm{R}_{0}$ the increase in economic value exceeds the decrease in genetic selection differential, so that the potential for economic gain increases with decreasing costs of the disease. This is illustrated in Fig. 2a of chapter 5, where the reduction in losses is lower when $\mathrm{R}_{0}$ improves from 4 to 3 than when $\mathrm{R}_{0}$ improves from 3 to 2.25 . Similarly, halving the value of $\mathrm{R}_{0}$ will reduce the infected proportion at the endemic equilibrium by less than $10 \%$ when $\mathrm{R}_{0}>10$, whereas it will remove the disease from the population when $1<\mathrm{R}_{0} \leq 2$ (Eq. 8 , chapter 5). The above cases illustrate that intuition is a particular poor predictor of potential for economic gain and the economic value of $\mathrm{R}_{0}$.

It was shown that the costs made for improvement of a trait should be aligned with its contribution to $\Delta \mathrm{H}$ (chapter 7). When the distinction between the breeding goal and index is not formal, however, it may be tempting to put extra emphasis on traits for which recording involves high costs. For example, costs of a disease challenge test are high, hence to make such efforts count, a breeding company may put much weight on improvement of $\mathrm{R}_{0}$. In this case the emphasis on $\mathrm{R}_{0}$ in the breeding goal would be aligned with costs made for its improvement, instead of the other way around. Given the non-intuitive relation between $R_{0}$ and its economic value, overemphasis on $R_{0}$ is easy to imagine. 
In the extreme case of a single-trait breeding goal, the emphasis on the breeding goal trait will be optimum. As breeding programs become more advanced, the number of traits included in the breeding goal tends to increase. When more traits are included in the breeding goal, the relative emphasis on each trait becomes increasingly complex to optimize. The optimization is particularly complex when there is no formal distinction between the index and breeding goal, and all recorded traits are also included in the breeding goal. This probably applies to many aquaculture breeding programs. Furthermore, aquaculture breeding programs commonly use desired gains indexes instead of economic values to balance the relative emphasis on breeding goal traits (Nielsen et al., 2014). As illustrated for FilletFat, inappropriate emphasis on breeding goal traits easily leads to forgone $\Delta H$. Goddard (1998) argued that suboptimal emphasis on breeding goal traits is the largest cause of inefficiency in breeding programs. This risk will be larger for advanced breeding programs that record many traits than for simple breeding programs that record few traits. Economic values optimize the relative emphasis on breeding goal traits, hence their derivation remains a relevant topic in research towards the future as breeding programs tend to become more advanced.

\subsubsection{Multidimensional optimization}

NPV can be defined as a function of the number of selection candidates (chapter 6 ). $\Delta \mathrm{H}$ can be defined as a function of the budget allocated to the numbers of phenotyped and genotyped full-sibs per family in performance tests (chapter 7). For the optimization of a breeding program as a whole the objective should be defined as a function of all activities simultaneously. The feasible region of a solution, however, increases dramatically with the number of activities. In other words, optimization becomes more complex when the number of variables increases.

In any optimization method it is worthwhile to consider whether the number of variables can be reduced beforehand. A lower number of variables to be optimized means faster convergence at the optimum. For example, the number of phenotyped and the number of genotyped full-sibs per family in a performance test were considered as two separate activities in the optimization of the breeding program for Atlantic salmon (chapter 7). The number of genotyped full-sibs per family was constrained by the number that was phenotyped. Marginal gains in $\Delta \mathrm{H}$ per unit costs for any given number of full-sibs per family were higher for genotyping than for phenotyping, hence the unconstrained optimum 
number genotyped was higher than the optimum number phenotyped (results not shown). Given the constraint on the number genotyped, both numbers were equal at the optimum, hence for both activities only a single variable, i.e. the number phenotyped and genotyped, needs to be considered in the optimization. Thus, the number of variables to be optimized could have been reduced to two instead of four, making the optimization much more efficient.

It is difficult to maximize the objective of a breeding program by optimizing multiple design variables simultaneously. The optimization is particularly difficult when the objective is to maximize NPV, because the annual budget for the breeding program is an additional variable to be optimized. Maximization of $\Delta \mathrm{H}$ with a limited budget is, therefore, discussed first. To maximize $\Delta \mathrm{H}$, the optimization problem can be reduced to multiple subproblems of lower complexity. This can be done by dividing the total budget for the breeding program in parts that are allocated to different sets of activities. Since each part of the budget involves fewer activities than the breeding program as a whole, the complexity of these problems is reduced compared to the original problem. These subproblems can thus be solved more easily. The shadow value of each part of the budget can be estimated as the marginal gain in the objective function per unit cost from relaxing the budget constraint. The shadow value of the budget for selection candidates decreases with an increasing number (chapter 6), and the shadow value of the budget for the number of full-sibs per selection candidate in performance tests decreases with an increasing number (chapter 7). Thus, irrespective of the activity, the shadow value of each part of the budget decreases with an increasing part of the budget. To arrive at the optimum, budget can be moved from the part with the lowest shadow value to the part with the highest shadow value in an iterative approach. When the shadow value of the budget constraint of each subproblem is equal, the budget allocation over and within each part of the budget is optimized. Thus, the global optimum is returned when the shadow value of each part of the budget is equal. Instead of the actual optimum, a solution close to the optimum may also be satisfactory, because the optimum is expected to be rather flat. To solve the optimization for the more complex maximization of NPV, first the allocation of limited budget over activities can be optimized for the objective to maximize $\Delta H$ as before. Second, the shadow value of the budget can be used to decide on the optimum budget (Fig. 4c, chapter 7). The relative allocation of budget over activities is expected to remain close to the optimum with a change in total budget (Fig. 5c, chapter 7). 
The grid search as used in the optimization of the breeding program for Atlantic salmon (chapter 7) is a 'brute-force' method to solve an optimization problem, and more efficient algorithms may be available. Dekkers et al. (1996) used response surface methodology to fit a polynomial of explanatory variables to the response variable. $\Delta \mathrm{H}$ increases at a decreasing rate when an activity increases while others are held constant (chapter 7), but this relation cannot be described by a polynomial, hence a polynomial cannot provide an accurate description of the objective function. Furthermore, gain in the objective function will generally be robust to moderate changes in the allocation of budget over activities around the optimum. Although this is a pro in itself, it poses a con for optimization, because even minor lack of fit of the polynomial may result in convergence at a false optimum. Response surface methodology, therefore, seems inferior to grid search for the optimization of breeding program design. The flat optimum will also pose a difficulty in alternative optimization methods. A further complexity is that many activities in a breeding program are integers instead of continuous differentiable variables, e.g., the number of full-sibs per family in a performance test only takes whole round numbers. For grid search, however, integers are advantageous compared to continuous variables, because they take only a limited number of possible values. When the number of options to be explored in grid search is too large, a two-step approach can be followed. In the first step a sparse grid is used to narrow down the feasible region of the solution. In the second step a dense grid is used to pinpoint the solution within this smaller region. Thus, grid search seems not too bad after all.

\subsubsection{Evaluation at the same rate of inbreeding}

In the optimizations of breeding program design, differences in predicted $\Delta \mathrm{F}$ have been ignored (chapter 6 and 7). For the purpose of optimization, however, alternative breeding program designs should be evaluated at the same rate of inbreeding $(\Delta \mathrm{F})$ (Quinton et al., 1992), or the effects of $\Delta \mathrm{F}$ should be explicitly accounted for in the objective function. Here, $\Delta \mathrm{F}$ is considered unconstrained when selection is based only on $\mathrm{H}$, whereas $\Delta \mathrm{F}$ is considered constrained when the increase in mean kinship is constrained, i.e. optimum contribution selection (Meuwissen, 1997). When $\Delta \mathrm{F}$ is unconstrained, a higher selection intensity leads to a higher $\Delta \mathrm{F}$. A higher $\Delta \mathrm{F}$ will increase the effects of inbreeding depression and loss in genetic variance. Thus, when $\Delta \mathrm{F}$ is unconstrained, the evaluation of alternative breeding program designs should account for inbreeding depression and loss in genetic variance due to inbreeding as in Smith (1969). His method, however, is inadequate 
for situations where $\Delta \mathrm{F}$ is constrained. When $\Delta \mathrm{F}$ is constrained, the effects of inbreeding depression and loss in genetic variance are equal for alternative breeding program designs, hence are irrelevant to their ranking. Still, the constraint on $\Delta \mathrm{F}$ comes at a cost.

As a simple example, consider two breeding programs simulated in SelAction (Rutten et al., 2002). SelAction can only predict $\Delta \mathrm{H}$ for situations where $\Delta \mathrm{F}$ is unconstrained. For the first breeding program $\Delta \mathrm{H}=100 /$ generation and $\Delta \mathrm{F}=1 \%$ /generation. For the second breeding program $\Delta \mathrm{H}=€ 110 /$ generation and $\Delta \mathrm{F}=1.5 \% /$ generation. Optimum contribution selection will be implemented to constrain $\Delta \mathrm{F}$ to $1 \%$ generation in both breeding programs. Which program is superior?

A constraint on $\Delta \mathrm{F}$ will reduce $\Delta \mathrm{H}$ when the unconstrained $\Delta \mathrm{F}$ exceeds its tolerable level. Thus, to evaluate breeding programs at the same constrained $\Delta \mathrm{F}$, a penalty could be added to $\Delta \mathrm{H}$ for the predicted unconstrained $\Delta \mathrm{F}$ above its tolerable level. This penalty should be equal to the shadow value of $\Delta \mathrm{F}$. Here, the shadow value is the marginal increase in the objective function from relaxation of the constraint, i.e. $\partial(\Delta \mathrm{H}) / \partial(\Delta \mathrm{F})$ evaluated at, e.g., $\Delta \mathrm{F}=1 \%$ /generation. For existing breeding programs this shadow value can be estimated from previous generations applying optimum contribution selection. The objective of optimum contribution selection is to maximize $\Delta \mathrm{H}$ at a predefined (and constrained) $\Delta \mathrm{F}$ (Meuwissen, 1997). Using the method of Lagrange, any increase in $\Delta \mathrm{F}$ beyond the predefined level is penalized by a Lagrangian multiplier, which is equal to the shadow value of the constraint on $\Delta \mathrm{F}$. When another method is used for optimum contribution selection, e.g., semidefinite programming (Pong-Wong and Woolliams, 2007) or differential evolution (Carvalheiro et al., 2010), the shadow value may be estimated as the marginal increase in $\Delta \mathrm{H}$ from a small relaxation of the constraint on $\Delta \mathrm{F}$. The product of the shadow value and the predicted unconstrained $\Delta \mathrm{F}$ above its tolerable level should be subtracted from $\Delta \mathrm{H}$ to evaluate alternative breeding program designs at the same $\Delta \mathrm{F}$. When the constrained $\Delta \mathrm{F}$ increases, $\Delta \mathrm{H}$ increases at a decreasing rate (Clark et al., 2013). The shadow value, therefore, decreases when the constrained $\Delta \mathrm{F}$ increases. In other words, proportionally more $\Delta \mathrm{H}$ is lost as the constraint on $\Delta \mathrm{F}$ becomes stricter. Although shadow values will differ for alternative breeding program designs, these differences are not expected to have much effect on their ranking when all alternatives do not differ in breeding goal and derive from the same baseline breeding program, e.g., evaluating alternative designs to an existing breeding program. Thus, when $\Delta \mathrm{F}$ is constrained, alternative 
breeding program designs can be compared by penalizing the predicted unconstrained $\Delta \mathrm{F}$ above its tolerable level by the same shadow value, which is estimated from previous selection rounds.

To continue with the example above, let the tolerable $\Delta \mathrm{F}$ be $1 \%$ /generation and the shadow value be $€ 20 /$ generation per $\%$ increase in $\Delta \mathrm{F}$. This constraint on $\Delta \mathrm{F}$ would not affect $\Delta \mathrm{H}$ of the first breeding program, but it would lower $\Delta \mathrm{H}$ of the second program by $€ 10 /$ generation. Thus, both breeding programs rank equally. If the shadow value would be higher, e.g., because $\Delta \mathrm{F}$ is constrained at a lower value, the first breeding program would be superior. If the shadow value would be lower, e.g., because $\Delta \mathrm{F}$ is constrained at a higher value, the second breeding program would be superior.

\subsection{Conclusion}

Annual economic benefits of selective breeding in European aquaculture were predicted to increase cumulatively by about 100 million euro each year. This rate of economic gain may be lower in reality due to some optimistic assumptions. Nevertheless, the current rate of economic gain is expected to increase towards the future. Benchmarking drives concentration of the breeding industry, which can increase the market share of strains of superior genetic merit at the expense of inferior strains. The adoption of new technologies to improve production efficiency can further increase economic gain, whereby the improvement of FCR by reducing fat content has most potential.

As breeding programs become more advanced, the relative emphasis on breeding goal traits becomes increasingly complex to optimize. In particular for $\mathrm{R}_{0}$ the economic value is far from intuitive, so that the emphasis on its improvement in breeding programs is likely to be suboptimal. Suboptimal emphasis on breeding goal traits appears to be the most important source of forgone economic gains in aquaculture breeding programs. Furthermore, current efforts by breeding companies to improve $\mathrm{R}_{0}$ are not justified by expected economic benefits, simply because these are unknown (except for sea lice). Therefore, the derivation of economic values, in particular for $\mathrm{R}_{0}$, remains a relevant topic in research.

The optimization of breeding program design can further improve their economic efficiency. The net present value or gain in the aggregate genotype for a given budget can be increased by shortening the genetic lag, optimization of the number of selection 
candidates, and optimization of the allocation of budget over performance tests. A stepwise approach can be used to optimize all these activities within a given breeding program. A penalty on the predicted unconstrained rate of inbreeding beyond its tolerable level allows for the evaluation of alternative designs at the same constrained rate of breeding. In competition among breeding companies optimization of design can provide an extra edge. Extra gains from the optimization of a breeding program design, however, are small, and cannot make up for relatively large forgone gains due to inappropriate emphasis on breeding goal traits.

\subsection{References}

Carvalheiro, R., de Queiroz, S.A., Kinghorn, B., 2010. Optimum contribution selection using differential evolution. Rev Bras Zootecn. 39, 1429-1436.

Clark, S.A., Kinghorn, B.P., Hickey, J.M., van der Werf, J.H., 2013. The effect of genomic information on optimal contribution selection in livestock breeding programs. Genet Sel Evol. 45, 44.

de Verdal, H., Komen, H., Quillet, E., Chatain, B., Allal, F., Benzie, J.A.H., Vandeputte, M., 2017. Improving feed efficiency in fish using selective breeding: a review. Rev Aquac. 10, 1-19.

Dekkers, J.C.M., Vandervoort, G.E., Burnside, E.B., 1996. Optimal Size of Progeny Groups for Progeny-Testing Programs by Artificial Insemination Firms. J Dairy Sci. 79, 2056-2070.

Dupont-Nivet, M., Vandeputte, M., Vergnet, A., Merdy, O., Haffray, P., Chavanne, H., Chatain, B., 2008. Heritabilities and GxE interactions for growth in the European sea bass (Dicentrarchus labrax L.) using a marker-based pedigree. Aquaculture. 275, 81-87.

FAO, 2015. Fisheries and aquaculture software. FishStatJ - software for fishery statistical time series. FAO Fisheries and Aquaculture Department. Rome.

Fraslin, C., Dupont-Nivet, M., Haffray, P., Bestin, A., Vandeputte, M., 2018. How to genetically increase fillet yield in fish: New insights from simulations based on field data. Aquaculture. 486, 175-183.

Gjedrem, T., 1997. Flesh quality improvement in fish through breeding. Aquacult Int. 5, 197-206.

Goddard, M.E., 1998. Consensus and debate in the definition of breeding objectives. J Dairy Sci. 81, 6-18.

Haffray, P., Bugeon, J., Rivard, Q., Quittet, B., Puyo, S., Allamelou, J.M., Vandeputte, M., DupontNivet, M., 2013. Genetic parameters of in-vivo prediction of carcass, head and fillet yields by internal ultrasound and 2D external imagery in large rainbow trout (Oncorhynchus mykiss). Aquaculture. 410, 236-244.

Haffray, P., Bugeon, J., Pincent, C., Chapuis, H., Mazeiraud, E., Rossignol, M.-N., Chatain, B., Vandeputte, M., Dupont-Nivet, M., 2012. Negative genetic correlations between production traits and head or bony tissues in large all-female rainbow trout (Oncorhynchus mykiss). Aquaculture. 368-369, 145-152.

Houston, R.D., 2017. Future directions in breeding for disease resistance in aquaculture species. Rev Bras Zootecn. 46, 545-551.

Kause, A., 2019. FISHBOOST Deliverable report 6.4. Rainbow trout: Economic benefits and desired gains for important traits. 1-8.

Kause, A., Kiessling, A., Martin, S.A.M., Houlihan, D., Ruohonen, K., 2016. Genetic improvement of feed conversion ratio via indirect selection against lipid deposition in farmed rainbow trout (Oncorhynchus mykiss Walbaum). Brit J Nutr. 116, 1656-1665.

Klepper, S., 1996. Entry, exit, growth, and innovation over the product life cycle. Am Econ Rev. $86,562-583$.

Knap, P.W., Kause, A., 2018. Phenotyping for Genetic Improvement of Feed Efficiency in Fish: Lessons From Pig Breeding. Front Genet. 9. 
Kristjansson, O., Gjerde, B., Lillehammer, M., Jonasson, J., 2015. Genetic Parameters in Atlantic Salmon for Growth Rate and Carcass Quality Traits Recorded at the Same Body Weight or the Same Age. International Symposium of Genetics in Aquaculture XII, Santiago de Compostela.

Liu, Y.-X., Wang, G.-X., Wang, Y.-F., Si, F., Sun, Z.-H., Zhang, X.-Y., Wang, J.-D., Liu, H.-J., 2011. Estimation of genetic parameters for growth traits of Japanese flounder Paralichthys olivaceus using an animal model. Fisheries Sci. 77, 87-93.

Mas-Muñoz, J., Blonk, R., Schrama, J.W., van Arendonk, J., Komen, H., 2013. Genotype by environment interaction for growth of sole (Solea solea) reared in an intensive aquaculture system and in a semi-natural environment. Aquaculture. 410-411, 230-235.

McInerney, J.P., Howe, K.S., Schepers, J.A., 1992. A Framework for the Economic-Analysis of Disease in Farm Livestock. Prev Vet Med. 13, 137-154.

Meuwissen, T.H.E., 1997. Maximizing the response of selection with a predefined rate of inbreeding. J Anim Sci. 75, 934-940.

Moen, T., Torgersen, J., Santi, N., Davidson, W.S., Baranski, M., Odegard, J., Kjoglum, S., Velle, B., Kent, M., Lubieniecki, K.P., Isdal, E., Lien, S., 2015. Epithelial Cadherin Determines Resistance to Infectious Pancreatic Necrosis Virus in Atlantic Salmon. Genetics. 200, 13131326.

Nielsen, H.M., Amer, P.R., Byrne, T.J., 2014. Approaches to formulating practical breeding objectives for animal production systems. Acta Agr Scand A An Sci. 64, 2-12.

Pong-Wong, R., Woolliams, J.A., 2007. Optimisation of contribution of candidate parents to maximise genetic gain and restricting inbreeding using semidefinite programming. Genet Sel Evol. 39, 3.

Quinton, M., Smith, C., Goddard, M.E., 1992. Comparison of selection methods at the same level of inbreeding. J Anim Sci. 70, 1060-1067.

Rutten, M.J.M., Bijma, P., Woolliams, J.A., van Arendonk, J.A.M., 2002. SelAction: Software to predict selection response and rate of inbreeding in livestock breeding programs. J Hered. 93, 456-458.

Sae-Lim, P., Kause, A., Mulder, H.A., Martin, K.E., Barfoot, A.J., Parsons, J.E., Davidson, J., Rexroad III, C.E., Van Arendonk, J.A.M., Komen, H., 2013. Genotype-by-environment interaction of growth traits in rainbow trout (Oncorhynchus mykiss): A continental scale study. J Anim Sci. 91, 5572-5581.

Smith, C., 1969. Optimum Selection Procedures in Animal Breeding. Anim Prod. 11, 433-442.

Smith, C., 1983. Effects of changes in economic weights on the efficiency of index selection. J Anim Sci. 56, 1057-1064.

Tsairidou, S., Anacleto, O., Woolliams, J.A., Doeschl-Wilson, A., 2019. Enhancing genetic disease control by selecting for lower host infectivity and susceptibility. Heredity.

Vandeputte, M., Puledda, A., Tyran, A.S., Bestin, A., Coulombet, C., Bajek, A., Baldit, G., Vergnet, A., Allal, F., Bugeon, J., Haffray, P., 2017. Investigation of morphological predictors of fillet and carcass yield in European sea bass (Dicentrarchus labrax) for application in selective breeding. Aquaculture. 470, 40-49.

Yáñez, J.M., Houston, R.D., Newman, S., 2014. Genetics and genomics of disease resistance in salmonid species. Front Genet. 5. 
Summary 
To meet the global demand for fish in a more sustainable manner, aquaculture needs to increase its economic and resource use efficiency. This can be achieved by genetic improvement of aquaculture species in breeding programs. The aim of this thesis was to study the economic optimization of breeding programs in aquaculture.

The objective of chapter 2 was to evaluate the impact of selective breeding on European aquaculture. Surveys were conducted among breeding companies of five major species cultured in Europe: Atlantic salmon, rainbow trout, European seabass, gilthead seabream, and turbot. The market share was estimated as the combined egg or juvenile production of breeding companies relative to the total egg or juvenile production in Europe for each of the species in 2012. Cumulative genetic gain was estimated from the number of selected generations in current breeding programs, combined with genetic trends, reported selection responses in literature, and phenotypic differences. The combined market share of breeding companies ranged from $43-56 \%$ for seabass to $100 \%$ for turbot. The total volume of fish production in Europe that originated from selective breeding was 1653-1706 thousand tons, corresponding to $80-83 \%$ of the total aquaculture production. Over species, there were 37 breeding programs of which the majority performed family selection. Growth performance was universally selected upon. Cumulative genetic gain in growth performance varied from $+65 \%$ for turbot to $+900 \%$ for rainbow trout in terms of harvest weight, and from $+25 \%$ for turbot to $+200 \%$ for rainbow trout in terms of thermal growth coefficient. It is concluded that selective breeding has a major impact on European aquaculture and will contribute to future growth of the sector.

The objective of chapters $\mathbf{3}, \mathbf{4}$, and 5 was to develop methods for the derivation of economic values in aquaculture species. In chapter 3 a bio-economic model for the derivation of economic values of production traits was developed. The bio-economic model was used to simulate a grow-out farm for gilthead seabream. Gross margin was simulated at the current trait levels and after one genetic standard deviation change in each trait with the other traits remaining unchanged. Economic values were derived for thermal growth coefficient (TGC), thermal feed intake coefficient (TFC), mortality rate (M), and the standard deviation of harvest weight $\left(\sigma_{\mathrm{HW}}\right)$. Changes in gross margin showed that the order of economic importance of the traits was: TGC, TFC, M, and $\sigma_{H W}$. The bio-economic model was validated by comparison to a profit equation for a simplified production system. The bio-economic model can be applied to any aquaculture species, because it can include any limiting factor and/or environmental condition that affects production. In chapter 4 a 
method for the derivation of the economic value of $\mathrm{R}_{0}$ for macroparasites was developed. Macroparasites are a concern in aquaculture production and can be controlled by genetic improvement of the host population. $\mathrm{R}_{0}$ determines the rate at which parasites spread across the farmed population and is, therefore, the appropriate breeding goal trait. Costs of a disease are the sum of production losses and expenditures on disease control. Genetic improvement of $\mathrm{R}_{0}$ lowers the loss-expenditure frontier. Its economic effect depends on whether the management strategy is optimized or not. When $\mathrm{R}_{0} \leq 1$, the economic value of a further reduction is zero, because there is no risk of a major epidemic. When $R_{0}>1$ and management is optimized, the economic value increases with decreasing values of $R_{0}$, because both the mean number of parasites per host and frequency of treatments decrease at an increasing rate when $\mathrm{R}_{0}$ decreases. When $\mathrm{R}_{0}>1$ and management is not optimized, the economic value depends on whether genetic improvement is used for reducing expenditures or losses. For sea lice in Atlantic salmon the economic value follows from a reduction in expenditures with constant losses and is estimated to be $0.065 € / \mathrm{unit} \mathrm{R}_{0} / \mathrm{kg}$ production. In chapter 5 a method for the derivation of the economic value of $R_{0}$ for microparasitic diseases was developed. Microparasitic diseases are caused by bacteria and viruses. Genetic improvement of resistance to microparasitic diseases in breeding programs is desirable and should aim to reduce $R_{0}$. Genetic improvement of $R_{0}$ for microparasitic diseases is assumed to reduce production losses while expenditures on disease control are unaffected. Microparasitic diseases are classified as epidemic when there are incidental outbreaks, and as endemic when the disease is virtually always present and the infected fraction of the population varies around its endemic equilibrium. For both types of disease the economic value depends on the value of $\mathrm{R}_{0}$, production losses per infected animal, and the size of the population. Additionally, for epidemic diseases the economic value depends on the frequency of infection from an outside source. For both epidemic and endemic microparasitic diseases the economic value is highest at intermediate values of $\mathrm{R}_{0}$, it approaches zero when $R_{0}$ increases to large values, and it is zero when $R_{0} \leq 1$.

The objective of chapters 6 and 7 was to study the optimization of breeding program design. In chapter 6 cost-benefit analysis was used to evaluate alternative breeding program designs for gilthead seabream, with and without multiplier tier. For each design the number of selection candidates was optimized to maximize the net present value. The baseline breeding program was profitable after 5 years and reached a net present value of 2.9 million euro in year 10. For a short time horizon putting priority on improvement of the 
multiplier tier over the nucleus was more profitable than putting priority on nucleus improvement, and vice versa for a long time horizon. Use of a multiplier tier increased the delay between costs made for selection and resulting benefits. Thus, avoiding the use of a multiplier tier increased the net present value of the breeding program in the short term. The optimum number of selection candidates increased with the length of the time horizon and production output. Using too many selection candidates relative to the optimum leads to less reduction in net present value than using too few selection candidates. In chapter 7 the allocation of budget over performance tests was optimized with the objective to maximize gain in the aggregate genotype in a breeding program for Atlantic salmon. Gain in the aggregate genotype was defined as a function of the numbers of full-sibs of selection candidates that were phenotyped in a challenge test for sea lice resistance, phenotyped in a slaughter test, genotyped in the challenge test, and genotyped in the slaughter test. These activities were subject to a constraint on budget. Using grid search, the allocation of budget over activities was optimized to maximize gain in the aggregate genotype. Gain in the aggregate genotype at the optimum was $€ 367 /$ ton per generation. The optimum was rather flat, but close to the extremes gain in the aggregate genotype was compromised. Sensitivity analyses revealed that maximum gain in the aggregate genotype was sensitive to the budget and the relative emphasis on breeding goal traits, and less so to the cost of phenotyping in the challenge test and the cost of genotyping. The relative allocation of budget over activities at the optimum was sensitive to the cost of genotyping and the relative emphasis on breeding goal traits, and less so to the budget and the cost of phenotyping. Although potential gains from optimizing group sizes and genotyping effort may be small, they come at no extra cost.

In first part of the general discussion in chapter 8 the economic impact of selective breeding on European aquaculture was evaluated. Estimates of $\Delta \mathrm{H}$ were combined with 2012 market shares of breeding companies per species, based on which economic benefits were predicted to increase cumulatively by about 100 million euro each year. The role of benchmarking as a driver of concentration in the breeding industry is discussed. Concentration of the breeding industry and the adoption of new technology to improve production efficiency in breeding programs can further increase the annual increase in economic benefits. The second part of the general discussion provides a synthesis of results in this thesis on the economic optimization of breeding programs. The definition of the breeding goal is discussed using results of chapters 3,4 , and 5 . It is argued that intuition is 
a poor predictor of economic values, hence is likely to result in suboptimum emphasis on breeding goal traits. The optimization of a breeding program as a whole is complex, because there is a large number of variables to be optimized. Methods to reduce complexity and to solve such a multidimensional optimization problem are discussed. In the optimization of breeding programs differences in the predicted rate of inbreeding should be accounted for. When the rate of inbreeding is controlled by optimum contribution selection, it is proposed to penalize the predicted unconstrained rate of inbreeding above its tolerable level by its shadow value. It is concluded that the optimization of breeding programs can improve the economic efficiency of aquaculture. 



\section{Acknowledgements}


First of all I wish to thank Hans Komen, my promotor. You took a leap of faith when you offered me a position as $\mathrm{PhD}$ candidate back in 2014. I am grateful for your thrust back then, and ever since. You have let me work independently, introduced me to many people in the field, and often put me forward to present my work. You helped me to turn ideas into readable narratives. Paul Berentsen, my first supervisor, I wish to thank you for the effort you have put in drawing my attention to the details. I have much appreciated your way of working and building a paper together. Helmut Saatkamp, my second supervisor and Paul's successor, you frequently invited me to organize additional meetings. Although I seldom made use of these invitations, I have always appreciated your commitment as a daily supervisor. Your expertise on economics of livestock diseases helped me move forward when I got stuck on the economic value of disease resistance, which finally resulted in my best paper. Your and Hans' natural tendency to turn every discussion into a brainstorm secured that I kept an open mind and broadened my perspective.

I might not have started this $\mathrm{PhD}$ if Kees Kloet would not have given me every opportunity to explore future career paths at times that my previous job at fish farm Silt BV came to an end. Kees, thank you for introducing me to the practical side of aquaculture and your support in starting this $\mathrm{PhD}$. It was at this same fish farm, while working with Robbert Blonk, that I first realized the potential of genetic improvement in aquaculture. Robbert, thanks for sharing your enthusiasm and sparking my interest for breeding programs in aquaculture.

During my PhD I have greatly benefitted from being part of the chair group Animal Breeding and Genomics. With so much expertise concentrated in a single group, it has been a truly inspiring place to work. I would like to thank Mathieu Besson for questioning my often too bold assumptions. Piter Bijma, your ability to turn steps in my inimitable reasoning from implicit to explicit is unique and has greatly helped to clarify ideas in this thesis. John Bastiaansen, our many discussions on aquaculture breeding programs made me feel part of something larger than just my own project. Lisette Bourquin, you have made many parts of my PhD so much easier, for which I am grateful. Good science requires more than hard work. I am grateful for the good company of many colleagues. Thanks for joining me for a walk in the afternoon, for playing tennis, and for having your ass kicked during a game of foosball. 
This $\mathrm{PhD}$ was part of the project FISHBOOST. The project has enabled me to get to know many great scientists and major players in the aquaculture breeding industry. Because of them, I really enjoyed the annual project meetings and EAS conferences, which were the primary scientific symposia ${ }^{1}$ for FISHBOOST. Being part of this consortium enabled me to collaborate with industry and academic partners. Kostas Tzokas, thank you for welcoming me at Andromeda in Greece, for showing your facilities, and sharing production data on gilthead seabream and European seabass. Havard Bakke, thank you for welcoming me at SalmoBreed in Norway, for taking me to one of the producers, and your input to our discussions on economic values and breeding program design. Santiago Caballero, thank you for welcoming me to CETGA in Spain to explain your work on turbot. Jesus Fernandez and Beatriz Villanueva, thank you for inviting me to INIA in Spain and for introducing me to the stochastic simulation of breeding programs.

Tot slot wil ik Lenneke, familie en vrienden bedanken. Lenneke, je kent me soms beter dan dat ik mezelf ken. Je voelt feilloos aan wanneer ik even uit moet razen, tegengas kan gebruiken, en wanneer ik uitgelaten moet worden. Elk succesje wil je vieren: niet om het succes, maar om het vieren. Dankjewel voor je aanmoediging, liefde, en het maken van boodschappenlijstjes. Familie, jullie hebben me van jongs af aan de wereld laten ontdekken. Jullie hebben me gestimuleerd mijn interesse te volgen en me verder te ontwikkelen. In jullie bijzijn voel ik me altijd thuis. Vrienden, bedankt voor zowel jullie interesse als desinteresse voor mijn werk. Soms is het leuk wat over werk te delen; meestal is het veel leuker om met totaal andere zaken bezig te zijn en je te realiseren dat werk niet zo belangrijk is als het soms lijkt.

\footnotetext{
${ }^{1}$ The word symposium stems from the ancient Greek word sympinein, which means "to drink together".
} 

Curriculum Vitae 


\begin{abstract}
About the author
Kasper Janssen was born on the $29^{\text {th }}$ of September 1986 in Meerlo, the Netherlands. His concern about the rapid loss of biodiversity in our world's oceans motivates him to make aquaculture a better alternative to unsustainable fisheries. In 2004 he started his study Animal Sciences at Wageningen University, where specialized on aquaculture. He did a minor thesis at the Institute of Marine Research in Norway, an internship at the Hellenic Centre for Marine Research (HCMR) in Greece, and a major thesis at Wageningen University. After his graduation in 2010 he was employed as an aquaculture biologist at the HCMR in Greece, where he helped to develop larval rearing protocols to close the lifecycle of bluefin tuna. Bluefin tuna is a prime example of a species whose stocks have collapsed under intense fisheries pressure. In 2012 Kasper was employed as a farm manager at Silt BV, a Dutch farm for yellowtail kingfish produced in recirculating aquaculture systems. Farmed yellowtail kingfish provides a sustainable alternative to tuna. Kasper was responsible for the daily operation of the farm, data management, and reproduction. He received one month training on reproduction and larval rearing of yellowtail kingfish at ACAAR in Fremantle, Australia. As a farm manager involved with reproduction, he realized the potential of genetic improvement. This potential motivated him to start his $\mathrm{PhD}$ on the economic optimization of breeding programs in aquaculture in 2014. He did his $\mathrm{PhD}$ under supervision of Prof. Dr Hans Komen at the chair group of Animal Breeding and Genomics in the project FISHBOOST. During two years of his $\mathrm{PhD}$ he was part-time employed by Wageningen Livestock Research, where he worked on the development and design of breeding programs in aquaculture.
\end{abstract}




\section{Peer-reviewed publications}

Janssen, K., Saatkamp, H.W., Komen, H., 2019. Economic optimization of full-sib test group size and genotyping effort in a breeding program for Atlantic salmon. Submitted

Janssen, K., Komen, H., Saatkamp, H.W., de Jong, M.C.M, Bijma, P., 2018. Derivation of the economic value of $\mathrm{R}_{0}$ for macroparasitic diseases and the application to sea lice in salmon. Genetics Selection Evolution 50:47.

Janssen, K., Saatkamp, H., Komen, H., 2018. Cost-benefit analysis of aquaculture breeding programs. Genetics Selection Evolution 50:2

Omasaki, S., Janssen, K., Besson, M. Komen, H., 2017. Economic values of growth rate, feed intake, feed conversion ratio, mortality and uniformity for Nile tilapia. Aquaculture 481

Janssen, K., Berentsen, P., Besson, M., Komen, H., 2017. Derivation of economic values for production traits in aquaculture species. Genetics Selection Evolution 49:5

Janssen, K., Chavanne, H., Berentsen, P., Komen, H., 2017. Impact of selective breeding in European aquaculture. Aquaculture 472: 8-16

Chavanne, H., Janssen, K., Hofherr, J., Contini, F., Haffray, P., Aquatrace Consortium, Komen, H., Nielsen, E., Bargelloni, L., 2016. A comprehensive survey on selective breeding programs and seed market in the European aquaculture fish industry. Aquaculture International 24: 1-21. 


\section{Completed training activities}

The basic package (3 ECTS)

WIAS introduction day

2015

Couse on essential skills

2015

Ethics and philosophy in life sciences

2016

\section{Disciplinary competences (17.9 ECTS)}

Courses Genetic improvement of livestock

2015

Introduction to R for statistical analysis 2015

Financial management in agriculture 2016

Orientation on mathematical modelling in biology 2016

Emerging technologies in animal breeding 2017

Getting started in ASReml 2017

Literature review 2015

$\begin{array}{ll}\text { Quantitative genetics discussion group 2014-18 } & \text { 2015 }\end{array}$

Professional competences (5.8 ECTS)

$\begin{array}{ll}\text { Courses Societal impact } & 2015\end{array}$

Techniques for writing and presenting a scientific paper 2015

PhD workshop carousel 2015-16

Mobilising your - scientific - network 2016

Effective behavior in your professional surroundings 2016

$\begin{array}{ll}\text { Theatre skills for lecturers } & 2016\end{array}$

Presenting with impact 2016

\section{Presentations (4 ECTS)}

Oral International Symposium on Genetics in Aquaculture, Santiago de 2015

European Aquaculture Society, Edinburgh, Scotland 2016

WIAS Science Day, Wageningen. 2017

European Association of Animal Production, Tallinn, Estonia. 2017

$I^{\text {st }}$ price animal genetics

European Aquaculture Society, Dubrovnik, Croatia 2017

World Congress on Genetics Applied to Livestock Production, Auckland, 2018

New Zealand. Travel grant LEB-foundation

World Aquaculture Society, Montpellier, France 2018

Poster Aquaculture, Montpellier, France. Poster 2015

WIAS Science Day, Wageningen. 2016

International Symposium on Genetics in Aquaculture, Cairns, Australia 2018

Teaching competences (6 ECTS)

Co-organize course on Societal impact 2015

Assistant in course on Animal breeding and genetics 2015

Assistant in course on Genetic improvement of livestock 2016

Teacher in course on Design of breeding programs, Sukamandi, Indonesia 2018

Teacher in Advanced aquaculture breeding workshop, Montpellier, France 2018 



\section{Colophon}

The research leading to these results has received funding from the European Union's Seventh Framework Programme (KBBE.2013.1.2-10) under grant agreement no 613611. A travel grant from the LEB foundation is gratefully acknowledged.

Cover design by Kasper Janssen

Printed by: DigiForce || Proefschrift Maken 

